\title{
WestVirginiaUniversity
}

THE RESEARCH REPOSITORY @ WVU

Graduate Theses, Dissertations, and Problem Reports

2001

\section{Pretreatment and enzymatic hydrolysis of lignocellulosic materials}

Wei Cheng

West Virginia University

Follow this and additional works at: https://researchrepository.wvu.edu/etd

\section{Recommended Citation}

Cheng, Wei, "Pretreatment and enzymatic hydrolysis of lignocellulosic materials" (2001). Graduate Theses, Dissertations, and Problem Reports. 1172.

https://researchrepository.wvu.edu/etd/1172

This Thesis is protected by copyright and/or related rights. It has been brought to you by the The Research Repository @ WVU with permission from the rights-holder(s). You are free to use this Thesis in any way that is permitted by the copyright and related rights legislation that applies to your use. For other uses you must obtain permission from the rights-holder(s) directly, unless additional rights are indicated by a Creative Commons license in the record and/ or on the work itself. This Thesis has been accepted for inclusion in WVU Graduate Theses, Dissertations, and Problem Reports collection by an authorized administrator of The Research Repository @ WVU. For more information, please contact researchrepository@mail.wvu.edu. 


\title{
Pretreatment and Enzymatic Hydrolysis \\ of
}

\section{Lignocellulosic Materials}

\author{
Wei Cheng
}

Thesis submitted to the

College of Engineering and Mineral Resources

at West Virginia University

in partial fulfillment of requirements

for the degree of

Master of Science

in

Chemical Engineering

\author{
Ray Y. K. Yang, Ph.D., Chair. \\ Ben Dawson-Andoh, Ph.D. \\ Rakesh K. Gupta, Ph.D. \\ Department of Chemical Engineering \\ Morgantown, West Virginia \\ 2001
}

Keywords: lignocellulosics, pretreatment, enzymatic saccharification, membrane reactor, surfactant

Copyright 2001 Wei Cheng 


\begin{abstract}
Pretreatment and Enzymatic Hydrolysis of Lignocellulosic Materials
\end{abstract}

\title{
Wei Cheng
}

This research aims to increase the efficiency of utilizing lignocellulosic materials, which have great potential as future energy and chemical feed stocks, and may finally substitute the diminishing hydrocarbon resources. This work involved two main parts: a) comparison of efficiency of different pretreatment methods on lignocellulosic materials; and b) enhancing enzymatic hydrolysis in a continuous tubular membrane reactor (TMR) process.

The alkaline oxidation pretreatment method was found to be more efficient than ammonia steeping pretreatment in lignin removal and digestible cellulose enrichment for the raw substrates chosen for this study, namely, yellow poplar (hardwood) and corn cob (herbaceous crop).

A combination of reactor incline and shaking speed of $46.7^{\circ} / 180 \mathrm{rpm}$ produced continuous and steady transportation of insoluble substrates through the hollow fibers of polymeric TMR, when no cellulolytic enzymes were added, due probably to the homogenous suspension of solid substrate inside the hollow fibers. This is of great importance, since increasing the homogeneity of insoluble substrate in reaction mixture enhanced the enzyme-substrate contact, a factor crucial to higher hydrolysis rate. This combination was applied for all the later continuous enzymatic hydrolysis experiments in TMR.

Both surfactants, Pluronic F68 and Tergitol NP 9, were effective in enhancing the enzymatic hydrolysis of all the substrate investigated in our TMR system. This is proven by the increased steady state substrate conversion, when either surfactant is added. The greatest enhancement in steady state conversion (96.3\%) was for ammonia steeping pretreated corn cob, when surfactant Pluronic F68 was added. 


\section{Acknowledgements}

I would like to express my special thanks to the following people:

- Dr. Ray Y. K. Yang for his advice, guidance, criticism, valuable corrections, and support throughout this study.

- Dr. Ben Dawson-Andoh and Dr. Rakesh K. Gupta for their academic expertise, constructive comments and suggestions.

- Dr. Dady B. Dadyburjor, Dr. Charter D. Stinespring, Dr. John W. Zondlo and Dr. Peter G. Stansberry for their constant help and giving me chance to learn many new things.

- Mr. James Hall for his technical assistance in almost every stage of the project.

- Anantakirishnan Balakrishnan for listening to my ideas and giving many valuable suggestions.

- All the graduate students in the department of chemical engineering for their friendship, which has made life more pleasant in Morgantown.

- My family, grandmother and sister, last but not least, for their support and encouragement throughout the course of my education.

This project is funded by USDA. 


\section{Table of Content}

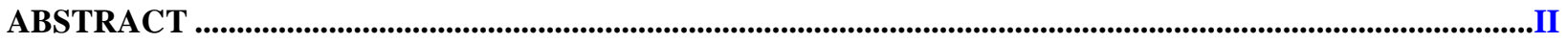

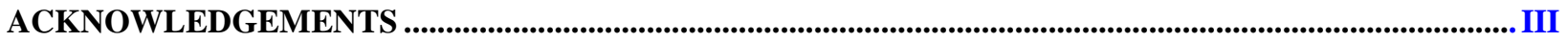

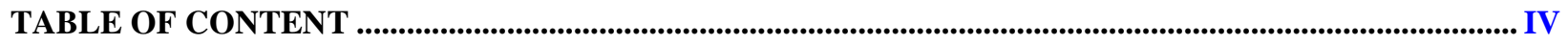

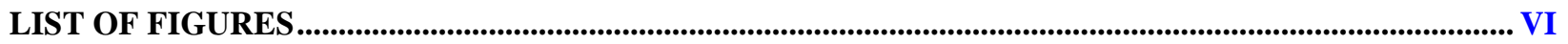

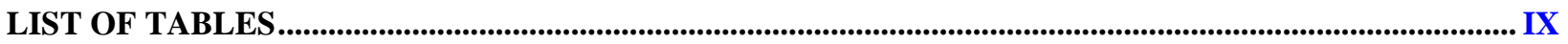

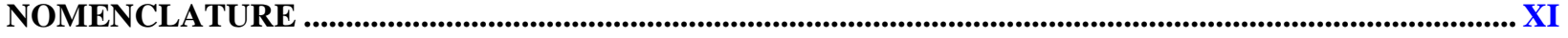

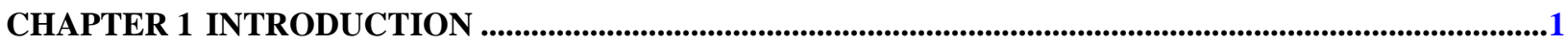

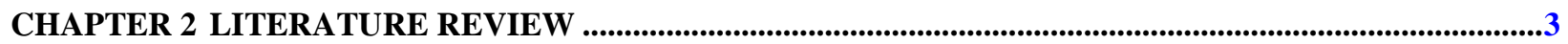

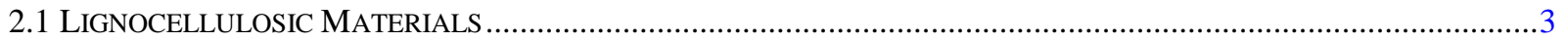

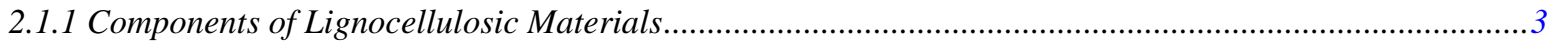

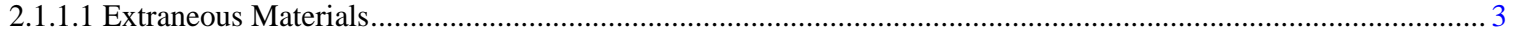

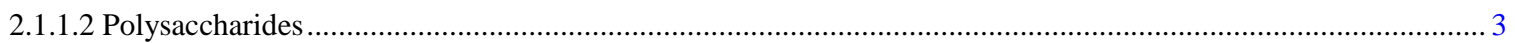

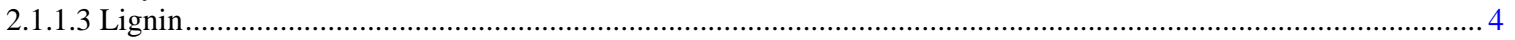

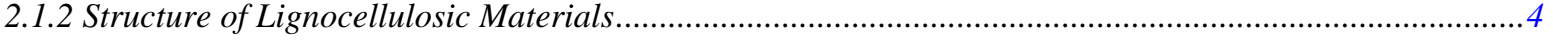

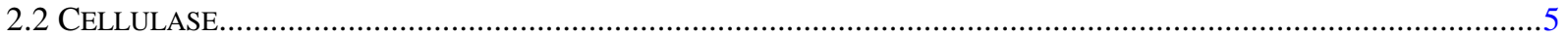

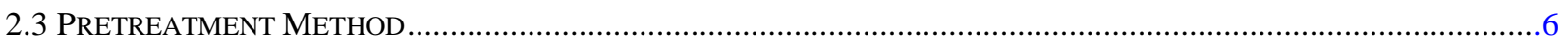

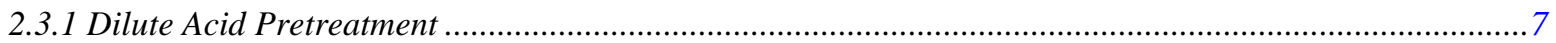

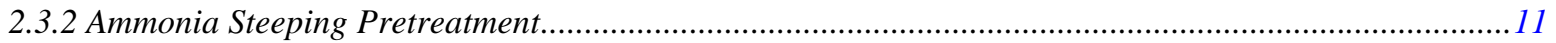

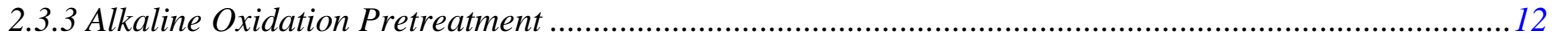

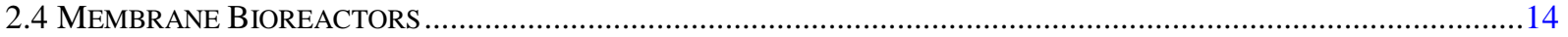

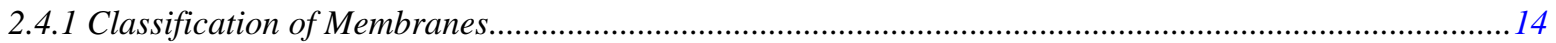

2.4.2 Cellulose Hydrolysis in Membrane Reactors .................................................................................. 15

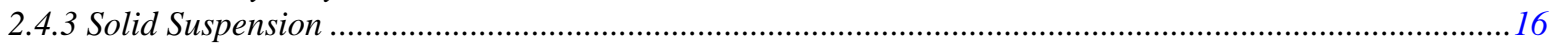

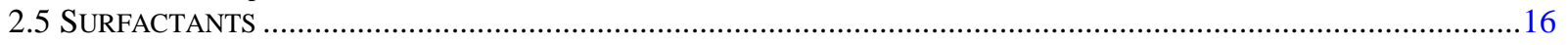

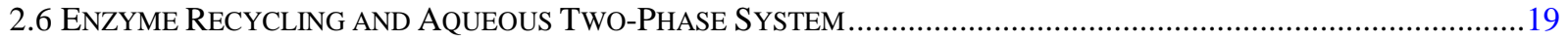

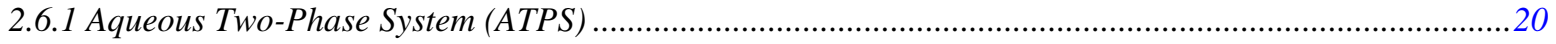

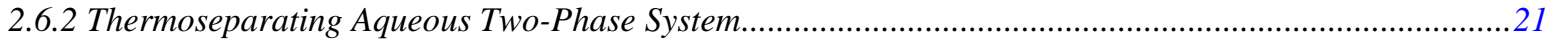

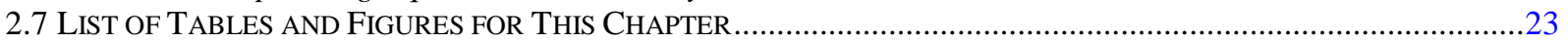

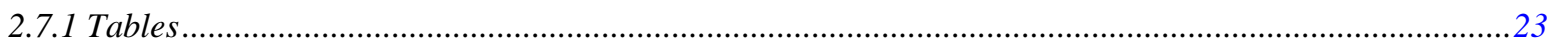

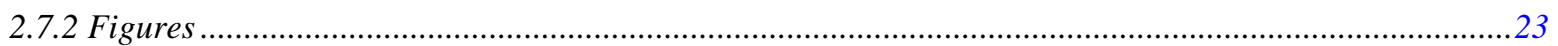

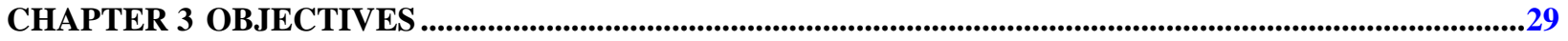

CHAPTER 4 EXPERIMENTAL DETAILS ........................................................................................................................31

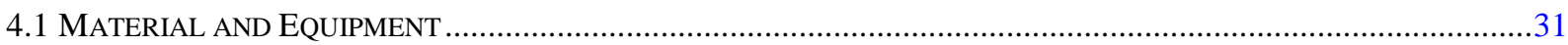

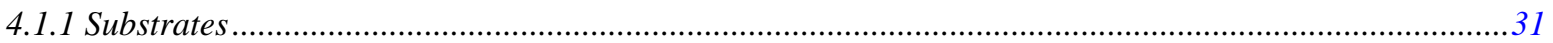

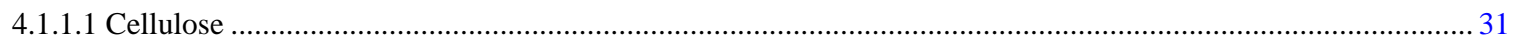

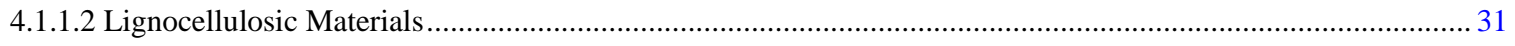

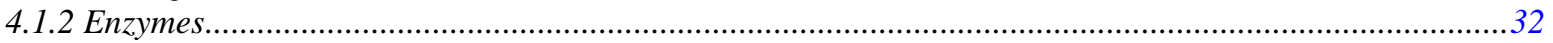

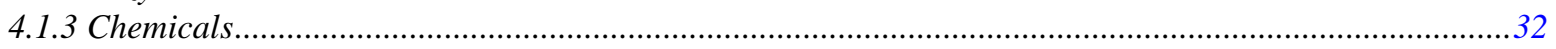

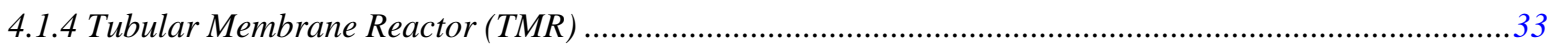

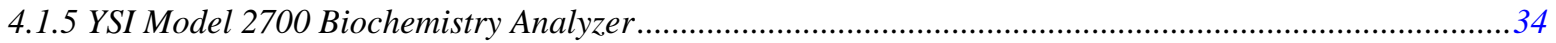

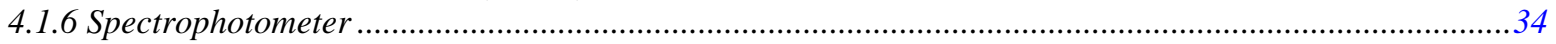

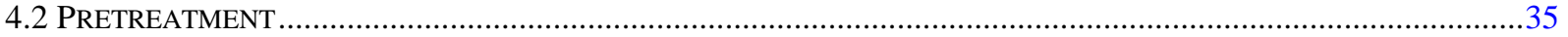




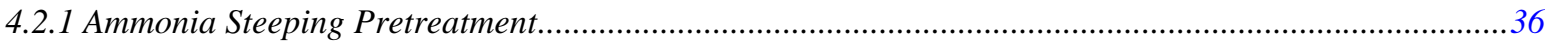

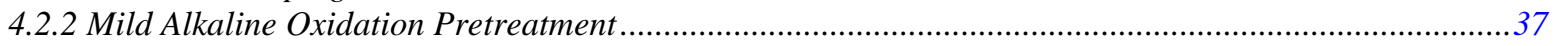

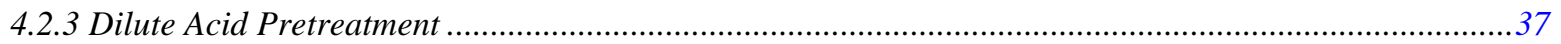

4.2.4 Comparison of Three Pretreatment Methods ……….............................................................................38

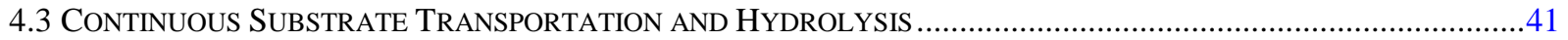

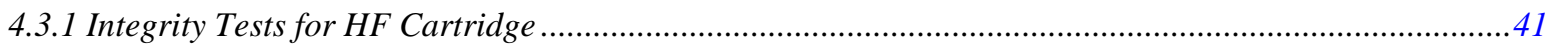

4.3.2 Continuous Transport of Substrate Particles through TMR …............................................................43

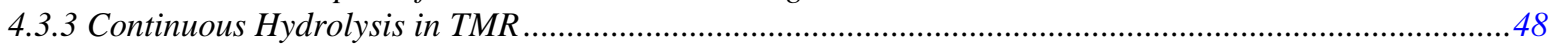

4.3.4 Use of Surfactants to Enhance Continuous Hydrolysis in TMR ..........................................................52

4.4 USE OF AQUEOUS TWO-PHASE SYSTEM FOR ENZYME RECOVERY ……...................................................53

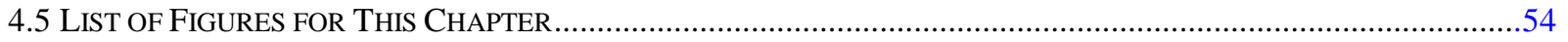

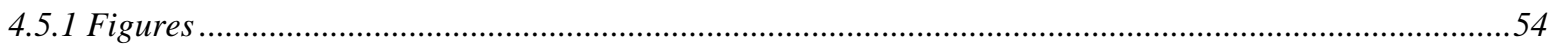

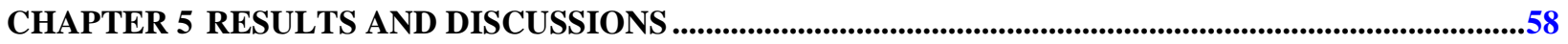

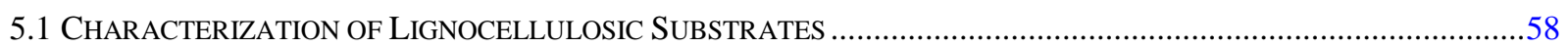

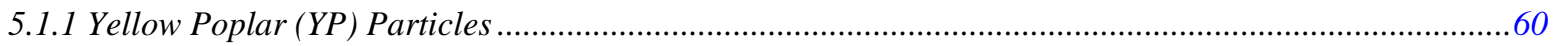

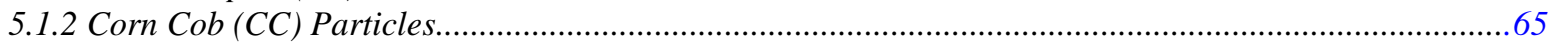

5.2 CONTINUOUS TRANSPORT OF SUBSTRATE PARTICLES THROUGH TMR …....................................................67

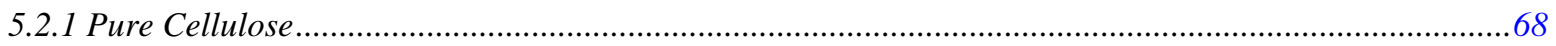

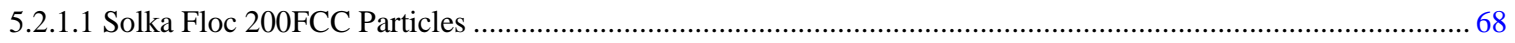

5.2.1.2 Solka Floc 900FCC Particles .............................................................................................................. 71

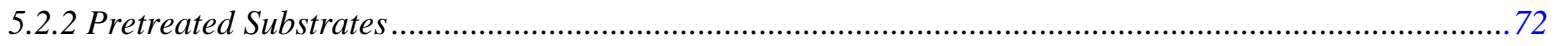

5.2.2.1 Alkaline Oxidation Yellow Poplar (AOYP) .................................................................................................... 73

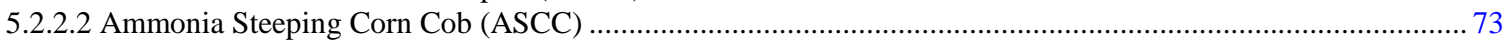

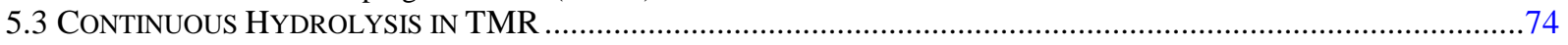

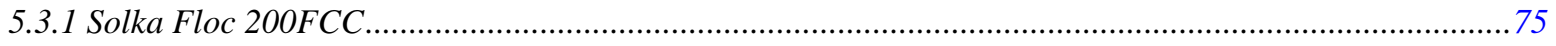

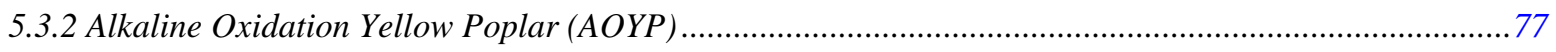

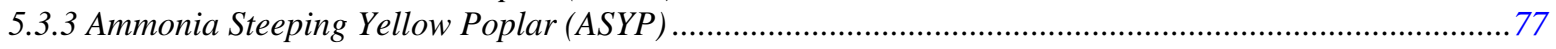

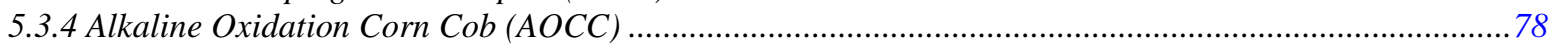

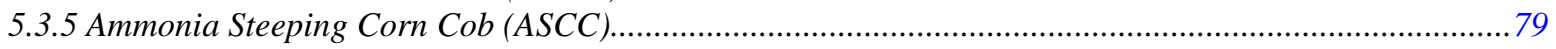

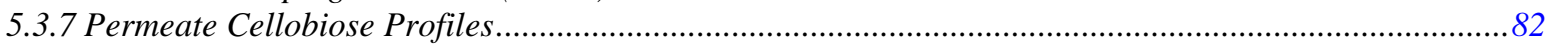

5.3.8 Summary of Continuous Hydrolysis Runs ................................................................................. 82

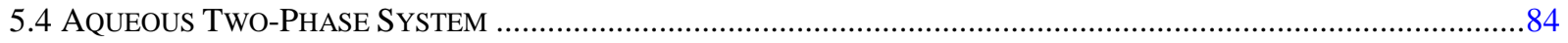

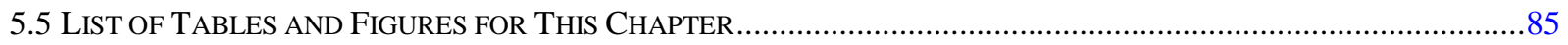

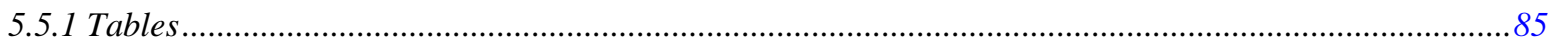

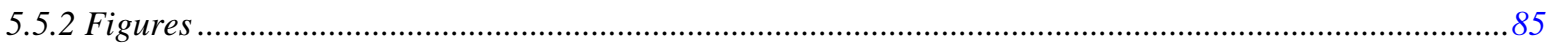

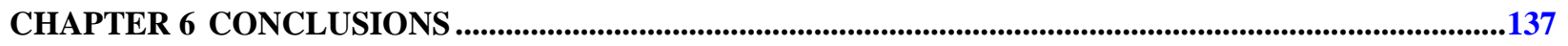

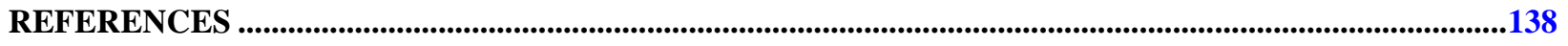

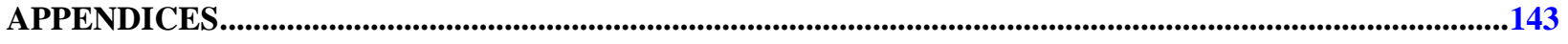

APPENDIX A. Data COLLECTED For SUBSTRATE CHARACTERIZATION RUNS.....................................................144

APPENDIX B. DATA COLLECTED For SUbSTRATE TRANSPORTATION RunS .....................................................148

APPENDIX C. DATA COLLECTED FOR CONTINUOUS HYDROLYSIS IN TMR …………........................................153

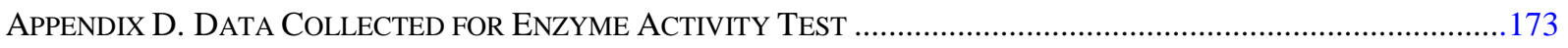




\section{List of Figures}

Figure 2.1. Distribution of Cellulose, Hemicellulose and Lignin in Wood Fiber Cell Wall..............26

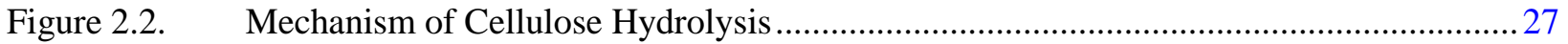

Figure 2.3. Membrane Reactor System: (a) CSTR --- Ultrafiltration Cell; (b) Hollow-Fiber Cartridge from Henley, Yang and Greenfield, 1980 ................................................................... 28

Figure 4.1. Experimental Setup for Solid Transportation in HF Cartridge .....................................55

Figure 4.2. Experimental Setup for Enzymatic Hydrolysis in HF Cartridge .................................. 56

Figure 4.3. Air Diffusion Test Apparatus (originally from A/G Technology Corporation Operating

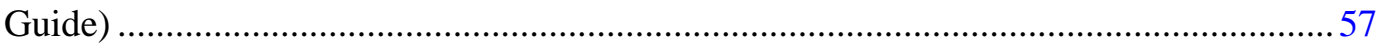

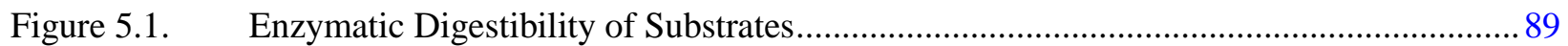

Figure 5.2. Final Digestibility versus Percentage Delignification for Yellow Poplar and Corn Cob .90

Figure 5.3. Weight of Cellulose (Solka Floc 200FCC) vs. Time (250rpm, 46. $7^{\circ}$, Retentate flow rate: $1.04 \mathrm{ml} / \mathrm{min}$ )

Figure 5.4. Weight of Cellulose (Solka Floc 200FCC) vs. Time (250rpm, $0^{\circ}$, Retentate flow rate: $0.96 \mathrm{ml} / \mathrm{min}$ ).

Figure 5.5. Weight of Cellulose (Solka Floc 200FCC) vs. Time (0rpm, 46.7 ${ }^{\circ}$, Retentate flow rate: $0.92 \mathrm{ml} / \mathrm{min}$ ).

Figure 5.6. Weight of Cellulose (Solka Floc 200FCC) vs. Time (150rpm, 46.7 $7^{\circ}$, Retentate flow rate: $1.02 \mathrm{ml} / \mathrm{min}$ )

Figure 5.7. Weight of Cellulose (Solka Folc 900FCC) Vs. Time (180rpm, 46.7 ${ }^{\circ}$, Retentate flow rate: $1.05 \mathrm{ml} / \mathrm{min}$, Permeate flow rate: $0.26 \mathrm{ml} / \mathrm{min}$ )

Figure 5.8a. Weight of Pretreated Yellow Poplar (AOYP) vs. Time (180rpm, 46.7 ${ }^{\circ}$, Retentate flow rate: $1.20 \mathrm{ml} / \mathrm{min}$, Permeate flow rate: $0.21 \mathrm{ml} / \mathrm{min}$ )

Figure 5.8b. Weight of Pretreated Yellow Poplar (AOYP) vs. Time (180rpm, 46.7 ${ }^{\circ}$, Retentate flow rate: $1.07 \mathrm{ml} / \mathrm{min}$, Permeate flow rate: $0.30 \mathrm{ml} / \mathrm{min}$ )

Figure 5.9a. Weight of Pretreated Corn Cob (ASCC) vs. Time (180rpm, 46.7 $7^{\circ}$, Retentate flow rate: $1.08 \mathrm{ml} / \mathrm{min}$, Permeate flow rate: $0.27 \mathrm{ml} / \mathrm{min}$ )

Figure 5.9b. Weight of Pretreated Corn Cob (ASCC) vs. Time (180 rpm, 46.7 ${ }^{\circ}$, Retentate flow rate: $1.08 \mathrm{ml} / \mathrm{min}$, Permeate flow rate: $0.30 \mathrm{ml} / \mathrm{min}$ ).

Figure 5.10. Substrate Conversion and Glucose Concentrations vs. Time --- Solka Floc 200FCC, no Surfactant. 100

Figure 5.11. Substrate Conversion and Glucose Concentrations vs. Time --- Solka Floc 200FCC, with Tergitol 
Figure 5.12. Substrate Conversion and Glucose Concentrations vs. Time --- Solka Floc 200FCC, with Pluronic

Figure 5.13. Substrate Conversion and Glucose Concentrations vs. Time --- AOYP, no Surfactant 103

Figure 5.14. Substrate Conversion and Glucose Concentrations vs. Time --- AOYP, with Tergitol .104

Figure 5.15. Substrate Conversion and Glucose Concentrations vs. Time --- AOYP, with Pluronic. 105

Figure 5.16. Substrate Conversion and Glucose Concentrations vs. Time --- ASYP, no Surfactant.. 106

Figure 5.17. Substrate Conversion and Glucose Concentrations vs. Time --- ASYP, with Tergitol .. 107

Figure 5.18. Substrate Conversion and Glucose Concentrations vs. Time --- ASYP, with Pluronic .108

Figure 5.19. Substrate Conversion and Glucose Concentrations vs. Time --- AOCC, no Surfactant. 109

Figure 5.20. Substrate Conversion and Glucose Concentrations vs. Time --- AOCC, with Tergitol . 110

Figure 5.21. Substrate Conversion and Glucose Concentrations vs. Time --- AOCC, with Pluronic. 111

Figure 5.22. Substrate Conversion and Glucose Concentrations vs. Time --- ASCC, no Surfactant . 112

Figure 5.23. Substrate Conversion and Glucose Concentrations vs. Time --- ASCC, with Tergitol.. 113

Figure 5.24. Substrate Conversion and Glucose Concentrations vs. Time -- ASCC, with Pluronic... 114

Figure 5.25. Distribution of Cellobiose and Glucose in Permeate Stream --- Solka Floc 200FCC, no Surfactant. 115

Figure 5.26. Distribution of Cellobiose and Glucose in Permeate Stream --- AOYP, no Surfactant . 116

Figure 5.27. Distribution of Cellobiose and Glucose in Permeate Stream --- AOYP, with Tergitol .. 117

Figure 5.28. Distribution of Cellobiose and Glucose in Permeate Stream --- AOYP, with Pluronic . 118

Figure 5.29. Distribution of Cellobiose and Glucose in Permeate Stream --- ASYP, no Surfactant .. 119

Figure 5.30. Distribution of Cellobiose and Glucose in Permeate Stream --- ASYP, with Tergitol... 120

Figure 5.31. Distribution of Cellobiose and Glucose in Permeate Stream --- ASYP, with Pluronic.. 121

Figure 5.32. Distribution of Cellobiose and Glucose in Permeate Stream --- AOCC, no Surfactant 122

Figure 5.33. Distribution of Cellobiose and Glucose in Permeate Stream --- AOCC, with Tergitol.. 123

Figure 5.34. Distribution of Cellobiose and Glucose in Permeate Stream --- ASCC, no Surfactant.. 124

Figure 5.35. Distribution of Cellobiose and Glucose in Permeate Stream --- ASCC, with Tergitol .. 125

Figure 5.36. Distribution of Cellobiose and Glucose in Permeate Stream --- ASCC, with Pluronic.. 126

Figure 5.37. Conversion of Solka Floc 200FCC to Glucose in a TMR …....................................... 127

Figure 5.38. Conversion of AOYP to Glucose in a TMR …........................................................... 128

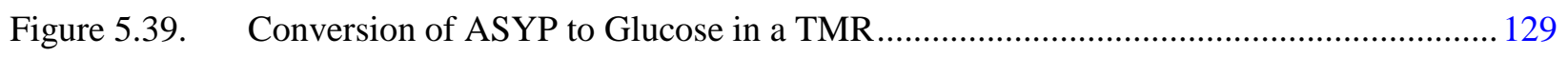

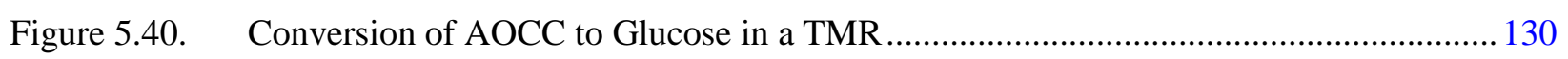

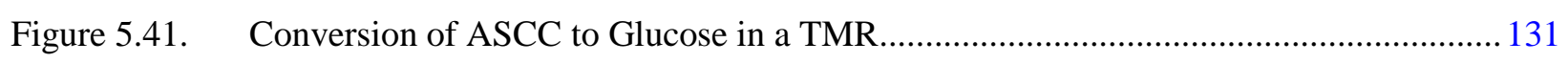

Figure 5.42. Effect of Presoaking Time on Substrate Conversion .................................................... 132

Figure 5.43. Distribution of Cellobiose in Permeate Stream --- AOYP............................................ 133 
Figure 5.44. Distribution of Cellobiose in Permeate Stream --- ASYP ............................................. 134

Figure 5.45. Distribution of Cellobiose in Permeate Stream --- AOCC........................................... 135

Figure 5.46. Distribution of Cellobiose in Permeate Stream --- ASCC ............................................ 136

Figure B 5.3. Weight of Cellulose (Solka Floc 200FCC) vs. Time (250rpm, 46.7 ${ }^{\circ}$, Retentate flow

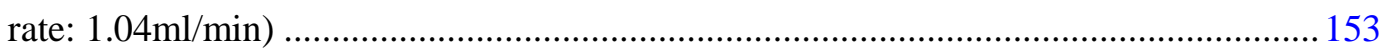

Figure B 5.4. Weight of Cellulose (Solka Floc 200FCC) vs. Time (250rpm, $0^{\circ}$, Retentate flow rate: $0.96 \mathrm{ml} / \mathrm{min}$ ). 154

Figure B 5.5. Weight of Cellulose (Solka Floc 200FCC) vs. Time ( $0 \mathrm{rpm}, 46.7^{\circ}$, Retentate flow rate: $0.92 \mathrm{ml} / \mathrm{min}$ ). 155

Figure B 5.6. Weight of Cellulose (Solka Floc 200FCC) vs. Time (150rpm, 46.7 ${ }^{\circ}$, Retentate flow rate: $1.02 \mathrm{ml} / \mathrm{min}$ ). 156

Figure B 5.7. Weight of Cellulose (Solka Floc 900FCC) vs. Time (150rpm, 46.7 ${ }^{\circ}$, Rentenate flow rate: $1.05 \mathrm{ml} / \mathrm{min}$, Permeate flow rate: $0.26 \mathrm{ml} / \mathrm{min}$ ) 157 


\section{List of Tables}

Table 2.1a Summary of conditions used in dilute acid pretreatment reported in literature ....................24

Table 2.1b Summary of results obtained from dilute acid pretreatment reported in literature.................25

Table 5.1 Characterization of Yellow Poplar, Corn Cob and Solka Floc............................................. 87

Table 5.2 Summaries of Continuous Hydrolysis Experiments in TMR ….............................................. 88

Table A.1a Total Solid Content of Yellow Poplar ............................................................................... 144

Table A.1b Total Solid Content of Lignocellulosic Materials and Solka Floc 900FCC (1) .................. 144

Table A.1c Total Solid Content of Lignocellulosic Materials and Solka Floc 900FCC (2) .................. 145

Table A.2 Characterization of Yellow Poplar ...................................................................................... 146

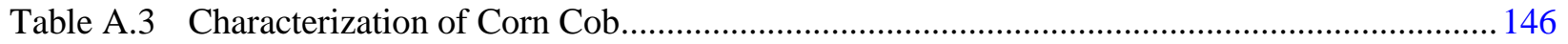

Table A.4 Enzymatic Digestibility Test of Different Substrates, first run ........................................ 147

Table A.5 Enzymatic Digestibility Test of Different Substrates, second run .................................... 147

Table B.1a Solka Floc 200FCC --- 250rpm $/ 46.7^{\circ}$, retentate flow rate: $1.07 \mathrm{ml} / \mathrm{min}$, first run............... 148

Table B.1b Solka Floc 200FCC--- 250rpm $/ 46.7^{\circ}$, retentate flow rate: $1.02 \mathrm{ml} / \mathrm{min}$, second run ............. 148

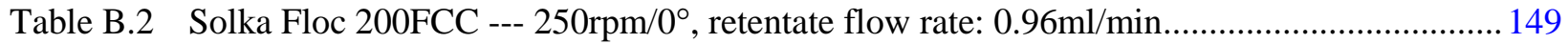

Table B.3 Solka Floc 200FCC --- 0rpm $/ 46.7^{\circ}$, retentate flow rate: $0.92 \mathrm{ml} / \mathrm{min}$................................ 149

Table B.4 Solka Floc 200FCC --- 150rpm $/ 46.7^{\circ}$, retentate flow rate: $1.02 \mathrm{ml} / \mathrm{min}$............................. 150

Table B.5 Solka Floc 900FCC --- $180 \mathrm{rpm} / 46.7^{\circ}$, retentate flow rate: $1.05 \mathrm{ml} / \mathrm{min}$, permeate flow rate:

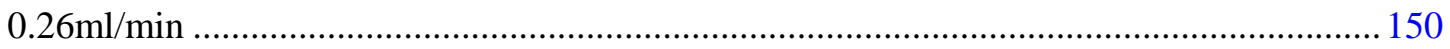

Table B.6 Alkaline Oxidation Yellow Poplar, first run --- $180 \mathrm{rpm} / 46.7^{\circ}$, retentate flow rate:

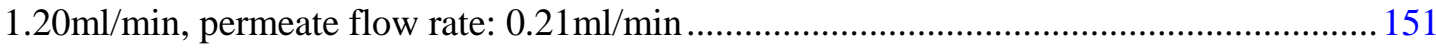

Table B.7 Alkaline Oxidation Yellow Poplar, second run --- $180 \mathrm{rpm} / 46.7^{\circ}$, retentate flow rate: $1.07 \mathrm{ml} / \mathrm{min}$, permeate flow rate: $0.30 \mathrm{ml} / \mathrm{min}$ 151

Table B.8 Ammonia Steeping Corn Cob, first run --- $180 \mathrm{rpm} / 46.7^{\circ}$, retentate flow rate: $1.08 \mathrm{ml} / \mathrm{min}$, permeate flow rate: $0.27 \mathrm{ml} / \mathrm{min}$

Table B.9 Ammonia Steeping Corn Cob, second run---180rpm $/ 46.7^{\circ}$, retentate flow rate: $1.08 \mathrm{ml} / \mathrm{min}$, permeate flow rate: $0.30 \mathrm{ml} / \mathrm{min}$ 152

Table C.1 Solka Floc 200FCC Continuous Hydrolysis --- no surfactant............................................ 158

Table C.2 Solka Floc 200FCC Continuous Hydrolysis --- with Tergitol …........................................ 159

Table C.3 Solka Floc 200FCC Continuous Hydrolysis --- with Pluronic.............................................. 160

Table C.4 Alkaline Oxidation Yellow Poplar Continuous Hydrolysis --- no surfactant ...................... 161

Table C.5 Alkaline Oxidation Yellow Poplar Continuous Hydrolysis --- with Tergitol ....................... 162

Table C.6 Alkaline Oxidation Yellow Poplar Continuous Hydrolysis --- with Pluronic........................ 163 
Table C.7 Ammonia Steeping Yellow Poplar Continuous Hydrolysis --- no surfactant ...................... 164

Table C.8 Ammonia Steeping Yellow Poplar Continuous Hydrolysis --- with Tergitol ....................... 165

Table C.9 Ammonia Steeping Yellow Poplar Continuous Hydrolysis --- with Pluronic ...................... 166

Table C.10 Clkaline Oxidation Corn Cob Continuous Hydrolysis --- no surfactant .............................. 167

Table C.11 Alkaline Oxidation Corn Cob Continuous Hydrolysis --- with Tergitol.............................. 168

Table C.12 Alkaline Oxidation Corn Cob Continuous Hydrolysis --- with Pluronic .............................. 169

Table C.13 Ammonia Steeping Corn Cob Continuous Hydrolysis --- no surfactant............................. 170

Table C.14 Ammonia Steeping Corn Cob Continuous Hydrolysis --- with Tergitol.............................. 171

Table C.15 Ammonia Steeping Corn Cob Continuous Hydrolysis --- with Pluronic .............................. 172

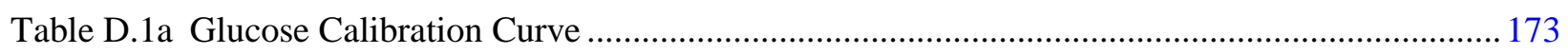

Table D.1b Enzyme Dilution vs. Glucose Concentration ................................................................ 173 


\section{Nomenclature}

AIL: Acid insoluble lignin

AO: Alkaline oxidation

AS: Ammonia steeping

ASL: Acid soluble lignin

$\mathrm{C}_{\mathrm{bm}}$ : $\quad$ Mean outlet cellobiose concentration of TMR $(\mathrm{mg} / \mathrm{ml}$ or $\mathrm{mg} / \mathrm{L})$;

$$
\mathrm{C}_{\mathrm{bm}}=\frac{\mathrm{C}_{\mathrm{br}} * \mathrm{v}_{\mathrm{r}}+\mathrm{C}_{\mathrm{bp}} * \mathrm{v}_{\mathrm{p}}}{\mathrm{v}_{\mathrm{r}}+\mathrm{v}_{\mathrm{p}}}
$$

$\mathrm{C}_{\mathrm{bp}}$ : Permeate (shell side outlet) cellobiose concentration $(\mathrm{mg} / \mathrm{ml}$ or $\mathrm{mg} / \mathrm{L}$ )

$\mathrm{C}_{\mathrm{br}}: \quad$ Retentate (lumen side outlet) cellobiose concentration $(\mathrm{mg} / \mathrm{ml}$ or $\mathrm{mg} / \mathrm{L}) ; \mathrm{C}_{\mathrm{br}}=\mathrm{C}_{\mathrm{gr}} * \frac{\mathrm{C}_{\mathrm{bp}}}{\mathrm{C}_{\mathrm{gp}}}$

CC: Corn cob

$\mathrm{C}_{\mathrm{gm}}: \quad$ Mean outlet glucose concentration of TMR (mg/ml); $\mathrm{C}_{\mathrm{gm}}=\frac{\mathrm{C}_{\mathrm{gr}} * \mathrm{v}_{\mathrm{r}}+\mathrm{C}_{\mathrm{gp}} * \mathrm{v}_{\mathrm{p}}}{\mathrm{v}_{\mathrm{r}}+\mathrm{v}_{\mathrm{p}}}$

$\mathrm{C}_{\mathrm{gp}}$ : Permeate (shell side outlet) glucose concentration $(\mathrm{mg} / \mathrm{ml}$ or $\mathrm{mg} / \mathrm{L}$ )

$\mathrm{C}_{\mathrm{gr}}$ : $\quad$ Retentate (lumen side outlet) glucose concentration $(\mathrm{mg} / \mathrm{ml}$ or $\mathrm{mg} / \mathrm{L}$ )

$\mathrm{C}_{\mathrm{tm}}$ : $\quad$ Mean outlet concentration of glucose and cellobiose combined $(\mathrm{mg} / \mathrm{ml}$ or $\mathrm{mg} / \mathrm{L})$;

$$
\mathrm{C}_{\mathrm{tm}}=\frac{\left(\mathrm{C}_{\mathrm{gr}}+\mathrm{C}_{\mathrm{br}}\right) * \mathrm{v}_{\mathrm{r}}+\left(\mathrm{C}_{\mathrm{gp}}+\mathrm{C}_{\mathrm{bp}}\right) * \mathrm{v}_{\mathrm{p}}}{\mathrm{v}_{\mathrm{r}}+\mathrm{v}_{\mathrm{p}}}=\mathrm{C}_{\mathrm{gm}}+\mathrm{C}_{\mathrm{bm}}
$$

$\mathrm{E}_{0}: \quad$ Enzyme concentration inside enzyme reservoir $(\mathrm{mg} / \mathrm{ml})$

$\mathrm{E}_{\mathrm{R}}: \quad$ Enzyme concentration inside TMR $(\mathrm{mg} / \mathrm{ml})$

$\mathrm{F}_{\mathrm{R}}: \quad$ Surfactant concentration inside TMR $(\mathrm{mg} / \mathrm{ml})$

HF: Hollow Fiber

p: $\quad$ Productivity of glucose and cellobiose combined (mg/min); 


$$
\mathrm{p}=\frac{\left\lfloor\left(\mathrm{C}_{\mathrm{gr}}+\mathrm{C}_{\mathrm{br}}\right) * \mathrm{v}_{\mathrm{r}}+\left(\mathrm{C}_{\mathrm{gp}}+\mathrm{C}_{\mathrm{bp}}\right) * \mathrm{v}_{\mathrm{p}}\right\rfloor}{1000}
$$

$\mathrm{S}_{0}: \quad$ Substrate concentration inside substrate reservoir $(\mathrm{mg} / \mathrm{ml})$

$\mathrm{S}_{\mathrm{R}}: \quad$ Substrate concentration inside TMR $(\mathrm{mg} / \mathrm{ml})$

TMR: Tubular membrane reactor

$\mathrm{v}_{\mathrm{p}}$ : Permeate flow rate $(\mathrm{ml} / \mathrm{min})$

$\mathrm{v}_{\mathrm{r}}: \quad$ Retentate flow rate $(\mathrm{ml} / \mathrm{min})$

$\mathrm{X}_{\mathrm{G}}$ : Substrate conversion to glucose;

$$
\begin{aligned}
& \mathrm{X}_{\mathrm{G}}=\frac{\left[\overline{\mathrm{C}_{\mathrm{gr}}} * \mathrm{v}_{\mathrm{r}}+\overline{\mathrm{C}_{\mathrm{gp}}} * \mathrm{v}_{\mathrm{p}}\right] * \Delta \mathrm{t}}{\text { solid injected during } \Delta \mathrm{t}}=\frac{\left[\overline{\mathrm{C}_{\mathrm{gr}}} * \mathrm{v}_{\mathrm{r}}+\overline{\mathrm{C}_{\mathrm{gp}}} * \mathrm{v}_{\mathrm{p}}\right] * \Delta \mathrm{t}}{\mathrm{S}_{0} *\left(\mathrm{v}_{\mathrm{r}}+\mathrm{v}_{\mathrm{p}}\right) * \Delta \mathrm{t}} \\
& \overline{\mathrm{C}_{\mathrm{gr}}} \text { and } \overline{\mathrm{C}_{\mathrm{gp}}} \text { are the averaged values over } \Delta \mathrm{t}
\end{aligned}
$$

YP: Yellow poplar

Subscripts:

0: $\quad$ Inside the reservoir

$\mathrm{R}: \quad$ Inside the reactor

b: Cellobiose

g: $\quad$ Glucose

$\mathrm{m}: \quad$ Mean value of permeate and retentate

p: $\quad$ Permeate

r: $\quad$ Retentate

t: $\quad$ Both glucose and cellobiose 


\section{Chapter 1 Introduction}

Sustained economical growth depends on having a secure supply of raw material inputs. Although hydrocarbon continues to play a successful role in the economic development, it is a diminishing raw material. There are many similarities existing between biomass and crude oil when compared as energy and chemical feed stock. Yet biomass has the advantage of being a renewable and sustainable source of carbon in the form of polymeric and monomeric components. Renewable carbon is produced at a huge rate in the biosphere; about $77 \times 10^{9}$ tons is fixed annually. Currently, it is the general absence of low-cost processing technology that prevents the effective use of this huge amount of renewable resource.

Technology and research challenges associated with converting biomass into commodity products are related to overcoming the recalcitrance of cellulosic material (converting cellulosic biomass into reactive intermediate) and product diversification (converting reactive intermediates into useful products). Advances are needed in developing pretreatment technology to make cellulosic materials more accessible to enzyme hydrolysis [Lynd et al., 1999].

Pretreatment usually targets hemicellulose, lignin or both, in order to make biomass more accessible. In this M.S. project, we will concentrate on three different pretreatment methods, i.e., ammonia steeping [Cao et al., 1996; Dominguez et al., 1997; Gong et al., 1997 and Tsao et al., 1996], alkaline oxidation [Curreli et al., 1997; Patel and Bhatt, 1991], and the classical dilute acid pretreatments [Grohmann et al., 1984 and 1985; Nguyen et al., 1998; Knappert et al., 1980 and 1981; Torget et al., 1990, 1991 and 1992; Torget and Hsu, 1994; Spindler et al., 1990 and 1991]. The aim is: 1) to compare the efficiency of these three pretreatments and 2) to prepare 
adequate amounts of pretreated lignocellulosic substrates from Ammonia Steeping and Alkaline Oxidation method for use in the tubular membrane reactor (TMR), where enzymatic hydrolysis is later performed.

A well-known issue in enzymatic hydrolysis of cellulose is product inhibition. One of the approaches to overcome product inhibition and hence to enhance the enzymatic hydrolysis is the use of ultrafiltration (UF) membrane reactor [Henley et al., 1980]. Some previous work using cellulose, not lignocellulose, as feed has also been done in our lab, using both polymeric and ceramic TMRs [Gauba, 1993 and Layton, 1991]. This M.S. project aims to further improve the performance of this system technically and economically.

Application of surfactants has been known to enhance enzyme-substrate contact and hence enzymatic hydrolysis of cellulosic materials. It has also been reported that surfactants have the function of protecting enzymes from deactivation and thus help enzyme activity to last longer, which is very helpful in both long-term enzymatic hydrolysis and enzyme recycling. In our study, surfactants will be used to enhance the enzymatic hydrolysis of pretreated lignocellulosic material.

Enzyme recovery and recycling is very important in further improving process efficiency. In this project, preliminary study on enzyme partitioning in aqueous two-phase system (ATPS) will be conducted. The results might provide some information for recovering and recycling enzymes and unreacted substrates in some future studies. 


\section{Chapter 2 Literature Review}

\subsection{Lignocellulosic Materials}

Wide spectrum of lignocellulosic biomass exists, including agricultural residues, herbaceous crops, deciduous (hard wood) and coniferous (soft wood) trees, and municipal solid waste. These biomass exhibit a wide range of susceptibilities to pretreatment and saccharification due to their compositional and structural differences.

\subsubsection{Components of Lignocellulosic Materials}

Cellulosic materials are composed of three major components, extraneous substances, polysaccharides, and lignin [Fan et al., 1987, §2.1].

\subsubsection{Extraneous Materials}

The extraneous substance refers to all the non-cell wall materials. Based on their solubility in water and neutral organic solvents, they can be classified as extractives, e.g., terpenes, resins and phenols, and non-extractives (mainly inorganics present in ash minerals), e.g., alkali, alkali earth carbonates and oxalates.

\subsubsection{Polysaccharides}

Polysaccharide, also called glycans, comprises high molecular weight carbohydrates, namely cellulose and hemicellulose. 
Cellulose is a linear polymer of D-glucose linked by $\beta-1,4$ linkages to form a highly crystalline material that is resistant to enzymatic hydrolysis. Since cellulose is a homopolysaccharide, it can also be named after its only type of monosaccharide building block glucose, as glucans.

Hemicellulose is composed of short chain polysaccharides, and it is the principal non-cellulosic fraction of polysaccharides. The role of this component is to provide a linkage between lignin and cellulose. In its natural state, hemicellulose exists in amorphous form. It can be divided into three groups, xylans, mannans and galactans. The xylans are present as arabinoxylans, glucoronoxylans or arabinoglucuronoxylans. It is a polymer of 4-O-methylglucuronoxylan and 4-O-methyl-glucuronoarabinoxylans linked by a $\beta$-D-(1 $\rightarrow 4)$ bond, similar to the linkage between glucose units in cellulose.

\subsubsection{Lignin}

Lignin is essentially a three-dimensional phenylpropane polymer with phenylpropane units held together by ether and carbon-carbon bonds. Lignin possesses a high molecular weight and is amorphous in nature.

\subsubsection{Structure of Lignocellulosic Materials}

The intricate structure and typical distribution of chemical constituents (cellulose, hemicellulose, lignin) inside cell wall is depicted in Figure 2.1 [Fan et al, 1987].

The bottom two figures show that a typical wood cell wall is composed of the primary wall (P), the thin outer layer of the secondary wall (S1), the substantial middle layer of the secondary wall 
(S2) and the very thin inner layer of the secondary wall (S3). Surrounding the fiber is the heavily lignified and stiff middle lamellae (M) shared by adjacent fibers.

The top one figure shows distribution of chemical constituents inside each layer of the cell wall. The middle lamellae is mainly composed of lignin, with a thickness of 1-2 $\mu \mathrm{m}$. Lignin forms a physical barrier at the outer periphery of each individual wood fiber. The primary wall is usually very thin. The secondary wall thickens during the cell growth and contains the majority of the cellulose.

\subsection{Cellulase}

Cellulase refers to a group of enzymes that contribute to the degradation of cellulose to glucose. A brief illustration of these enzyme components can be found in Figure 2.2.

In most cellulolytic organisms, several cellulase components form a cellulase complex, which synergistically hydrolyze cellulosic substrates. The major components of cellulase are

endoglucanases, exoglucanases, $\beta$-glucosidases and exoglucosidases. Endoglucanases act randomly on soluble and insoluble cellulose chains. Exoglucanases, which include cellobiohydrolases (CBHs), act progressively to preferentially liberate cellobiose (in some cases glucose) from the ends of cellulose chain. $\beta$-glucosidases liberate D-glucose from cellobiose dimers, and exoglucosidases preferentially hydrolyze soluble cellodextrins of intermediate chain length [Himmel et al., 1999]. 
Inhibition of forward reaction as a result of accumulation of end product is a fairly common phenomenon for enzyme reactions. Cellulase enzymes are no exception. The main products formed during the cellulose-cellulase hydrolysis reaction are cellobiose and glucose. The activities of endo- and exo- glucanase components of the cellulase are fairly strongly inhibited by the presence of cellobiose, while $\beta$-glucosidase activity is inhibited by the presence of glucose. While researchers generally agree that product inhibition decreases the rate of cellulose hydrolysis, there has been some confusion regarding the exact type and mechanism of the inhibition. Holtzapple et al. (1990) have summarized the results of nearly 40 inhibition studies and concluded different types of inhibition and the inhibitors.

\subsection{Pretreatment Method}

The slow degradation of native lignocellulosics is governed by their structure features such as 1) cellulose present in biomass is highly crystalline, 2) lignin barrier surrounding cellulose hinders attack from enzyme and acid, and 3) the reactive sites are very limited, due to the fact that the capillaries in the biomass are too small to allow the entry of reactive molecules, especially the large enzyme molecules [Fan et al., 1987].

Successful pretreatments are known to disrupt lignin seal to increase accessibility of cellulose to enzyme, disrupt highly ordered structure of cellulose, and increase pore volume as well as available surface area.

Many different pretreatment methods have been proposed according to the above general guideline, including physical, e.g., mechanical pulverization, exposure to supersonic wave or 
supercritical fluid; chemical, e.g., use of acid or alkali; physicochemical, e.g., steam explosion or ammonia fiber explosion; and biological, e.g., use of white rot or brown rot fungi. The most well studied ones are dilute acid and steam explosion pretreatments.

To choose a particular method from many available pretreatment method, there are many considerations such as: 1) the pretreatment process itself should be economical and environmentally friendly; 2) the pretreatment must help to obtain the highest yield of carbohydrate portion of lignocellulosic material, which should be readily hydrolyzed with minimum amount of enzyme into fermentable sugars.

\subsubsection{Dilute Acid Pretreatment}

Exposure to dilute acid at high temperature, usually around $140 \sim 180^{\circ} \mathrm{C}$, has been developed as a pretreatment of lignocellulosics prior to enzymatic saccharification, to improve overall saccharification rate and yield. This process essentially leads to hydrolysis of hemicellulose. Hemicellulose removal increases porosity of the native lignocellulosics and thus enzymatic accessibility to their cellulosic fraction.

Two commonly used feed particle sizes of lignocellulosic substrates in dilute acid pretreatment are 2mm [Nguyen et al., 1998; Spindler et al., 1990 and 1991; Torget et al., 1990, 1991 and 1992], and +60 -80 mesh size [Grohmann et al., 1985; Knappert et al., 1980 and 1981; Torget and Hsu, 1994]. The $+60-80$ size (equivalent to $0.175-0.246 \mathrm{~mm}$ diameter) is suitable for laboratory scale evaluation of the effectiveness of the pretreatment, while the $2 \mathrm{~mm}$ diameter have taken the industrial scale up into consideration. 
Knappert et al. $(1980,1981)$ pioneered dilute acid pretreatment. Their early experiments were conducted at relatively severe conditions at temperature ranging from 160 to $222^{\circ} \mathrm{C}$, sulfuric acid concentrations of $0 \sim 1.5 \%$ and short pretreatment time of less than 1 minute. It has been found that dilute acid pretreatment is efficient for all lignocellulosic substrates. This improvement in enzyme digestibility becomes more significant as the pretreating temperature and/or acid concentration are increased. The increased susceptibility to enzymatic attack was attributed to a combination of factors, such as creation of micropores by the removal of hemicellulose, a transient change in crystallinity and a gross reduction of degree of polymerization. Since severe conditions tend to degrade sugar, which is unfavorable to overall process economics, later attempts were made to optimize the pretreatment by performing it at milder reaction conditions.

Complete removal of hemicellulose from lignocellulosic material during the pretreatment is a necessary prerequisite for successful enzymatic hydrolysis of the cellulosic fraction [Grohmann et al., 1984]. This observation was confirmed by the same authors in an attempt to optimize dilute acid pretreatment on wheat straw and debarked aspen in 1985. Torget et al. (1990, 1991 and 1992) and many others further confirmed that high enzymatic digestibility of glucan in pretreated lignocellulosic material almost always coincide with complete removal of xylan, a group of hemicellulose, which is a polymer of 4-O-methylglucuronoxylan and 4-O-methylglucuronoarabinoxylan liked by $\beta$-D- $(1 \rightarrow 4)$ bond, as mentioned in Section 2.1.1.2.

Extensive studies on dilute acid pretreatment have been conducted over short rotation hardwood and herbaceous crops, as they are the most promising candidates of lignocellulosic biomass in the U.S. Since major part of weight loss of lignocellulosic material during dilute acid 
pretreatment is caused by solubilization of hemicellulose, the change of dry weight loss of lignocellulosic material can be used as a parameter to monitor the progress of pretreatment and to determine the completion of pretreatment [Torget et al., 1991]. Pretreatment of hard wood (poplar hybrid NE388, poplar hybrid N11 and sweetgum) and herbaceous substrate (switchgrass, weeping lovegrass and sericea lespedeza) by dilute sulfuric acid at $140^{\circ} \mathrm{C}$ were completed in $15-$ 30 minutes, but they were completed within 5 minutes at $160^{\circ} \mathrm{C}$. Only a very small amount of lignin $(<15 \%)$ and glucan were solubilized. After being pretreated at the same condition $\left(160^{\circ} \mathrm{C} / 10\right.$ minutes $)$, the pretreated grasses had less remaining cellulose content and reached slightly lower digestibility of cellulose than the pretreated hardwoods in the subsequent enzymatic hydrolysis test. But these pretreated grass seemed to digest 2-3 times faster than pretreated hard wood [Torget et al., 1990].

Similar results were observed by Torget et al. (1991) in pretreating other hardwood (silver maple, sycamore and black locust) and herbaceous samples (corn cobs, corn stover). For example, enzymatic saccharification of pretreated corn residues (including corn cob and corn stover) was essentially completed after only 24 hours, which is $2-3$ times faster than that of pretreated hardwood reported by Torget et al. (1990). The cellulose digestibility of corn residue, by enzyme, reached $90-100 \%$ after $5-10$ minutes of pretreatment at $160^{\circ} \mathrm{C}$. After only 5 minutes at $140^{\circ} \mathrm{C}, 90 \%$ of the cob cellulose is already digestible (to subsequent hydrolysis). The much shorter pretreatment time required for these corn-derived substrates make them excellent substrates for enzymatic saccharification. 
In recent years, as more and more substrates are involved in the study, high enzymatic digestibility of pretreated substrates is still found to coincide with the complete removal of xylan for pretreatment at $140-160^{\circ} \mathrm{C}$. However, strong temperature (pretreatment temperature) effects on the digestibility of cellulose fraction of flatpea hay and reed canary grass pretreated in the range of $140-180^{\circ} \mathrm{C}$ does not seem to be solely related to the removal of hemicellulose. The temperature induced changes in cell wall structure and porosity might also have a strong influence on the effectiveness of dilute acid pretreatment [Torget et al., 1992].

A summary of the conditions applied to and the corresponding results obtained from dilute acid pretreatment for different substrates are listed in Table 2.1a and Table 2.1b, respectively. Overall, dilute acid pretreatment is effective in removing the hemicellulose fraction from lignocellulose. The amount of lignin and cellulose dissolved during this pretreatment method is usually minor.

In general, pretreatment conditions that favor high enzymatic digestibility substantially degrade hemicellulosic sugars. Grohmann et al. (1985) and many others have indicated that dilute acid solubilization of hemicellulose in hardwoods and other agricultural residues exhibited a biphasic phenomenon: when the amount of xylan remaining in the solid residue was plotted vs. time, two distinctly different slopes were observed. As a result of this observation, it has been proposed that xylan in lignocellulosic biomass composes of two fractions --- one easy and one hard to hydrolyze during pretreatment. Lately, Torget et al. (1994) proposed a two-step dilute acid pretreatment, targeting at two different xylan existing simultaneously in biomass by applying temperatures of $140^{\circ} \mathrm{C}$ and $170^{\circ} \mathrm{C}$ in sequence. This is achieved by pumping the hydrolysate, 
which contains solubilized hemicellulose from the first step $\left(140^{\circ} \mathrm{C}\right)$, out of the reactor and washing the substrate residue to remove all acid. Only after this washing step, the temperature is further increased to $170^{\circ} \mathrm{C}$ for the second-step pretreatment. This method was superior both in the yield of xylose equivalents and the enzymatic digestibility of the pretreated biomass. It also decreased the amount of xylan being degraded to furfural during pretreatment.

The idea of two step dilute acid hydrolysis has also been practiced by Nguyen et al. (1998) on soft wood species (douglas fir and ponderosa pine), with the first step operating at lower temperature of $170 \sim 190^{\circ} \mathrm{C}$ to degrade the easy-digest hemicellulose, followed by a wash step to take the solubilized hemicellulose before a second step of pretreatment at higher temperature of $200 \sim 230^{\circ} \mathrm{C}$ to deal with the hard to digest hemicellulose.

\subsubsection{Ammonia Steeping Pretreatment}

Ammonia steeping employs liquid ammonia as a strong swelling agent for cellulose. This pretreatment was first patented by Lehmann (1905). The benefits of this method include: solubilizing lignin, chemically swelling cellulose and disruption of crystalline structure of cellulose, and increase in accessible surface area of cellulose.

Recently, a relatively new approach combining ammonia steeping and mild dilute acid pretreatments was reported [Cao et al., 1996; Dominguez et al., 1997; Gong et al., 1997; and Tsao et al., 1996]. The method involves first steeping of lignocellulosic biomass in aqueous ammonia at ambient temperature to remove lignin, acetate, and extractives. This is followed by a dilute acid pretreatment that hydrolyzes hemicellulose fraction of the partially delignified 
material obtained from the first step. Finally the cellulose fractions resulted were collected after thorough washing. The advantage of this new method is a step-by-step separation of lignin, hemicellulose and cellulose from the biomass. Around $80 \sim 90 \%$ of lignin can be removed through the ammonia steeping step. The high quality (purity) lignin obtained can be used for synthesis of polymers and chemicals. Hemicellulose was kept intact during the steeping step and the overall yield of xylan is pretty high in the second step. Since all the lignin, acetate, alkali extractives and hemicellulose are removed during the combined pretreatment, less enzyme is needed downstream to effectively hydrolyze the enriched cellulose to glucose. This method has found successful application in pretreating both corncob and poplar wood.

This pretreatment was chosen for use in our study, due to its mild reaction condition, yet strong capacity for removing both lignin and hemicellulose.

\subsubsection{Alkaline Oxidation Pretreatment}

The alkaline oxidation pretreatment, as implied by its name, is the combination of the alkaline and oxidative pretreatments. Alkaline pretreatment utilizes dilute alkaline solution to cause lignocellulosic material to swell, leading to increase in its internal surface area, decrease in crystallinity and degree of polymerization of cellulose fraction. It also causes disruption of lignin structure, and separation of structural linkages between lignin and carbohydrates. The basic mechanism of alkali pretreatment is saponification of intermolecular ester bonds cross-linking xylan hemicellulose and other polymeric materials, such as lignin and other hemicellulose [McMillan, 1994]. The removal of cross-linking ester bonds leads to the swelling of cellulosic materials. Oxidative pretreatment utilizes oxidizing agents to cause structural modification of 
lignocellulose by allowing the agents to penetrate inside the biomass and to oxidize it [Fan et al., 1987].

In weak alkaline media, $\mathrm{H}_{2} \mathrm{O}_{2}$ only selectively acts on phenolic compounds originated from partial scission of lignin, causing its degradation without changing the cellulosic fraction of the lignocellulosic material [Curreli et al., 1997].

Using only $\mathrm{H}_{2} \mathrm{O}_{2}$ pretreatment in alkaline environment alone [Patel and Bhatt, 1991] or combining it with a preceding alkali pretreatment step [Curreli et al., 1997] are both found to be effective in pretreating lignocellulosic biomass.

Compared to other pretreatment processes, alkaline oxidation pretreatment has its own advantage in breaking down the crystalline structure of cellulose and in decomposing lignin into only $\mathrm{CO}_{2}$, $\mathrm{H}_{2} \mathrm{O}$ and carboxylic acid. Besides, inhibitory substances like furfural and hydroxymethylfurfural are not produced unlike in most other pretreatment methods.

This method was also chosen as one of the pretreatment methods in our study, due to its mild reaction condition (ambient temperature and pressure), more importantly its capability of removing majority of lignin --- 92\% removal of lignin [Dominguez et al. 1997], and no accumulation of enzyme-inhibitory substance, such as furfural and hydroxymethylfurfural. 


\subsection{Membrane Bioreactors}

Membrane technology, and ultrafiltration in particular, is well suited to take care of the rigorous demands of the products of biotechnology, such as enzymes and microorganisms. One of the applications of ultrafiltration is in the area of continuous bioreactors for enzymatic and microbial conversion.

\subsubsection{Classification of Membranes}

Membranes can be broadly classified as organic and inorganic membranes. The "first" generation of membranes is organic cellulose acetate with applications in reverse osmosis (RO) and ultrafiltration (UF). Their limitation in temperature and $\mathrm{pH}$ range led to the development of the "second" generation, which are polymeric membranes. Polymeric membranes can operate at wider range of temperature and $\mathrm{pH}$, as compared to cellulose acetate membranes and thus have found wide application in RO, UF, and microfiltration (MF). However due to their thermoinstability, polymeric membranes are not suitable for very high temperature operation environment.

The "third" generation membranes, inorganic membranes, made mainly from zirconium and aluminum oxides, have many physical and chemical properties that make them superior than the earlier membranes. But they also have their disadvantage such as high production cost and the difficulty of producing low nominal molecular weight cut-off (NMWC) modules.

Some detailed information on membrane classification can be found in Gauba (1993). 


\subsubsection{Cellulose Hydrolysis in Membrane Reactors}

As discussed earlier (Section 2.2), the rate of enzymatic hydrolysis of lignocellulosic material is very much affected by the accumulation of the inhibitory products. Thus it is desirable to reduce the concentration of soluble sugars in hydrolysate. The two common methods would be 1) simultaneous saccharification and fermentation and 2) use of membrane reactor. The ultrafiltration membrane acts as a selective barrier that confine enzyme together with unreacted substrate inside the reactor, while letting the inhibitory products sugars (mainly glucose and cellobiose) penetrate through continuously.

The advantage and disadvantage of simultaneous saccharification and fermentation has been summarized by Layton (1991). The idea of utilizing membranes for continuous removal of inhibitory products was first demonstrated by Ghose and Kostick (1970), by using flat ultrafiltration. The polymeric hollow-fiber (HF) membranes were used to enhance enzymatic hydrolysis by Henley et al. (1980), and Jones and Yang (1980). These works were later extended by many others including Layton (1991) and Gauba (1993).

Figure 2.3 illustrates the common set up of both flat-membrane reactor and hollow-fiber reactors used in Henley et al (1980). Basically, the system consisted of a CSTR (continuous stir tank reactor) operated in series with either a stirred ultrafiltration cell or a hollow fiber cartridge. Their results suggest that ultrafiltration membrane bioreactors effectively improve the overall glucose yield. The tubular membrane reactors not only outperform the non-membrane reactors, they are also superior than the flat-membrane reactors. This is due to the following reasons: 1) Tubular membrane reactors (TMRs) have significantly more surface area per reactor volume 
than the flat-membrane reactors, which allows more inhibitory products to be removed; 2) The cross-flow pattern in TMRs make them less susceptible to flux-limiting phenomena like concentration polarization; 3) The configuration of the TMRs allows inhibitory products to be removed as soon as they are produced; and 4) TMRs can be easily scaled up by connecting them in parallel.

\subsubsection{Solid Suspension}

Enzyme-substrate contact is critical for enzymatic hydrolysis reaction. Efforts have been made to improve enzyme-substrate contact by increasing flow rate, using different orientations of reactor (horizontal, vertical etc.), and also adding pulsatile pump at the inlet of the TMR to produce more homogenous solid substrate suspension, thus improving the chance of enzyme-substrate contact. Layton (1991) used a fairly high recycling flow rate of $395 \mathrm{ml} / \mathrm{min}$ to ensure the substrate was uniformly mixed with enzyme throughout the batch hollow-fiber membrane reactors. It was found by Gauba (1993) that incorporation of a pulsatile pump in the polymeric membrane system was effective in improving the performance of the membrane bioreactor, by reducing the demand for enzyme by more than $50 \%$, in order to produce the same steady state substrate conversion from the same initial and reaction conditions. It also prevented potential plugging in the case of polysulfone hollow-fiber reactor when flow rate was low.

\subsection{Surfactants}

It has been found that some surfactants, especially non-ionic surfactants, can enhance enzymatic hydrolysis of cellulosic materials. Many studies have been carried out during the last two 
decades and several theories have been proposed to explain the action of surfactants during enzymatic hydrolysis.

There have been two main theories. The first one [Castanon and Wilke, 1981; Helle et al., 1993] is that adsorption and orientation of surfactant render the substrate more accessible by enzymes. The surfactant is adsorbed on the substrate by hydrophobic interactions. This causes the polar groups of the surfactant to point out towards the surrounding aqueous medium, which leads to the increased hydrophilicity of substrate. Because of this amphiphilic characteristics, surfactant brings the substrate quickly into intimate contact with enzymes and allows the enzymes to reach otherwise inaccessible substrate sites.

The second major theory is that surfactant hinders the immobilization of enzymes by reducing their strength of adsorption onto the insoluble substrate. It is believed that in the absence of surfactant, enzymes adsorbed first onto the cellulose functional groups do not desorb after hydrolysis reaction is done on that site. The result is that these enzymes can no longer contribute to further hydrolysis of the remaining cellulose. Meanwhile, free enzyme concentration is lowered in the reaction mixture, as is the hydrolysis rate. Even worse than that, the adsorbed enzyme will slowly deactivate. Surfactant alters the interaction between enzyme and substrate, reducing the binding strength and assist enzyme to reenter the solution [Castanon et al., 1981; Helle et al., 1993; Kaya et al., 1995]. Surfactant makes a hydrophilic environment around the enzymes and makes it easy for them to desorb from the reacted cellulose functional group [Park et al., 1992]. Since the binding strength, with which the enzyme is held onto the insoluble substrate, is reduced, the deactivation associated with irreversible enzyme adsorption is reduced, 
and long-term performance of enzymatic saccharification is enhanced. The reduced binding strength also allows cellulase to move more rapidly along the cellulose chain and enhances the hydrolytic rate, without complete desorption [Kaya et al., 1995].

Other theories include: 1) Non-ionic surfactants disperse enzyme more effectively in solution and enable them to bind to more substrate site [Kaya et al., 1995]; 2) The inactivation of cellulase by shaking and shear can be reduced by the addition of surfactant, such as high molecular weight polyethylene glycol [Reese, 1980]; and 3) Surfactant, especially Tween family, acts as an enzyme stabilizer, which protects enzyme from thermal deactivation, and thus increase optimal temperature of enzymatic hydrolysis by $10^{\circ} \mathrm{C}$ than that of surfactant-free hydrolysis. It is also found that Tween acts as a lignin disrupter since it can enhance the enzymatic digestibility of cellulose fraction of substrate, which indicates that the available site to enzyme is increased when surfactant is added. This increase of available reactive cellulose sites can only be achieved by disruption of the lignocellulosic matrix [Karr et al., 1998].

Pluronic F68 is a non-ionic surfactant. It is an ethylene oxide (EO) propylene oxide block copolymer with a $\mathrm{M}_{\mathrm{W}}$ of 8000 and $\mathrm{N}_{\mathrm{PO}} / \mathrm{N}_{\mathrm{EO}}$ ratio of 0.20 . It was found to outperform other nonionic surfactants (Pluronic F88, Tween 20 and Tween 80) in enhancing enzymatic saccharification of waste newsprint [Wu and Ju, 1998]. With 2\%(w/v) Pluronic F68 added, cellulose conversion with $2 \mathrm{~g} / \mathrm{L}$ cellulase reached $52 \%$, as compared to $48 \%$ conversion achieved with $10 \mathrm{~g} / \mathrm{L}$ cellulase in a surfactant-free system. This indicates that surfactant can dramatically decrease the enzyme dosage necessary to achieve a certain substrate conversion. 
Another nonionic surfactant Tergitol TP-9 (Tergitol NP-9) was found to be most effective in increasing the cellulose activity among 10 surfactants investigated, representing various ionic natures (anionic, cationic and nonionic). It was able to increase the amounts of reducing sugars after enzymatic hydrolysis by $60 \%$, compared to the control reaction with no surfactant added [Kaya et al., 1995].

Literature to date indicate that these two non-ionic surfactants are more effective in enhancing enzymatic hydrolysis of pure cellulose in batch reaction than many other surfactants, it is wise to choose these two surfactants for our study of continuous hydrolysis of pure cellulose and pretreated lignocellulosic materials. We will start with investigating their effect on Solka Floc hydrolysis in our continuos $\mathrm{HF}$ membrane reactor system, to check out whether any improvement could be achieved. Furthermore, we want to apply these two surfactants to the hydrolysis of pretreated lignocellulosic material, also in the HF membrane reactor system, to find out more information.

\subsection{Enzyme Recycling and Aqueous Two-Phase System}

In the enzymatic conversion of lignocellulosic materials, the major part of cost comes from the cost of enzyme. Various strategies have been used to cut down the cost of enzymatic hydrolysis. One approach is to increase the productivity and specific activity of cellulase via advances in molecular biotechnology and protein engineering. Alternatively, one can reuse and recycle cellulase to increase efficiency and decrease cost associated with hydrolysis steps [Gregg and Saddler, 1996]. 
There are two possible enzyme recovery scenarios: recovery of enzyme after complete hydrolysis and recovery of enzyme after partial hydrolysis [Gregg et al., 1996]. The main drawback with the former would be associated with the overall slow rate of the process and the economic burden associated with the extra capital and operating costs required to provide the time necessary to obtain complete hydrolysis. The alternative way is recycling enzyme after the initial logarithm phase of hydrolysis. This is based on the fact that after initial logarithm phase ( 24 hours), most of the cellulosic substrates are already solubilized. To recover enzyme at this stage will ensure steep hydrolysis rate associated with initial stage of hydrolysis. The removal of sugar while recycling the enzyme is an efficient way of reducing end-product inhibition. The recycling of enzyme after partial hydrolysis would have the advantage of shorter incubation time and reduced product inhibition compared to recycling of enzyme after complete hydrolysis.

\subsubsection{Aqueous Two-Phase System (ATPS)}

The aqueous two-phase system (ATPS) may be a promising solution to cellulase recycling. ATPS is obtained by mixing either aqueous solutions of two water-soluble polymers together or the aqueous solution of one polymer with salt. The two polymers or polymer and salt partition and form the top and bottom phases, where target and interference substances will be distributed. Since both upper and lower phases have very high water contents, biomolecules and cells will not denature.

Factors influencing partitioning in aqueous two-phase systems are: the charge of the partitioned molecules, the ionic composition of the medium, the choice of polymers, the polymer molecular weights, and the polymer concentration. By changing the composition of the phase system, it is 
possible to obtain a distribution of particles or macromolecules more or less completely to one of the phase. Low-molecular-weight compounds are distributed more evenly between the phases. As a rule, the larger the molecular weight of a substance, the more one-sided partitioning is possible [Tergitol et al., 1985 a].

One successful example in separating cellulase from the rest in the retentate stream for recycling was reported by Tjerneld et al. (1985 a, b). They studied several ATPSs and found that the most one-sided partition of cellulase to the bottom phase was obtained in the ATPS composed of dextran 40 with $M_{W}$ 40,000, and polyethylene glycol (PEG 40,000) with $M_{W}$ 35,000 - 40,000. In this dextran-polyethylene glycol system, cellulose is partitioned to the bottom phase. Since cellulolytic enzymes have strong affinity for particulate cellulose, the distribution of cellulase to the bottom phase increases as cellulose/enzyme (w/w) ratio is increased. This was found to be the most effective parameter to decrease the partition coefficient $K$ of the enzyme, which is defined as the ratio between the enzyme activity (IU/ml) in the top phase and the enzyme activity (IU/ml) in the bottom phase. When insoluble substrate is present in the reaction mixture, both enzyme and substrate will go to the bottom phase, while glucose being almost equally distributed in both phases.

\subsubsection{Thermoseparating Aqueous Two-Phase System}

A new development in the ATPS has been the introduction of thermoseparating polymers. Two phases can be formed by heating the aqueous solution of a thermoseparating polymer to above a critical temperature known as cloud point. One of the phases (usually bottom phase) will be enriched in the polymer while the other one will be depleted. An example of the 
thermoseparating polymer is random copolymers of ethylene oxide (EO) and propylene oxide (PO) segments (EOPO copolymers). Many studies of biomolecules partitioning in thermoseparating systems have been performed in systems containing EOPO copolymer [Persson et al., 1999].

By using a thermoseparating polymer to form aqueous two-phase system, the aqueous two-phase extraction and thermoseparating can be combined together. One such example is EOPO/dextran aqueous two-phase system. Target protein first partitions to an EOPO copolymer phase. A new two-phase system will form upon increase in temperature of this EOPO copolymer phase, after it is separated from the dextran phase. One of these secondary two phases is enriched with EOPO copolymer and the other one with basically water. The target protein can be extruded from the polymer rich phase and partition $100 \%$ to the water phase in the secondary new two-phase system. Thus it becomes possible to retrieve the target protein [Persson et al., 1999].

It is also possible to create an ATPS with only one thermoseparating polymer, by simply increasing the temperature of that thermoseparating polymer solution above its cloud point. One of these samples is UCON 50-HB-5100, an EOPO random copolymer with equal amount of weight of $\mathrm{EO}$ and $\mathrm{PO}$, and an average molecular weight of $\mathrm{M}_{\mathrm{W}} 4000$. The amino acids were able to be partitioned in this system. The partitioning strongly depended on the hydrophobicity of amino acid side chain [Johansson et al., 1995]. 


\subsection{List of Tables and Figures for This Chapter}

\subsubsection{Tables}

Table 2.1a Summary of conditions used in dilute acid pretreatment reported in the literature

Table $2.1 \mathrm{~b}$ Summary of results obtained from dilute acid pretreatment reported in the literature

\subsubsection{Figures}

Figure 2.1 Distribution of cellulose, hemicellulose, and lignin in the wood fiber cell wall (Copied from Fan et al., 1987)

Figure 2.2 Mechanism of Cellulose Hydrolysis (Copied from Gauba, 1993)

Figure 2.3 Membrane Reactor System: (A) CSTR - ultrafiltration cell; (B) Hollow-Fiber cartridge from Henley, Yang and Greenfield, 1980 (Copied from Layton, 1991) 
Table 2.1a Summary of conditions used in dilute acid pretreatment reported in literature

\begin{tabular}{|c|c|c|c|c|c|c|}
\hline Reference & Substrate & Substrate Size & $\begin{array}{l}\text { Pretreating } \\
\mathrm{T}\left({ }^{\circ} \mathrm{C}\right)\end{array}$ & Pretreating Time & $\begin{array}{l}\text { Sulfuric Acid } \\
\text { Concentration }\end{array}$ & Solid Concentration \\
\hline Knappert et al. (1981) & Poplar Wood & 60 mesh & $162 \sim 222$ & $3.6 \sim 12.7 \mathrm{sec}$ & $0 \sim 1.5 \%(\mathrm{w} / \mathrm{w})$ & $11.06 \sim 48.30(\mathrm{mg} / \mathrm{ml})$ \\
\hline Grohmann et al. (1984) & Wheat Straw & $\begin{array}{c}\text { passing through } \\
1 / 8 \text { in. screen }\end{array}$ & $95 \sim 160$ & $10 \sim 500 \mathrm{~min}$ & $0.5 \%(\mathrm{w} / \mathrm{w})$ & $10 \%(\mathrm{w} / \mathrm{w})$ \\
\hline \multirow[t]{2}{*}{ Grohmann et al. (1985) } & Wheat Straw & $2 \mathrm{~mm}$ dia. & $95 \sim 160$ & $0 \sim 500 \mathrm{~min}$ & $0.5 \%(\mathrm{w} / \mathrm{w})$ & $10 \%(\mathrm{w} / \mathrm{w})$ \\
\hline & Aspen Wood & $60 \sim 80$ mesh & $95 \sim 160$ & $0 \sim 1260 \mathrm{~min}$ & $0.5 \%(\mathrm{w} / \mathrm{w})$ & $10 \%(\mathrm{w} / \mathrm{w})$ \\
\hline \multirow[t]{6}{*}{ Torget et al. (1990) } & Poplar Hybrid NE388 ${ }^{1}$ & \multirow{6}{*}{$\begin{array}{l}\text { knife milled to } \\
\text { pass } 2 \mathrm{~mm} \\
\text { rejection screen }\end{array}$} & \multirow{6}{*}{140 and 160} & \multirow{6}{*}{$5 \sim 60 \mathrm{~min}$} & \multirow{6}{*}{$0.45 \sim 0.5 \%(\mathrm{v} / \mathrm{v})$} & \multirow{6}{*}{$10 \%(\mathrm{w} / \mathrm{w})$} \\
\hline & Poplar Hybrid NE11 ${ }^{2}$ & & & & & \\
\hline & Sweetgum & & & & & \\
\hline & Switchgrass & & & & & \\
\hline & Weeping Lovegrass & & & & & \\
\hline & Sericea Lespedeza & & & & & \\
\hline \multirow[t]{5}{*}{ Torget et al. (1991) } & Silver Maple & \multirow{5}{*}{$\begin{array}{l}\text { knife milled to } \\
\text { pass } 2 \mathrm{~mm} \\
\text { rejection screen }\end{array}$} & \multirow{5}{*}{140 and 160} & \multirow{5}{*}{$5 \sim 60 \mathrm{~min}$} & \multirow{5}{*}{$0.45 \sim 0.5 \%(\mathrm{v} / \mathrm{v})$} & \multirow{5}{*}{$10 \%(\mathrm{w} / \mathrm{w})$} \\
\hline & Sycamore & & & & & \\
\hline & Black Locust & & & & & \\
\hline & Corncob & & & & & \\
\hline & Corn Stover & & & & & \\
\hline \multirow[t]{2}{*}{ Torget et al. (1992) } & Reed Canary Grass & \multirow{2}{*}{$\begin{array}{l}\text { knife milled to } \\
\text { pass } 2 \mathrm{~mm} \\
\text { rejection screen }\end{array}$} & \multirow[b]{2}{*}{$140,160,180$} & \multirow[b]{2}{*}{$0 \sim 60 \mathrm{~min}$} & \multirow[b]{2}{*}{$0.55 \%(\mathrm{v} / \mathrm{v})$} & \multirow[b]{2}{*}{$10 \%(w / w)$} \\
\hline & Flat Pea Hay & & & & & \\
\hline \multirow[t]{4}{*}{ Spindler et al. (1991) } & Hybrid Populus NE388 ${ }^{3}$ & \multirow{4}{*}{$\begin{array}{l}\text { Wiley milled to } \\
2 \mathrm{~mm} \text { screen }\end{array}$} & \multirow{4}{*}{140} & \multirow{4}{*}{1 hour } & \multirow{4}{*}{$0.45 \%(\mathrm{v} / \mathrm{v})$} & \\
\hline & Hybrid Populus NE11 4 & & & & & \\
\hline & Aspen & & & & & \\
\hline & Sweetgum & & & & & \\
\hline
\end{tabular}


Table 2.1b Summary of results obtained from dilute acid pretreatment reported in literature

\begin{tabular}{|c|c|c|c|c|c|c|c|}
\hline Reference & Substrate & $\begin{array}{l}\text { Cellulose Yield } \\
\%\end{array}$ & $\begin{array}{c}\text { Final } \\
\text { Cellulose \% }\end{array}$ & $\begin{array}{l}\text { Hemicellulose } \\
\text { Loss \% }\end{array}$ & $\begin{array}{c}\text { Final } \\
\text { Hemicellulose } \\
\%\end{array}$ & $\begin{array}{c}\text { Lignin Loss } \\
\%\end{array}$ & $\begin{array}{c}\text { Final } \\
\text { Lignin \% }\end{array}$ \\
\hline Knappert et al. (1981) & Poplar Wood & & & & & & \\
\hline Grohmann et al. (1984) & Wheat Straw & & & & & & \\
\hline \multirow[t]{2}{*}{ Grohmann et al. (1985) } & Wheat Straw & & & & & & \\
\hline & Aspen Wood & & & & & & \\
\hline \multirow[t]{6}{*}{ Torget et al. (1990) } & Poplar Hybrid NE388 ${ }^{1}$ & 90 & & 96.3 & & 18 & \\
\hline & Poplar Hybrid NE1 $1^{2}$ & 91 & & 98.2 & & 17 & \\
\hline & Sweetgum & 84 & & 98.1 & & 17 & \\
\hline & Switchgrass & 82 & & 94.2 & & 4 & \\
\hline & Weeping Lovegrass & 82 & & 93.6 & & 12 & \\
\hline & Sericea Lespedeza & 92 & & 87.2 & & 3 & \\
\hline \multirow[t]{5}{*}{ Torget et al. (1991) } & Silver Maple & 87 & & 97.3 & & 13 & \\
\hline & Sycamore & 85 & & 98.2 & & 6 & \\
\hline & Black Locust & 83 & & 97.2 & & 16 & \\
\hline & Corncob & 86 & & 100 & & 26 & \\
\hline & Corn Stover & 75 & & 93.8 & & 9 & \\
\hline \multirow[t]{2}{*}{ Torget et al. (1992) } & Reed Canary Grass & 78 & & 100 & & ND & \\
\hline & Flat Pea Hay & 81 & & $87-100$ & & ND & \\
\hline \multirow[t]{4}{*}{ Spindler et al. (1991) } & Hybrid Populus NE388 ${ }^{3}$ & & 69.5 & & 1.5 & & 29 \\
\hline & Hybrid Populus NE11 ${ }^{4}$ & & 72.0 & & 0.5 & & 29 \\
\hline & Aspen & & 63.3 & & 4.0 & & 29 \\
\hline & Sweetgum & & 68.0 & & 0.9 & & 29 \\
\hline
\end{tabular}

1: Populus maximowiczii $\times P$. trichocarpa

2: Populus trichocarpa $\times$ P. deltoides
3: Populus maximowiczii $\times$ P. nigra

4: Populus trichocarpa $\times$ P. deltoides (same as 2) 

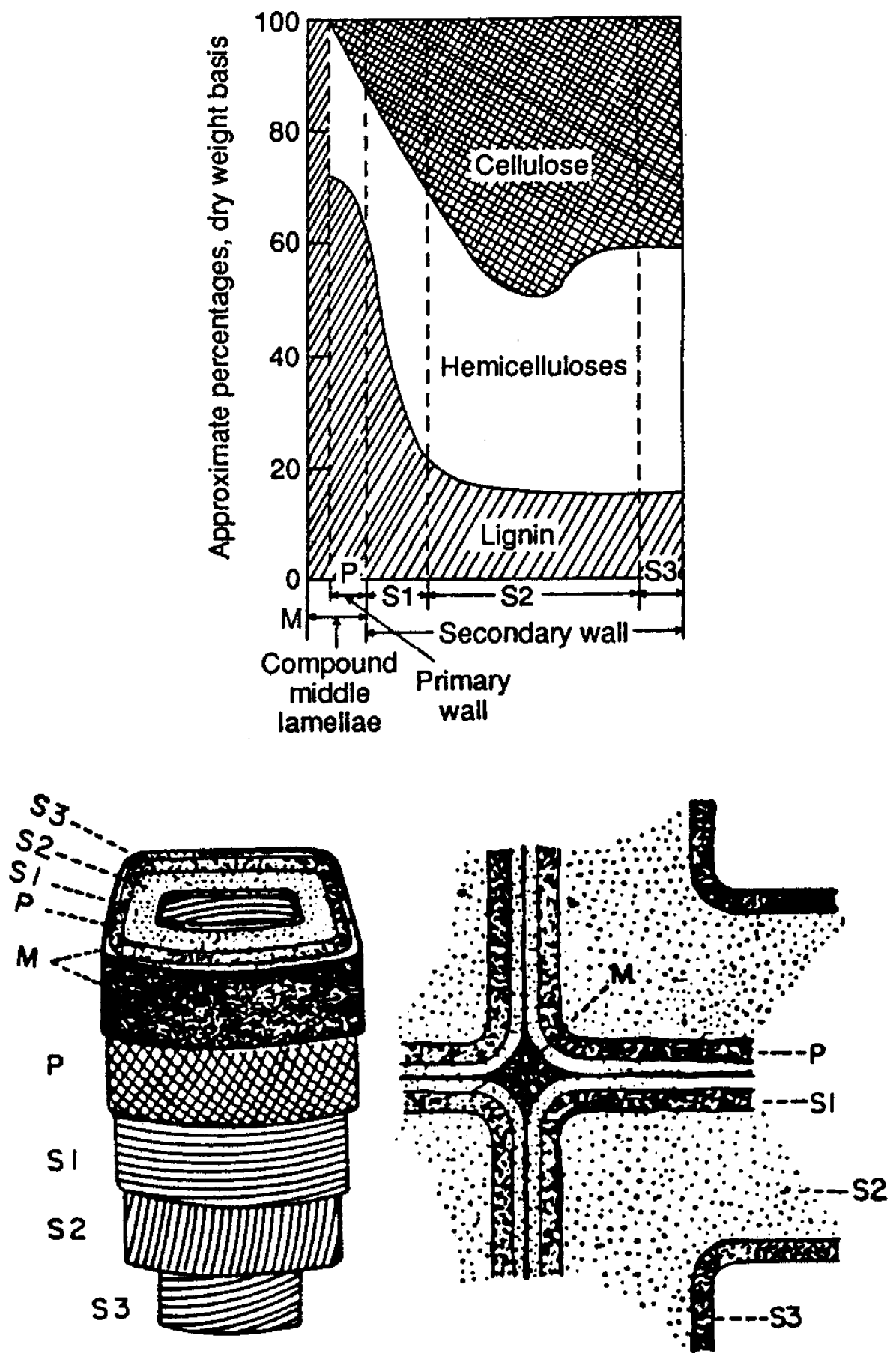

Figure 2.1. Distribution of Cellulose, Hemicellulose and Lignin in Wood Fiber Cell Wall (Copied from Fan et al., 1987 


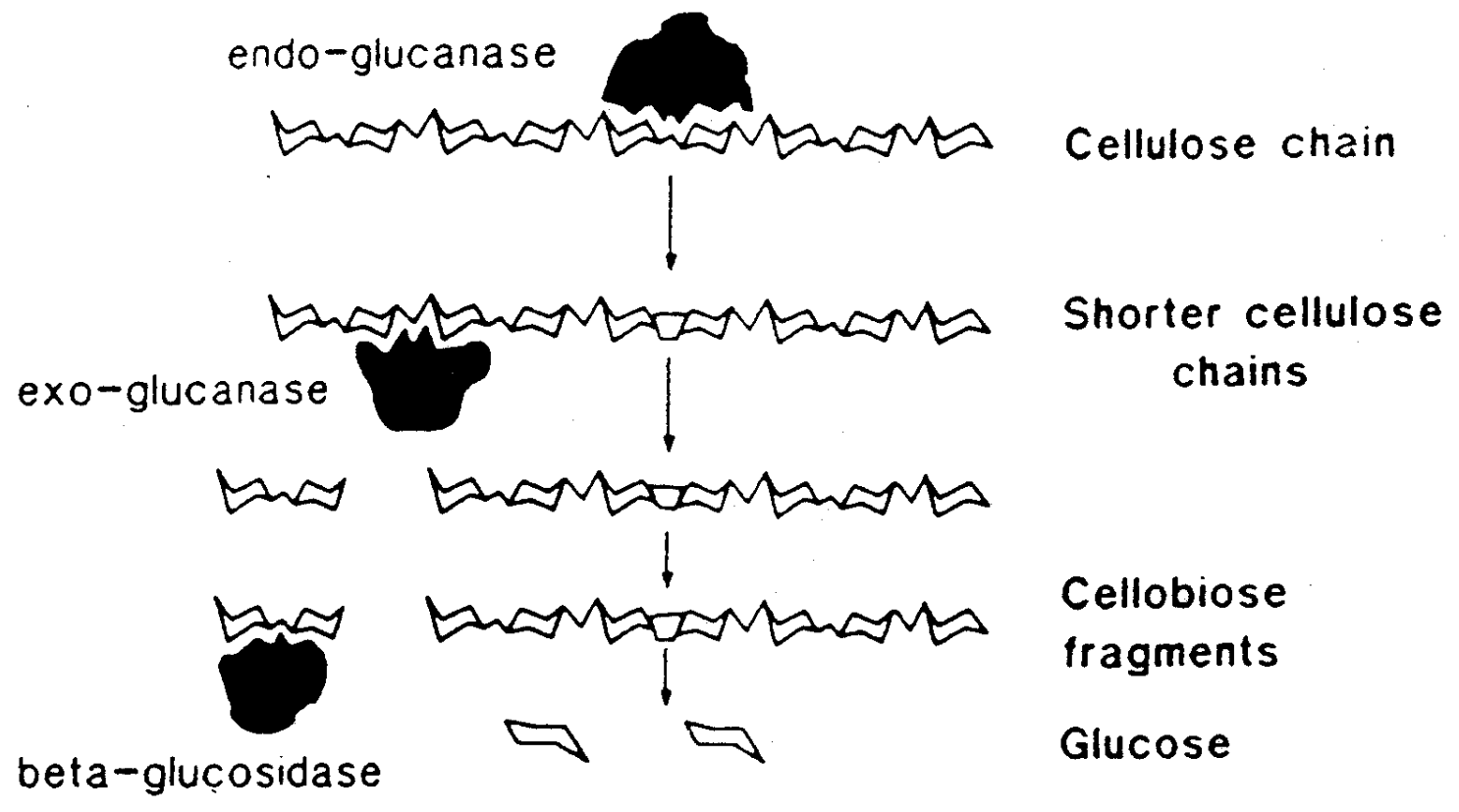

Figure 2.2. Mechanism of Cellulose Hydrolysis

(Copied from Wright, 1988) 


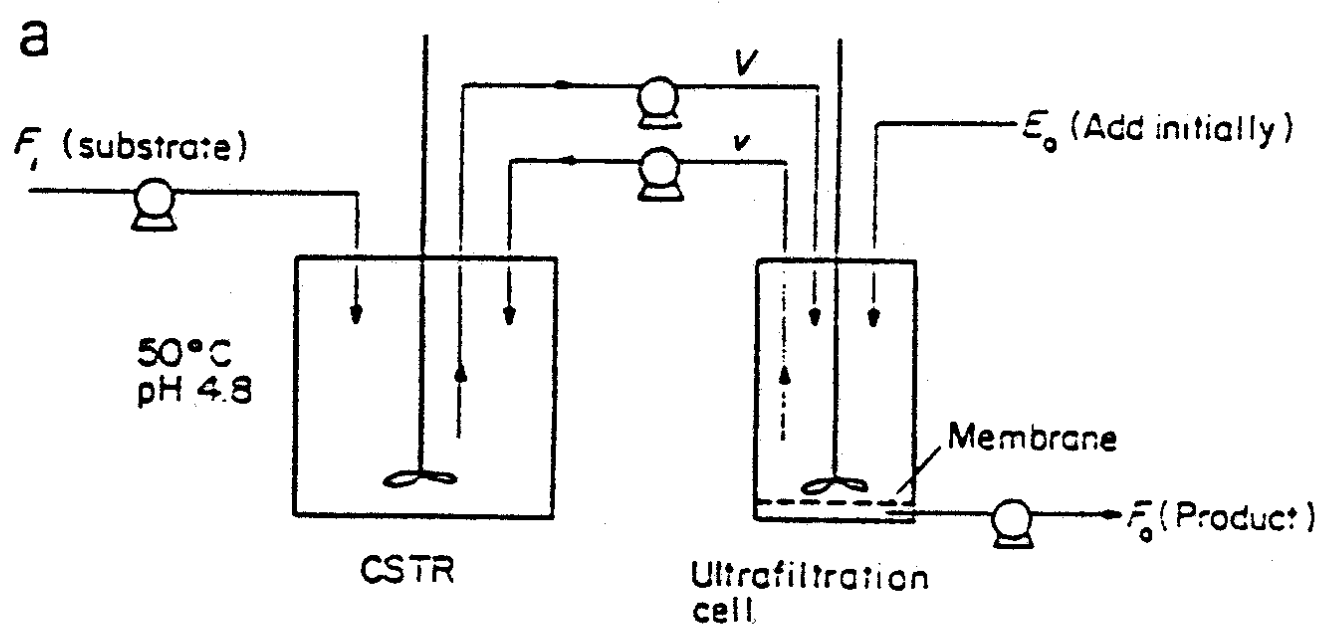

Al sieody sicie $F_{i}=F_{0}=V-v$

b

Bock to CSTP

(lumen side!

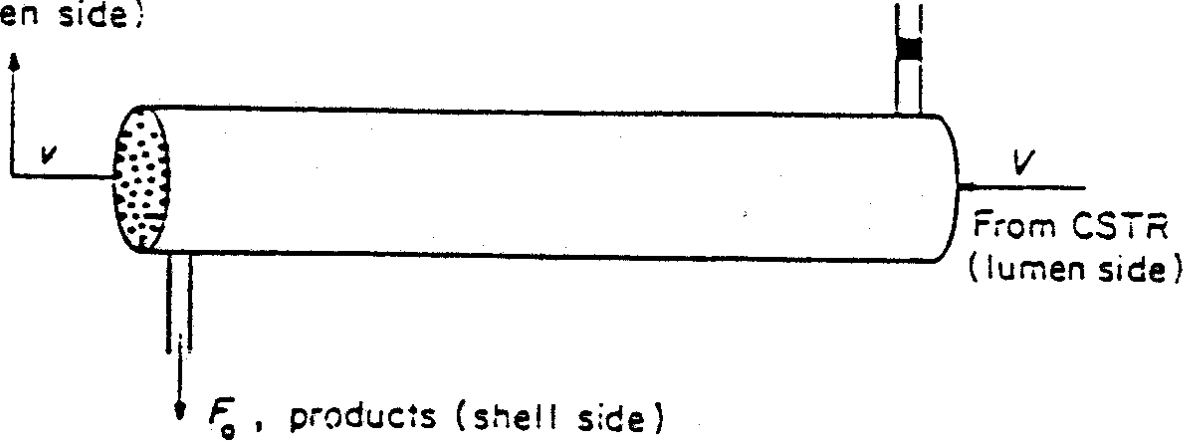

Figure 2.3. Membrane Reactor System: (a) CSTR --- Ultrafiltration Cell; (b) Hollow-Fiber Cartridge from Henley, Yang and Greenfield, 1980

(Copied from Layton, 1991) 


\section{Chapter 3 Objectives}

Objectives of this research at the beginning of this project included the following two parts:

A) To compare the efficiency of three pretreatment methods: ammonia steeping, alkaline oxidation and dilute acid pretreatments. The main criterion was the suitability for incorporating them with the midstream TMR process being developed in this lab.

Pretreated (by ammonium steeping and alkaline oxidation methods) yellow poplar (Liriodendrum tulipifera) and corn cob particles were used as feed for HF cartridge reactor, and the hydrolysis results were compared with that using pure cellulose. The literature data of dilute sulfuric acid pretreatment was used in our study to save time and redundant effort.

B) To improve the performance of enzymatic hydrolysis in HF cartridge reactor with focus on the use of polymeric type (polysulfone) TMR.

1. To improve solid substrate suspension and transportation

To find an optimal combination of shaking speed and inclination angle of HF cartridge reactor that would help to achieve more homogeneous suspension and more smooth transportation of solid substrates through the HF cartridge reactor.

2. To conduct continuous enzymatic hydrolysis in TMR with and without surfactants

Pluronic 68 and Tergitol NP-9 were chosen as the surfactants to enhance the hydrolysis of five different types of substrate in continuous hydrolysis in a TMR. The steady state substrate conversion was compared within each type based upon the different surfactant condition, including none surfactant, with Tergitol and with Pluronic.

3. To apply aqueous two phase system (ATPS) to recycle enzyme

Thermoseparating EOPO copolymers, UCON 50-HB-5100 (EO50PO50; cloud point 50 ${ }^{\circ} \mathrm{C}, 10-$ $20 \%$ solution) and $\mathrm{EO} 30 \mathrm{PO} 70$ (cloud point $40^{\circ} \mathrm{C}, 10 \%$ solution), was to be used separately to 
create ATPS. The ATPS was to be used to separate enzyme from the retentate stream of the TMR. The water phase enriched with enzyme was to be recycled back into the TMR to improve the efficiency of the system. Means of integration of the ATPS recycle streams with the TMR was also included in the initial project design.

Due to time limitation, EO30PO70 was not procured, and major parts of B.3 were not performed. 


\section{Chapter 4 Experimental Details}

\subsection{Material and Equipment}

\subsubsection{Substrates}

\subsubsection{Cellulose}

Solka Floc 200FCC (Fiber Sales \& Development Corp.) is used as the model material for cellulose in this study. Solka Floc is the trade name for a family of finely divided fibrous powders produced from purified cellulose. It is virtually ash free and contains over $99 \%$ of cellulose when dry. The average fiber length of Solka Floc 200FCC is $35 \mu \mathrm{m}$ and that of Solka Floc 900 FCC about $110 \mu \mathrm{m}$. Solka Floc 200FCC serves as a base for comparison with other types of substrates, such as raw and pretreated lignocellulosic materials.

\subsubsection{Lignocellulosic Materials}

We have chosen yellow poplar (YP) and corn cob (CC) as the representative raw lignocellulosics for this study. YP represents the hardwood category and CC represents the herbaceous crops. YP chips with size ranging from 0.1 to $0.5 \mathrm{~mm}$ were obtained from National Renewable Energy Laboratory (NREL) and stored in the freezer compartment (below $0^{\circ} \mathrm{C}$ ) of a refrigerator. $\mathrm{CC}$ samples (Grit-o'cobs) of all sizes: coarse (814), medium (1420), fine (2040) and very fine (4060), were produced from the wood ring of corn cob by the Andersons, Inc.. The grade represents the screen's mesh size used in sizing. For example, Grit-o'cobs 4060 are the granulates which pass through a 40 mesh screen, but retained on a 60 mesh screen. 
Pretreated lignocellulosic substrates were prepared from YP and CC following the procedure described in Section 4.2. The YP chips used for pretreatment were air-dried at room temperature for three days before Wiley-milled to pass through a 0.5 -mm sieve. For CC, the $-40+60$ mesh size, equivalent to $0.25-0.425 \mathrm{~mm}$, was chosen as pretreatment feed. These choices ensure that pretreated particles will be much smaller in dimension compared to the inner diameter of the each hollow fiber in the HF cartridge, which is $1 \mathrm{~mm}$, so that they will pass through the polysulfone TMR without clogging it.

\subsubsection{Enzymes}

Cellulase sample of Multifect GC (lot 301-98288-129) received from Genencor International Inc. in 2000 was used for all runs reported in this thesis. We followed NREL LAP 006 [Adney and Baker, 1996] and found that the activity of this lot of Multifect GC to be 69.4 FPU/ml (as the average value of three separate runs) was reasonably close to the value of $65 \mathrm{FPU} / \mathrm{ml}$ reported by NREL [Nieves et al., 1998].

Novo's Novozym 188 (lot 2544/DCN00029) as a $\beta$-glucosidase enzyme preparation was also used in our study.

\subsubsection{Chemicals}

Surfactants Pluronic F68 and F88 were received from BASF Corporation. Ucon lubricant 50HB-5100 and Tergitol NP-9 (Tergitol TP-9) surfactant were obtained from Union Carbide Corporation. 


\subsubsection{Tubular Membrane Reactor (TMR)}

\section{1) Hollow Fiber Membrane Reactor}

A polysulfone membrane module from $A / G$ Technology was utilized in this study. The A/G Technology ultrafiltration (UF) membranes have a unique microporous supporting structure. Unlike conventional asymmetric membranes which have thin rejecting skin (the membrane) supported by a macrovoid supporting layer, the A/G Technology hollow-fibers have integral membrane and microporous supporting layer. The absence of macrovoids in these membranes allows much higher-pressure difference across the membrane. The membrane can operate at pressure up to $35 \mathrm{psi}$ and temperature up to $80^{\circ} \mathrm{C}$. The $\mathrm{pH}$ range of polysulfone membrane can be as wide as from 1 to 13 . We use an UFP-10-E-4 cartridge reactor throughout our experiments. This cartridge contains 50 hollow fibers, each of which has an inner diameter of $1 \mathrm{~mm}$ and a length of $25 \mathrm{~cm}$. The total membrane area is $420 \mathrm{~cm}^{2}$ for this cartridge. The housing of the HF cartridge has a length of $36.2 \mathrm{~cm}$ and an outer diameter of $2 \mathrm{~cm}$. The lumen (inside the hollow fibers) of HF cartridge holds up to $12 \mathrm{ml}$ and the shell (between the hollow fibers inside the cartridge holder) holds up to $30 \mathrm{ml}$.

\section{2) Water Jacket}

Since temperature is a crucial parameter in enzyme reaction, a water jacket was built around the HF cartridge to help maintain hydrolysis temperature around the optimal reaction temperature of the enzyme used. This water jacket is made of polyacrylic, with a length of $30.48 \mathrm{~cm}$ (1 foot) and inner diameter of $7.62 \mathrm{~cm}$ (3 inches). 


\section{3) Shaker and Cartridge Holder}

The Lab Line \#3520 shaker was used to adjust the rotating speed of the HF cartridge. A cartridge holder was made from 2 pieces of aluminum plates (each $3^{\prime \prime}$ wide and 14" long), and a piece of stainless steel rod (1/3" diameter and $16^{\prime \prime}$ long). The cartridge holder has adjustable inclination, so that the HF cartridge could assume a number of inclines from the horizontal position of the shaker plate. The extend of incline was to be expressed as degree of angle. The detail of the TMR combination is shown in Figures 4.1 and 4.2.

\subsubsection{YSI Model 2700 Biochemistry Analyzer}

YSI Model 2700 Biochemistry Analyzer is a laboratory instrument capable of rapid measurement of a number of different analytes including D-glucose, L-lactate, sucrose, lactose, galactose, ethanol, methanol, starch and hydrogen peroxide. This model has dual channel and can measure the concentration of two different analytes simultaneously. When only single channel is used, the analyzer provides a 90 second measurement of glucose. In this study it was mainly used to analyze glucose concentration from different hydrolysate.

\subsubsection{Spectrophotometer}

Milton Roy Spectronic Genesys 5 spectrophotometer is an easy-to-use, UV/Visible wavelength (200 to $1100 \mathrm{~nm})$ spectrophotometer. 


\subsection{Pretreatment}

Among all the pretreatment methods developed so far, we have chosen the following three methods for comparison of their suitability for use in the TMR process being developed in our lab:
A) Ammonia Steeping Pretreatment
B) Alkaline Oxidation Pretreatment
C) Classical Dilute Acid Pretreatment

One main reason pretreatment $\mathrm{A}$ and $\mathrm{B}$ are chosen among others is because they are able to dissolve not only hemicellulose but also lignin content of lignocellulosic materials. This is important since lignin is known to have negative effect on enzyme activity, by irreversibly adsorbing cellulase and slowly deactivating them. By removing the lignin fraction from lignocellulosics at upstream pretreatment stage, it is possible to achieve higher glucose yield in mid-stream TMR hydrolysis section of the process. The removal of lignin also makes it easier for post-hydrolysis enzyme recovery, since less enzyme will be adsorbed on the substrate residue. Besides, both these two methods have mild pretreating condition (temperature less than $100^{\circ} \mathrm{C}$ ), and low chemical consumption.

The reason method $\mathrm{C}$ is chosen is because it is the most well studied pretreatment method and many papers have been published applying this method on different substrates. Our aim is to compare the efficiency of both A and B with C. With analytical method used in this study, the comparison will be only based on the efficiency of lignin removal, mainly acid insoluble lignin. 


\subsubsection{Ammonia Steeping Pretreatment}

A two step pretreatment method described by Cao et al., (1996); Dominguez et al., (1997); Gong et al., (1997) and Tsao et al., (1996), is performed in this study:

\section{1) Ammonia Steeping}

This step is used to remove lignin, acetate and extractives. Dry YP particles were mixed with $20 \%(\mathrm{w} / \mathrm{v})$ aqueous ammonia with a solid to liquid ratio of 1 to $5(1 \mathrm{~g}: 5 \mathrm{ml})$ in a $500-\mathrm{ml}$ flask and were incubated on a shaker at $25^{\circ} \mathrm{C}$ for 24 hours. The mixture was then filtered to separate the partially delignified YP particle from the ammonia solution, which contains solubilized lignin, acetates and extractives. The solid residue was then washed intensively with deionized distilled (DD) water till $\mathrm{pH}$ reaches 5, and vacuum-dried overnight. The same procedure was applied to CC, except that the ammonia concentration was half of that used in YP.

\section{2) Dilute Acid Hydrolysis}

This step was used to hydrolyze the hemicellulose fraction of the delignified solid material, which had been separated from solubilized lignin in the previous step. The partially delignified solid residues from the first step were subjected to further treatment by $1 \%(\mathrm{w} / \mathrm{v})$ hydrochloric acid solution (equivalent to $0.3 \mathrm{M} \mathrm{HCl}$ ) at $100^{\circ} \mathrm{C}$ for 1 hour with a solid to liquid ratio of 1 to 5 (1g: $5 \mathrm{ml})$. The solid cellulose fractions were separated from the hemicellulose hydrolysate by filtration and then washed with DD water to remove residual acid. The pretreated material was then vacuum-dried at room temperature overnight. The final product was kept at $4^{\circ} \mathrm{C}$ for future chemical analysis, digestibility test and application in HF membrane reactor. 


\subsubsection{Mild Alkaline Oxidation Pretreatment}

The procedure as described by Curreli et al. (1997) was followed in our study. The same particle sizes for $\mathrm{YP}$ and $\mathrm{CC}$, as used in ammonia steeping pretreatment, were used here for fair comparison. This pretreatment method contained the following two steps:

1) Dilute $\mathrm{NaOH}$ to solubilize hemicellulose

About 12 grams of substrate were suspended in $300 \mathrm{ml}$ of $1.5 \%$ (w/v) $\mathrm{NaOH}$. The mixture was then shaken in a water-bath set at $40^{\circ} \mathrm{C}$ for 24 hours. The pretreated substrate was then collected and thoroughly washed with DD water, resuspended in $300 \mathrm{ml}$ of $0.1 \mathrm{M}$ acetic acid and washed again with DD water till $\mathrm{pH}$ reaches 5. Finally it was vacuum dried at room temperature.

2) Combination of dilute $\mathrm{NaOH}$ and $\mathrm{H}_{2} \mathrm{O}_{2}$ to oxidize lignin

After the substrate was pretreated as described above, it was resuspended in $270 \mathrm{ml}$ of $1.67 \%$ (w/v) $\mathrm{NaOH}$. After a few minutes of stirring, $30 \mathrm{ml} \mathrm{of} \mathrm{H}_{2} \mathrm{O}_{2}(3 \%$ (w/v)) was added to make a final concentration of $0.3 \%(\mathrm{w} / \mathrm{v}) \mathrm{H}_{2} \mathrm{O}_{2}$ in the reaction mixtures. The final $\mathrm{NaOH}$ concentration was $1.5 \%(\mathrm{w} / \mathrm{v})$. The suspension was then shaken at room temperature for 24 hours in dark. After that, the solid residue was thoroughly washed and collected as in the first stage. Again the solid was vacuum dried at room temperature overnight before they were stored at $4^{\circ} \mathrm{C}$ for future usage.

\subsubsection{Dilute Acid Pretreatment}

Dilute acid pretreatment method has been extensively employed at NREL to prepare different substrates for use in simultaneous saccharification and fermentation process in their Ethanol Project. There have been many articles describing this procedure. In NREL LAP 007 [Hsu D. 
1995], the experiment was carried out in a 1-L stirred reactor (Parr Co.) constructed from Carpenter 20Cb-3 stainless steel. The reactor was charged with $10 \%$ (w/w, on a moisture free basis) slurry of biomass in deionized water. When desired temperature of the reactor content was reached, dilute sulfuric acid was injected to adjust $\mathrm{pH}$ to equal to 1.5 , and timing of the hydrolysis started. About 10 minutes after the hydrolysis was started, the reaction was terminated. The reactor was then immersed in ice water mixture until the pressure inside the reactor was equalized with the pressure outside. The reactor was then quickly opened and the reaction was quenched by addition of 4 times of water as the original reaction liquid. The pretreated materials were immediately collected by filtration through a medium porosity glass filter. The solids were the washed with hot $\left(85^{\circ} \mathrm{C}\right)$ water until filtrate reached a $\mathrm{pH}$ value of 5.0. The solid residues were stored wet at $-20^{\circ} \mathrm{C}$ for digestibility studies or air-dried at $45^{\circ} \mathrm{C}$ for chemical analyses. Details of this procedure can be found in NREL LAP 007 [Hsu D. 1995]. Optimal pretreatment conditions were expected to be substrate dependent [Hsu D. 1995].

\subsubsection{Comparison of Three Pretreatment Methods}

The ammonia steeping and alkaline oxidation pretreatment methods were compared with respect to their suitability for the TMR process being developed in our lab, based on bench-scale experimental data collected in this study, such as those obtained from the digestibility test, lignin test, and the continuous hydrolysis runs in the HF cartridge. The literature data (basically those regarding lignin removal/residue lignin) for dilute acid pretreatment were also used for comparison. Characterization of the raw and pretreated lignocellulosic substrates was the first step towards a fair comparison of the pretreatment methods. 
The following analytical procedures associated with characterization of lignocellulosics were used in this study:

1) Determination of Total Solids in Biomass --- NREL LAP 001 [Ehrman T, 1994]

This method involves drying samples at $105^{\circ} \mathrm{C}$ in a convection oven and measuring the weights of samples before and after drying. The total solid content of sodium tartrate was also measured along with the samples as a method-verification standard, since the moisture content of this substance is not greatly affected by the storage condition. The published total solids of sodium tartrate is $84.38 \%$.

2) Enzymatic Digestibility of Lignocellulosic Biomass --- NREL LAP 009 [Brown and Torget, 1996]

Both raw and pretreated substrates were subjected to enzymatic hydrolysis following the procedure of NREL LAP 009. In this procedure, a saturating level of commercially available cellulase preparation (equivalent to $60 \mathrm{FPU} / \mathrm{g}$ cellulose) was used and hydrolysis time up to one week was employed in order to determine the maximum possible extent of digestibility for both native and pretreated lignocellulosic materials chosen. $\beta$-glucosidase, approximately equivalent to $64 \mathrm{pNPGU/g}$ cellulose, was also added to ensure that all the cellobiose could be completely converted to glucose. The reaction temperature and $\mathrm{pH}$ were kept at $50^{\circ} \mathrm{C}$ and 4.8 respectively. Gentle rotation (about $70 \mathrm{rpm}$ ) was used to ensure the complete mixing of substrate and enzyme. Since this process took about a whole week, antibiotics tetracycline and cyclohexamide were added to prevent the growth of microorganisms during the digestion. The increase in substrate digestibility as a result of pretreatment is one of the main criteria for judging the efficiency of a pretreatment method. 
3) Determination of Acid-Insoluble Lignin (AIL) in Biomass --- NREL LAP 003 [Templeton and Ehrman]

Biomass was first hydrolyzed with $72 \%$ (w/v) $\mathrm{H}_{2} \mathrm{SO}_{4}$ at $30^{\circ} \mathrm{C}$ for 2 hours, with regular stirring to ensure complete mixing and wetting of the sample. The sample was then transferred to a serum bottle and diluted to a final concentration of $4 \%(\mathrm{w} / \mathrm{v})$ acid. The bottle was tightly sealed and autoclaved at $121 \pm 1^{\circ} \mathrm{C}$ for one hour. The residue was collected by filtration and washed with adequate amount of DD water, before it was dried at $105 \pm 3^{\circ} \mathrm{C}$ till constant weight was achieved. The filtrate was collected and stored at $4^{\circ} \mathrm{C}$ for future analysis of acid-soluble lignin to be described in the next section. Finally the solid sample was ignited at $575 \pm 25^{\circ} \mathrm{C}$ in a muffle furnace (Thermolyne FB1415M) till carbon was eliminated. The amount of acid insoluble lignin was determined by the weight difference of the solid residues before and after burning in the muffle furnace.

4) Determination of Acid-Soluble Lignin (ASL) in Biomass --- NREL LAP 004 [Ehrman T, 1996]

In this procedure, a spectrophotometer was used to check the concentration of ASL in the hydrolysate of biomass, produced from NREL LAP 003 [Templeton and Ehrman]. The absorbance of the hydrolysate was measured at $205 \mathrm{~nm}$ wavelength in the spectrophotometer, using $4 \%(\mathrm{w} / \mathrm{v}) \mathrm{H}_{2} \mathrm{SO}_{4}$ solution as reference blank. The amount of the acid-soluble lignin in the hydrolysate was then calculated using the absorptivity value (extinction coefficient) of ASL. The absorptivity value specified in NREL 004 is $110 \mathrm{~L} / \mathrm{g}-\mathrm{cm}$, which is consistent with the value used in TAPPI procedure and represents an average value found for different woods and pulps. 
The hydrolysate was diluted (together with the reference blank, which is the $4 \%(\mathrm{w} / \mathrm{v}) \mathrm{H}_{2} \mathrm{SO}_{4}$ ) to make the absorbance reading of the hydrolysate to fall into the accurate detection range (0.2-0.7) of the spectrophotometer.

\section{5) Others}

Wiley mill (model ED-5) was used to reduce particle size of YP chips to pass through a $0.5 \mathrm{~mm}$ screen. Willey mill has the feature of being able to minimize changes in sample due to temperature rise, moisture loss and contamination during the grinding process. This feature is important in retaining the moisture content and may be the microporous structure of our samples.

Eventually, the pretreated lignocellulosics was fed to our mid-stream TMR and hydrolysis result compared with that of pure cellulose --- Solka Floc 200FCC.

\subsection{Continuous Substrate Transportation and Hydrolysis}

One of the main purposes of this research is to enhance the performance of the midstream tubular membrane reactor (TMR) section of the process being developed in our lab.

\subsubsection{Integrity Tests for HF Cartridge}

The "air diffusion" test is a simple practical means of determining the integrity of ultrafiltration membranes. Since the A/G Technology ultrafiltration HF membranes are supported by microporous sublayer as mentioned in Section 4.1.4, they have the most stringent air diffusion 
specifications in the industry [A/G Technology Corp. Operating Guide, 1997]. The set up is shown in Figure 4.3.

There are two steps in the test [A/G Technology Corp. Operating Guide, 1997]:

1) Cartridge Wetting and Set-up

The cartridge was thoroughly cleaned, flushed and fully wetted. After draining the cartridge of excessive liquid, it was installed by connecting inlet (feed side) to test loop. The cartridge outlet (reject side) and the permeate fitting closest to cartridge outlet were blocked. The flexible tubing was connected to permeate fitting closest to cartridge inlet (feed side) and the other end of the flexible tubing placed into an inverted graduate cylinder, which was immersed in and filled completely with water.

\section{2) Air Diffusion Test}

Inlet air pressure was adjusted to be about 3 psig and valve V-1 was opened. After initial bubbling subsided, air pressure was gradually increased over the next 15 seconds to about 15 psig. The end of the flexible permeate tubing line was placed into the inverted graduate cylinder, and the air diffusion rate in cc/min was measured using a stopwatch. Air diffusion rate was then divided by the membrane area to get the air diffusion value (volume of air diffused per unit time per unit membrane area). Air diffusion value for A/G Technology ultrafiltration membranes should be less than $3 \mathrm{cc} / \mathrm{min} / \mathrm{sq} . f t$. (less than $33 \mathrm{cc} / \mathrm{min} / \mathrm{sq} . \mathrm{m}$.) at $15 \mathrm{psig}$. 


\subsubsection{Continuous Transport of Substrate Particles through TMR}

Gauba (1993) concluded that the use of a pulsatile pump in a TMR improved its performance and overcome potential plugging problem in the case of a HF reactor with low flow rate. However for a HF reactor in horizontal position at low flow rate, pulsation of fluid as a result of using a pulsatile pump tended to move the settled solid particles back and forth locally. Vertical position of the HF reactor, on the other hand, led to too short a residence time for the particles. In this project, we pioneered an alternative approach of combining incline and shaking of the HF reactor as a means to achieve continuous and steady transportation of the particles through the reactor system.

Based on the fact that while gravitational force moved particles downwards towards the outlet of the HF cartridge, the shaking motion kept the particles suspended longer above the HF wall on their way through the HF cartridge, optimal combination of shaking speed and inclination was determined here to achieve more homogenous suspension, in order to help create more chance for substrate-enzyme contact in continuous hydrolysis runs to be described in Section 4.3.3. The set up of this set of experiments is depicted in Figure 4.1.

The system consisted of a deionized distilled (DD) water reservoir and a well-stirred substrate reservoir. Liquid (either DD water from DD water reservoir, or substrate solution injected into the inlet of HF cartridge) was continuously drawn into the HF membrane reactor, by the retentate pump located at point $\mathrm{C}$. The alternative introduction of liquid (DD water or substrate solution) into the reactor was achieved by changing the setting of the 3-way valve (made of polypropylene) located at point A --- at the bottom of "substrate injection tube (SIT)". The SIT 
was a piece of PVC tubing and had the following dimension $1 / 4^{\prime \prime} \mathrm{ID}, 3 / 8^{\prime \prime} \mathrm{OD}$, and $2.5^{\prime \prime}$ length. The homogeneously suspended substrate solution was picked up from substrate reservoir via a pipette and was injected into the SIT every 3 minutes. Immediately after an injection, the 3-way valve at point $\mathrm{A}$ was turned to let SIT and HF cartridge inlet connect to each other, and the substrate inside the SIT was drawn into the reactor. When the substrate was completely drained from the SIT, the 3-way at point A was quickly turned back into its normal position to connect DD water reservoir with the HF cartridge inlet, and let only DD water flow into the HF cartridge reactor.

In order to study the solid transportation pattern through the HF cartridge, two pieces of tubing (BDC and BEC) both $1 / 4^{\prime \prime} \mathrm{ID}$, were connected to the outlet of HF cartridge to alternatively collect solid particles coming out of the HF cartridge. During each time interval (45 minutes), only one of these two tubing was in use and the other one was disconnected. The situation was vise versa for the next time interval. Solid particles inside the retentate stream settled down while flowing through either BDC or BEC during a certain time interval. At the end of each time interval, the currently charged tubing was disconnected and the solid particles inside collected, washed, dried, and the dry weight of the particles measured. Meanwhile, the other tubing was charged with solid particles. Since there was no enzyme added to the system, no reaction occurred, thus the substrate was not consumed. By plotting both the weight of substrate injected into and also that came out of the HF cartridge for each time interval and also by comparing these two weights, information regarding whether and when a steady state of substrate transportation was reached was found. 
The DD (deionized, distilled) water reservoir was filled with DD water in this set of experiments. As far as particle transportation was concerned, this was the worst scenario, since no enzymes were used in these runs and the size of particles remained the same through out each run. In the hydrolysis situation, substrate particles were partially digested, and hence their size reduced while passing through the HF cartridge, so homogeneous suspension inside the HF cartridge could be easier to achieve.

Circulating water was not used here, which means no temperature control was employed. This was based on the assumption that within small range, temperature has little effect on the state of solid suspension and transportation.

Permeate side was blocked in runs when Solka Floc 200FCC transportation was investigated. The original thought was that since transportation run did not involve enzymatic hydrolysis and thus no glucose was produced, it was not necessary to have a permeate stream. But in the later runs for Solka Floc 900FCC, YP and CC transportation, the permeate flow rate was kept the same as in the hydrolysis runs $(\sim 0.26 \mathrm{ml} / \mathrm{min})$ using a low flow permeate pump (VWR Scientific 54856 - 070, Variable Speed Pump). The aim of keeping this permeate flow rate was to have operation conditions in the solid transportation runs as close as possible to those of hydrolysis run.

By changing the shaking speed from 0 to $250 \mathrm{rpm}$ and cartridge holder inclination from 0 to $90^{\circ}$, an optimal combination of these two factors to suspend lignocellulosic materials as 
homogeneously as possible and transport them as smoothly as possible was found, in order to enhance the continuous enzymatic hydrolysis to be described in the coming section.

The detailed procedure of each experiment is given below:

1) About 3g of Solka Floc 200FCC or $2.25 \mathrm{~g}$ of pretreated substrate was soaked in $300 \mathrm{ml}$ deionized, distilled (DD) water in a beaker for 3 hours at room temperature in advance. Gently stirring (at $120 \mathrm{rpm}$ ) of the substrate solution was applied using a magnetic stirrer (Fisher Scientific, 11- 498-7S) during this presoaking period. The stirring speed of this magnetic stirrer was increased to $250 \mathrm{rpm}$ right before the experiment started, to ensure a homogeneously mixing of the substrate solution in its reservoir throughout the whole duration of an experiment.

2) Fluid was continuously drawn into the HF cartridge by the retentate pump (Cole Parmer \#7550-90) located near point $\mathrm{C}$, with a preset flow rate of $0.9 \mathrm{ml} / \mathrm{min}$. Actual flow rate was measured with a graded cylinder at the end of each interval (45 minutes).

3) An amount of $0.77 \mathrm{ml}$ of the homogeneously mixed Solka Floc 200FCC solution, or $1.00 \mathrm{ml}$ of pretreated substrate solution, was injected into substrate injection tube (SIT) every 3 minutes, via a pipette (Acura 821 Micropipette, $200-1000 \mu \mathrm{l}$ ). First, pipette was adjusted to take exactly $0.77 \mathrm{ml}$ or $1.00 \mathrm{ml}$ volume of liquid, and then immersed into the well stirred substrate reservoir, usually into the middle liquid level to take up the preset amount of substrate solution. Once the right amount of solution was drawn, the pipette was quickly moved to the top of the SIT to dispense all the substrate solution inside it (called injection in 
our experiment description). Immediately after each injection, the 3-way valve was turned to connect SIT with inlet of HF cartridge. The valve was later turned back to its original position usually in about 1 minute, after all the injected substrate solution left SIT. This way, the DD water was continuously drawn into the HF cartridge until the next injection takes place. Hence constant solid substrate feed rate was maintained for a continuous-flow system.

4) Cartridge holder was set at different angles of inclination. The HF cartridge was turned $180^{\circ}$ along its long axis (as shown at the right bottom corner of Figure 4.1), alternatively to the right and left, in the middle of each time interval (about 22 min from the starting time of that interval). The shaker was set at $0,150,180,250 \mathrm{rpm}$.

5) Samples were collected after each time interval of $45 \mathrm{~min}$, by taking the outlet tubing BDC or BEC out of the set up and transfer the solid collected in the tubing onto a filter paper. The tubing was extensively flushed by DD water before it was fixed back onto the HF cartridge outlet. Meanwhile, retentate stream from HF cartridge was collected in the other tubing till the end of next interval. At the end of each experiment, the HF cartridge was also thoroughly flushed to collect the particles remained inside its lumen.

6) Solid substrate was collected by using Nalgene filter holder with receiver (Nalgene 3004000). The weighing dish and glass fiber filter paper (VWR brand, Grade No. 691 --- pore size $1.5 \mu \mathrm{m}$, diameter $4.7 \mathrm{~cm}$ ) to be used with the filter holder, were pre-weighed. After the substrate solution inside $\mathrm{BDC}$ or BEC was transferred into the filter receiver, vacuum was applied to speed up the collection of substrate particles onto the filter paper, which was later 
oven-dried at $105{ }^{\circ} \mathrm{C}$, and weighed together with the previous weighing dish again. The dry weights of Solka Floc and lignocellulosic particles collected during each interval were determined as the difference of dry weight of weighing dish and filter paper with or without the solid substrates.

\subsubsection{Continuous Hydrolysis in TMR}

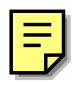

The configuration of experimental set up (Figure 4.2) was similar to the one used in the solid transportation experiment. One of the most significant differences was that cellulolytic enzyme solution instead of DD water was used. The system consisted of a gently stirred enzyme reservoir and a well-stirred substrate reservoir. Liquid (either enzyme solution from enzyme reservoir, or substrate solution injected into the inlet of HF cartridge) was continuously drawn into the HF membrane reactor, again by the retentate pump located at point $\mathrm{C}$. The alternative introduction of liquid (enzyme or substrate solution) into the reactor was achieved by changing the setting of the 3-way valve located at the bottom of SIT. The homogeneously suspended substrate solution was picked up from substrate reservoir via a pipette and was injected into the SIT every 3 minutes. Immediately after an injection, the 3-way valve at point A was turned to let SIT and HF cartridge inlet connect to each other, and the substrate inside the SIT was drawn into the reactor for about one minute time. When the substrate was completely drained from the SIT, the 3-way at point A was turned back to its normal position to connect only enzyme reservoir with the HF cartridge inlet, and let enzyme solution enter the HF cartridge reactor.

For all the experiments, the reaction temperature was maintained at $45^{\circ} \mathrm{C}$ by circulating hot water from a water bath $\left(47^{\circ} \mathrm{C}\right)$, through the water jacket around the $\mathrm{HF}$ cartridge. The same 
circulating hot water was used to keep the enzyme reservoir at $45 \pm 1^{\circ} \mathrm{C}$. Hot plate stirrer was used to keep substrate reservoir at $46 \sim 47^{\circ} \mathrm{C}$. An acetate buffer solution of $\mathrm{pH} 4.5$ was used to prepare both enzyme solution and substrate solution, thus to maintain the $\mathrm{pH}$ in the HF reactor to be around 4.5 .

This set of continuous hydrolysis experiments was designed to examine the conversion of substrate (pure cellulose and pretreated lignocellulosics) under certain conditions. So, the main focus was glucose concentration in permeate and retentate streams. One piece of tubing (1/4" ID) was used to connect the outlet of HF cartridge with the retentate pump. This tubing was long enough to retain all the substrate residue and prevent them from clogging the retentate pump. Periodically, the samples were taken from retentate and permeate streams. All samples were centrifuged immediately after they are collected. The supernatant was analyzed for glucose using YSI 2700 analyzer immediately after centrifugation step.

Step by step procedure:

1) Both water bath and hot plate stirrer was set at $47^{\circ} \mathrm{C}$. Circulating water was continuously pumped to maintain the appropriate temperature for both HF cartridge and the enzyme solution in the reservoir, with the enzyme solution temperature at $45 \pm 1^{\circ} \mathrm{C}$. The hot plate stirrer was used to keep substrate solution temperature at $46 \sim 47{ }^{\circ} \mathrm{C}$.

2) About $3 \mathrm{~g}$ of Solka Floc 200FCC (or about 2.25g of pretreated substrates) was soaked in 300 $\mathrm{ml}$ of $\mathrm{pH} 4.5$ acetate buffer, with/without surfactant, in a beaker for 24 hours at $47^{\circ} \mathrm{C}$ in 
advance. Gentle stirring at $120 \mathrm{rpm}$ was applied while presoaking the substrate. The stirring speed was changed to $250 \mathrm{rpm} 2.5$ hours before the experiment started.

3) Cartridge holder was set at $46.7^{\circ}$ of inclination. The shaker was set at $180 \mathrm{rpm}$.

4) One liter of acetate buffer solution $(\mathrm{pH} 4.5)$ was pumped by retentate pump through both lumen and shell side of HF cartridge to degas the whole system, including all the tubing with a flow rate of $10 \mathrm{ml} / \mathrm{min}$ for about 45 minutes.

5) Then, pre-warmed enzyme solution of $0.6 \mathrm{~g} / \mathrm{L}$ was drawn into the HF cartridge reactor through the retentate pump with a set flow rate of $0.9 \mathrm{ml} / \mathrm{min}$ for another 45 minutes to substitute the buffer inside the lumen of HF cartridge.

6) First pair of samples (retentate --- from point B, and permeate --- from point F) were taken as soon as the HF cartridge was filled with enzyme solution, but before the first substrate injection. This was considered to be equivalent to $0 \%$ substrate conversion.

7) Immediately after the first pair of samples were taken, the permeate pump was started, and then the first injection of substrate. An amount of $1 \mathrm{ml}$ of the homogeneously mixed substrate solution was injected to SIT every 3 minutes, via a pipette. The 3-way valve at point A was set to connect the SIT with the inlet of HF cartridge. It took about 1 min for the all these injected substrate solution to leave the injection tube. The 3-way valve was then set back to connect enzyme reservoir with the inlet of HF cartridge at this time. Overall, approximately 
$1 / 3$ of the run time, the HF cartridge reactor received no flow from enzyme reservoir. During those periods, the HF receives $1 \mathrm{ml}$ per 3 minute of liquid from substrate reservoir via injection.

8) Samples (retentate --- from point $\mathrm{B}$, and permeate --- from point F) were taken every 15 minutes in the first one hour, and every 30 minutes afterwards. Glucose concentration was measured almost immediately after samples were taken.

Sampling technique: First, collection of permeate sample was started by placing a microcentrifuge tube (Fisher Scientific $03-407-16,0.6 \mathrm{ml}$ Flat Top Microcentrifuge Tubes) at the outlet of the permeate pump. Since the permeate flow rate was set at around $0.27 \mathrm{ml} / \mathrm{min}$, it usually took about $1.5-2$ minutes to collect $0.5 \mathrm{ml}$ of permeate stream for analysis. Meanwhile, sample from the retentate side was taken into a second micro-centrifuge tube, by instantly opening and closing the 3-way valve at point B. The retentate sample was then sat on ice for 11.5 minutes to quench the hydrolysis reaction, while waiting for the permeate sample collection to be completed. Both retentate and permeate samples were then centrifuged at $6000 \mathrm{rpm}$ (Labnet 1201 Mini centrifuge) for about 1.5 minutes before their supernatants were used for glucose analyzing in the YSI 2700 Biochemistry Analyzer.

9) Samples were also taken hourly from permeate and kept frozen for future cellobiose analysis. The procedure for cellobiose analysis was similar to that of Gauba (1993):

a) $2 \mathrm{~g} / \mathrm{L}$ solution of $\beta$-glucosidase was prepared.

b) Test tube containing permeate sample was placed in boiling water for 15 minutes to denature enzyme; the boiled sample was then centrifuged at $3300 \mathrm{rpm}$ for 20 minutes. 
c) $2 \mathrm{ml}$ of $\beta$-glucosidase solution was pipetted to $2 \mathrm{ml}$ permeate sample.

d) Sealed test tube of permeate sample was incubated at $45^{\circ} \mathrm{C}$ for 24 hours.

e) After incubation, the sample was boiled in $100^{\circ} \mathrm{C}$ water for another 15 minutes.

f) The permeate samples were analyzed for glucose concentration before and after incubation. Cellobiose concentration was calculated from the difference of these two measurements.

10) The reaction was stopped when steady state glucose concentration was reached.

11) Back flush HF cartridge with $75 \sim 100 \mathrm{~L}$ of DD water.

\subsubsection{Use of Surfactants to Enhance Continuous Hydrolysis in TMR}

Two non-ionic surfactants Pluronic F68 and Tergitol NP-9 were incorporated in continuous enzymatic hydrolysis of pretreated lignocellulose. These surfactants were found in the literature (Section 2.5) to be more efficient than many other surfactants, in enhancing enzymatic hydrolysis of cellulosic materials. Our goal was to find out whether the same benefits still held under HF cartridge environment. First, around $1.7 \mathrm{~g}$ of surfactant was added into $2 \mathrm{~L}$ of $\mathrm{pH} 4.5$ acetate buffer. This buffer was then used to prepare both substrate solution (24 hours prior to hydrolysis started) and enzyme solution (1 hour prior to hydrolysis started). Since the volume of enzyme or substrate added to prepare enzyme or substrate solution in the reservoirs was negligible, the surfactant concentration in the reservoirs remained the same as that of the original $2 \mathrm{~L}$ buffer. The surfactant concentration inside the HF cartridge during each run was also considered to be the same as that of the original buffer. 


\subsection{Use of Aqueous Two-Phase System for Enzyme Recovery}

As described in section 2.6, enzyme recycling is of great importance to the overall efficiency of the TMR process. Aqueous two phase system was created to process the cellulase enzyme solution and to demonstrate its use on the TMR system.

A method containing only one thermo-separating polymer UCON 50-HB-5100 [Johansson et al., 1995] was used in an attempt to retrieve cellulase enzyme from acetate buffer solution $(\mathrm{pH}=$ 4.5). UCON 50-HB-5100 was added to the enzyme solution to make a final polymer concentration of $20 \%(\mathrm{w} / \mathrm{w})$, and the temperature of this mixture was increased to $60^{\circ} \mathrm{C}, 10^{\circ} \mathrm{C}$ above the cloud point of this polymer, in order to let the UCON $50 \mathrm{HB}-5100 /$ water ATPS to happen. After 16-18 hours, the equilibrium of enzyme partition into two phases was reached. Due to time limitation, only protein concentration of the original enzyme solution and the upper phase was monitored using Bio-Rad DC protein assay.

The standard assay protocol [Bio-Rad Laboratories, DC Protein Assay Instruction Manual, 2000] was followed for protein concentration determination:

1. 3-5 dilutions of protein standard (Bio-Rad Protein Standard I, bovine gamma globumin), containing $0.2-1.5 \mathrm{mg} / \mathrm{ml}$ of protein, was prepared.

2. $100 \mu \mathrm{l}$ of standard or sample was pipetted into clean, dry test tubes.

3. $500 \mu \mathrm{l}$ of reagent A (alkaline copper tartrate solution) was added to each test tube, and vortexed.

4. $4.0 \mathrm{ml}$ reagent $\mathrm{B}$ (dilute Folin reagent) was then added to each test tube and vortexed immediately. 
5. After 15 minutes, absorbance was read at $750 \mathrm{~nm}$. The absorbance was stable for at least one hour.

6. The protein standard was used to prepare a calibration curve, with $\mathrm{x}$-axis as protein concentration and y-axis as the corresponding absorbance value at $750 \mathrm{~nm}$. By using this calibration curve, the protein concentration in any sample was calculated, if their absorbance at $750 \mathrm{~nm}$ was known.

\subsection{List of Figures for This Chapter}

\subsubsection{Figures}

Figure 4.1 Experimental Setup for Enzymatic Hydrolysis in HF Membrane Reactor Figure 4.2 Experimental Setup for Solid Transportation in HF Membrane Reactor Figure 4.3 Air Diffusion Test Apparatus (A/G Technology) 


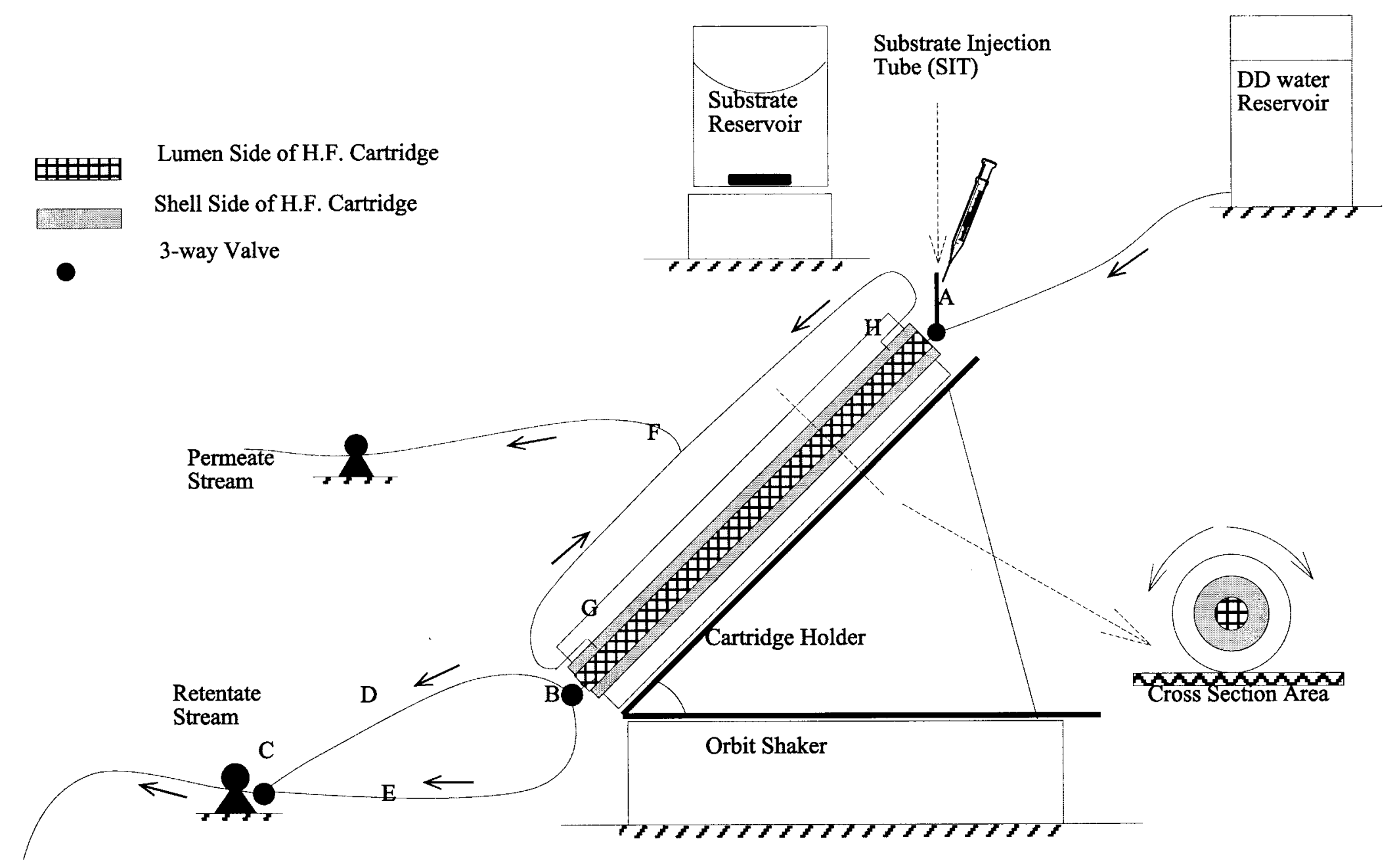

Figure 4.1. Experimental Setup for Solid Transportation in HF Cartridge 


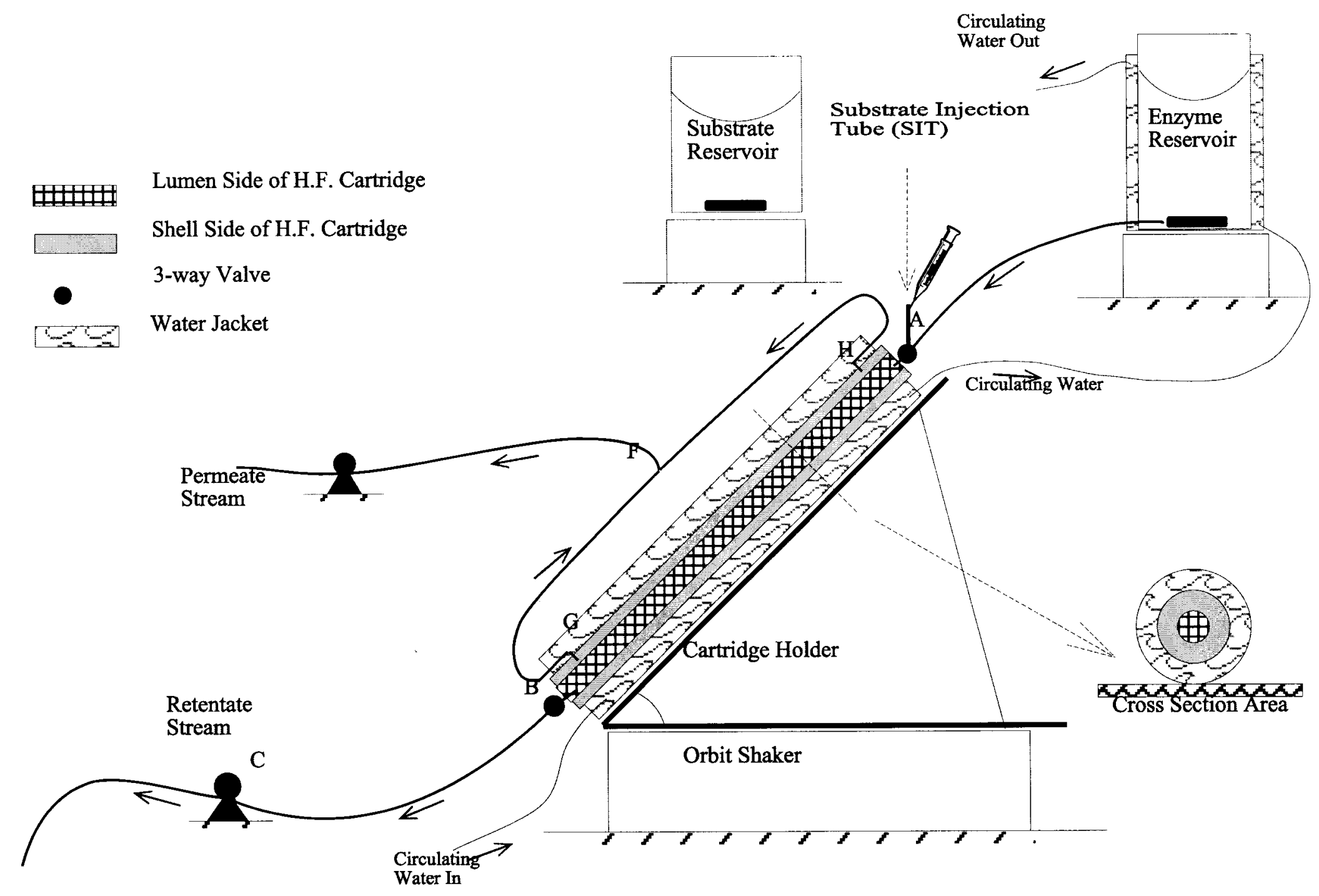

Figure 4.2. Experimental Setup for Enzymatic Hydrolysis in HF Cartridge 


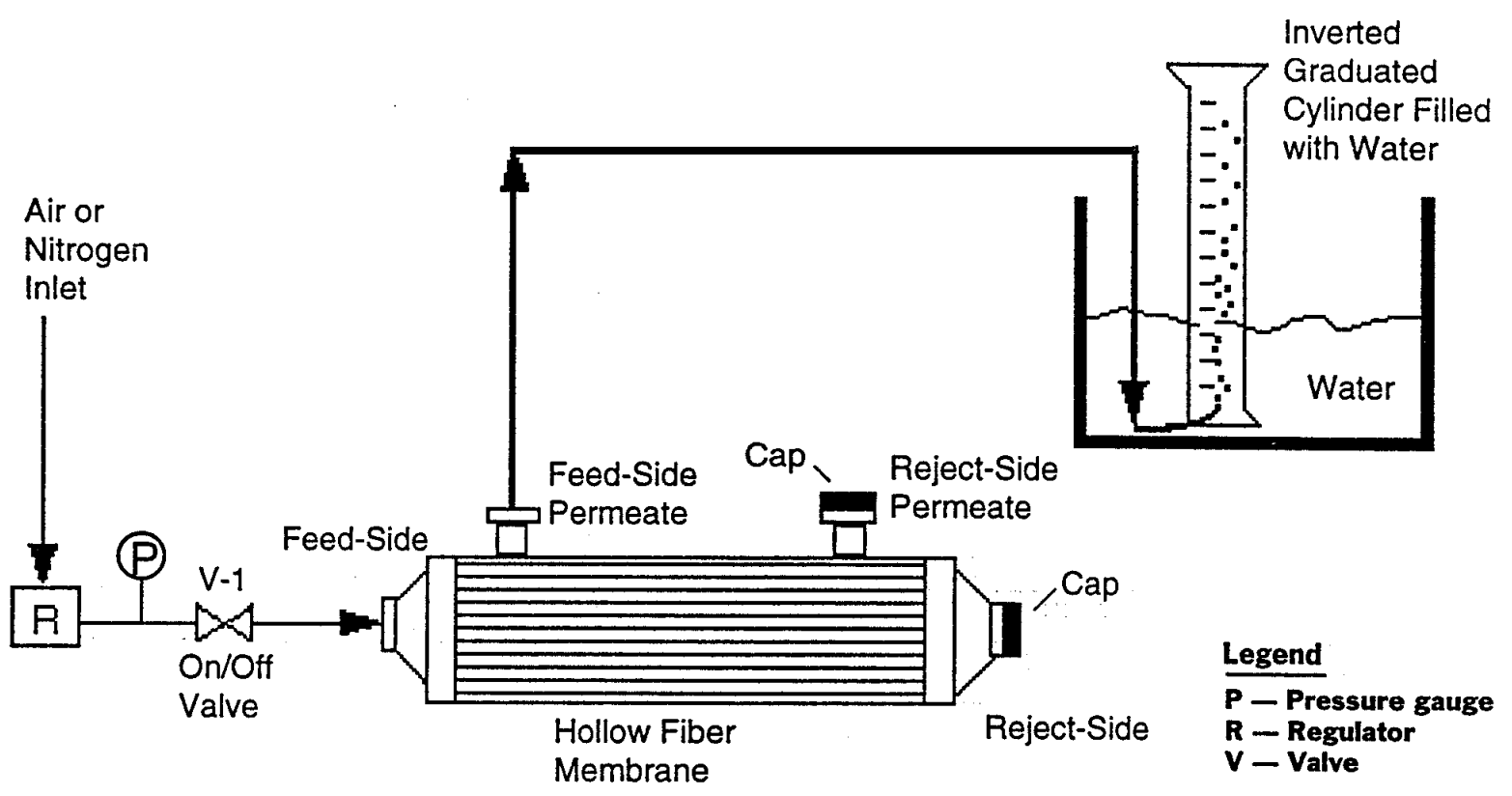

Figure 4.3. Air Diffusion Test Apparatus (originally from A/G Technology Corporation Operating Guide) 


\section{Chapter 5 Results and Discussions}

\subsection{Characterization of Lignocellulosic Substrates}

The following NREL laboratory analytical procedures (LAPs) have been applied to characterize Willey-milled raw yellow poplar, as well as yellow poplar milled and pretreated by ammonia steeping (ASYP) and by alkaline oxidation (AOYP).

1) NREL LAP 001 --- Determination of Total Solid Content [Ehrman, 1994]

2) NREL LAP 003 --- Determination of Acid Insoluble Lignin (AIL) [Templeton and Ehrman, 1995]

3) NREL LAP 004 --- Determination of Acid Soluble Lignin (ASL) [Ehrman, 1996]

4) NREL LAP 009 --- Enzymatic Saccharification to Determine Maximum Digestibility [Brown and Torget, 1996]

Multifect GC (cellulase) and Novozym 188 ( $\beta$-glucosidase) were the enzymes used for maximum digestibility determination, following NREL LAP 009 [Brown and Torget, 1996]. In NREL LAP 009 [Brown and Torget, 1996], cellulose digestibility (\%) is calculated by the following definition:

$$
\text { digestibility }(\%)=\frac{\text { grams of cellulose digested from the added cellulose }}{\text { grams of cellulose added }} \times 100
$$

In order to determine the grams of cellulose added, one needs to know the percentage of cellulose inside the substrate investigated. Generally, hard wood contains about 50\% cellulose (dry base), 23\% hemicellulose, and 22\% lignin. Herbaceous materials and agricultural residues contain a somewhat higher proportion of hemicellulose $(30-33 \%)$ relative to cellulose (38 - 
$45 \%)$, and have lower levels of lignin (10 - 17\%) [McMillan, 1994]. The amount of lignin in softwoods is appreciably higher than in hardwoods, usually between $25-35 \%$, the cellulose content is about $46 \%$ and the hemicellulose content about $21 \%$ [Lynd et al, 1999]. It has also been reported that the cellulose content of hybrid poplar is $42.9 \%$ [Tsao et al, 1996] and that of corn cob to be $44.88 \%$ [Gong et al, 1997]. The information above gives us a rough idea about the composition of our raw $\mathrm{YP}$ and raw $\mathrm{CC}$, and might be used to give a rough estimation of cellulose digestibility of the raw substrates. Yet, the cellulose content of the pretreated substrate needed in order to find out the cellulose digestibility (defined by Eq. 5.1) of the pretreated substrates, which we are most interested in, is not really available. Thus our calculation has been modified to represent substrate digestibility (\%) defined below:

$$
\text { digestibility }(\%)=\frac{\text { grams of cellulose digested from the added substrate }}{\text { grams of substrate added }} \times 100
$$

with the assumption that grams of cellulose digested

$$
\begin{aligned}
= & \text { grams of glucose produced } \\
= & \text { reading of glucose concentration from glucose analyzer }(\mathrm{g} / \mathrm{L}) \times \text { volume } \\
& \text { of the reaction mixture }(0.01 \mathrm{~L})
\end{aligned}
$$

To summarize the above, "digestibility" used here is the "digestibility of the whole substrate", the "digestibility" of NREL LAP 009 [Brown and Torget, 1996] is the "digestibility of the cellulose fraction of the substrate". This factor would greatly reduce the value of $\%$ digestibility obtained in this work, since "the amount of substrate added" used in Eq. (5.2) is almost always much larger than "the amount of cellulose added" in Eq. (5.1). In this section, we will use 
"substrate conversion" (in \% or fraction) to replace digestibility defined by Eq. (5.2) and use "cellulose conversion" as the digestibility defined by Eq. (5.1).

\subsubsection{Yellow Poplar (YP) Particles}

In Figure 5.1, the results of two independent digestibility tests for each pretreated CC, YP and Solka Floc are reported. The results from the first run is indicated by "1" after the species name, and similarly " 2 " indicating the results from the second run. For example, AOYP 1 means the substrate conversion data obtained on AOYP from the first run, and the AOYP 2 is the data obtained on the same species during the second run. The digestibility of raw material is only investigated once, so it is not differentiated by "1", or "2". As we can see from Figure 5.1, these two independent digestibility tests gave very similar results. So, we use the average value of these two runs and focus on the difference between different substrates.

As we can see from Figure 5.1, both AOYP and ASYP are much easier to be hydrolyzed by enzyme than the raw YP. This is demonstrated not only by their higher final substrate conversion, but also by their faster hydrolysis rate initially, as indicated by a steeper initial gradient. ASYP has a final substrate conversion of $\sim 16 \%$, which is 3 times higher than that of raw YP (4.73\%). AOYP has an even better final substrate conversion at about 29\%, which is 6 times more than that of the raw YP, under the same experimental condition. As mentioned earlier, the final substrate conversion is the indication of enzymatically digestible cellulose content of a specific sample. The final substrate conversion data of these three different YPs thus could be interpreted in a second way: AOYP has the highest amount of digestible cellulose content, followed by ASYP and finally raw YP. This sequence indicates both pretreatments are 
effective in activating the substrate, with the alkaline oxidation method being more capable of doing so.

The results from both lignin (AIL and ASL) tests and the digestibility tests are summarized and presented in Table 5.1. The values in this table are the averaged values from at least two independent samples. For example, each \%AIL or \%ASL was obtained from four independent samples. The column titles used in Table 5.1 are explained as follows:

1) Size: average particle size of raw or pretreated substrates.

The average particle size is expressed in length $\times$ width. The average sizes of the YP species were determined by the average value of 20 particles, randomly choosing under an optical microscope. Since the irregularity of particle shape is more severe for corn cob particles, 30 particles were chosen for each type of corn cob (Raw CC, AOCC and ASCC) to determine their average particle sizes.

2) \% AIL: weight percentage of Acid Insoluble Lignin in each sample (before or after pretreatment).

3) \% ASL: weight percentage of Acid Soluble Lignin in each sample (before or after pretreatment).

4) total dry weight loss: weight percentage of dry weight loss during pretreatment, caused by removal of lignin, hemicellulose, cellulose, or other components from the raw substrates.

$$
\text { total dry weight loss }=\frac{\mathrm{W}_{\mathrm{i}}-\mathrm{W}_{\mathrm{f}}}{\mathrm{W}_{\mathrm{i}}} \times 100 \% \text {, }
$$

where $\mathrm{W}_{\mathrm{i}}=$ dry weight of raw substrate to be pretreated 


$$
\mathrm{W}_{\mathrm{f}}=\text { dry weight of this substrate, after pretreatment is done }
$$

5) AIL removal: weight percentage of Acid Insoluble Lignin (Klason lignin) removed during a pretreatment.

$$
\text { AIL removal }=\frac{\mathrm{W}_{\mathrm{i}-\mathrm{AIL}}-\mathrm{W}_{\mathrm{f}-\mathrm{AIL}}}{\mathrm{W}_{\mathrm{i}-\mathrm{AIL}}} \times 100 \%,
$$

where $\mathrm{W}_{\mathrm{i}-\mathrm{AIL}}=$ weight of Klason lignin in the raw YP (or CC) to be pretreated

$$
\mathrm{W}_{\mathrm{f}-\mathrm{AIL}}=\text { weight of Klason lignin in this } \mathrm{YP}(\text { or } \mathrm{CC}) \text {, after pretreatment is done }
$$

6) ASL removal: weight percentage of Acid Soluble Lignin removed during a pretreatment.

$$
\text { ASL removal }=\frac{\mathrm{W}_{\mathrm{i}-\mathrm{ASL}}-\mathrm{W}_{\mathrm{f}-\mathrm{ASL}}}{\mathrm{W}_{\mathrm{i}-\mathrm{ASL}}} \times 100 \%,
$$

where $\mathrm{W}_{\mathrm{i}-\mathrm{ASL}}=$ weight of acid soluble lignin in the raw $\mathrm{YP}$ (or $\mathrm{CC}$ ) to be pretreated

$$
\mathrm{W}_{\mathrm{f}-\mathrm{ASL}}=\text { weight of acid soluble lignin in this } \mathrm{YP} \text { (or CC), after pretreatment is done }
$$

7) total lignin removal: weight percentage of total lignin (AIL and ASL) removed during a pretreatment.

$$
\text { total lignin removal }=\frac{\mathrm{W}_{\mathrm{i}-\mathrm{AIL}+\mathrm{ASL}}-\mathrm{W}_{\mathrm{f}-\mathrm{AIL}+\mathrm{ASL}}}{\mathrm{W}_{\mathrm{i}-\mathrm{AIL}+\mathrm{ASL}}} \times 100 \%,
$$

where $\mathrm{W}_{\mathrm{i}-\mathrm{AIL}+\mathrm{ASL}}=$ weight of total lignin in the raw $\mathrm{YP}$ (or CC) to be pretreated

$$
\mathrm{W}_{\mathrm{f}-\mathrm{AIL}+\mathrm{ASL}}=\text { weight of total lignin in the same } \mathrm{YP} \text { (or CC), after pretreatment is done }
$$

8) digestible cellulose content (final substrate conversion): the substrate conversion value, when the curves level off (usually after 72 hours' hydrolysis) in Figure 5.1. This value can also be 
called maximum substrate conversion, and it is the amount of enzymatically digestible cellulose present in each sample.

It is obvious from Table 5.1 that alkaline oxidation pretreatment was able to effectively remove AIL (also know as Klason lignin), and thus reduce the final \%AIL in YP. It is observed that \%AIL did not decrease in YP after ammonia steeping pretreatment. One possible reason is that this pretreatment (ammonia steeping) causes significant amount of other components, mostly the hemicellulose and some cellulose, to be dissolved from the raw substrate. The net effect is that the weight percentage lignin content in the pretreated substrate may remain the same or even slightly increase, even though in reality some lignin is removed from the original raw substrate.

One hypothetical example is demonstrated in the following table. If one starts with 100g (dry weight) of raw milled YP, containing $45 \mathrm{~g}$ cellulose, $30 \mathrm{~g}$ hemicellulose and $25 \mathrm{~g}$ total lignin. Suppose after certain pretreatment, the total dry weight loss is $50 \mathrm{~g}$, among which $9 \mathrm{~g}$ cellulose, $29 \mathrm{~g}$ hemicellulose and also $12 \mathrm{~g}$ total lignin. In this case, the weight percentage of lignin in the pretreated substrate is $26 \%$, slightly higher than that of the original substrate $25 \%$. Although $12 \mathrm{~g}$ of lignin is removed from the starting material, the lignin content after pretreatment actually increased!

\begin{tabular}{|lc|c|c|c|}
\cline { 3 - 5 } \multicolumn{1}{c|}{} & & Raw Substrate & Pretreated Substrate & Removal \\
\hline Cellulose & $(\mathrm{g})$ & 45 & 36 & 9 \\
\hline Hemicellulose & $(\mathrm{g})$ & 30 & 1 & 29 \\
\hline Lignin & $(\mathrm{g})$ & 25 & 13 & 12 \\
\hline Total & $(\mathrm{g})$ & 100 & 50 & 50 \\
\hline Lignin content & $(\%)$ & 25 & 26 & 50 \\
\hline
\end{tabular}


Finally we compared these two pretreatment methods with the classical dilute acid pretreatment on their ability to remove Klason lignin (AIL) from poplar wood. As listed in Table 2.1b, dilute acid pretreatment was able to remove $18 \%$ and $17 \%$ of Klason lignin from poplar hybrid NE388 ${ }^{1}$ and poplar hybrid $\mathrm{NE} 11^{2}$, respectively [Torget et al., 1990]. In our study ammonia steeping pretreatment was able to remove $26.88 \%$ Klason lignin, while alkaline oxidation pretreatment was able to remove slightly more, $30.13 \%$ Klason lignin from raw milled yellow poplar. The final Klason lignin content of hybrid populus NE388 ${ }^{3}$ and hybrid populus NE $11^{4}$ were both $29 \%$ after dilute acid pretreatment [Spindler et al., 1991]. The final Klason lignin content of our yellow poplar was $25.04 \%$ and $21.97 \%$, after ammonia steeping and alkaline oxidation respectively, both lower than the $29 \%$. By comparing Klason lignin removal and final Klason lignin content data, it appears that both ammonia steeping and alkaline oxidation method are more effective in dissolving Klason lignin, compared to the dilute acid pretreatment. Since lignin is hypothesized to interfere hydrolysis by blocking access to cellulose and irreversibly binding hydrolytic enzyme, high lignin removal and low final lignin content are beneficial to cellulose hydrolysis. This feature of the ammonia steeping as well as alkaline oxidation enhances efficiency of both hydrolysis and enzyme recycling.

Acid soluble lignin is not often monitored in the literature. This may be because the amount of acid soluble lignin in biomass is much less than that of acid insoluble lignin, as shown in Table 5.1 for both YP and CC. Since ASL usually contributes to less than $1 / 10$ of the total lignin amount, the change in ASL content contributes very little to the change of total lignin content as compared to that of the AIL. That might be the reason why only acid insoluble lignin amount and 
its change are analyzed in most of the literature. Further discussions of the rest of the data in Table 5.1 will be presented in the next section.

\subsubsection{Corn Cob (CC) Particles}

The same set of NREL procedures were also applied to raw and pretreated CC (AOCC and ASCC). The results of digestibility tests are also shown in Figure 5.1. The summarized results of lignin (AIL and ASL) tests together with digestible cellulose content values are given in Table 5.1.

Solka Floc 200FCC was used as a control in this study and had a final substrate conversion as high as $86.3 \%$ after 100 hours (see Figure 5.1). This value tells us that the enzymatically digestible cellulose content of Solka Floc is $86.3 \%$, although its total cellulose content is higher, usually more than $99 \%$. The difference between these two values, $99 \%$ and $86.3 \%$, gives the amount of enzymatically indigestible cellulose in Solka Floc. Although "indigestible cellulose" can not be hydrolyzed by enzyme under the experimental condition of the digestibility test (NREL LAP 009), they can be hydrolyzed into glucose by sulfuric acid in a two stage hydrolysis process (the process applied to hydrolyze all the polysaccharides into their sugar monomers before determining their amount by HPLC --- NREL LAP 002). It is reasonable to assume that close to $100 \%$ of Solka Floc 200FCC is cellulose. Hence the final cellulose conversion, defined by Eq. (5.1), is also $86.3 \%$, the same is the final substrate conversion.

It was observed from Table 5.1 that corn cob was more susceptible to both pretreatments, since the total dry weight loss, the extent of Klason lignin (AIL) removal, and also the final substrate 
conversion of CC were all much higher compare to those of YP pretreated by the same methods. Between the two different pretreatment methods applied to corn cob, the alkaline oxidation still outperformed ammonia steeping method, by removing about $90 \%$ of the original Klason lignin (AIL) from the raw CC and helping to achieve a final substrate conversion of $55.63 \%$ for AOCC. This final substrate conversion value indicates that the enzymatically digestible cellulose content of AOCC is $55.63 \%$, which is more than $60 \%$ of the enzymatically digestible cellulose content of Solka Floc 200FCC (86.3\%).

In Figure 5.1, higher initial substrate conversion is observed in AOCC (AOCC 1) than the Solka Floc 200FCC (Solka 1), at the first sampling point --- 5.5 hours. Repeated digestibility tests on all pretreated substrates and Solka Floc 200FCC, with more frequent sampling during the first 24 hours, showed pretty good repeatability. This set of repeated digestibility tests proved again that the AOCC (AOCC 2) had faster initial hydrolysis rate than Solka Floc 200FCC (Solka 2) from the first sampling point ( 2 hours), till its digestible cellulose was depleted at around 8 hours (This 8 hour time is estimated from the crossing-over point of curves Solka 2 and AOCC 2 in Figure 5.1). This may indicate that either the porosity of AOCC is larger than that of Solka Floc, or alkaline oxidation pretreatment effectively reduced the DP (degree of polymerization) of cellulose in AOCC, since both effects could contribute to faster hydrolysis.

We also plotted the final substrate conversion as a function of percent delignification (total lignin) for both substrates in Figure 5.2. With the limited amount of data for each species, the general trend is that digestible cellulose amount increases with increasing extent of delignification for each species. Interestingly, with almost the same extent of delignification 
(around 27\%) for YP, the digestible cellulose amount of AOYP (29\%) is much higher than that of ASYP (16\%). This could indicate that either ASYP has a less total cellulose content, or $\%$ of digestible cellulose among the total cellulose amount is less in the ASYP, or both might be true, with the same amount of total lignin removal.

As done in last section, we also compared the delignification efficiency of ammonia steeping and alkaline oxidation pretreatment with the dilute acid pretreatment method. The dilute acid pretreatment was able to remove $26 \%$ Klason lignin (AIL) from corn cob [Torget et al., 1991]. In our study, ammonia steeping method was able to remove $44.16 \%$ Klason lignin from raw CC and the \%AIL became $18.76 \%$ in the ASCC. More impressively, the alkaline oxidation was able to remove $91.52 \%$ of Klason lignin from raw $\mathrm{CC}$, leaving a final \%AIL as low as $2.87 \%$ in AOCC. So, the alkaline oxidation method is overall the most efficient in lignin removal for both YP and CC, followed by ammonia steeping method and finally the dilute acid pretreatment method.

\subsection{Continuous Transport of Substrate Particles through TMR}

One integrity test for the HF cartridge was performed in November 1999, prior to all the solid transportation runs, to check out the condition of the cartridge. The result of air diffusion of our HF cartridge was $1.77 \mathrm{ml} / \mathrm{min}-\mathrm{m}^{2}$, much lower than the critical value of $33 \mathrm{ml} / \mathrm{min}-\mathrm{m}^{2}$. So, at that point of time, the HF cartridge in use was intact and did not have pinhole. 


\subsubsection{Pure Cellulose}

\subsubsection{Solka Floc 200FCC Particles}

A series of experiments were conducted following the procedure described in Section 4.3.2, using a number of combinations of shaking speed and degree of inclination. These combinations include $250 \mathrm{rpm} / 46.7^{\circ}, 250 \mathrm{rpm} / 0^{\circ}, 0 \mathrm{rpm} / 46.7^{\circ}$, and $150 \mathrm{rpm} / 46.7^{\circ}$. From these experiments, a combination of $250 \mathrm{rpm}$ (rotating speed of shaker) and $46.7^{\circ}$ inclination (the maximum inclination that could be set on our previous wood cartridge holder) gave reasonably continuous and steady output of solid substrate with constant substrate input. Averaged result from two experiments with $250 \mathrm{rpm}$ and $46.7^{\circ}$ inclination is given in Figure 5.3. In this and other similar figures, flow rates through the hollow fibers, which were maintained to be as constant as possible, are also presented. The weight of cellulose output from the HF cartridge fluctuated around a constant weight of input cellulose particles to the cartridge, starting from the second time interval, 45 - 90 minutes. This indicated steady state with respect to solid transportation in the HF cartridge after 90 minutes.

Data collected for these two runs and other similar solid transportation runs are presented in Appendix B. The material balance is calculated as the total amount of substrate injected into the HF cartridge over the total amount of substrate collected (including the amount collected from the outlet tubing, and the amount retained inside HF cartridge at the end of each run) for one entire experiment. Since no chemical reaction takes place in solid transportation experiments, the calculated material balance should be reasonably close to 1 or $100 \%$. 
In one earlier experiment with half of the shaking speed and the same degree of inclination $\left(110 \mathrm{rpm} / 46.7^{\circ}\right)$, particle precipitation and accumulation at the immediate inlet and outlet of $\mathrm{HF}$ cartridge (inside transparent tubes) was observed. Although the exact situation inside the HF cartridge was not visible to us, from the amount of precipitation and accumulation of cellulose particles immediately at the inlet and outlet of the HF cartridge, it could be deduced that the solid particles were not transported smoothly inside the HF cartridge in that earlier run. This speculation was partially confirmed when the cellulose retained inside the HF cartridge were collected and measured at the end of the run. The amount of cellulose retained inside the HF, after 270 minutes, was $0.2244 \mathrm{~g}$ with $110 \mathrm{rpm} / 46.7^{\circ}$, which was about 4 times more than that of the two runs with $250 \mathrm{rpm} / 46.7^{\circ}$, where only about $0.0490 \mathrm{~g}$ cellulose, was retained in $\mathrm{HF}$ cartridge after 450 minutes. This suggested that fast shaking speed might be important to the smooth transportation of cellulose in TMR. Yet the results of other control experiments with "inclination only" or "shaking only" were necessary for confirmation. Control experiments were performed at both $250 \mathrm{rpm} / 0^{\circ}$ and $0 \mathrm{rpm} / 46.7^{\circ}$ (Figures 5.4 and 5.5).

Figure 5.4 shows that results at shaking speed of $250 \mathrm{rpm}$ with zero inclination, is very similar to that shown in Figure 5.3. The weight of the output cellulose fluctuated around the weight of input cellulose in the same fashion but with slightly greater amplitude. The only significant difference was that the first data point (weight of output cellulose) was slightly lower in this run, compared to the previous experiment with $250 \mathrm{rpm} / 46.7^{\circ}$.

Figures 5.5 shows the situation of a "no shaking" run during the first 225 minutes, since the experiment was cut to half to save the time. Yet it is still sufficient for us to figure out the overall 
trend of the solid suspension. When compared with Figure 5.3, it was found that output of cellulose from the HF cartridge during the first 90 minutes was significantly less in this "zero shaking" control experiment, where inclination was kept the same. During the third time interval (90-135 minutes), weight of output cellulose suddenly jumped to more than $100 \%$ of that of the input cellulose. This highly fluctuating solid output pattern was definitely not desirable, when the input of cellulose was almost constant. No conclusion could be drawn as to whether steady state on solid transportation is reached within the experimental period from Figure 5.5. Yet, table B.3 indicated that at the end of the run, 3 times more cellulose was retained inside the HF cartridge, compared to the run with $250 \mathrm{rpm} / 0^{\circ}$ (data shown in Table B.2). This indicated that with 0 $\mathrm{rpm} / 46.7^{\circ}$, the solid particles were not being transported as smoothly as could be. One possible reason could be that the particles were not homogeneously suspended inside the HF cartridge.

Based on the above data, it may be inferred that the particles inside the "with shaking" HF cartridge was transported more smoothly and may also be more homogeneously suspended than the stationary ones. This is based on the observation that 1) nearly $100 \%$ output over input of cellulose was reached earlier (usually during the second time interval, 45-90 minutes); 2) the fluctuation of the output weight of cellulose around the certain amount of input weight was less in amplitude; and 3) the cellulose retained in the HF at the end of an experiment was less in "with shaking" runs.

Nevertheless, inclination facilitated the transportation of particles through the HF cartridge, based on different amount of cellulose retained inside the HF cartridge during different runs. A case in point is that about $0.5600 \mathrm{~g}$ cellulose was retained inside HF cartridge after 300 minutes 
with $85 \mathrm{rpm} / 18.1^{\circ}$ (an even earlier run not presented here), about twice as much as cellulose retained after 225 minutes for $0 \mathrm{rpm} / 46.7^{\circ}$ run. Since shaking increased homogeneity of solid suspension, the less accumulation of solid in the later case could be attributed to its higher inclination.

A final experiment using Solka Floc 200FCC was performed with $150 \mathrm{rpm} / 46.7^{\circ}$. The aim of this experiment was to find out whether smooth transportation of solid substrates could still be achieved under lower shaking speed, where the risk of cellulase deactivation might be relatively reduced (Figure 5.6). In this case, slightly more accumulation of cellulose $(0.0580 \mathrm{~g})$ was found in the HF cartridge at 225 minutes, compared to $0.0490 \mathrm{~g}$ cellulose retention after 450 minutes with $250 \mathrm{rpm} / 46.7^{\circ}$ (Figure 5.3). Around $100 \%$ output occurred during third time interval (90135 minutes), after which the output curve was pretty smooth and close enough to the input curve. Overall, combination of $150 \mathrm{rpm} / 46.7^{\circ}$ was considered just enough to maintain an acceptably smooth solid transportation. Any combination of the same inclination and this and higher shaking speed would be good enough to smoothly transport substrate with a size like Solka Floc 200FCC.

\subsubsection{Solka Floc 900FCC Particles}

Figure 5.7 shows the results of solid transportation of Solka Floc 900FCC (110 $\mu \mathrm{m}$ fiber length), which was a middle ground between the Solka Floc 200FCC (35 $\mu$ m fiber length) and the pretreated substrates. This run was made before the pretreated substrate runs to reduce the potential risk that the pretreated substrates might block the HFs of the reactor. If fibers 3 times the length of Solka Floc 200FCC could pass through the HFs, it was more likely that the 
pretreated substrates with size 10 times as large at inlet, but decreasing in sizes over the length of the TMR could also pass through. Combination of $180 \mathrm{rpm} \& 46.7^{\circ}$ inclination was chosen for this run. One significant difference of this run was that the permeate stream was not blocked. Unlike all the previous runs for Solka Floc 200FCC, where the permeate flow rates were zero, the same permeate flow rate of around $0.27 \mathrm{ml} / \mathrm{min}$ was maintained in this run, as well as in the later solid transportation runs of both YP and CC.

The output pattern shown in Figure 5.7 is very similar to the Solka Floc 200FCC run with 250 $\mathrm{rpm} / 46.7^{\circ}$ (Figure 5.3), which indicated a smooth solid transportation through the TMR. Based on this result, the pretreated substrates AOYP and ASCC were used to perform the solid transportation experiments in TMR.

Another set of figures (Figure B 5.3 to Figure B 5.7) is presented in Appendix B, which are equivalent to Figure 5.3 to Figure 5.7 in this section. These appendix figures contain only the information of weight of cellulose, in bar chart format.

\subsubsection{Pretreated Substrates}

Particle sizes of both yellow poplar (YP) and corn cob (CC) were reduced marginally, after ammonia steeping pretreatment. There was greater reduction in particle sizes of alkaline oxidation pretreated YP and CC than their ammonia steeping pretreated equivalents. To ensure that these feeds, which were 10 times or larger in size than Solka Floc 200FCC (35 $\mu \mathrm{m}$ fiber length), could continuously pass through the HF cartridge, several solid transportation runs were conducted on representative pretreated substrates selected from each species. All these runs ( 2 on 
YP, and 2 on CC), were carried out under the following conditions: shaking speed of $180 \mathrm{rpm}$, inclination of $46.7^{\circ}$, retentate flow rate of $\sim 1.08 \mathrm{ml} / \mathrm{min}$, and permeate flow rate of $\sim 0.27 \mathrm{ml} / \mathrm{min}$.

\subsubsection{Alkaline Oxidation Yellow Poplar (AOYP)}

Between the two types of pretreated YP, AOYP was selected for the solid transportation study. Figure 5.8a shows that approximately $100 \%$ output (in weight) of AOYP was reached during the 45-90 minutes time interval. After this, the weight of the output AOYP fluctuated around the constant weight of AOYP input, a fairly good indication that AOYP particles could be transported continuously and smoothly inside the HFs without any prior reduction of size. Size reduction normally took place during hydrolysis runs. Results of a repeated AOYP solid transportation run (with minor differences in retentate and permeate flow rates) is shown in Figure 5.8b. These results were very reproducible.

\subsubsection{Ammonia Steeping Corn Cob (ASCC)}

Since ACSS particles were larger in size than AOCC, they were selected for the solid transportation run for CC. Results (Figure 5.9a) showed that the weight of output ASCC never attained the same as the weight of input ASCC during any time interval for the whole experimental period. The weight of the overall output of ASCC was about $87 \%$ of the weight of the overall input of ASCC during the whole experiment. This was a good indication that some of the ASCC particles fed into the HF cartridge were trapped inside the reactor using 180 $\mathrm{rpm} / 46.7^{\circ}$. A repeated run also showed the same trend (Figure 5.9b). 
Digestibility results presented in section 5.1.2, indicated that both ASCC and AOCC can be easily hydrolyzed in a TMR. In the enzymatic hydrolysis runs, quick hydrolysis helps to reduce particle size, by "eating" up the outer layer of substrate particle, or by actually breaking the substrate down into smaller pieces. Based on this understanding, it is anticipated that the pretreated CC particles would still have a continuous and smooth transportation inside the TMR, once enzyme was used in the continuous hydrolysis experiments.

Combination of $180 \mathrm{rpm} / 46.7^{\circ}$ was utilized for all the continuous enzymatic hydrolysis runs of this work. Since the particle size of substrate is gradually reduce during the enzymatic hydrolysis, continuous and smooth transportation of substrates in the enzymatic hydrolysis experiments can be reached. As the results presented in the next section indicate, combination of $180 \mathrm{rpm} / 46.7^{\circ}$ was satisfactory for constant enzymatic hydrolysis runs with and without surfactants.

\subsection{Continuous Hydrolysis in TMR}

One integrity test for the HF cartridge was performed in December 2000, prior to all the continuous hydrolysis runs to check out the condition of the cartridge. The air diffusion value of $1.83 \mathrm{ml} / \mathrm{min}-\mathrm{m}^{2}$ was much lower than the critical value of $33 \mathrm{ml} / \mathrm{min}-\mathrm{m}^{2}$, a clear indication that the HF cartridge was still free of pinhole, and thus possible enzyme leakage. This second integrity test was done one year after the first one, indicating that the HF cartridge used is very robust. 
Continuous hydrolysis runs were carried out using Solka Floc 200FCC and all four pretreated substrates, Alkaline Oxidation Yellow Poplar (AOYP), Ammonia Steeping Yellow Poplar (ASYP), Alkaline Oxidation Corn Cob (AOCC), and Ammonia Steeping Corn Cob (ASCC). For each of these five substrates, three different cases regarding surfactant, i.e., no surfactant, with Tergitol, and with Pluronic, were studied. The results of each case are shown in two separate sets of figures. Each of the first set of 15 figures (Figure $5.10 \sim 5.24$ ) contains four curves, three for glucose concentrations (right ordinate) and one for substrate conversion (left ordinate). The second set of 12 figures (Figure $5.25 \sim 5.36$ ) provide distribution of cellobiose and glucose in the permeate stream. Detailed experimental conditions associated with each run are listed in Table C.1 to Table C.15 in the Appendix C. Refer to Nomenclature for symbols used in figures and tables.

In order to clearly compare the effect of different surfactants on the hydrolysis performance of each substrate, another 5 figures (Figure 5.37 to Figure 5.41, one for each case) were plotted. Key results are summarized in Table 5.2, which will be discussed later. Refer to Nomenclature for symbols used in this table.

\subsubsection{Solka Floc 200FCC}

Figure 5.37 shows that steady state substrate conversion $\mathrm{X}_{\mathrm{G}}$ of Solka Floc with no surfactant is around $6.75 \%$. Both types of surfactants are effective in enhancing the hydrolysis of Solka Floc, with Pluronic F68 (22.3\% increase) slightly outperforming Tergitol NP-9 (21.0\% increase). 
As we may recall that the final substrate conversion of Solka Floc 200FCC could reach $86.30 \%$ in a batch reactor (Table 5.1), under the experimental condition of maximum digestibility test described in Section 4.2.4. It is worth noticing that the digestibility test was set up to find out the maximum extent of digestibility possible, thus much more intensive reaction conditions were applied compared to those used for the continuous hydrolysis in a TMR:

- The reaction time was much longer (by a factor of 432 or 1008) for digestibility test.

The time duration of digestibility test was usually 72 to 168 hours, yet mean residence time of substrate in a TMR was only around 10 minutes, even though an entire hydrolysis run in a TMR typically took about 5 to 7 hours, to ensure that a steady state substrate conversion was reached.

- Not only cellulase but also $\beta$-glucosidase were used in the digestibility test.

By adding $\beta$-glucosidase, cellobiose and other oligosaccharides could be hydrolyzed more completely, and rapidly into glucose.

- The enzyme dosage was much higher in the digestibility test.

For digestibility test: cellulase: substrate $=2: 1$ and $\beta$-glucosidase: substrate $=2: 1$, while for continuous hydrolysis in a TMR: cellulase: substrate $=0.24 \sim 0.27: 1$. Thus, the cellulase dosage in digestibility test was around 8 times more than that used in the TMR hydrolysis.

- The reaction temperature was also slightly different.

The temperature used in the digestibility test was $50^{\circ} \mathrm{C}$, slightly higher than that of the TMR hydrolysis, which was $45^{\circ} \mathrm{C}$.

These reasons above explain why the final substrate conversion of Solka Floc 200FCC reached $86.30 \%$ after 100 hours in the digestibility test, yet the steady state substrate conversion of the same substrate was only $6.75 \%$ in the continuous hydrolysis in a TMR. For a TMR with 
equivalent reaction time, the substrate conversion of Solka Floc 200FCC would have reached close to $86.3 \%$ even at a location well upstream from the TMR outlet.

\subsubsection{Alkaline Oxidation Yellow Poplar (AOYP)}

Steady state substrate conversion $\mathrm{X}_{\mathrm{G}}$ of AOYP with no surfactant was $2.11 \%$, around $1 / 3$ that of Solka Floc 200FCC (6.75\%) (Figure 5.38). This was a good match with the digestibility results presented in Section 5.1, where the digestible cellulose amount (approximated by the final substrate conversion) in AOYP (28.92\%) is approximately $1 / 3$ that of Solka Floc (86.30\%).

Similar enhancements of hydrolysis were observed if surfactants were added to the reaction system. The run with Pluronic addition again exhibited a better steady state conversion (23\% enhancement) than the run with Tergitol addition (about 16\% enhancement).

\subsubsection{Ammonia Steeping Yellow Poplar (ASYP)}

From Figure 5.39, the steady state substrate conversion $\mathrm{X}_{\mathrm{G}}$ for ASYP with no surfactant is $1.25 \%$, which is around 1/5 that of Solka Floc and about $60 \%$ of that of AOYP, if no surfactant is added. This low ratio somehow matches the digestibility results. As presented in Section 5.1, the digestible cellulose content of ASYP was 15.98\%, which was around 1/5 that of Solka Floc (86.3\%). This matching simply indicates that ASYP has much less amount of digestible cellulose than AOYP, thus it has lower steady state substrate conversion in a TMR. Again, both surfactants enhanced the hydrolysis of ASYP in our TMR system, but Tergitol giving a better steady state conversion (about $24 \%$ enhancement) verse the Pluronic run (20\% enhancement). 


\subsubsection{Alkaline Oxidation Corn Cob (AOCC)}

From Figure 5.40, the steady state substrate conversion $\mathrm{X}_{\mathrm{G}}$ of AOCC with no surfactant is $6.08 \%$, a value close to that $(6.75 \%)$ of Solka Floc under the same reaction condition. Since the digestible cellulose amount in AOCC is only $65 \%$ that of Solka Floc, but it yields a steady state conversion equal to $90 \%$ of the Solka inside our TMR system, this may indicate that AOCC has a faster hydrolysis rate in a TMR. This reflects well the observation made in the digestibility test that AOCC also has faster initial hydrolysis rate in the first 8 hours than Solka Floc in a batch digestion reactor. This indicates that alkaline oxidation is an effective pretreatment method for corn cob, for use in our TMR system.

In Figure 5.40, the same enhancing trend is observed, but with increased intensity. Tergitol is able to enhance steady state conversion of AOCC by about $47.6 \%$ and Pluronic give a $68.7 \%$ enhancement. These enhancements are much more significant than those observed in Solka and both pretreated YPs. Since AOCC has significantly larger particle size (by a factor of 2 to 3), compared to Solka and pretreated YPs, this might indicate that surfactants are more effective when applied to larger particles.

One interesting phenomenon observed in an early AOCC run (with Tergitol addition) was that the size of AOCC particles inside the substrate reservoir decreased gradually, during the time period of that run. The decrease in substrate size inside the substrate reservoir was concluded through the observation that the homogeneity of substrate solution inside the reservoir increased during the run. Since the substrate had been presoaked in $\mathrm{pH} 4.5$ buffer solution (containing Tergitol), with stirring for 4 hours before hydrolysis actually started, and was continuously 
stirred throughout that hydrolysis experiment. The decrease of substrate size during the time period of the experiment was thought to be caused by insufficient presoaking. So, the presoaking time of substrates was increased from 4 hours to 24 hours for all the later runs and for the repeated run for AOCC (with no surfactant and with Tergitol). The results of comparison of presoaking time will be summarized in a later section.

\subsubsection{Ammonia Steeping Corn Cob (ASCC)}

From Figure 5.41, steady state substrate conversion $\mathrm{X}_{\mathrm{G}}$ of ASCC with no surfactant is $6.18 \%$, also very close to the corresponding value of $6.75 \%$ for Solka Floc. Hydrolysis of ASCC is also enhanced by both Tergitol and Pluronic. This enhancement is the greatest, among all the pretreated substrates investigated in this project, at $73.6 \%$ and $96.3 \%$, for Tergitol and Pluronic respectively.

This was not expected, since the steady state substrate conversion $\mathrm{X}_{\mathrm{G}}$ of all the continuous hydrolysis runs in TMR is consistent with their digestible cellulose content determined by the digestibility tests. According to the digestibility test, the digestible cellulose content in ASCC is $48.40 \%$, less than that of AOCC, which is $55.63 \%$. Yet in continuous hydrolysis runs, ASCC reached a steady state substrate conversion of $6.18 \%$ (with no surfactant), $10.73 \%$ (with Tergitol) and $12.13 \%$ (with Pluronic), which are all higher than the corresponding values of $6.08 \%, 8.98 \%$ and $10.27 \%$ respectively, for AOCC, under the same surfactant condition. This might indicate that ASCC has some special feature, which makes it very suitable for reacting inside our TMR system, particularly under the influence of a surfactant. 


\subsubsection{Effect of Presoaking Time}

As mentioned in Section 5.3.4, the presoaking time might be a factor, which affects steady state conversions of Solka Floc and AOCC. The results of three paired runs with difference only in the presoaking time are presented in Figure 5.42. Subscript "4" after the species name indicate the hydrolysis performance after 4 hours presoaking, similarly subscript " 24 ” for those with 24 hours presoaking.

Curves Solka 4 and Solka 24 compare the effect of presoaking time on the hydrolysis of Solka Floc 200FCC with no surfactant added. As we can see the steady state conversion of Solka Floc is reached at 210 minutes after 24 hours presoaking, slightly earlier than 240 minutes needed for the 4 hours presoaking run. However, the steady state substrate conversion $\mathrm{X}_{\mathrm{G}}$ was not affected much.

Curves AOCC- $\mathrm{B}_{4}$ and AOCC- $\mathrm{B}_{24}$ compares the effect of presoaking time on the hydrolysis of AOCC with no surfactant added. This time the longer presoaking time not only helps hydrolysis reaction to reach steady state earlier, but also increases the value of steady state substrate conversion $\mathrm{X}_{\mathrm{G}}$ from about $4 \%$ to about $6 \%$, which is almost a $50 \%$ increase.

Curves AOCC- $\mathrm{T}_{4}$ and AOCC- $\mathrm{T}_{24}$ compares the effect of presoaking time on the hydrolysis of AOCC while Tergitol is added. It is obvious that the one with longer presoaking time reached steady state two hours earlier than the one with shorter presoaking. Yet the presoaking time did not seem to help yield a higher steady state substrate conversion $\mathrm{X}_{\mathrm{G}}$. As a matter of fact, longer presoaking time reduces $\mathrm{X}_{\mathrm{G}}$ to $9.0 \%$ from $9.5 \%$. 
Based on the above three cases, we can state that:

1) The presoaking time has stronger effect on the hydrolysis of larger particles than the smaller particles. This is obvious, since it is natural that larger particles require longer time to get completely wetted. The average fiber length of Solka Floc 200FCC is $35 \mu \mathrm{m}$ and the size of AOCC about $212 \times 121 \mu \mathrm{m}$ (length $\times$ width). Four hours presoaking seemed to be almost enough to wet Solka Floc 200FCC, since there is no significant difference in the steady state substrate conversions of Solka 4 and Solka 24 , even though the initial hydrolysis rate of Solka was slightly lower and it took slightly longer to reach the steady state conversion. As for bigger AOCC particles, four hours of presoaking might not seem to be enough for wetting. Since enzyme can not attach themselves to dry sites of substrates, the less wetted AOCC-B 4 has a slower initial hydrolysis rate, as well as a lower steady state substrate conversion, compared to the much wetted AOCC-B 24 .

2) The stirring during presoaking might also help in reducing the substrate particles. The size reduction was observed during the first 3 hours of hydrolysis of AOCC-T . The mechanical stirring of substrate solution while presoaking or during the run time, and the associated shear stress might have contributed to the AOCC size reduction. The longer the presoaking, the finer the particle sizes, and the faster the hydrolysis rate during the run time. This effect also favors the size of larger particles than the smaller ones such as Solka Floc.

3) The presoaking time makes less difference for surfactant added runs. One of the surfactant's functions is to make substrate more easily wetted and thus more accessible to cellulase enzyme. Since surfactant was added from the very beginning of the presoaking, in the 
substrate reservoir, it helped to wet the substrate during presoaking and was able to shorten the presoaking time required to thoroughly wet the substrate.

\subsubsection{Permeate Cellobiose Profiles}

From Figure 5.25 to Figure 5.36, we found that the distribution of cellobiose and glucose, expressed as weight percentage of cellobiose started at a relatively high value, usually above $50 \%$. This indicates there is more cellobiose produced at the initial stage of the start-up of a TMR. When the hydrolysis run in a TMR reached a steady state, the \% of cellobiose decreased to within the range of $25 \%$ to $45 \%$, depending on the substrate used.

Figure 5.43 to 5.46 show that the steady state $\%$ of cellobiose is slightly higher when surfactants are added, compared to corresponding none surfactant runs for each pretreated substrate. This indicates that the enhancement of substrate hydrolysis observed in Section 5.3.1 to 5.3.5, judged by only using steady state glucose concentration reached, might not reflect the overall effect that a surfactant might have on the continuous enzymatic hydrolysis, since not only the glucose concentrations, but also the cellobiose concentrations, were increased when surfactants were added.

\subsubsection{Summary of Continuous Hydrolysis Runs}

The summarized results from all 15 hydrolysis runs are presented in Table 5.2. The values listed in Table 5.2 are all steady state values. Refer to Nomenclature section for their calculations. Majority of the samples are presoaked for 24 hours before the hydrolysis reaction, only the 
samples with *, namely Solka Floc with Tergitol, and Solka Floc with Pluronic are presoaked for 4 hours.

The values of $\mathrm{C}_{\mathrm{gm}}, \mathrm{X}_{\mathrm{G}}$, and $\Delta \mathrm{X}_{\mathrm{G}}$ are calculated using steady state glucose concentration, which includes retentate glucose concentration, $\mathrm{C}_{\mathrm{gr}}$ and permeate glucose concentration, $\mathrm{C}_{\mathrm{gp}}$. Each of these two concentration values is the averaged value of a couple of steady state data points, chosen based on the relevant curve in a corresponding figure.

As for cellobiose, only permeate cellobiose concentration, $\mathrm{C}_{\mathrm{bp}}$, was measured. The retentate cellobiose concentrations, $\mathrm{C}_{\mathrm{br}}$, was calculated by assuming that the $\mathrm{C}_{\mathrm{b}} / \mathrm{C}_{\mathrm{g}}$ ratio (cellobiose concentration/ glucose concentration ratio) is the same in the retentate and the permeate stream. Refer to Nomenclature for calculation formula.

Mean outlet concentration $\mathrm{C}_{\mathrm{tm}}$ is obtained by simply adding up the mean glucose concentration $\mathrm{C}_{\mathrm{gm}}$ and mean cellobiose concentration $\mathrm{C}_{\mathrm{bm}}$ together. Combined productivity of glucose and cellobiose, $p$, is also obtained for each run, to see how much sugar is produced per unit time.

As we can see from Table 5.2, pretreated CCs have the same or even better hydrolytic performance than the model substrate Solka Floc 200FCC in our TMR system, regarding substrate conversion, and combined sugar productivity, especially when surfactants are added. 


\subsection{Aqueous Two-Phase System}

Aqueous two-phase system was created for separating cellulase in a $0.05 \mathrm{M}$ acetate buffer solution, following the procedure described in Section 4.4. Phase separation was observed after 4 hours with $20 \%$ (w/w) Ucon 50-HB-5100. The volumetric ratio of upper to bottom phase was about 3 . The upper phase is basically water, while the bottom phase was viscous and with light yellowish color (look very much alike the original Ucon 50-HB-5100), and should contain mainly the polymer. After letting 24 hours at $60^{\circ} \mathrm{C}$ for enzyme to reach equilibrium in both phases, the upper phase was examined in a UV spectrophotometer at $280 \mathrm{~nm}$ (the characteristic UV absorbing wavelength of protein), using the starting enzyme buffer solution as a blank. Absorbance value of 0.122 was obtained, which indicated the protein concentration was higher in the upper water phase than in the original enzyme buffer solution. This indicated that by using Ucon ATPS, cellulase was enriched in the top water phase.

Protein dying reagents were used in the second trial run, in order to determine protein concentration in the upper phase more accurately, thus to obtain better information regarding separation efficiency of enzyme in the Ucon polymer two phases. The separation procedure was exactly the same as described in the last paragraph, only the protein concentration measurement became slightly more sophisticated. Bio-Rad Reagent A and Reagent B were added to the upper phase to dye the proteins, after the separation process and prior to measuring its absorbance with UV spectrophotometer at $750 \mathrm{~nm}$. The exact protein concentration in the upper phase was then calculated with the help of calibration curve generated by applying the reagents to protein solution with known protein concentration. 
Second trial run of aqueous two phase system with UCON 50-HB-5100 confirmed that the protein concentration in the upper aqueous phase was slightly higher than that of the original enzyme buffer solution. Around $99 \%$ of the original protein was retrieved to the upper aqueous phase after letting the system to reach equilibrium for about 18 hours at $60^{\circ} \mathrm{C}$.

\subsection{List of Tables and Figures for This Chapter}

\subsubsection{Tables}

Table 5.1 Characterization of Yellow Poplar, Corn Cob and Solka Floc 200FCC

Table 5.2 Summaries of Continuous Hydrolysis Experiments in a TMR

\subsubsection{Figures}

Figure 5.1 Enzymatic Digestibility of Substrates

Figure 5.2 Final Digestibility versus Percentage Delignification for Substrates

Figures 5.3 - 5.6 Weight of Cellulose (Solka Floc 200FCC) vs. Time

Figure 5.7 Weight of Cellulose (Solka Floc 900FCC) vs. Time

Figures 5.8a \& b Weight of Pretreated Yellow Poplar (AOYP) vs. Time

Figures 5.9a \& b Weight of Pretreated Corn Cob (ASCC) vs. Time

Figures 5.10 - 5.12 Substrate Conversion and Glucose Concentrations vs. Time --- Solka Floc

Figures 5.13 - 5.15 Substrate Conversion and Glucose Concentrations vs. Time --- AOYP

Figures 5.16 - 5.18 Substrate Conversion and Glucose Concentrations vs. Time --- ASYP

Figures 5.19 - 5.21 Substrate Conversion and Glucose Concentrations vs. Time --- AOCC

Figures 5.22 - 5.24 Substrate Conversion and Glucose Concentrations vs. Time --- ASCC 
Figure 5.25 Distribution of Cellobiose and Glucose in Permeate Stream --- Solka Floc

Figures 5.26 - 5.28 Distribution of Cellobiose and Glucose in Permeate Stream --- AOYP

Figures 5.29 - 5.31 Distribution of Cellobiose and Glucose in Permeate Stream --- ASYP

Figures 5.32 - 5.33 Distribution of Cellobiose and Glucose in Permeate Stream --- AOCC

Figures 5.34 - 5.36 Distribution of Cellobiose and Glucose in Permeate Stream --- ASCC

Figure 5.37 Conversion of Solka Floc 200FCC to Glucose in a TMR

Figure 5.38 Conversion of AOYP to Glucose in a TMR

Figure 5.39 Conversion of ASYP to Glucose in a TMR

Figure 5.40 Conversion of AOCC to Glucose in a TMR

Figure 5.41 Conversion of ASCC to Glucose in a TMR

Figure 5.42 Effect of Presoaking Time on Substrate Conversion 
Table 5.1 Characterization of Yellow Poplar, Corn Cob and Solka Floc

--- value averaged from at least two independently tests

\begin{tabular}{|c|c|c|c|c|c|c|c|c|}
\hline Samples & $\begin{array}{c}\text { size }(\mu \mathrm{m}) \\
\mathrm{L} \times \mathrm{W}\end{array}$ & $\%$ AIL & $\%$ ASL & $\begin{array}{c}\text { total dry } \\
\text { weight loss }\end{array}$ & $\begin{array}{c}\text { AIL } \\
\text { removal }\end{array}$ & $\begin{array}{c}\text { ASL } \\
\text { removal }\end{array}$ & $\begin{array}{c}\text { total lignin } \\
\text { removal }\end{array}$ & $\begin{array}{c}\text { digestible cellulose content } \\
=\text { final substrate conversion }\end{array}$ \\
\hline Raw Milled YP & $263 \times 77$ & $24.85 \%$ & $2.45 \%$ & - & - & - & - & $4.73 \%$ \\
\hline Milled ASYP & $235 \times 46$ & $25.04 \%$ & $2.25 \%$ & $27.37 \%$ & $26.88 \%$ & $32.93 \%$ & $27.42 \%$ & $15.98 \%$ \\
\hline Milled AOYP & $174 \times 37$ & $21.97 \%$ & $3.01 \%$ & $20.94 \%$ & $30.13 \%$ & $2.97 \%$ & $27.69 \%$ & $28.92 \%$ \\
\hline Raw CC & $320 \times 180$ & $17.10 \%$ & $2.39 \%$ & - & - & - & - & $16.96 \%$ \\
\hline ASCC & $288 \times 150$ & $18.76 \%$ & $2.42 \%$ & $49.02 \%$ & $44.16 \%$ & $48.25 \%$ & $44.66 \%$ & $48.40 \%$ \\
\hline AOCC & $212 \times 121$ & $2.87 \%$ & $1.65 \%$ & $49.38 \%$ & $91.52 \%$ & $65.13 \%$ & $88.29 \%$ & $55.63 \%$ \\
\hline Solka Floc & $35(\mathrm{~L})$ & - & - & - & - & - & - & $86.30 \%$ \\
\hline
\end{tabular}


Table 5.2 Summaries of Continuous Hydrolysis Experiments in TMR

$\mathrm{X}_{\mathrm{G}}$ : Steady State Substrate Conversion

$\Delta \mathrm{X}_{\mathrm{G}}$ : Percentage enhancement of $\mathrm{X}_{\mathrm{G}}$ with surfactant over $\mathrm{X}_{\mathrm{G}}$ without surfactant

\begin{tabular}{|c|c|c|c|c|c|c|c|c|c|c|c|c|}
\hline Species & $\begin{array}{l}\text { Surfactant } \\
\text { Condition }\end{array}$ & $\begin{array}{c}\mathrm{S}_{\mathrm{R}} \\
(\mathrm{mg} / \mathrm{ml})\end{array}$ & $\begin{array}{c}\mathrm{C}_{\mathrm{gr}} \\
(\mathrm{mg} / \mathrm{ml})\end{array}$ & $\begin{array}{c}\mathrm{C}_{\mathrm{gp}} \\
(\mathrm{mg} / \mathrm{ml})\end{array}$ & $\begin{array}{c}\mathrm{C}_{\mathrm{gm}} \\
(\mathrm{mg} / \mathrm{ml})\end{array}$ & $\begin{array}{l}X_{\mathrm{G}} \\
(\%)\end{array}$ & $\begin{array}{l}\Delta \mathrm{X}_{\mathrm{G}} \\
(\%)\end{array}$ & $\begin{array}{c}\mathrm{C}_{\mathrm{br}} \\
(\mathrm{mg} / \mathrm{ml})\end{array}$ & $\begin{array}{c}\mathrm{C}_{\mathrm{bp}} \\
(\mathrm{mg} / \mathrm{ml})\end{array}$ & $\begin{array}{c}\mathrm{C}_{\mathrm{bm}} \\
(\mathrm{mg} / \mathrm{ml})\end{array}$ & $\begin{array}{c}\mathrm{C}_{\mathrm{tm}} \\
(\mathrm{mg} / \mathrm{ml})\end{array}$ & $\underset{(\mathrm{mg} / \mathrm{min})}{\mathrm{p}}$ \\
\hline \multirow{3}{*}{ Solka } & none & 1.7000 & 0.1324 & 0.0479 & 0.1147 & 6.75 & & 0.0386 & 0.0140 & 0.0334 & 0.1481 & 0.209 \\
\hline & Tergitol(4hrs)* & 1.8600 & 0.1796 & 0.0403 & 0.1518 & 8.16 & 21.0 & & & & & \\
\hline & Pluronic(4hrs)* & 1.8000 & 0.1650 & 0.0750 & 0.1485 & 8.25 & 22.3 & & & & & \\
\hline \multirow{3}{*}{ AOYP } & none & 1.7700 & 0.0400 & 0.0268 & 0.0374 & 2.11 & & 0.0127 & 0.0085 & 0.0119 & 0.0493 & 0.067 \\
\hline & Tergitol & 1.8200 & 0.0468 & 0.0347 & 0.0446 & 2.45 & 15.9 & 0.0177 & 0.0131 & 0.0168 & 0.0614 & 0.081 \\
\hline & Pluronic & 1.8200 & 0.0502 & 0.0346 & 0.0473 & 2.60 & 23.0 & 0.0168 & 0.0116 & 0.0158 & 0.0631 & 0.083 \\
\hline \multirow{3}{*}{ ASYP } & none & 1.7200 & 0.0215 & 0.0213 & 0.0214 & 1.25 & & 0.0083 & 0.0082 & 0.0083 & 0.0297 & 0.041 \\
\hline & Tergitol & 1.8800 & 0.0296 & 0.0272 & 0.0291 & 1.55 & 24.3 & 0.0185 & 0.0170 & 0.0182 & 0.0473 & 0.060 \\
\hline & Pluronic & 1.7500 & 0.0270 & 0.0225 & 0.0261 & 1.49 & 19.9 & 0.0164 & 0.0136 & 0.0158 & 0.0420 & 0.057 \\
\hline \multirow{3}{*}{ AOCC } & none & 1.7100 & 0.1092 & 0.0812 & 0.1040 & 6.08 & & 0.0433 & 0.0322 & 0.0412 & 0.1452 & 0.195 \\
\hline & Tergitol & 1.6800 & 0.1621 & 0.1048 & 0.1508 & 8.98 & 47.7 & 0.0848 & 0.0548 & 0.0789 & 0.2297 & 0.321 \\
\hline & Pluronic & 1.7400 & 0.1910 & 0.1298 & 0.1787 & 10.27 & 69.0 & & & & & \\
\hline \multirow{3}{*}{ ASCC } & none & 1.8400 & 0.1263 & 0.0637 & 0.1137 & 6.18 & & 0.0613 & 0.0309 & 0.0552 & 0.1688 & 0.220 \\
\hline & Tergitol & 1.7000 & 0.2023 & 0.1050 & 0.1824 & 10.73 & 73.6 & 0.1402 & 0.0728 & 0.1264 & 0.3088 & 0.435 \\
\hline & Pluronic & 1.8000 & 0.2391 & 0.1232 & 0.2183 & 12.13 & 96.3 & 0.1567 & 0.0808 & 0.1431 & 0.3614 & 0.481 \\
\hline
\end{tabular}

* Presoaking of substrate with surfactant for 4 hours; all others were presoaked for 24 hours. 


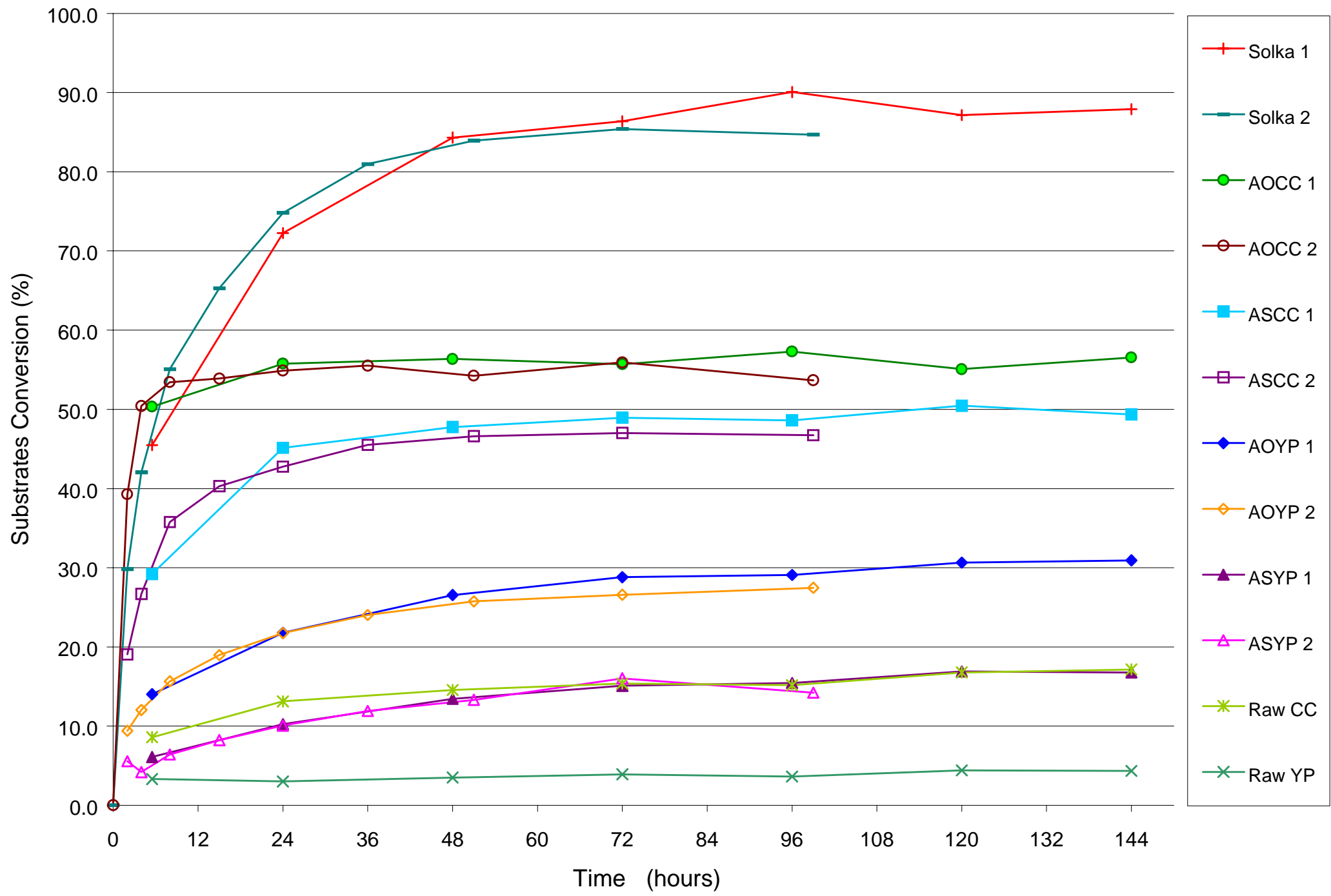

Figure 5.1. Enzymatic Digestibility of Substrates 


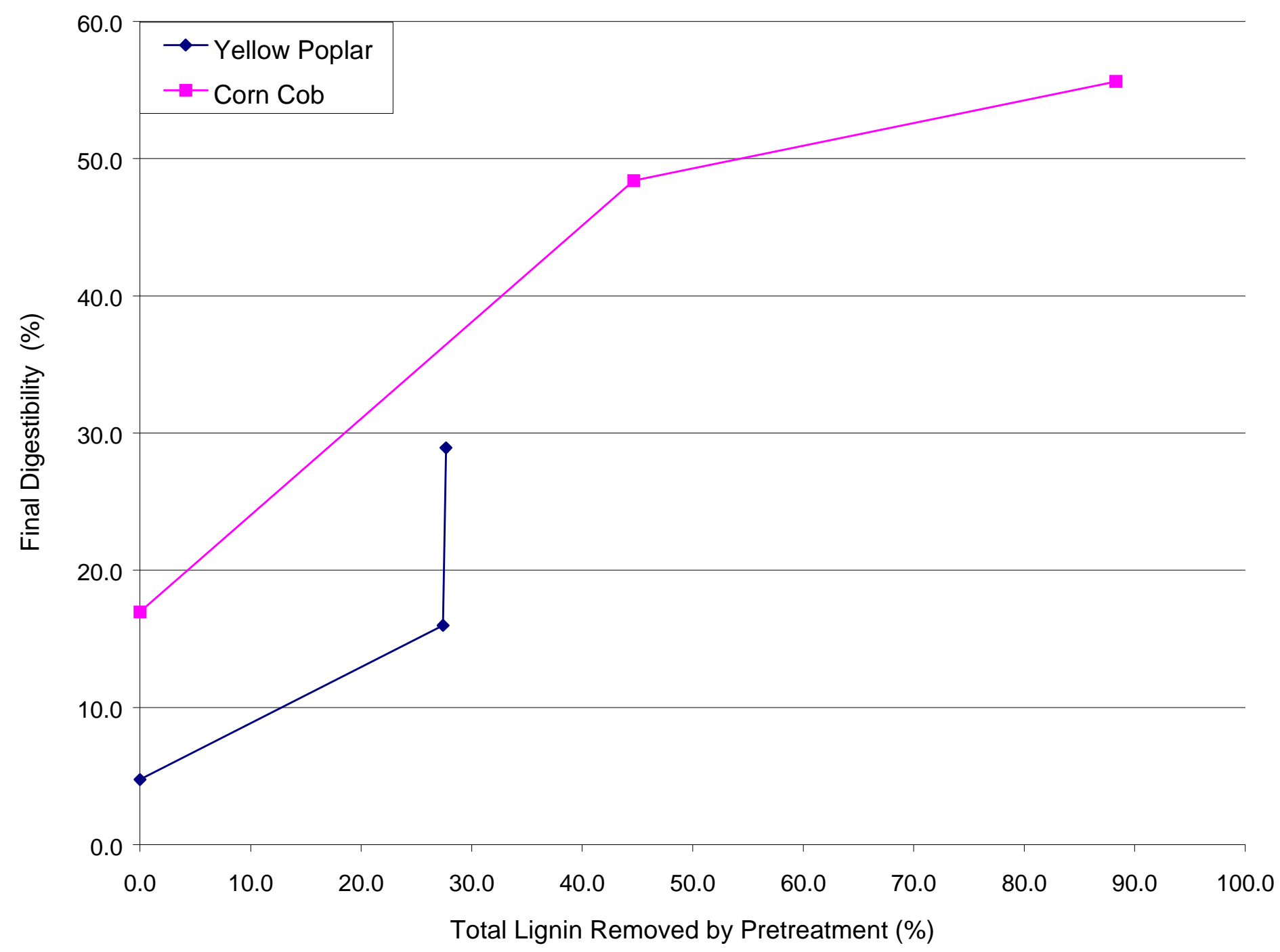

Figure 5.2. Final Digestibility versus Percentage Delignification for Yellow Poplar and Corn Cob 


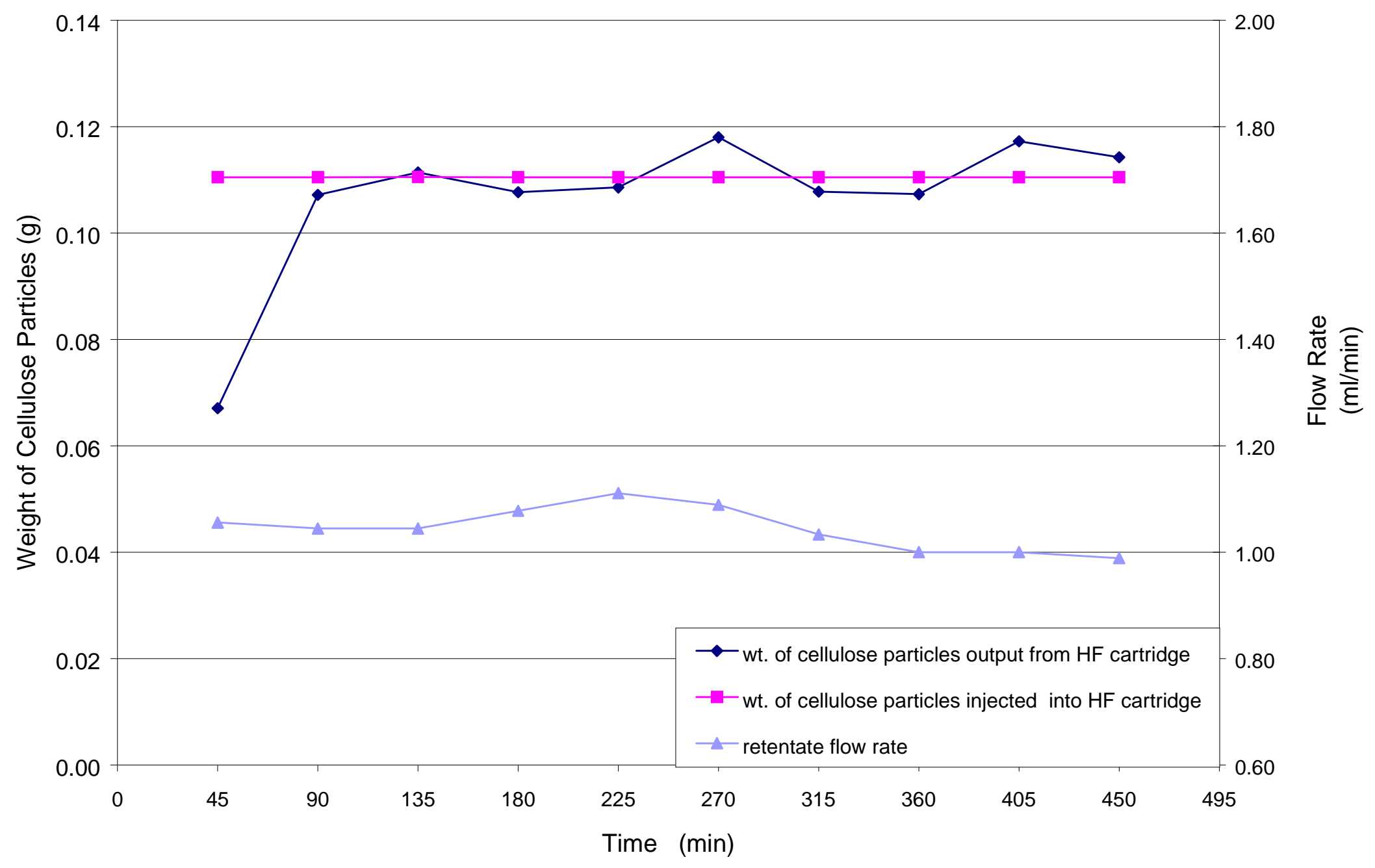

Figure 5.3. Weight of Cellulose (Solka Floc 200FCC) vs. Time (250rpm, $46.7^{\circ}$, Retentate flow rate: $1.04 \mathrm{ml} / \mathrm{min}$ ) 


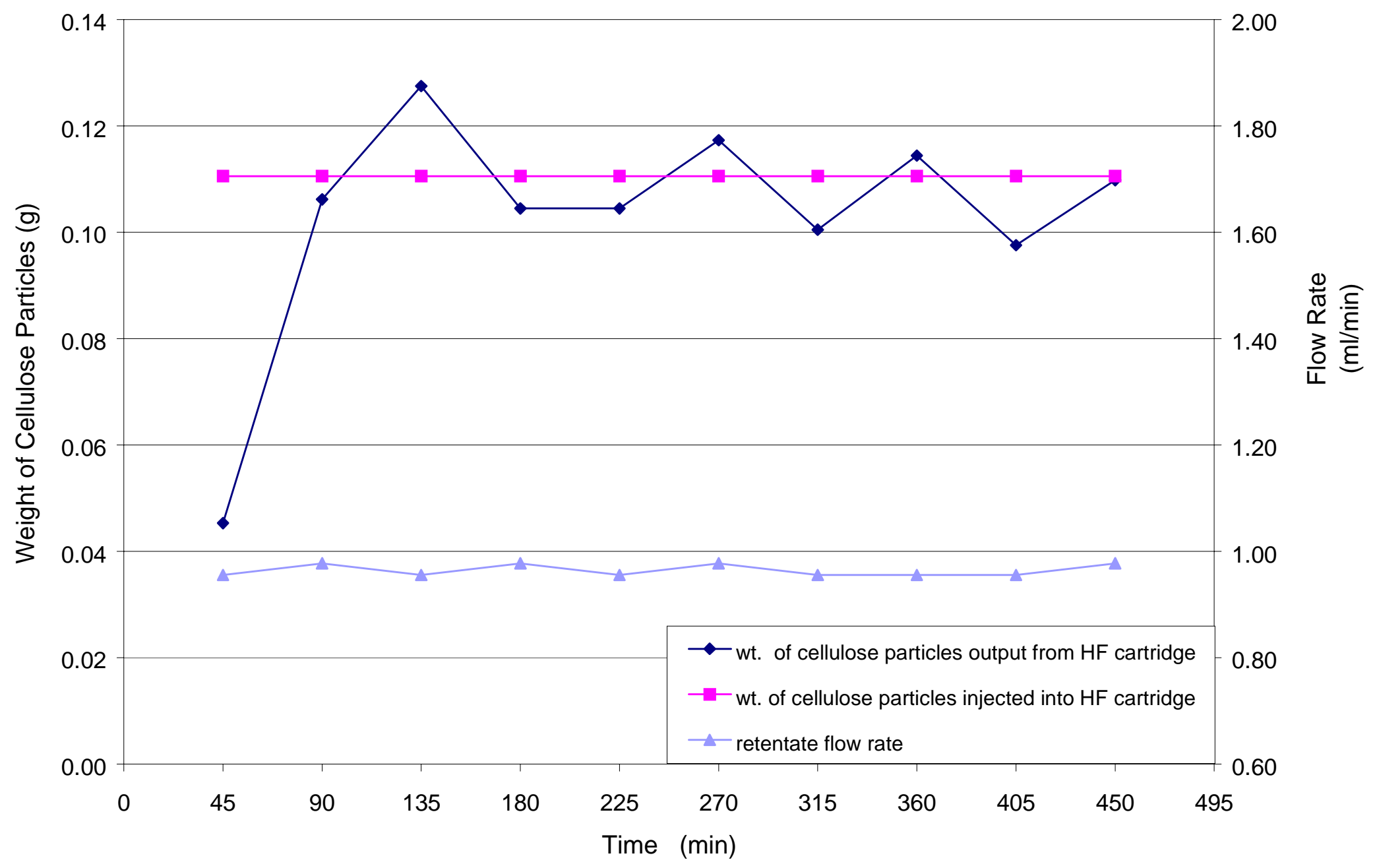

Figure 5.4. Weight of Cellulose (Solka Floc 200FCC) vs. Time (250rpm, $0^{\circ}$, Retentate flow rate: $0.96 \mathrm{ml} / \mathrm{min}$ ) 


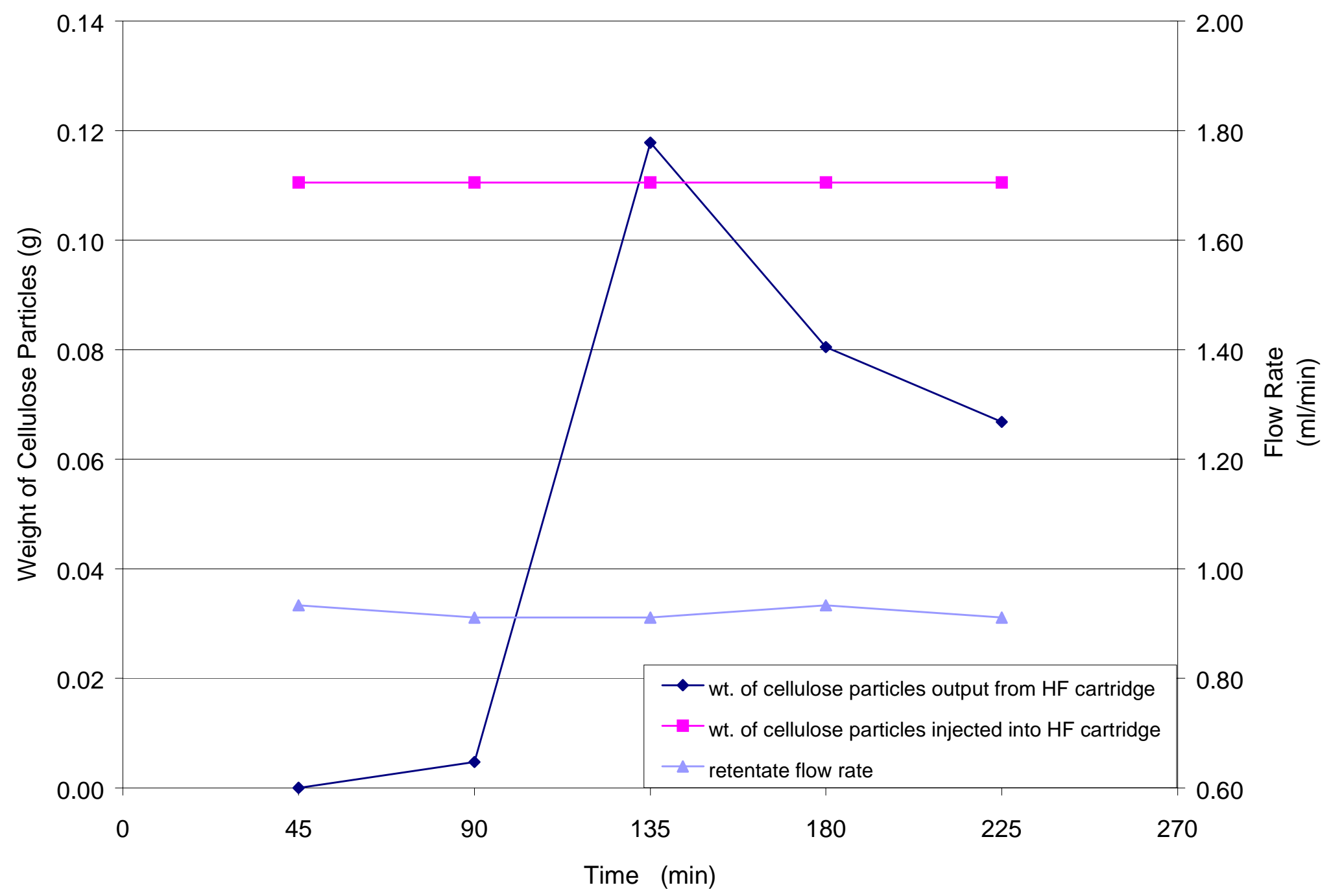

Figure 5.5. Weight of Cellulose (Solka Floc 200FCC) vs. Time (0rpm, $46.7^{\circ}$, Retentate flow rate: $\left.0.92 \mathrm{ml} / \mathrm{min}\right)$ 


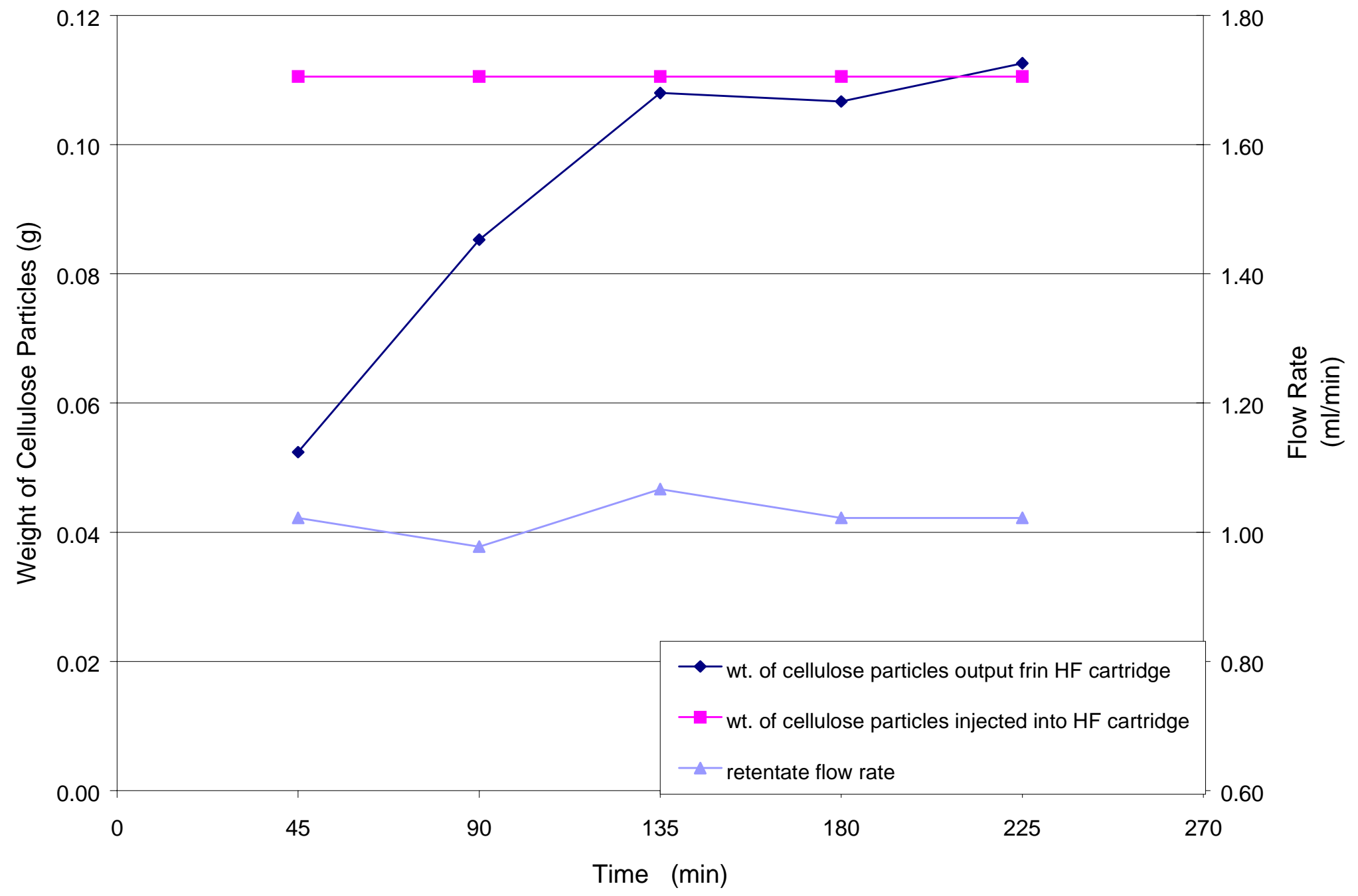

Figure 5.6. Weight of Cellulose (Solka Floc 200FCC) vs. Time (150rpm, $46.7^{0}$, Retentate flow rate: $1.02 \mathrm{ml} / \mathrm{min}$ ) 


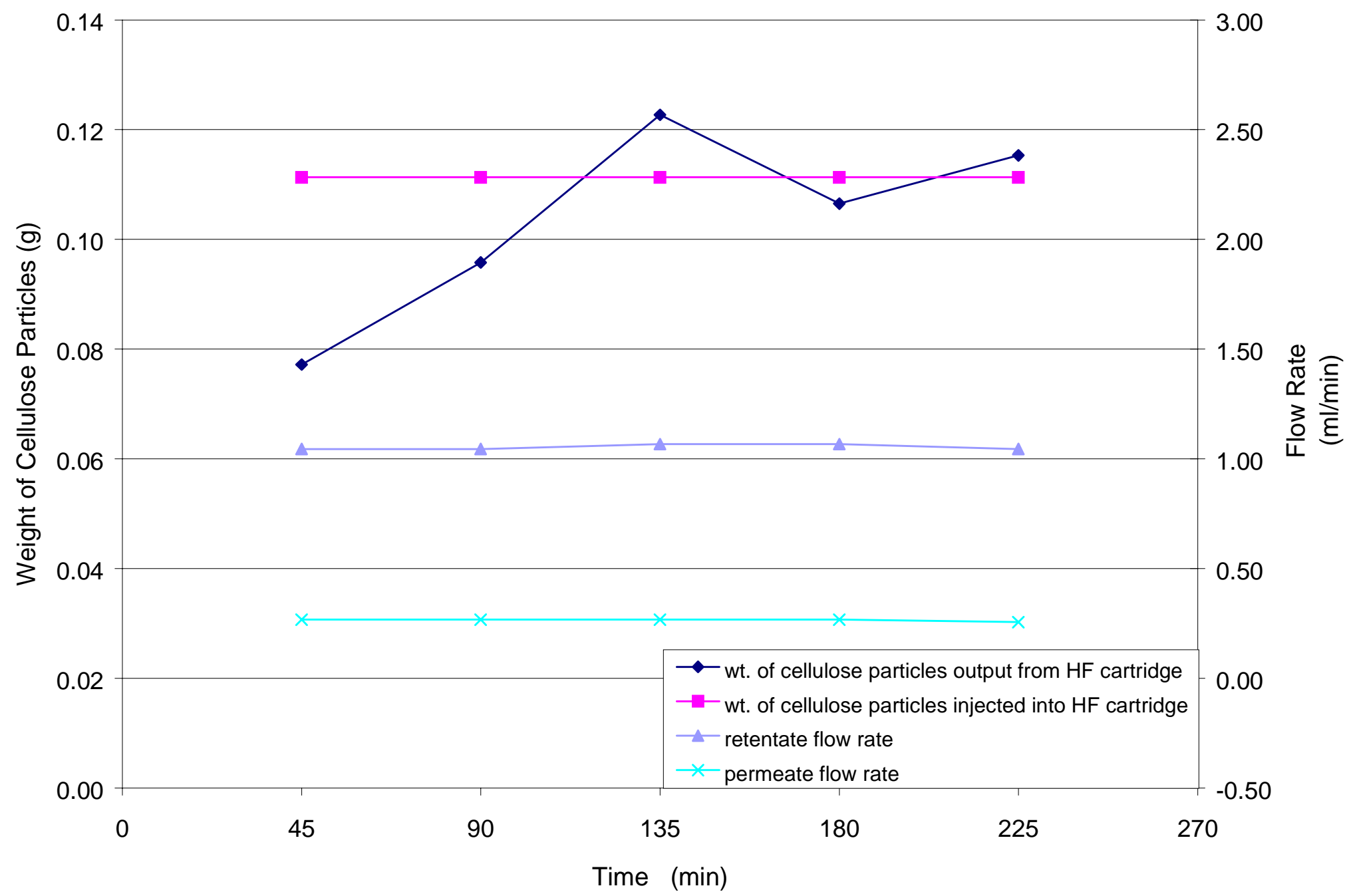

Figure 5.7. Weight of Cellulose (Solka Floc 900FCC) Vs. Time (180rpm, 46.7 ${ }^{0}$, Retentate flow rate: $1.05 \mathrm{ml} / \mathrm{min}$, Permeate flow rate: $0.26 \mathrm{ml} / \mathrm{min}$ ) 


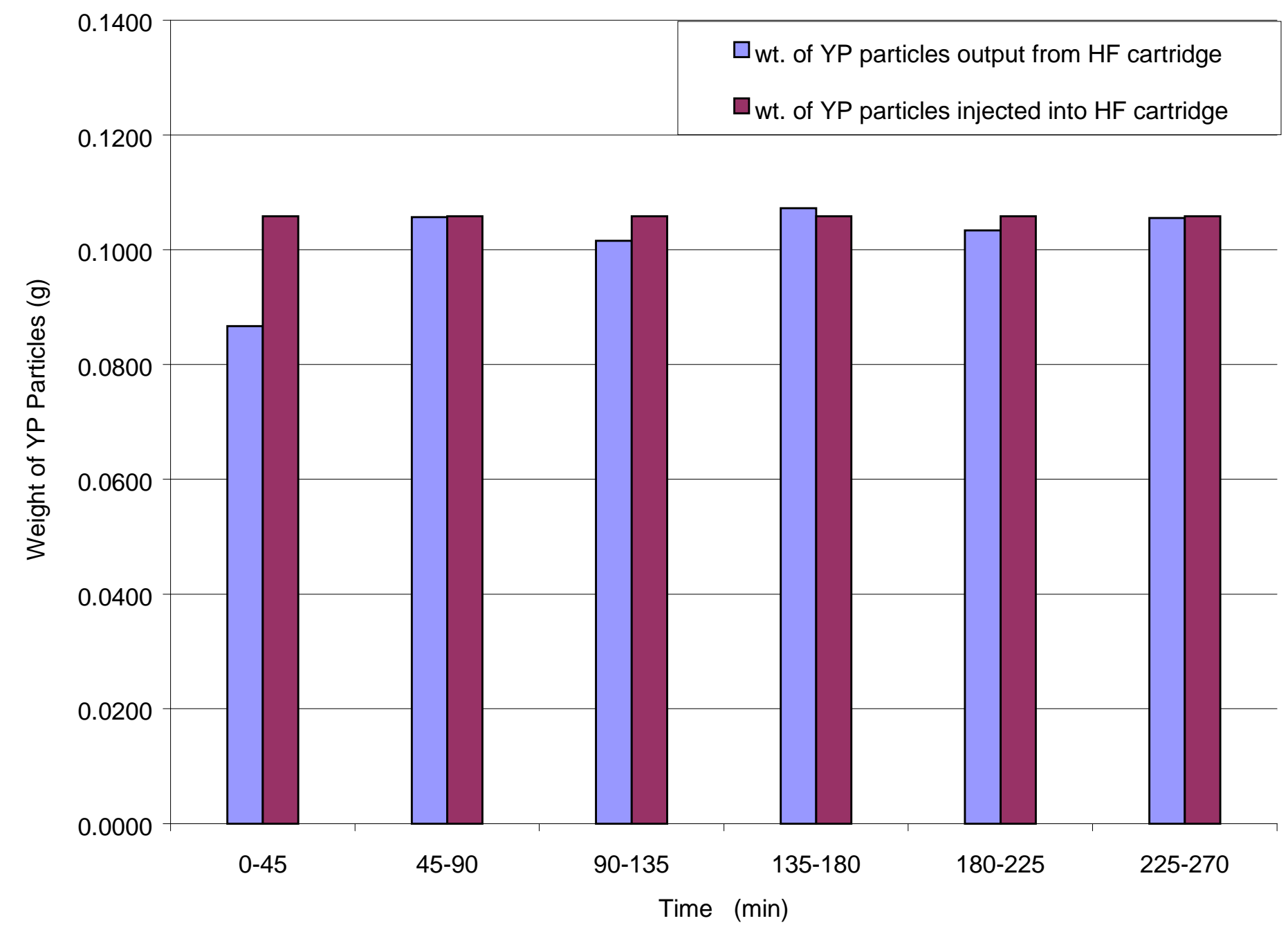

Figure 5.8a. Weight of Pretreated Yellow Poplar (AOYP) vs. Time (180rpm, $46.7^{\circ}$, Retentate flow rate: $1.20 \mathrm{ml} / \mathrm{min}$, Permeate flow rate: $0.21 \mathrm{ml} / \mathrm{min}$ ) 


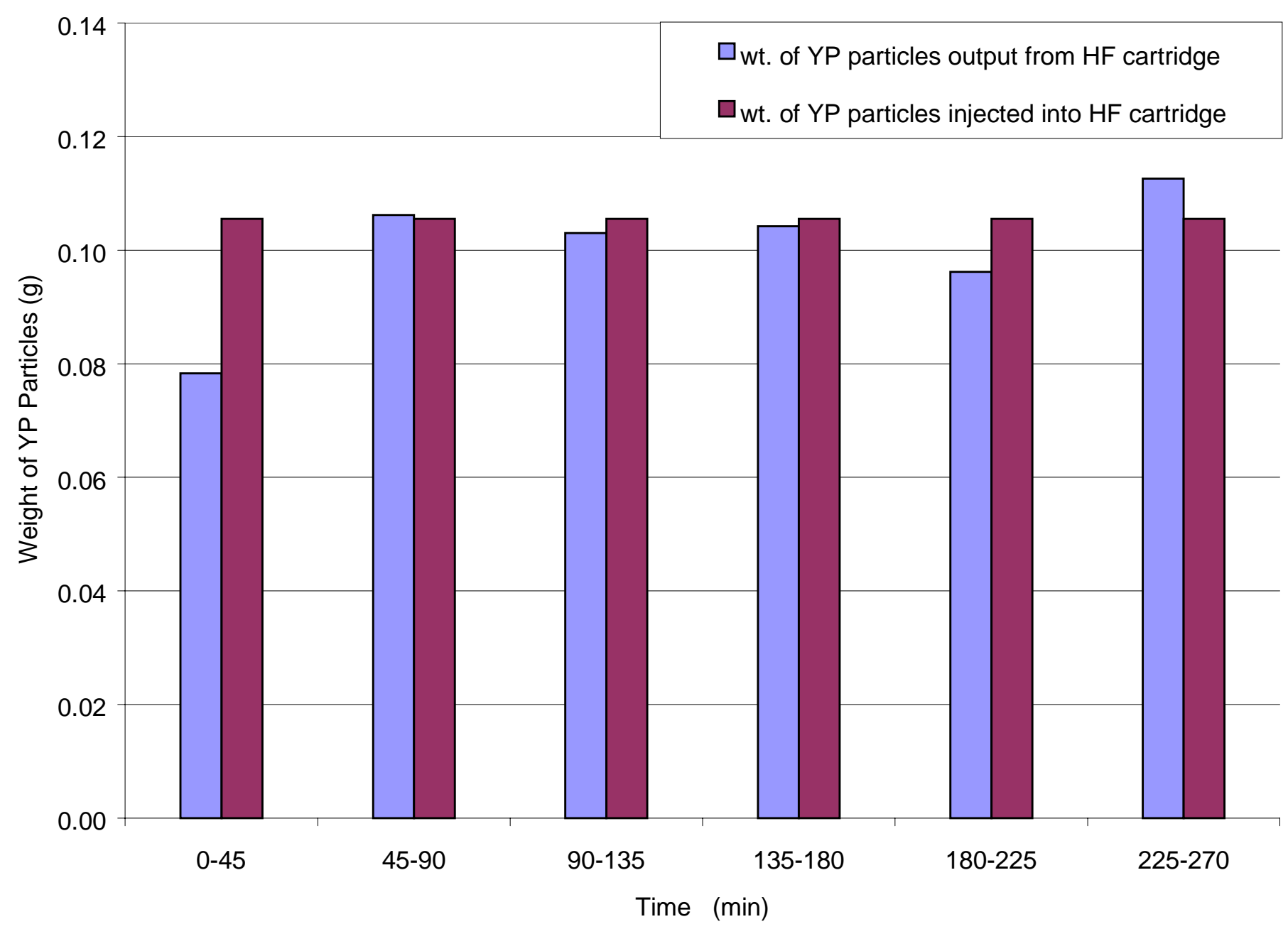

Figure 5.8b. Weight of Pretreated Yellow Poplar (AOYP) vs. Time (180rpm, $46.7^{\circ}$, Retentate flow rate: $1.07 \mathrm{ml} / \mathrm{min}$, Permeate flow rate: $0.30 \mathrm{ml} / \mathrm{min}$ ) 


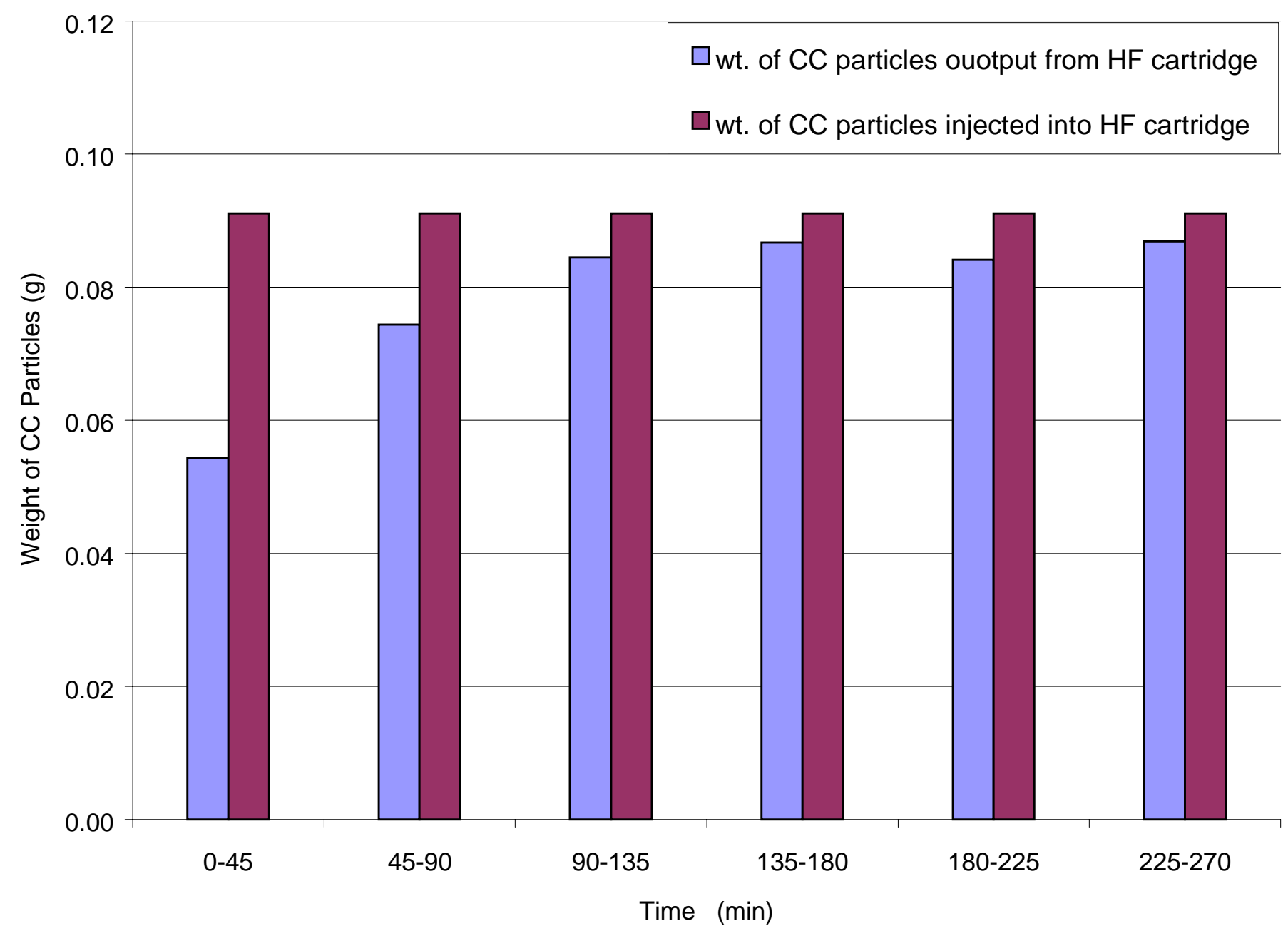

Figure 5.9a. Weight of Pretreated Corn Cob (ASCC) vs. Time (180rpm, $46.7^{\circ}$, Retentate flow rate: $1.08 \mathrm{ml} / \mathrm{min}$, Permeate flow rate: $0.27 \mathrm{ml} / \mathrm{min}$ ) 


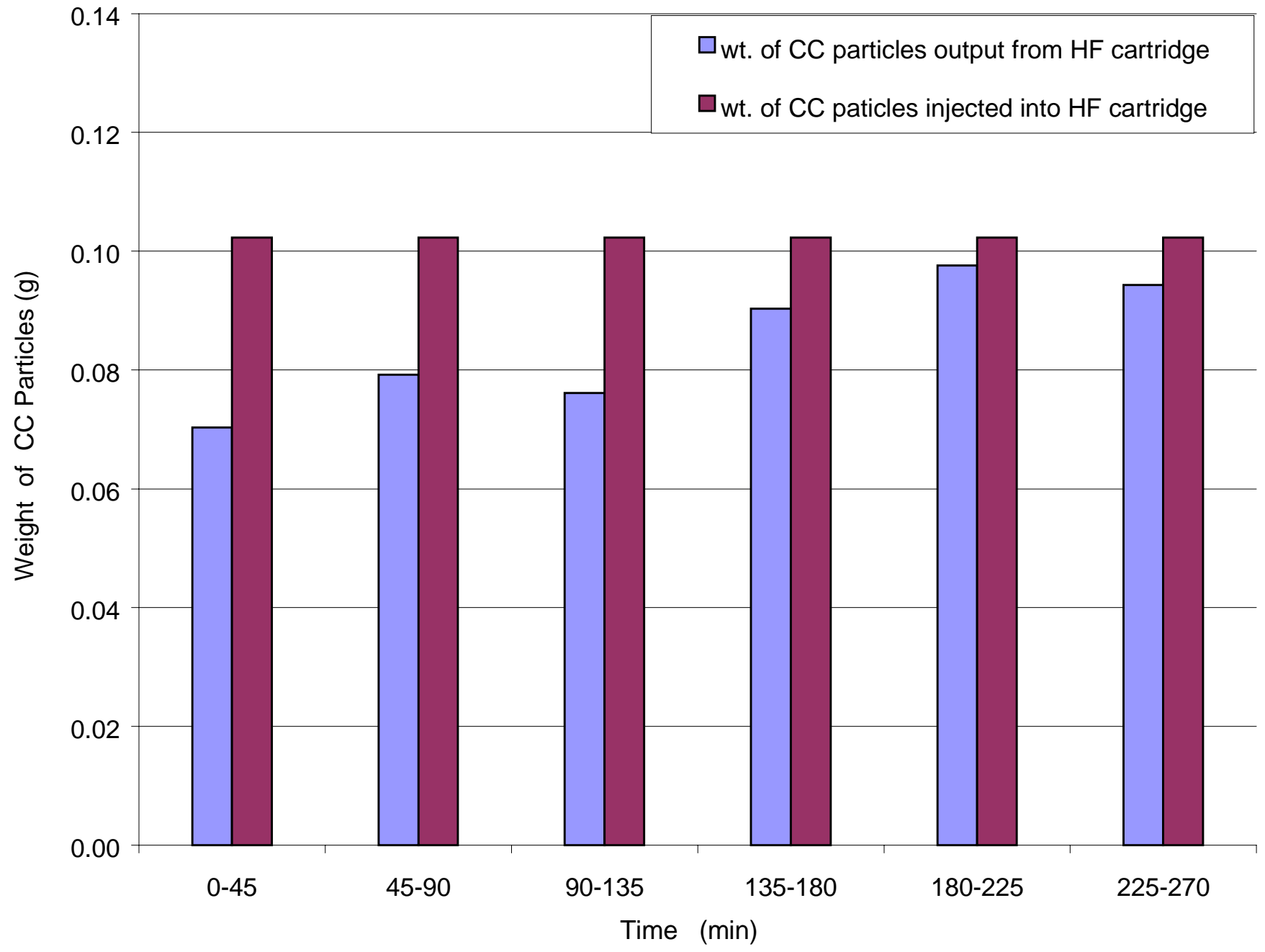

Figure 5.9b. Weight of Pretreated Corn Cob (ASCC) vs. Time $\left(180 \mathrm{rpm}, 46.7^{\circ}\right.$, Retentate flow rate:1.08ml/min, Permeate flow rate: $0.30 \mathrm{ml} / \mathrm{min}$ ) 


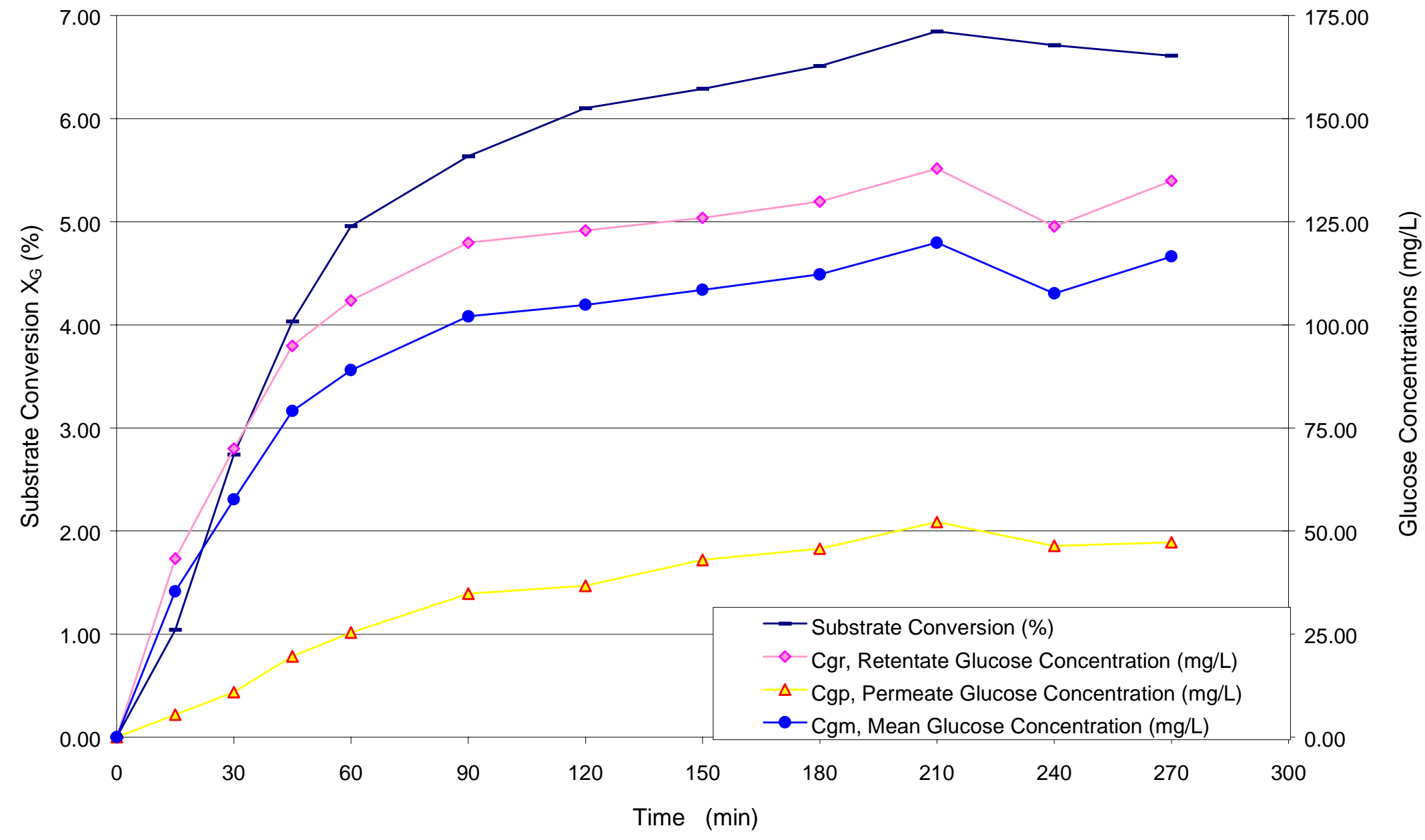

Figure 5.10. Substrate Conversion and Glucose Concentrations vs. Time --- Solka Floc 200FCC, no Surfactant 


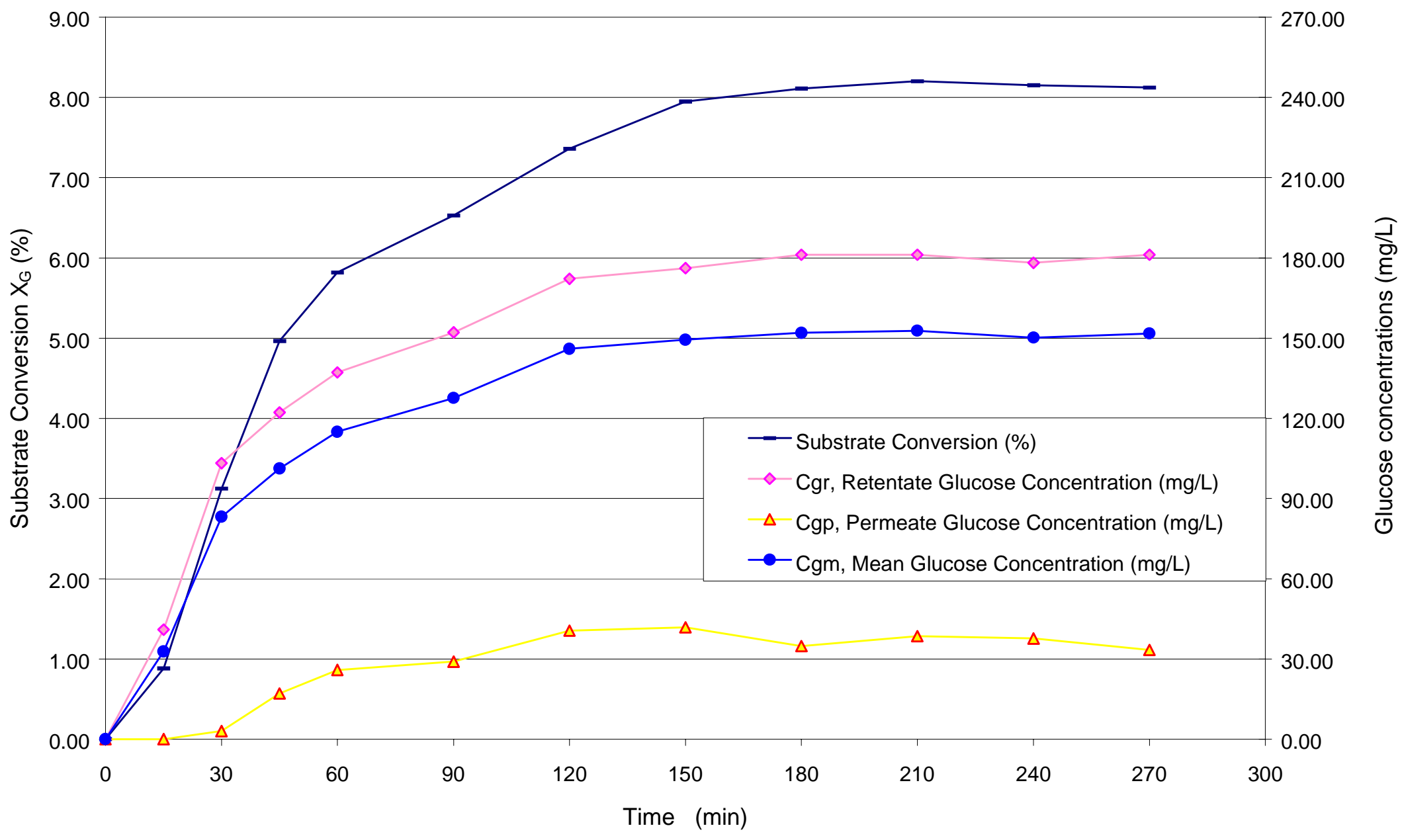

Figure 5.11. Substrate Conversion and Glucose Concentrations vs. Time --- Solka Floc 200FCC, with Tergitol 


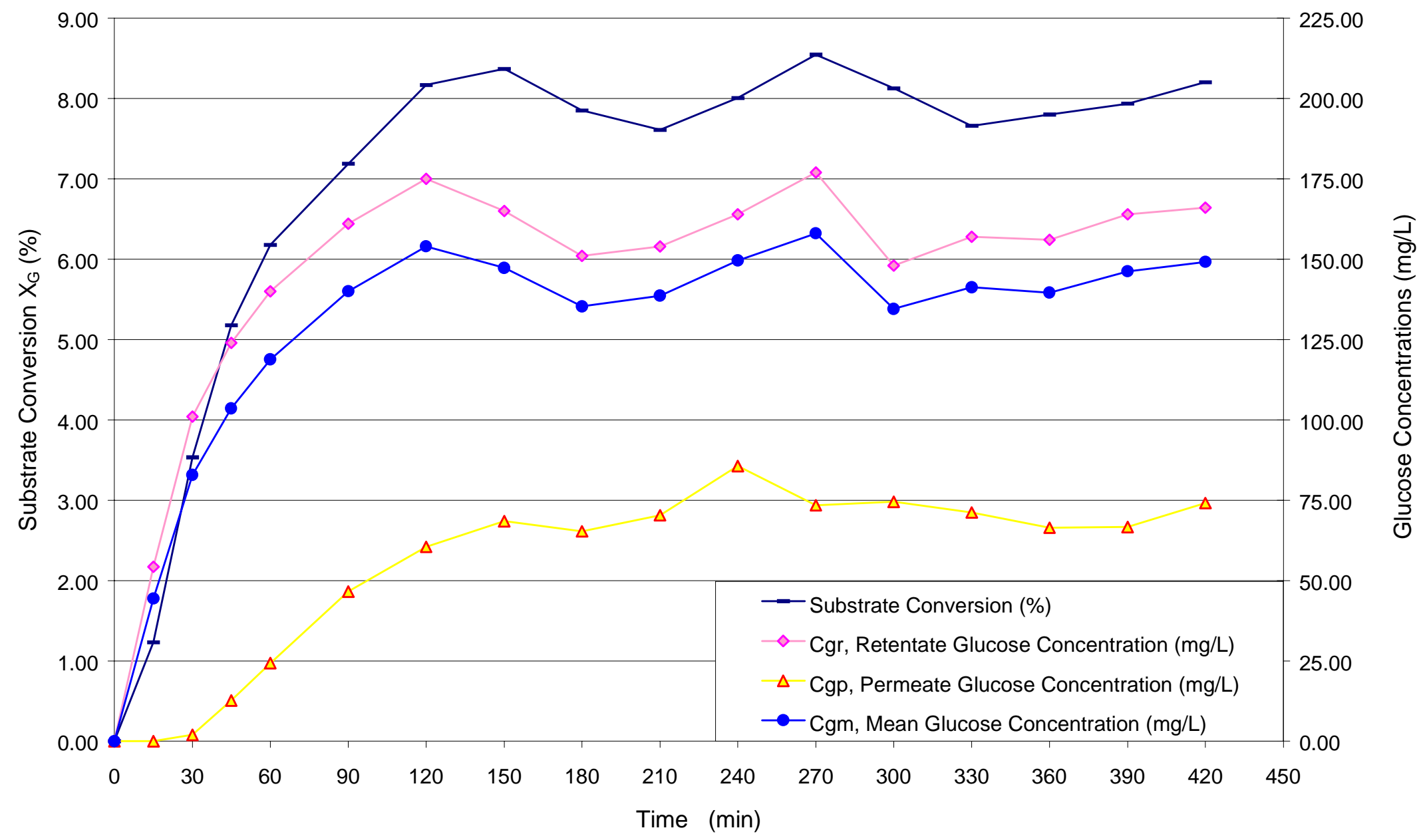

Figure 5.12. Substrate Conversion and Glucose Concentrations vs. Time --- Solka Floc 200FCC, with Pluronic 


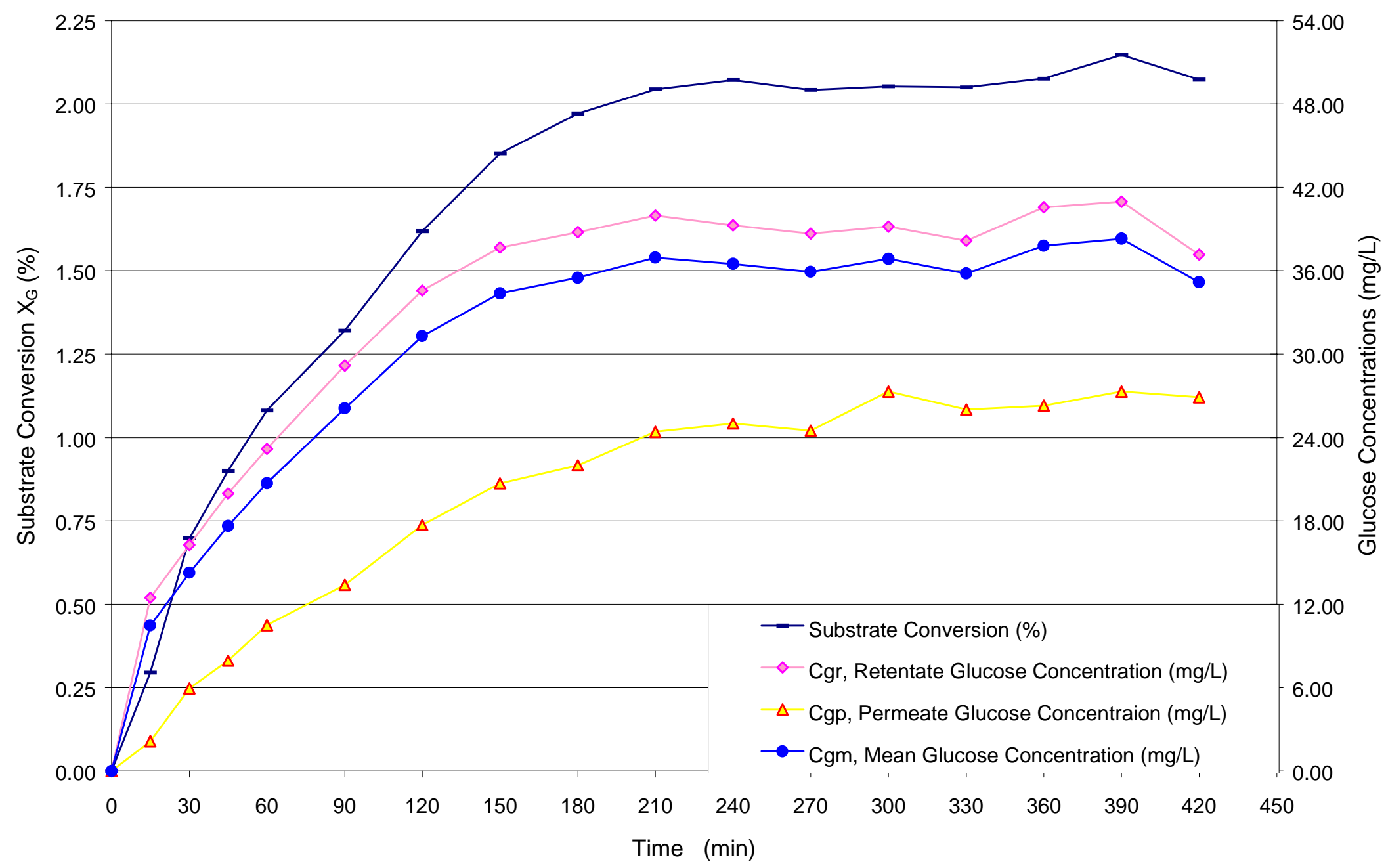

Figure 5.13. Substrate Conversion and Glucose Concentrations vs. Time --- AOYP, no Surfactant 


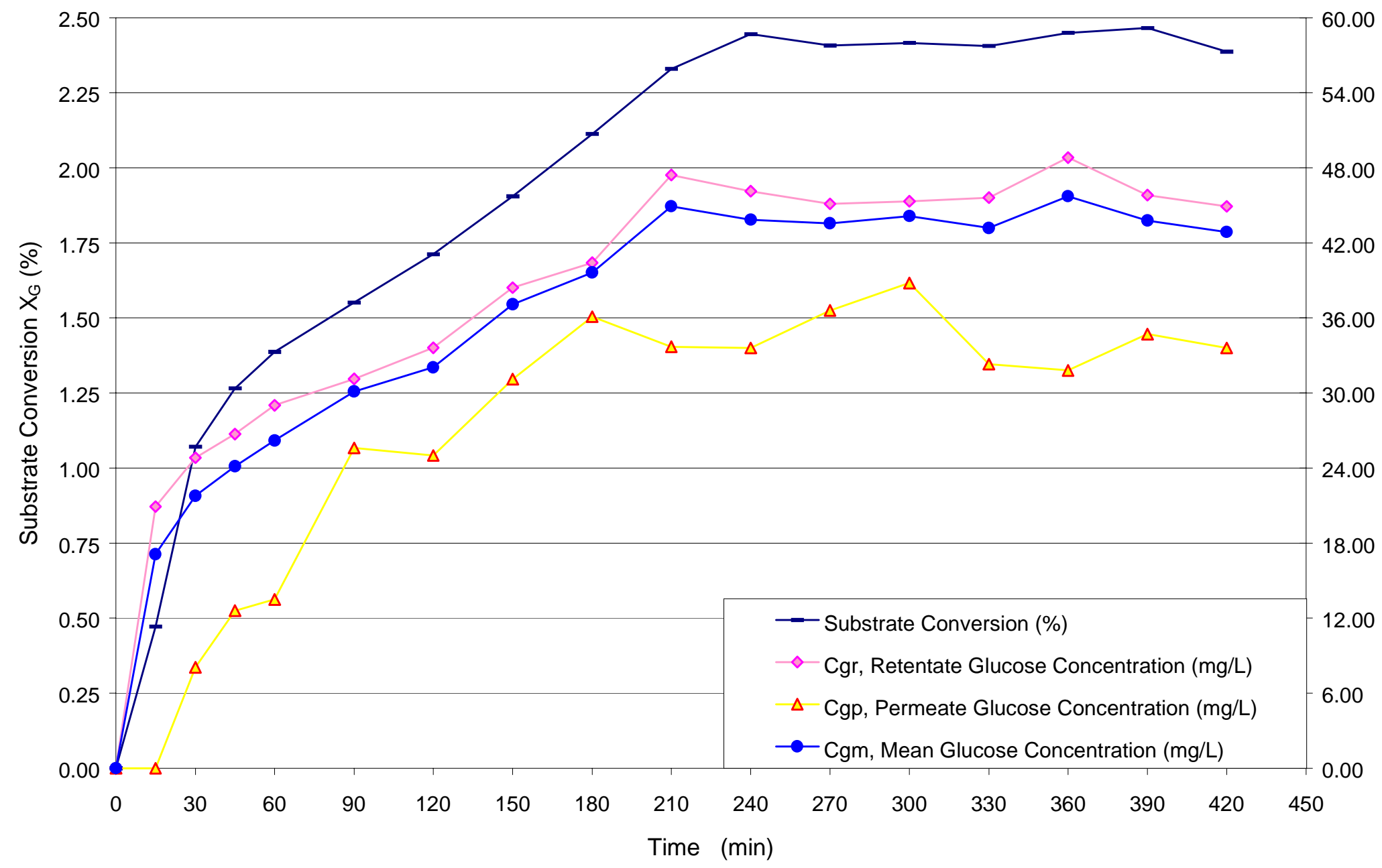

Figure 5.14. Substrate Conversion and Glucose Concentrations vs. Time --- AOYP, with Tergitol 


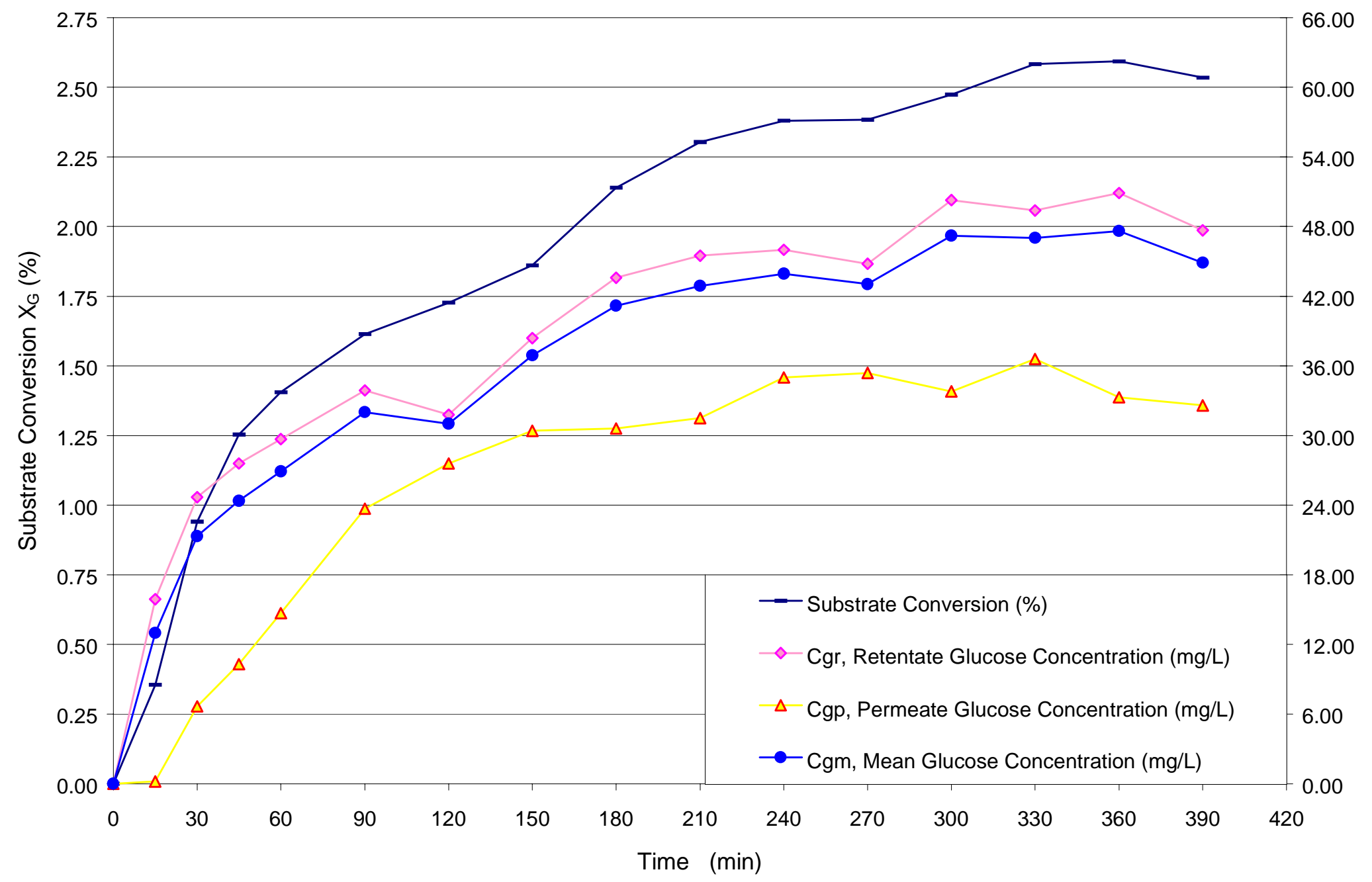

Figure 5.15. Substrate Conversion and Glucose Concentrations vs. Time --- AOYP, with Pluronic 


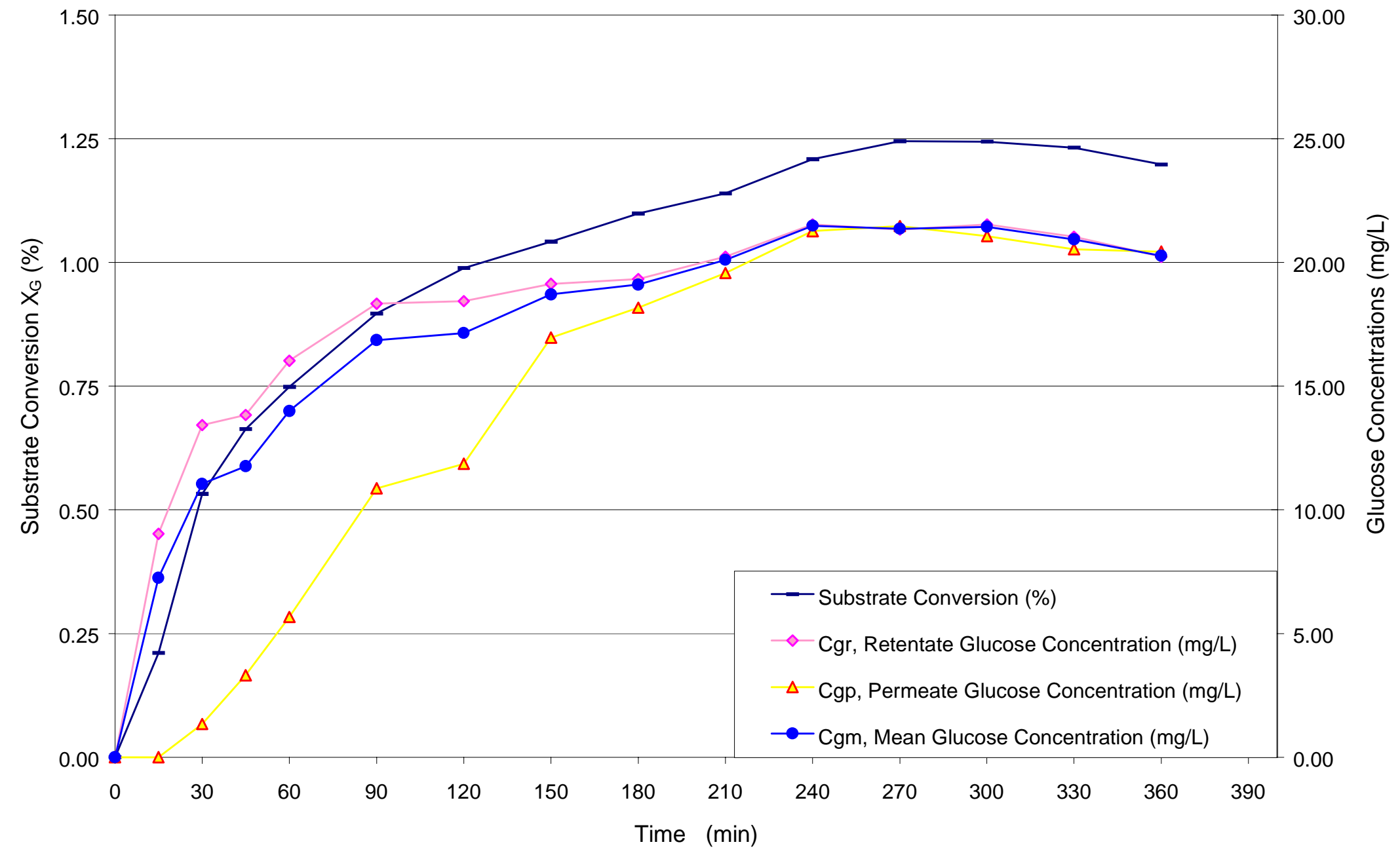

Figure 5.16. Substrate Conversion and Glucose Concentrations vs. Time --- ASYP, no Surfactant 


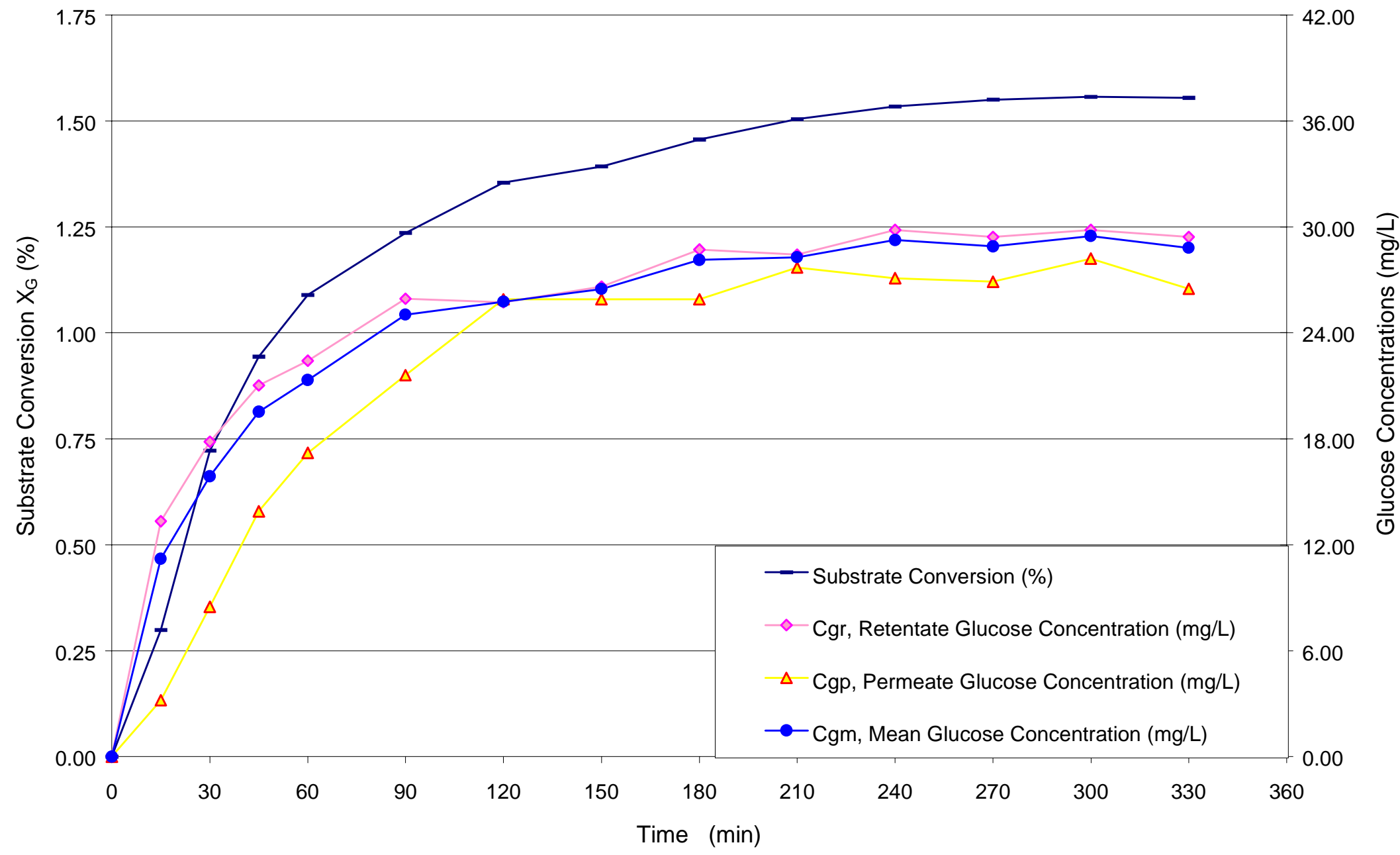

Figure 5.17. Substrate Conversion and Glucose Concentrations vs. Time --- ASYP, with Tergitol 


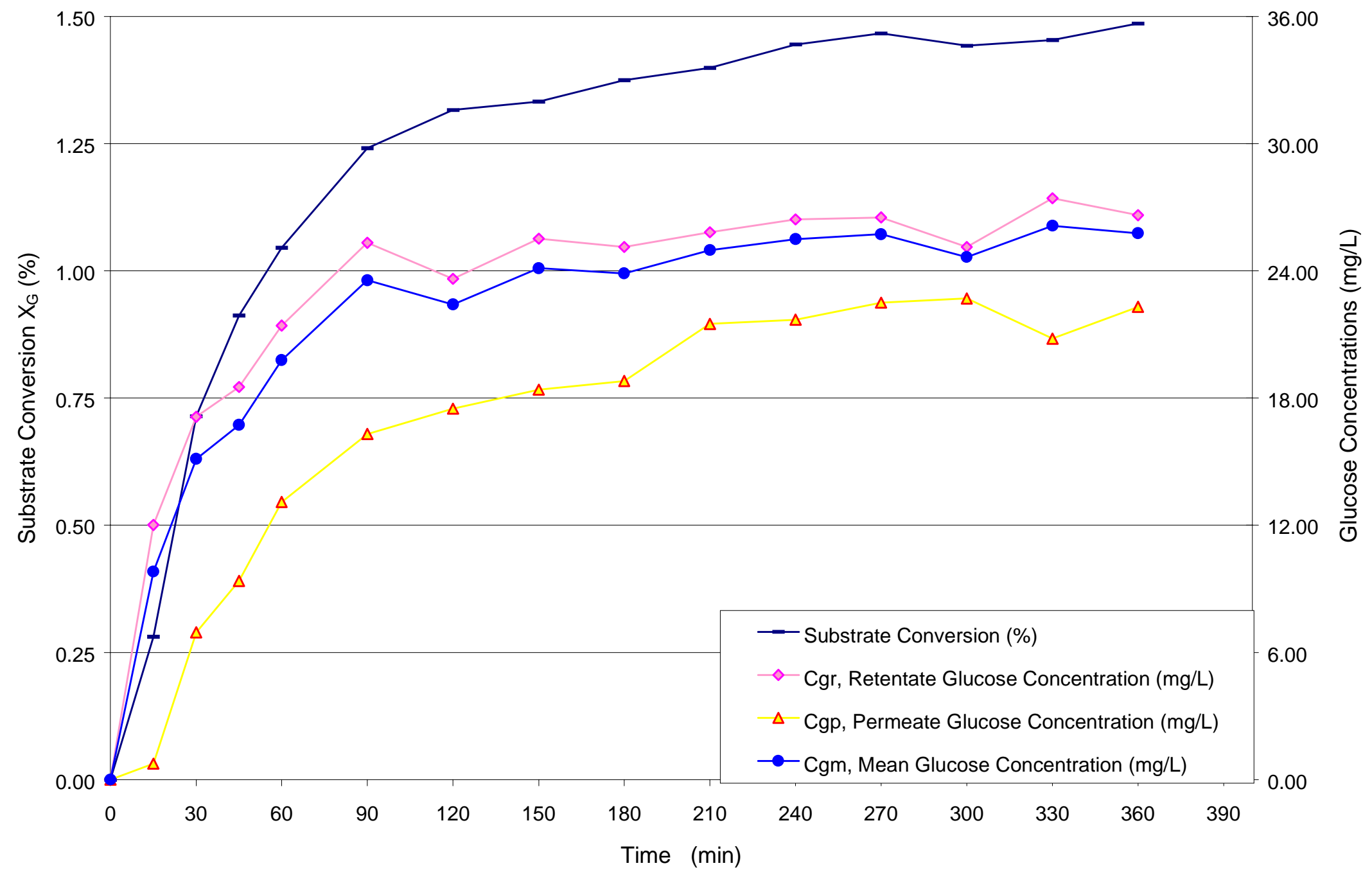

Figure 5.18. Substrate Conversion and Glucose Concentrations vs. Time --- ASYP, with Pluronic 


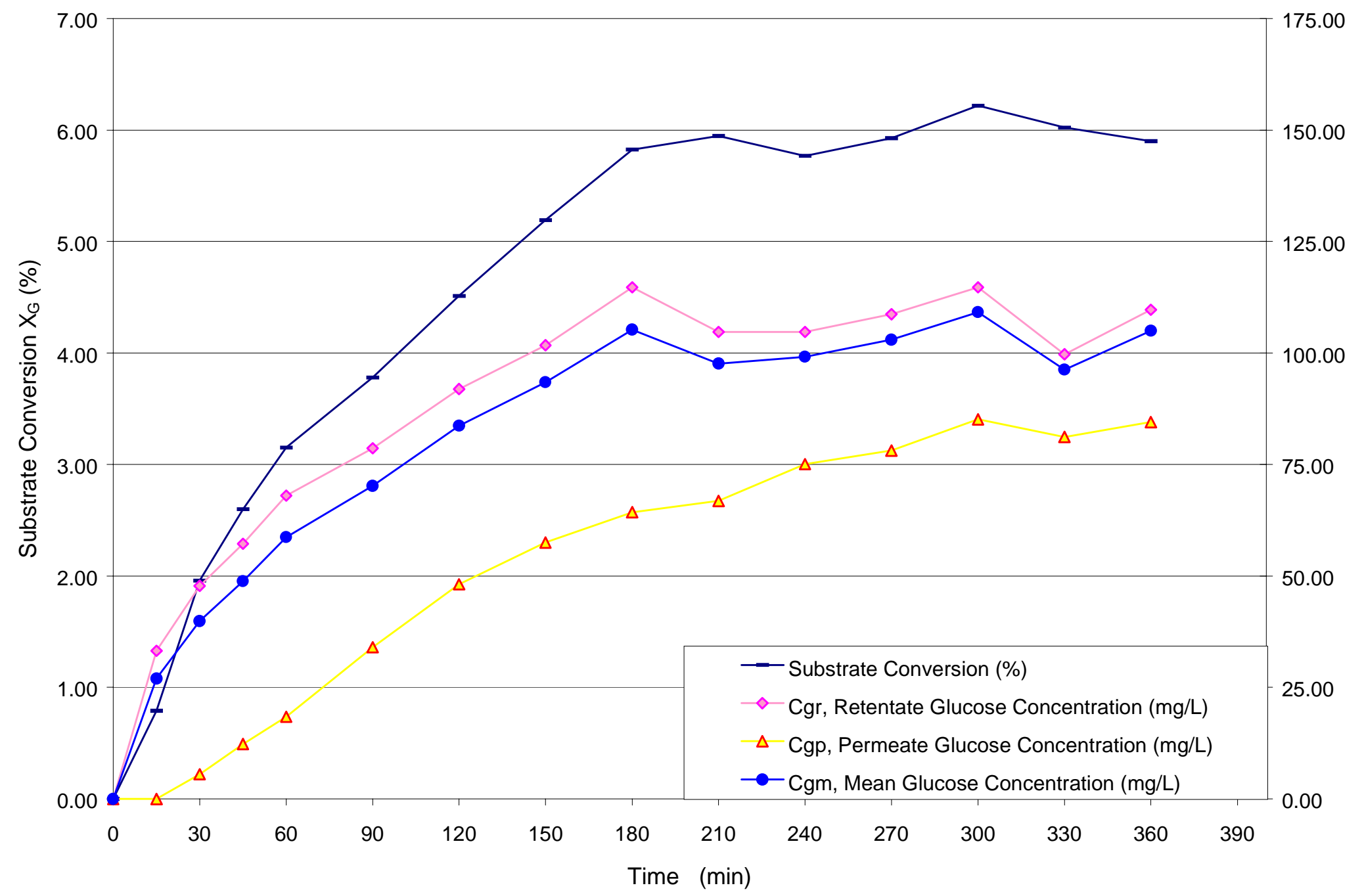

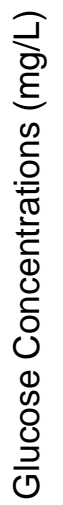

Figure 5.19. Substrate Conversion and Glucose Concentrations vs. Time --- AOCC, no Surfactant 


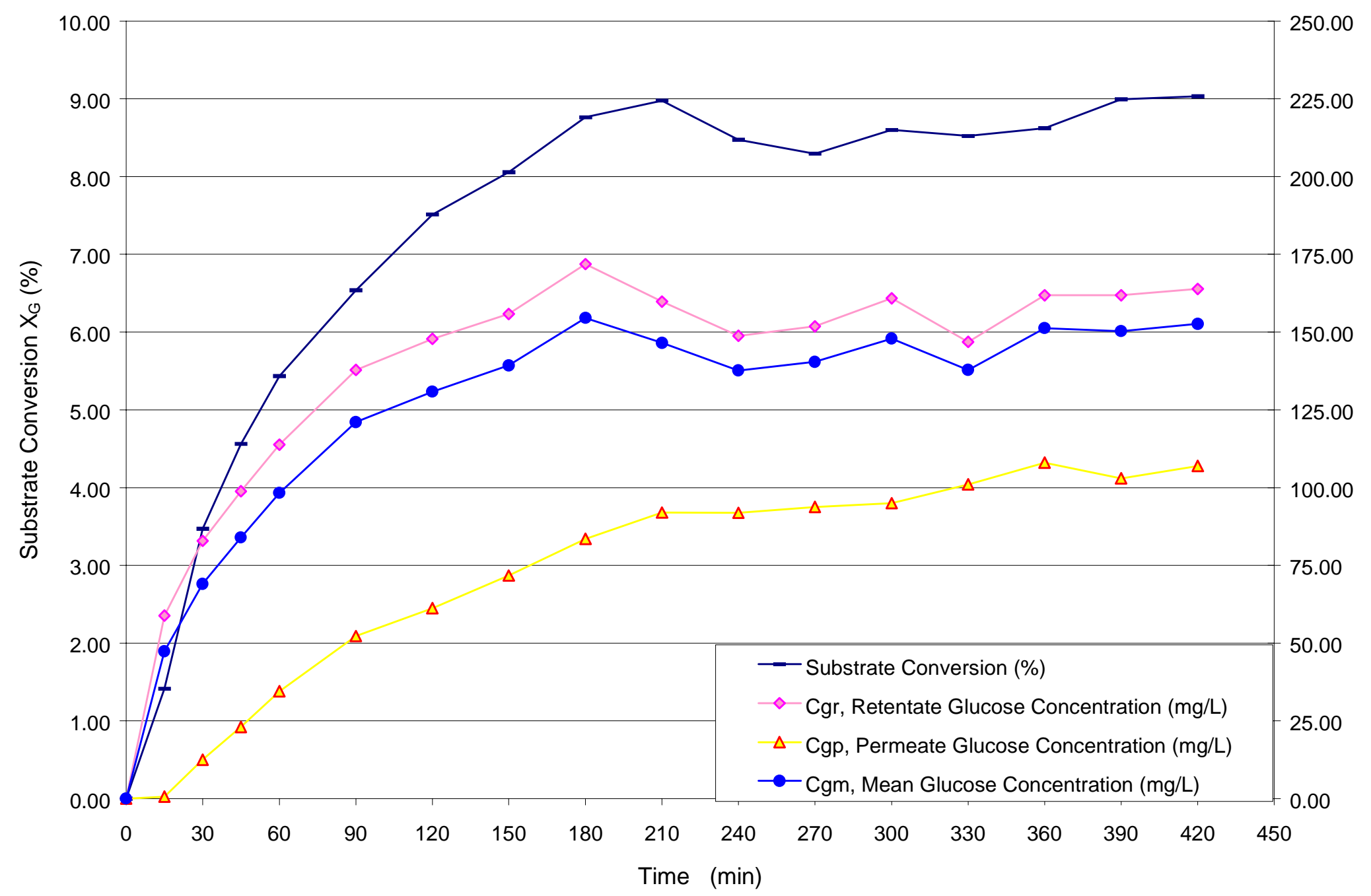

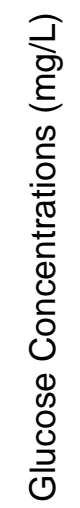

Figure 5.20. Substrate Conversion and Glucose Concentrations vs. Time --- AOCC, with Tergitol 


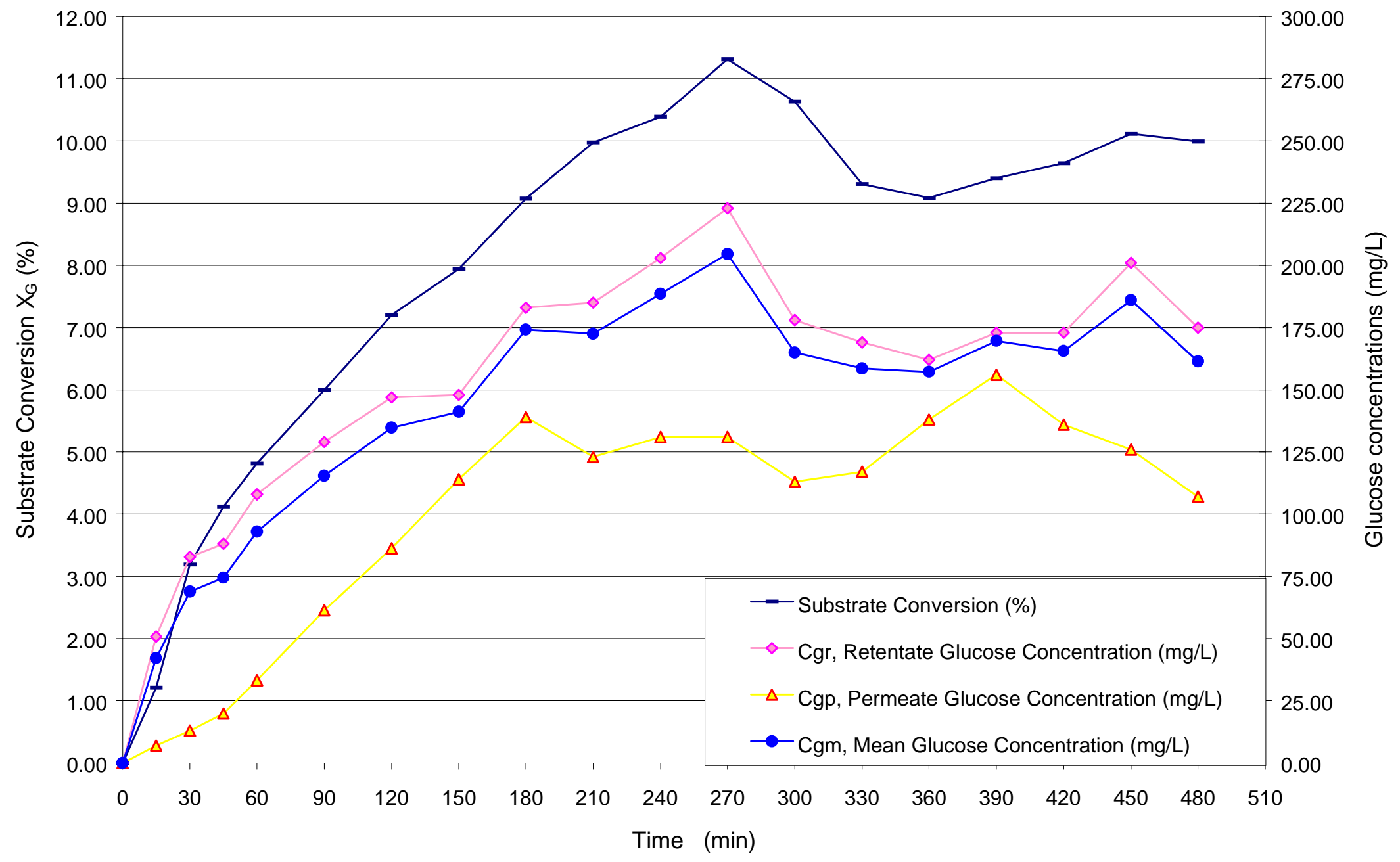

Figure 5.21. Substrate Conversion and Glucose Concentrations vs. Time --- AOCC, with Pluronic 


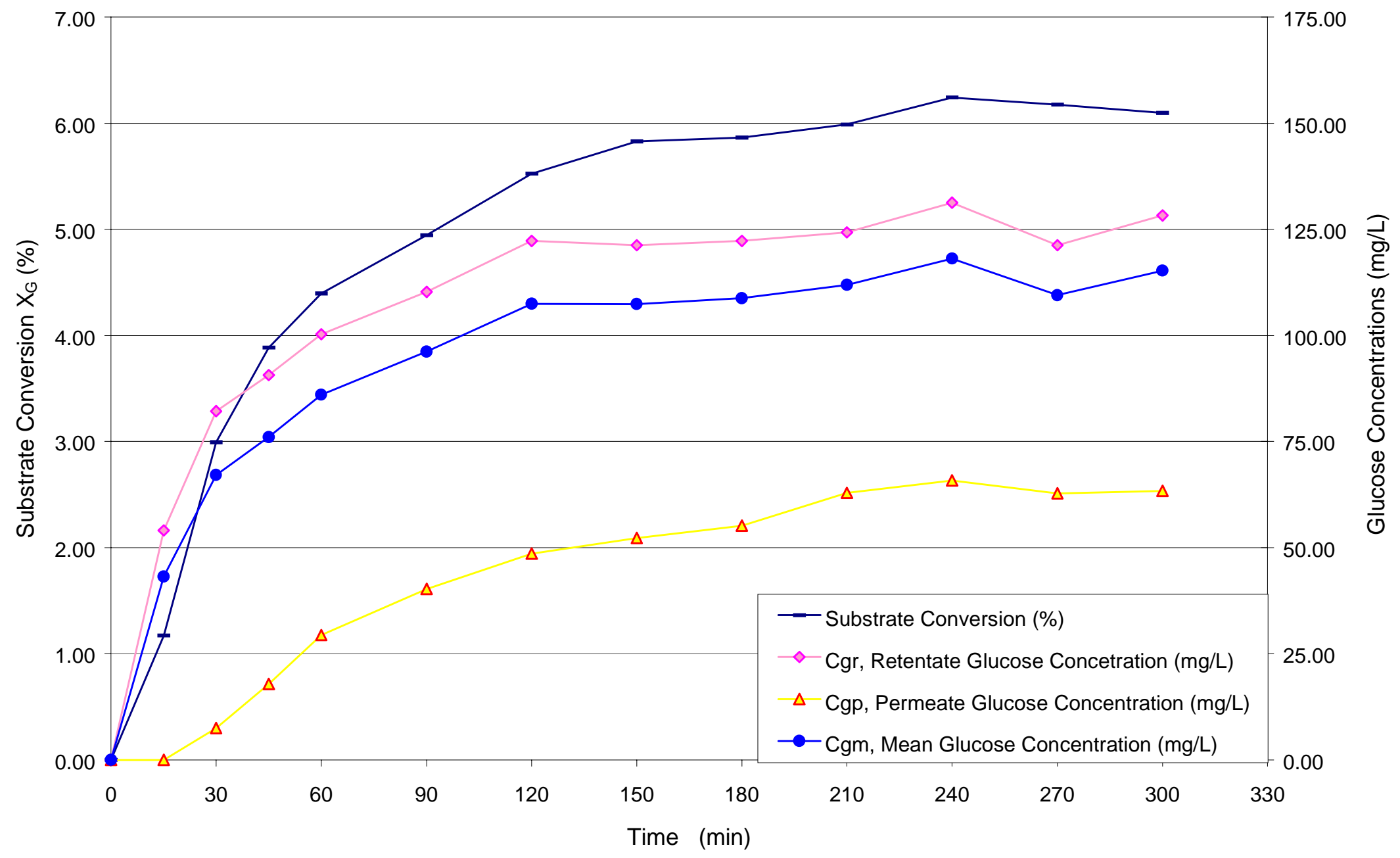

Figure 5.22. Substrate Conversion and Glucose Concentrations vs. Time --- ASCC, no Surfactant 


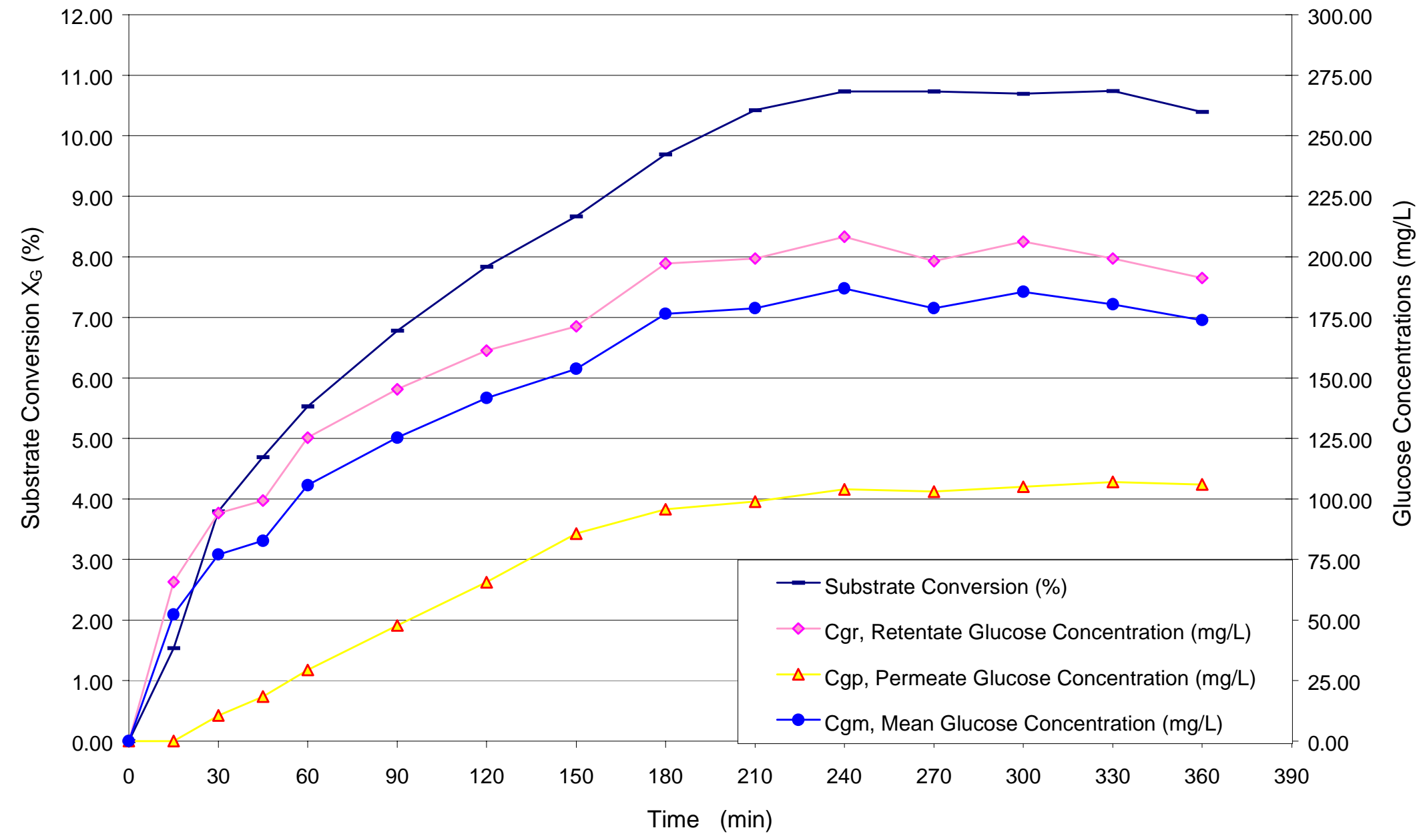

Figure 5.23. Substrate Conversion and Glucose Concentrations vs. Time --- ASCC, with Tergitol 


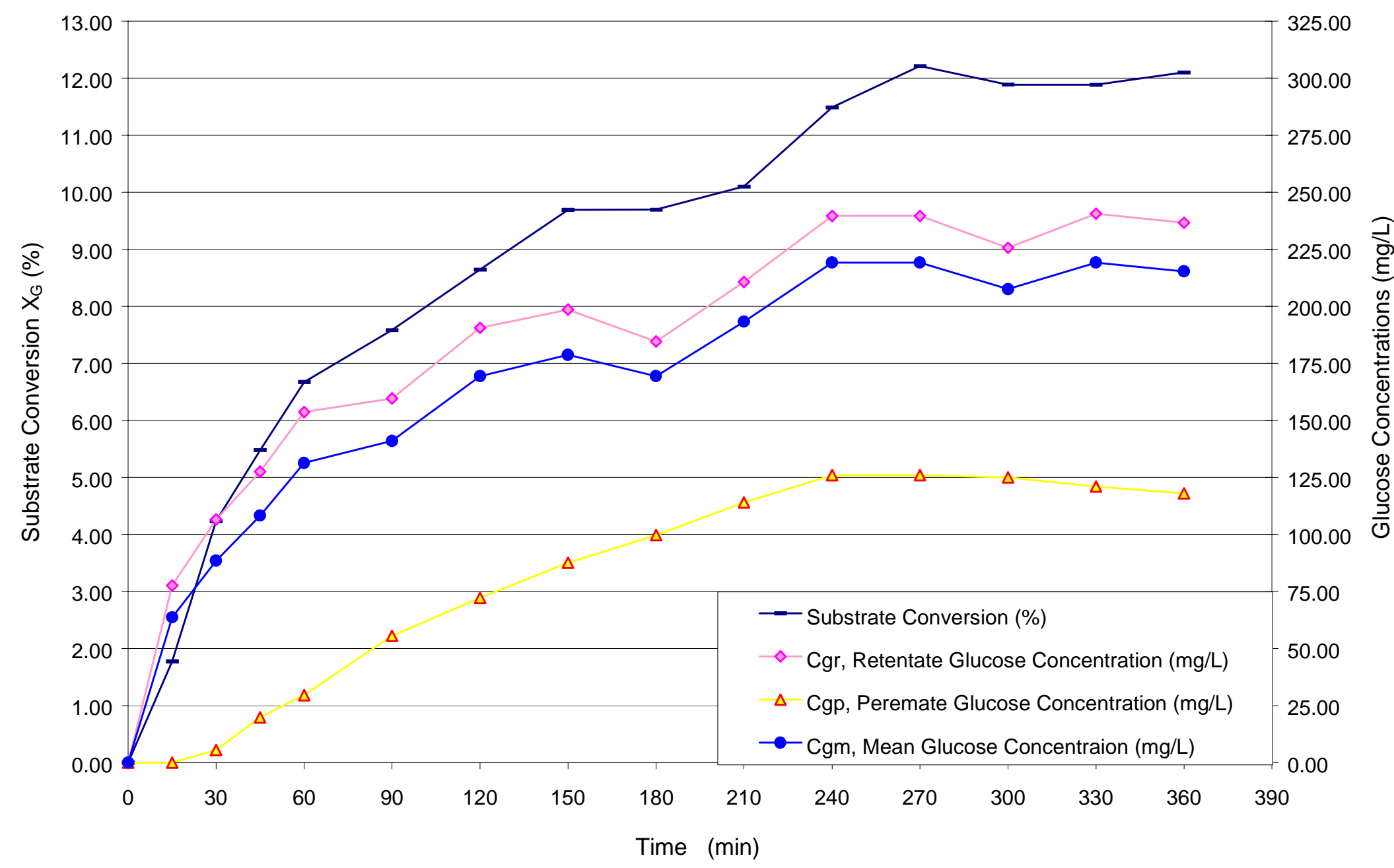

Figure 5.24. Substrate Conversion and Glucose Concentrations vs. Time -- ASCC, with Pluronic 


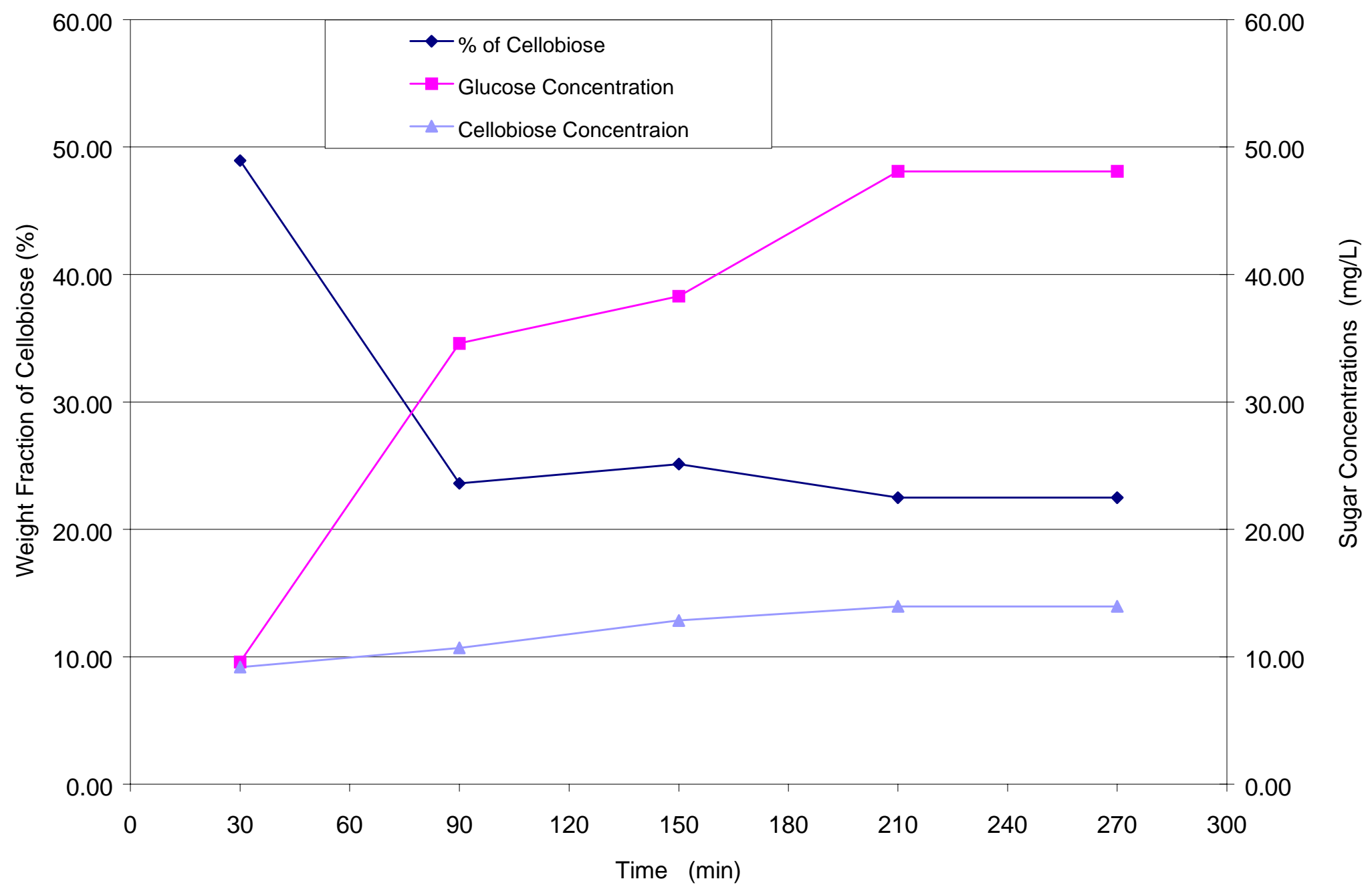

Figure 5.25. Distribution of Cellobiose and Glucose in Permeate Stream --- Solka Floc 200FCC, no Surfactant 


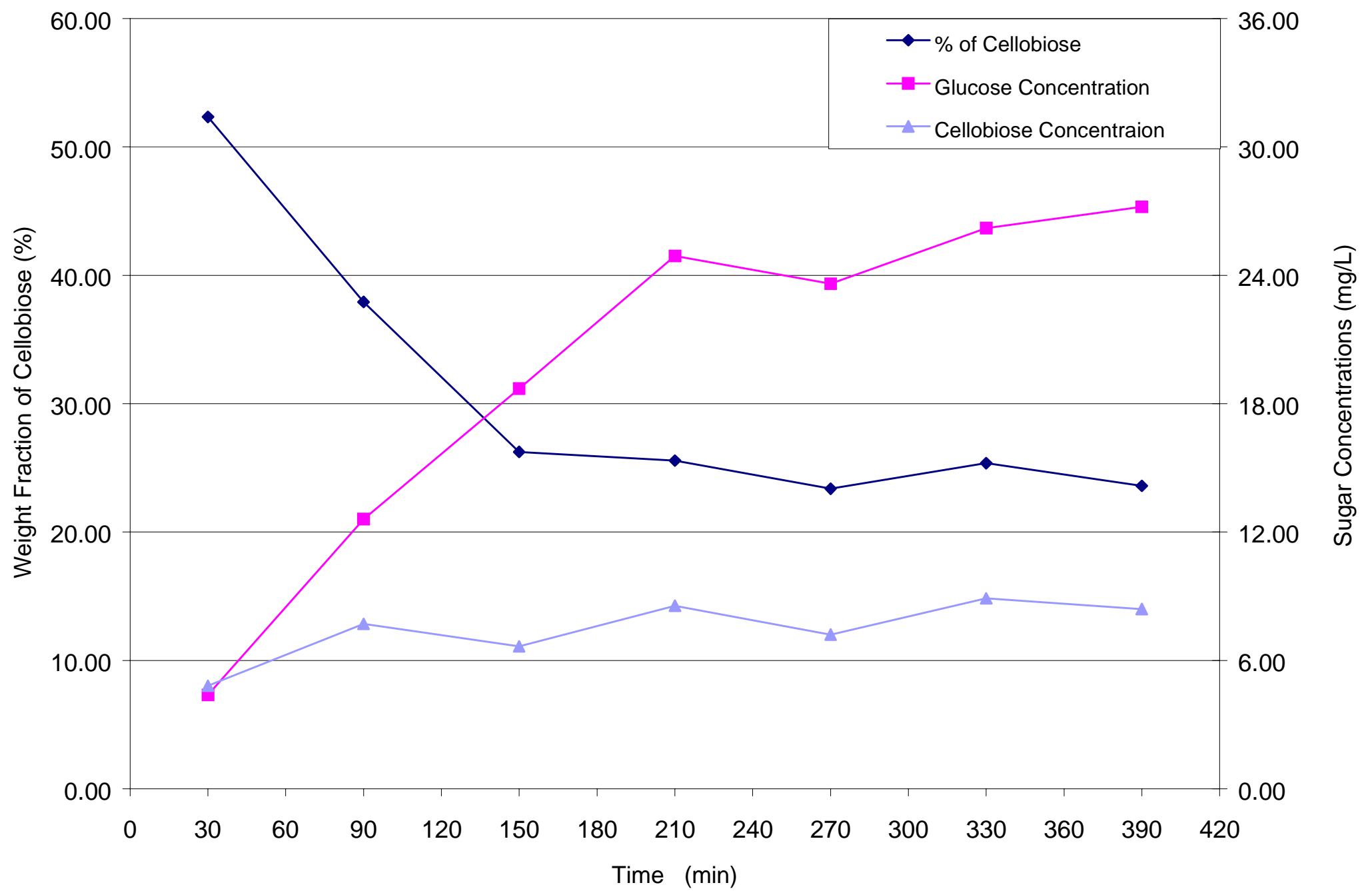

Figure 5.26. Distribution of Cellobiose and Glucose in Permeate Stream --- AOYP, no Surfactant 


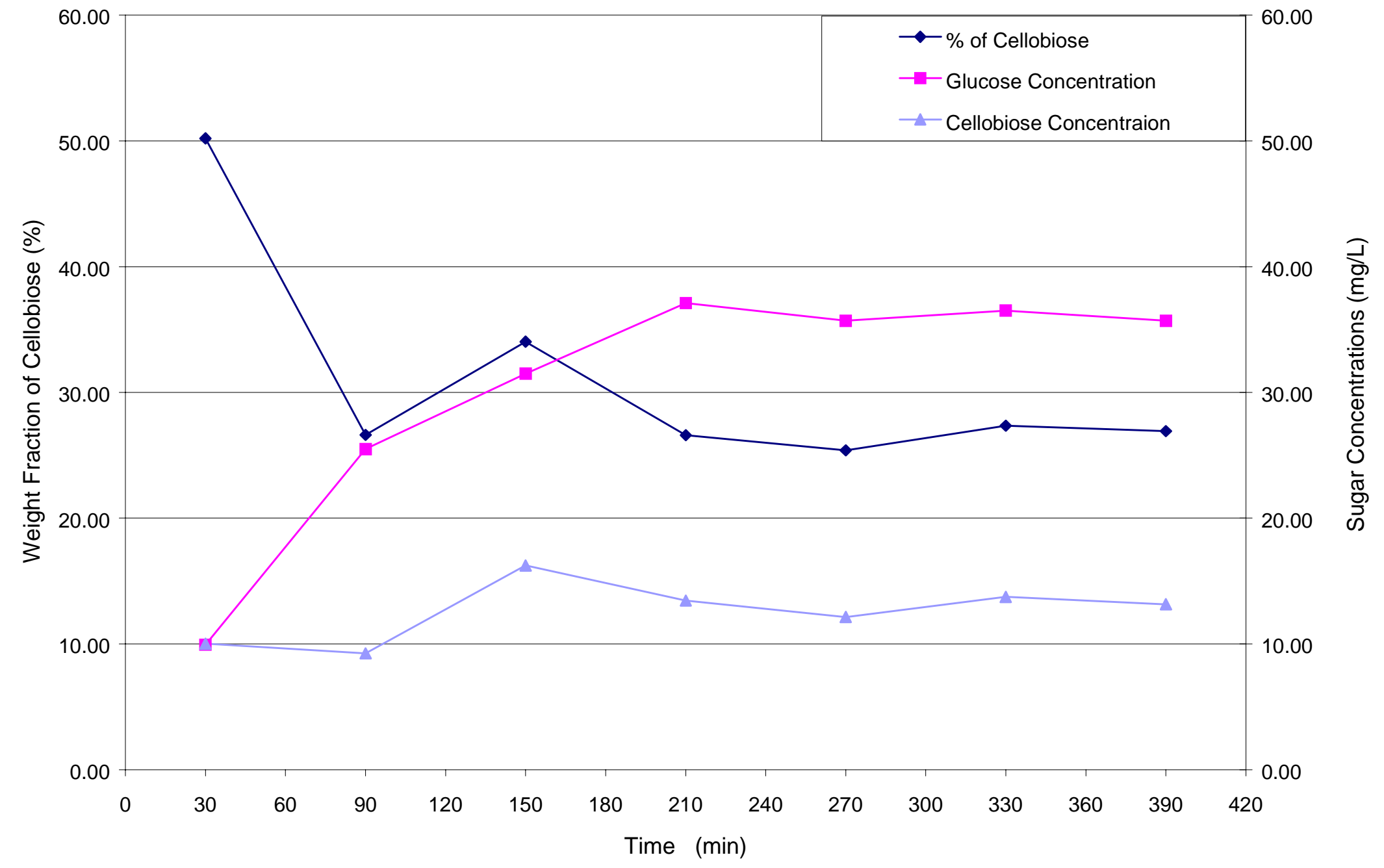

Figure 5.27. Distribution of Cellobiose and Glucose in Permeate Stream --- AOYP, with Tergitol 


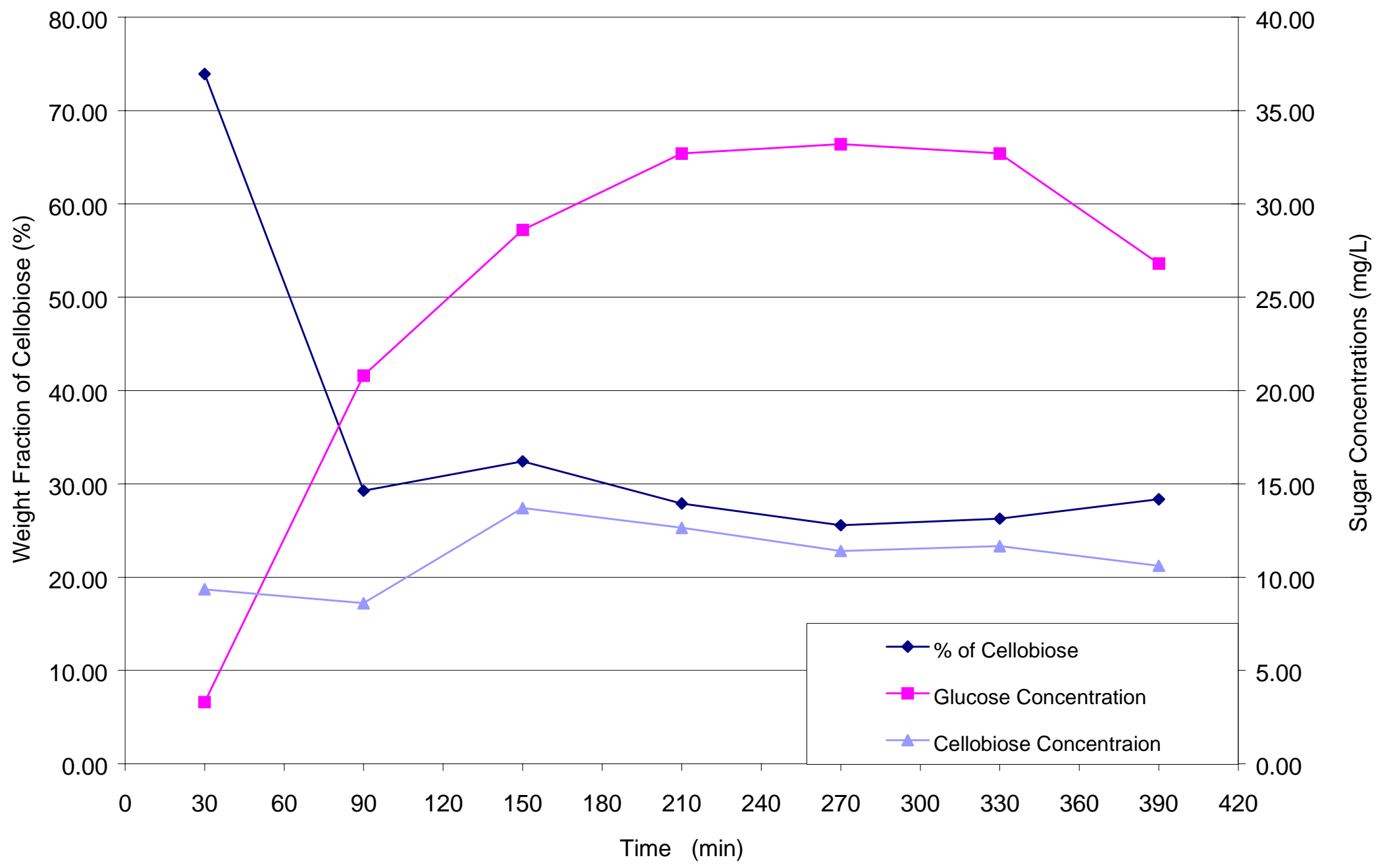

Figure 5.28. Distribution of Cellobiose and Glucose in Permeate Stream --- AOYP, with Pluronic 


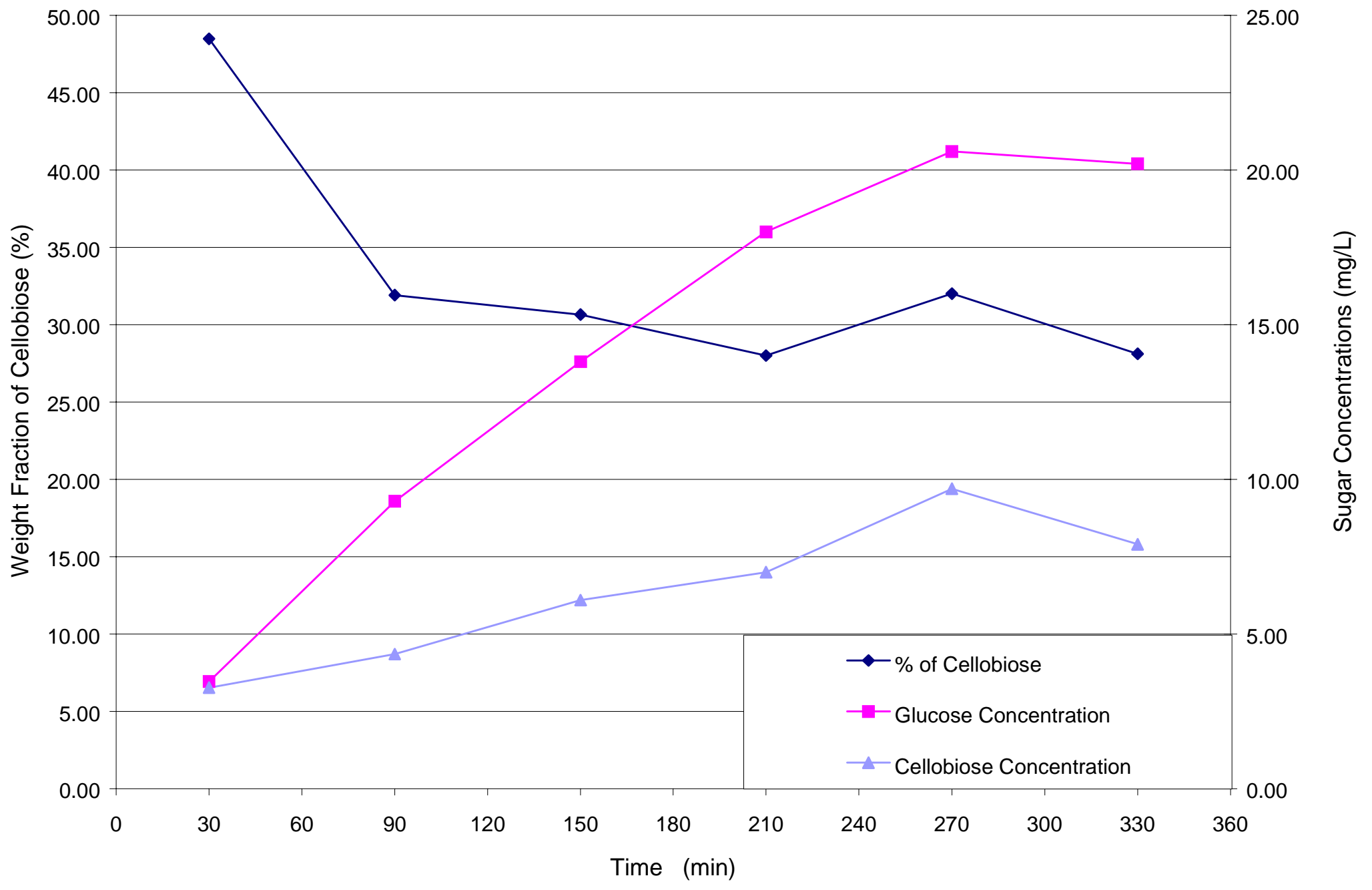

Figure 5.29. Distribution of Cellobiose and Glucose in Permeate Stream --- ASYP, no Surfactant 


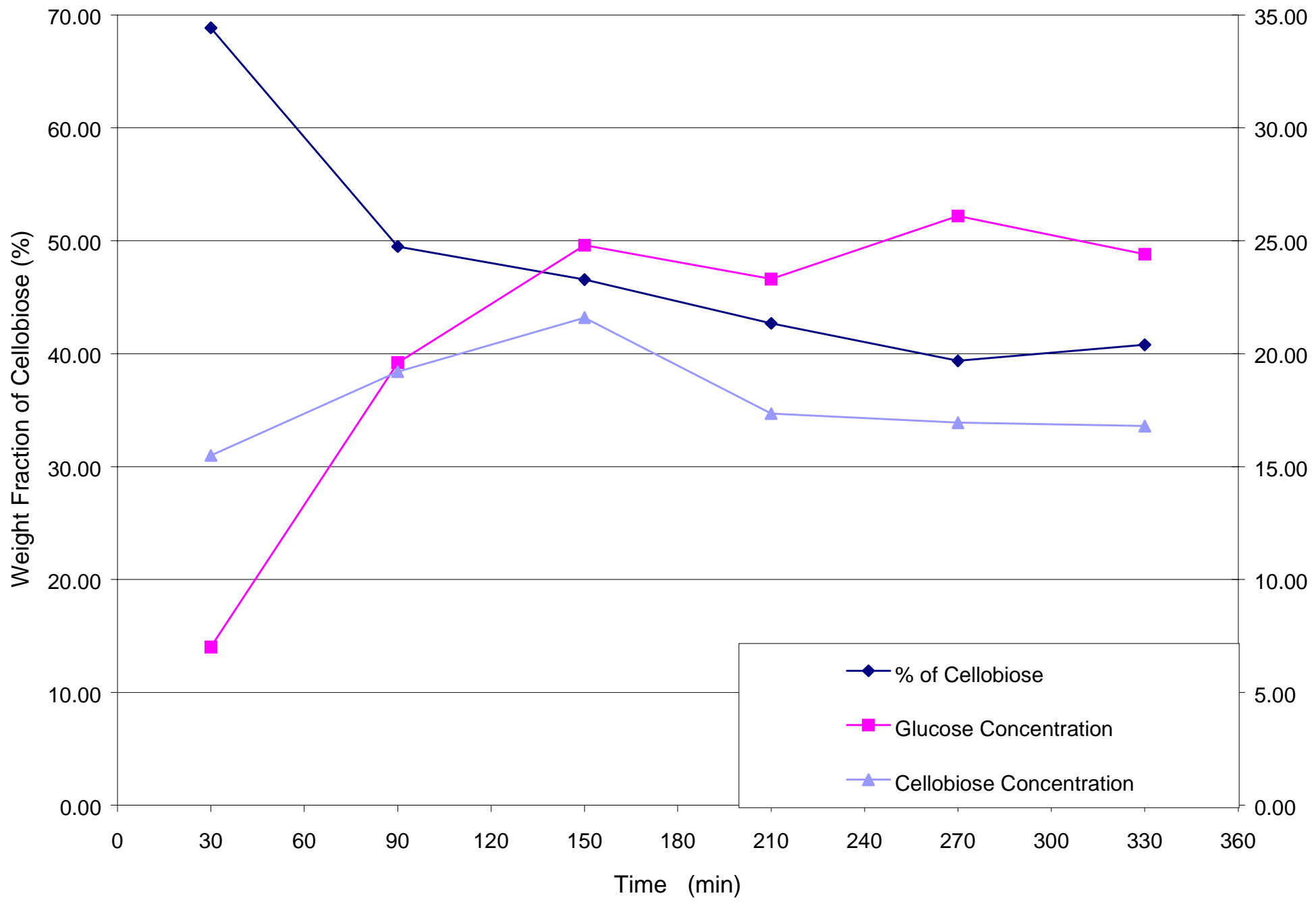

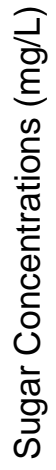

Figure 5.30. Distribution of Cellobiose and Glucose in Permeate Stream --- ASYP, with Tergitol 


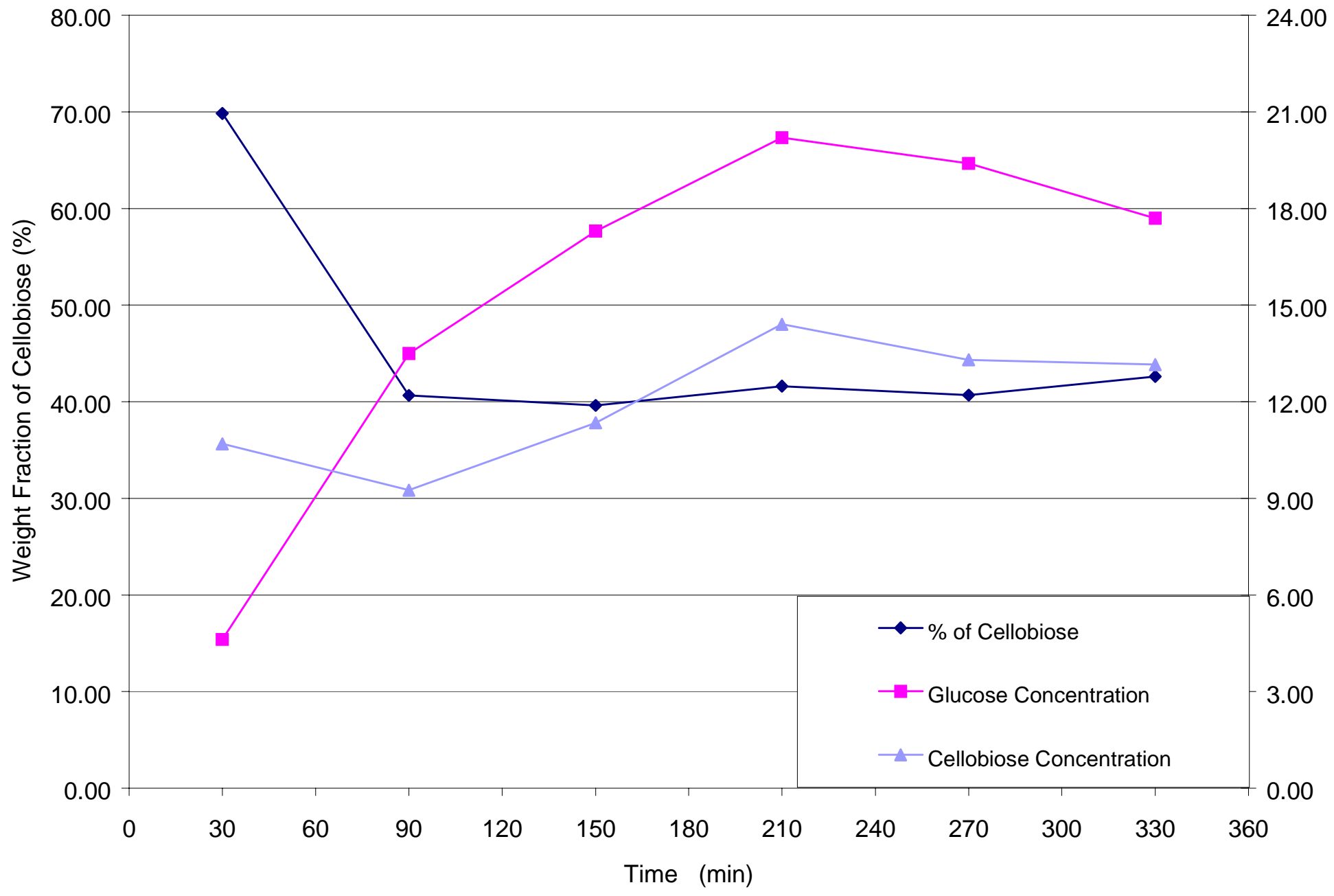

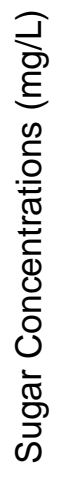

Figure 5.31. Distribution of Cellobiose and Glucose in Permeate Stream --- ASYP, with Pluronic 


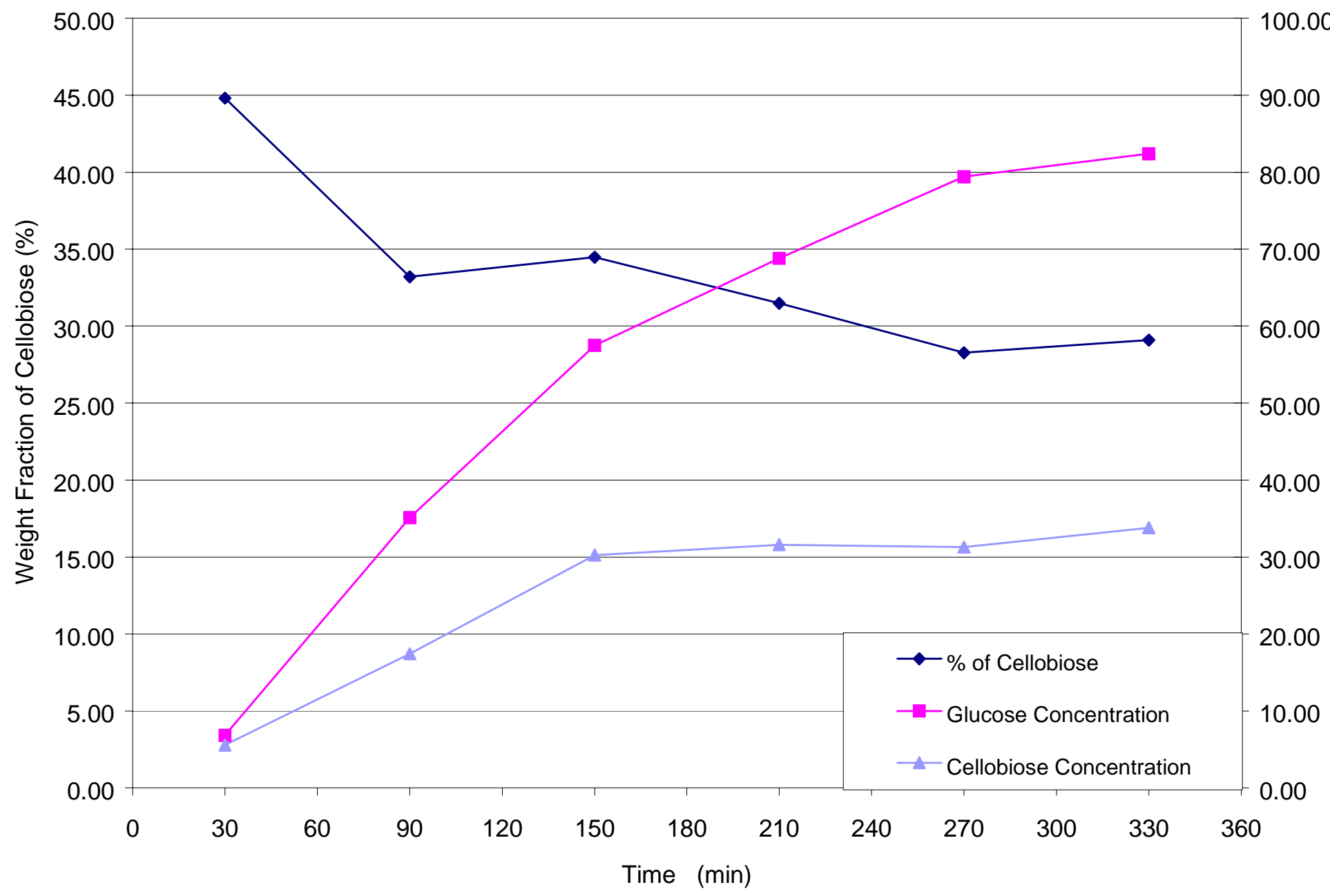

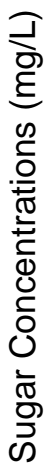

Figure 5.32. Distribution of Cellobiose and Glucose in Permeate Stream --- AOCC, no Surfactant 


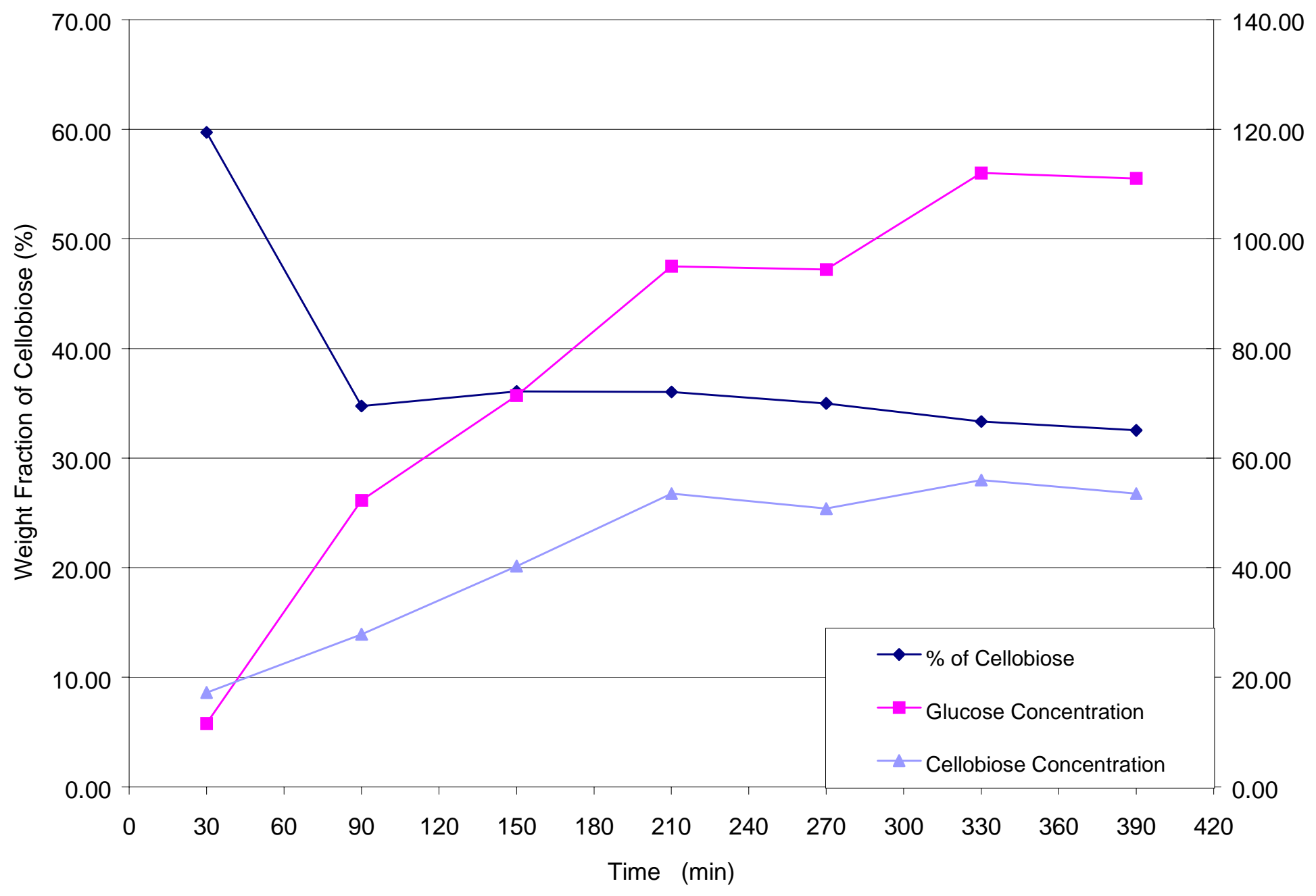

Figure 5.33. Distribution of Cellobiose and Glucose in Permeate Stream --- AOCC, with Tergitol 


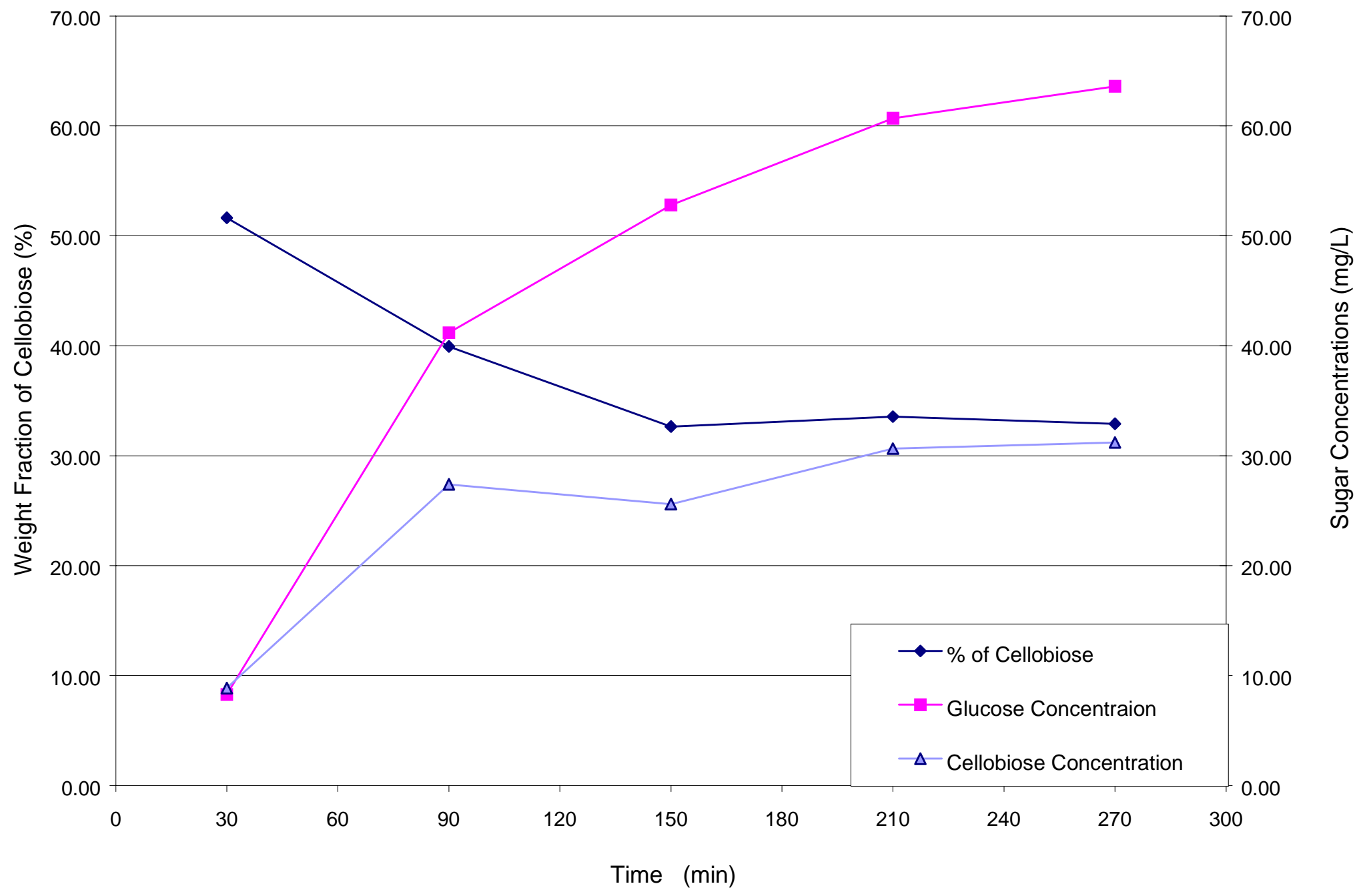

Figure 5.34. Distribution of Cellobiose and Glucose in Permeate Stream --- ASCC, no Surfactant 


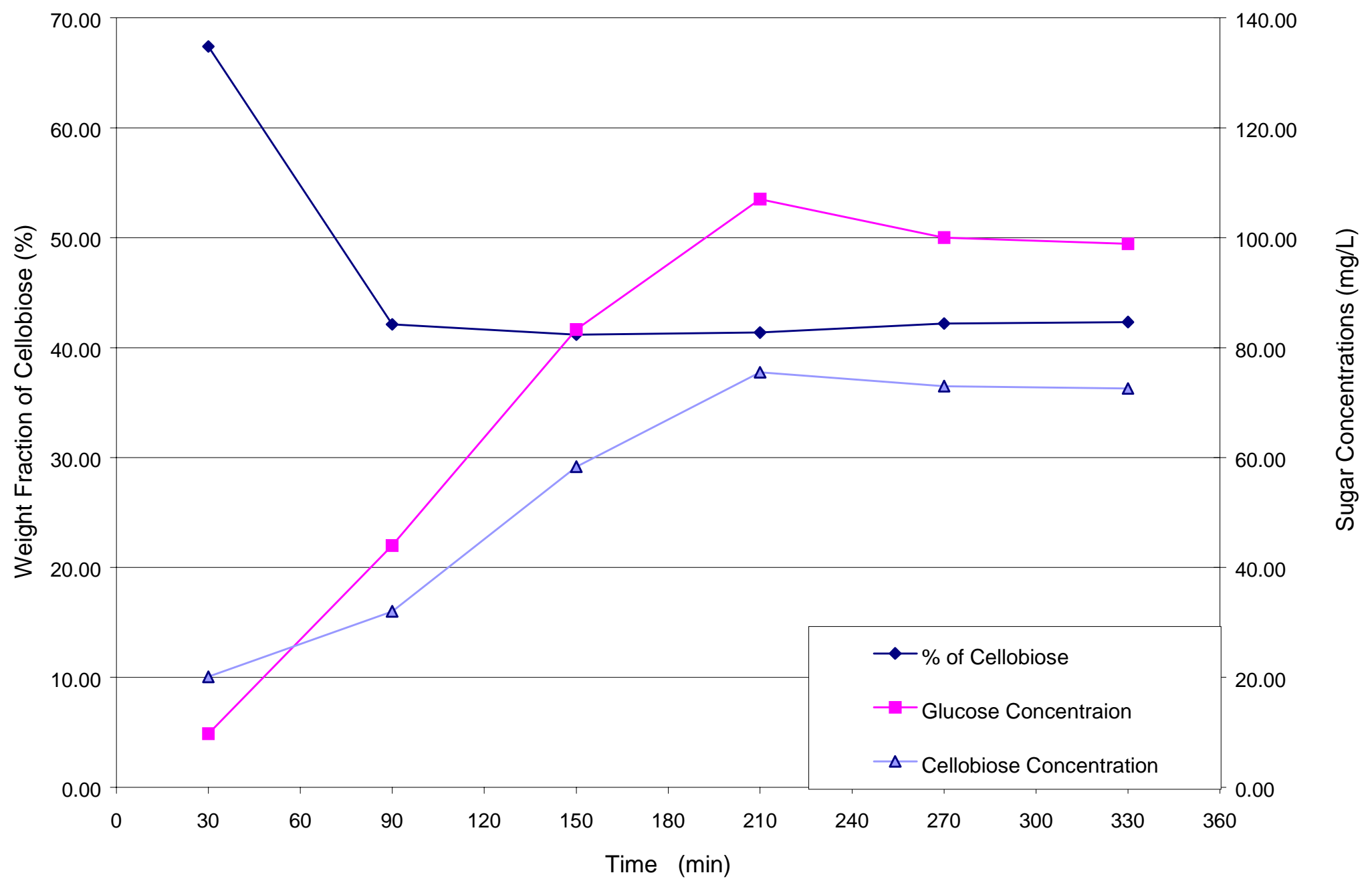

Figure 5.35. Distribution of Cellobiose and Glucose in Permeate Stream --- ASCC, with Tergitol 


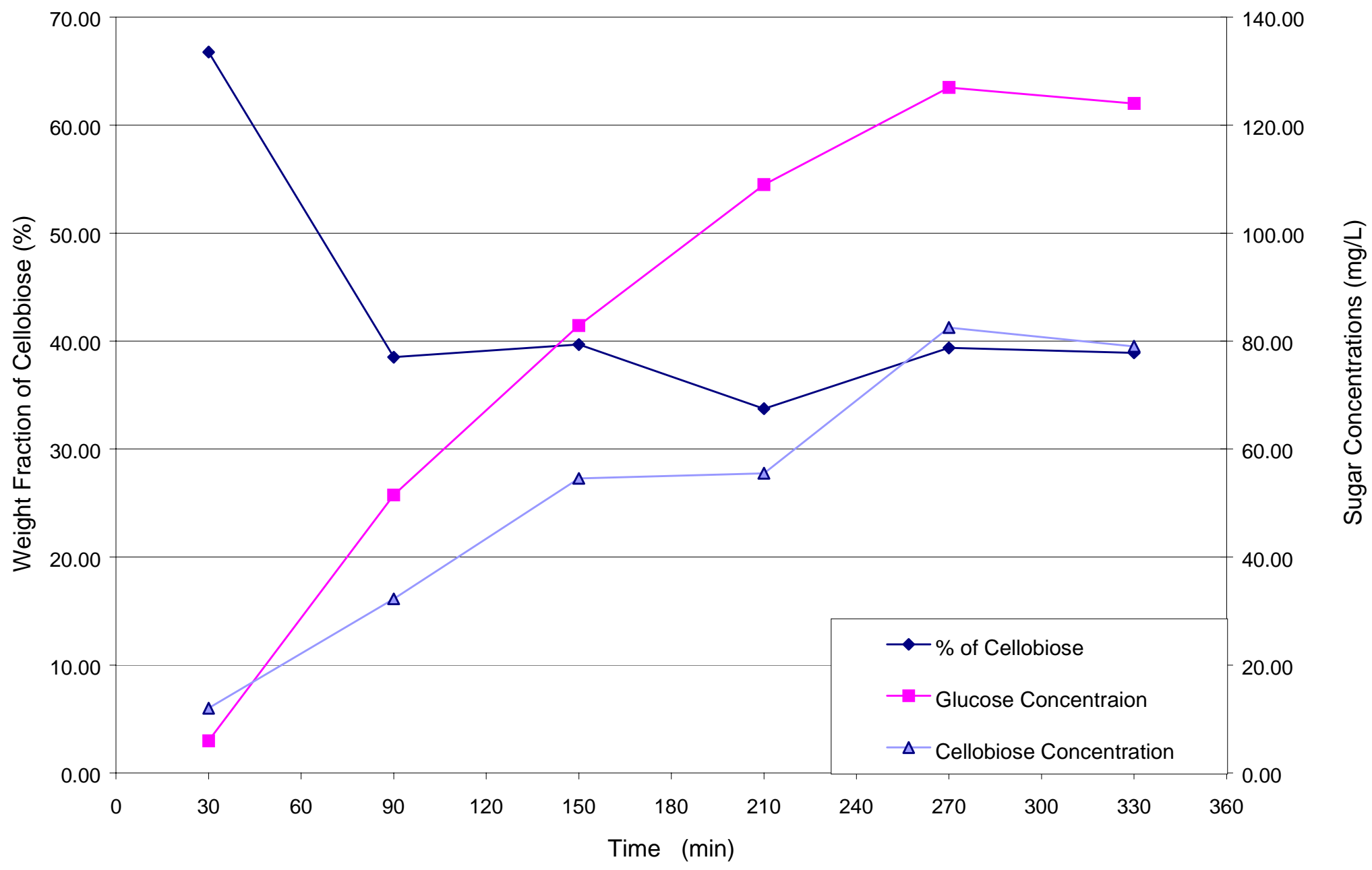

Figure 5.36. Distribution of Cellobiose and Glucose in Permeate Stream --- ASCC, with Pluronic 


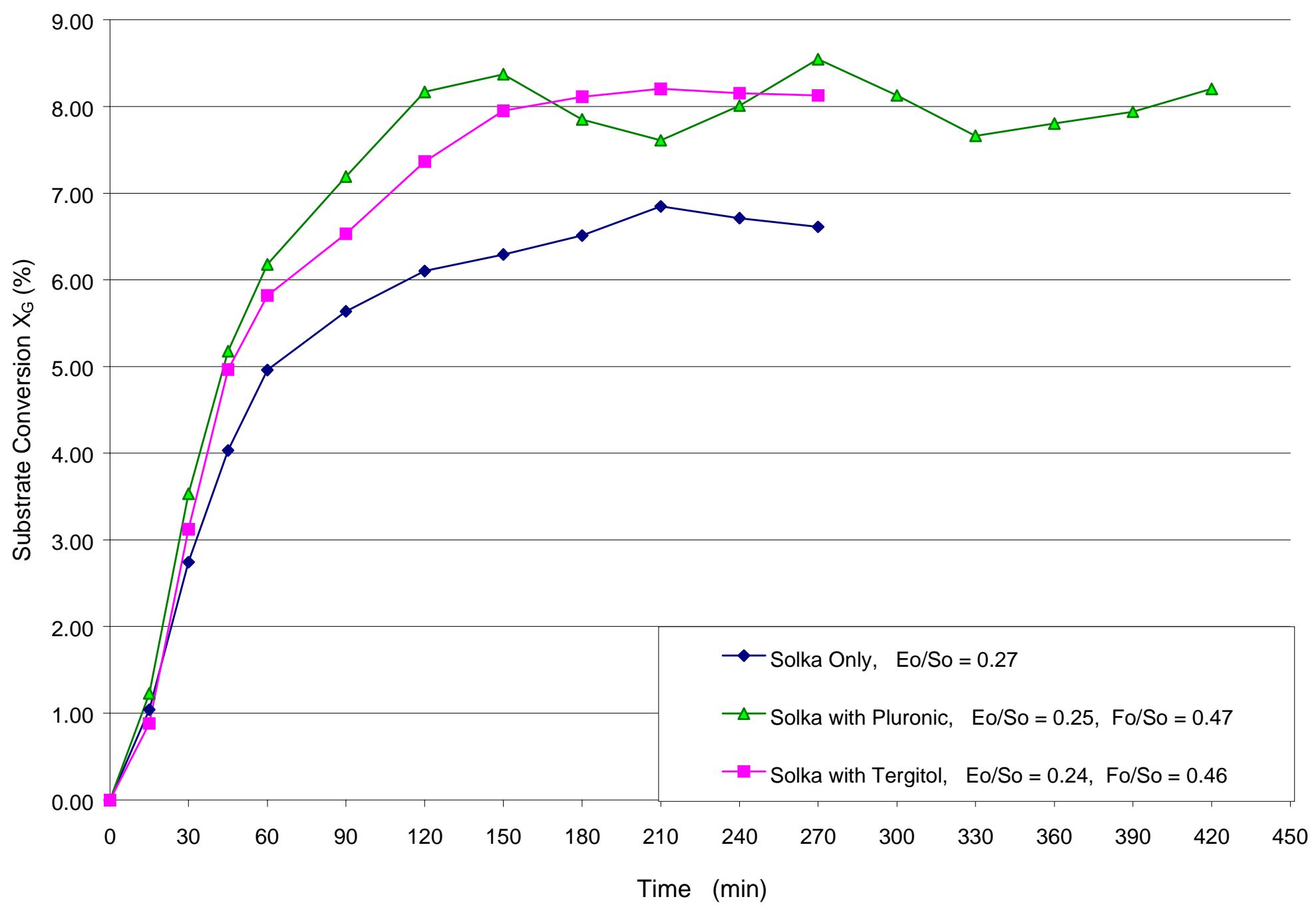

Figure 5.37. Conversion of Solka Floc 200FCC to Glucose in a TMR 


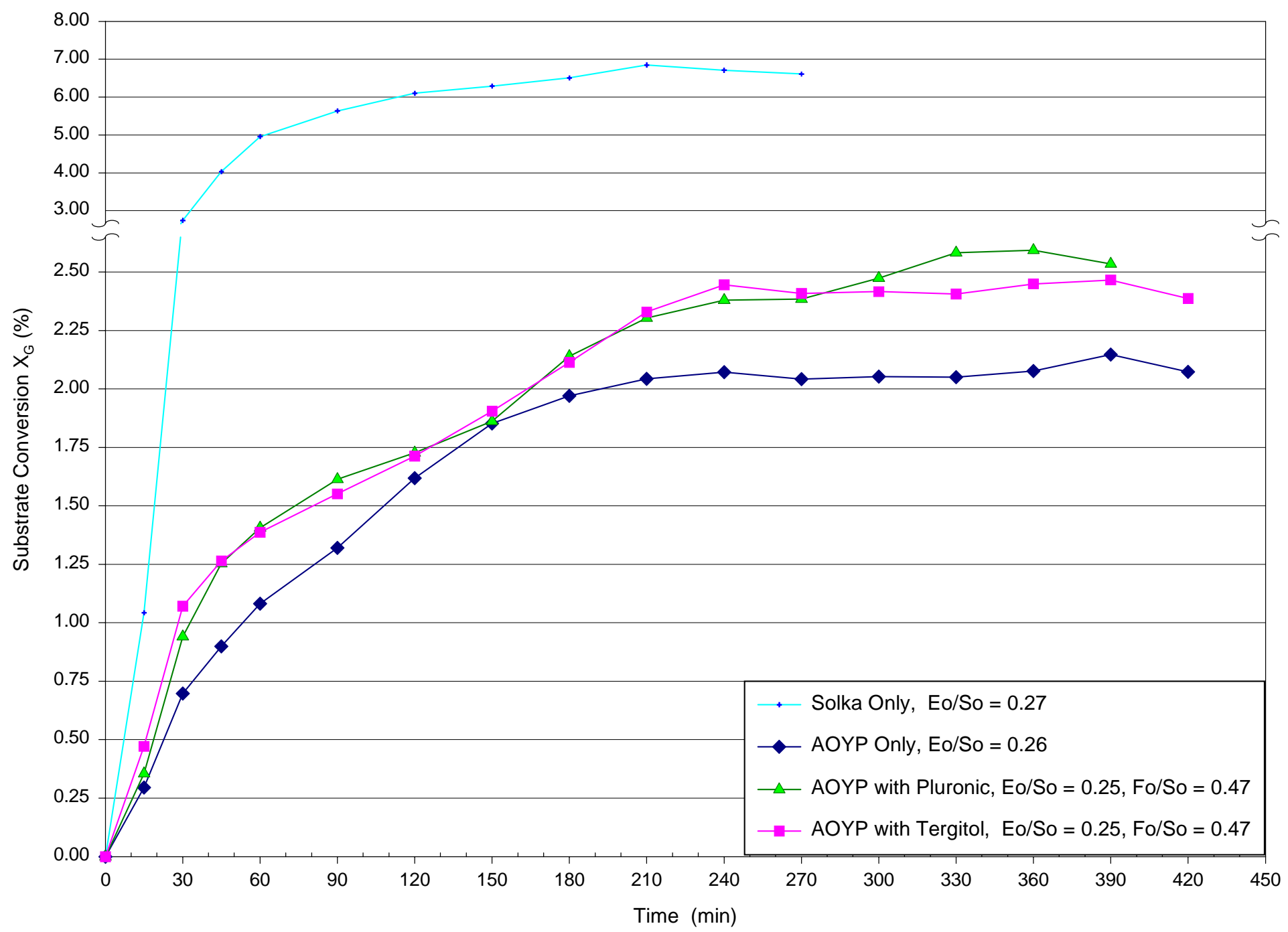

Figure 5.38. Conversion of AOYP to Glucose in a TMR 


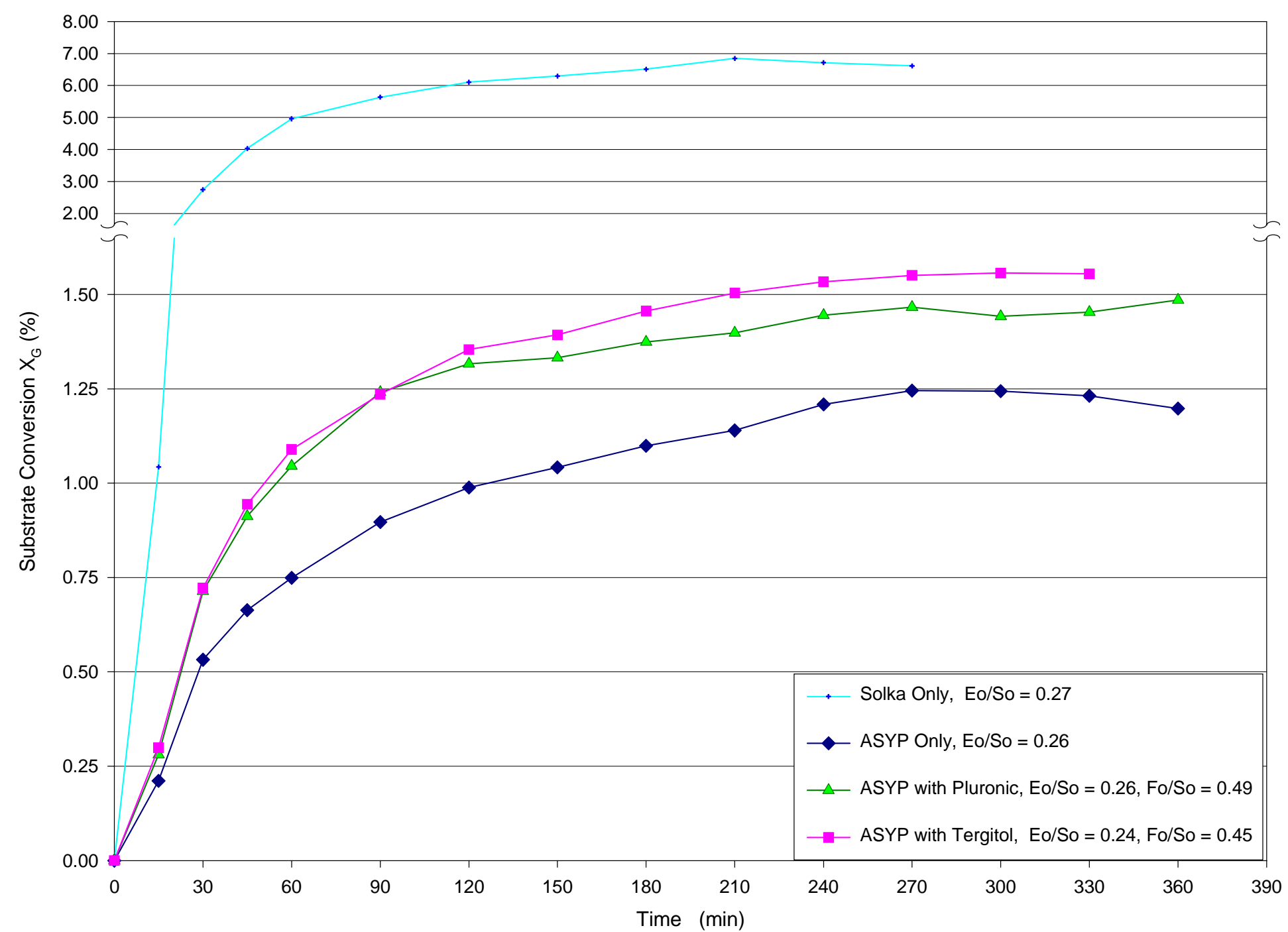

Figure 5.39. Conversion of ASYP to Glucose in a TMR 


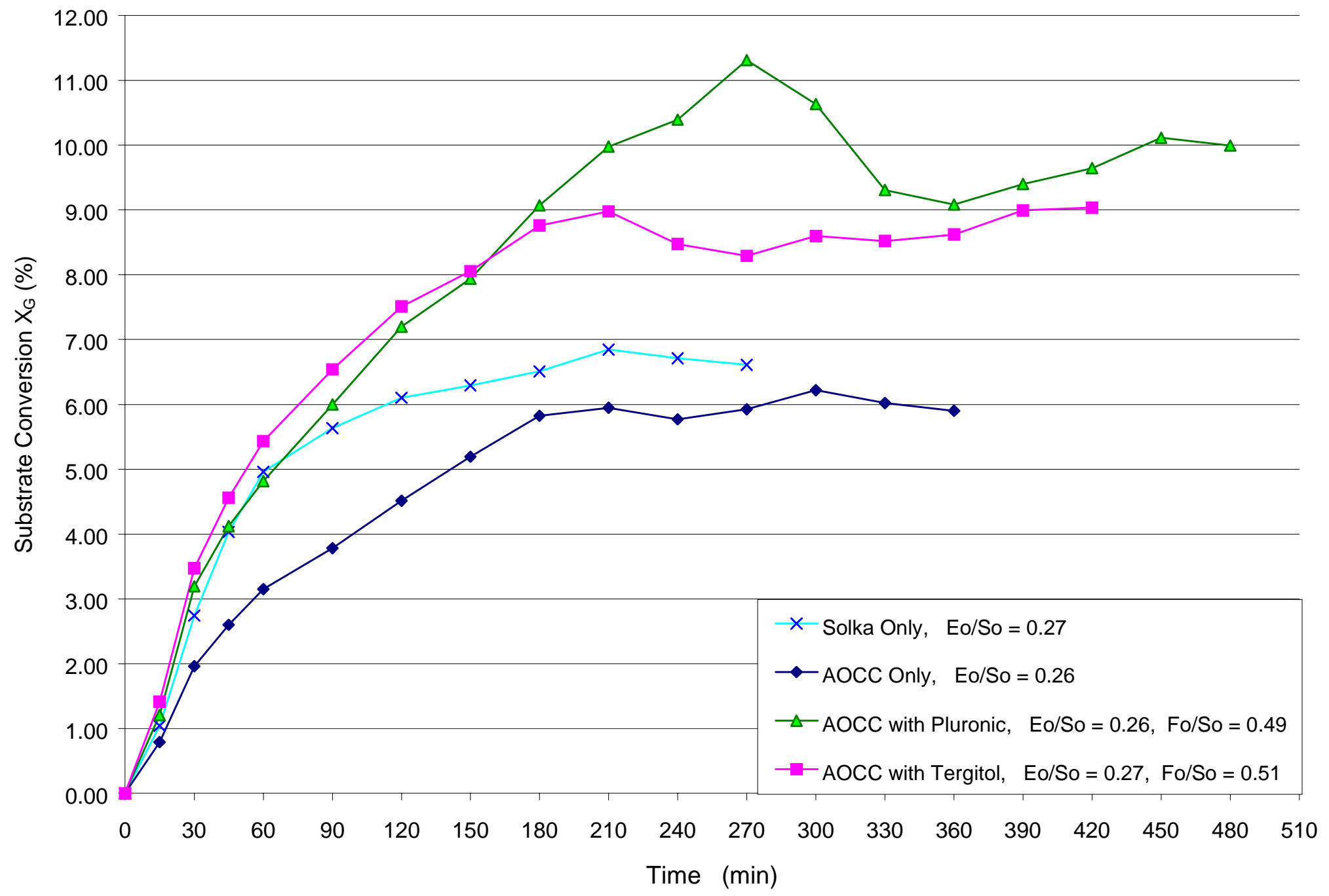

Figure 5.40. Conversion of AOCC to Glucose in a TMR 


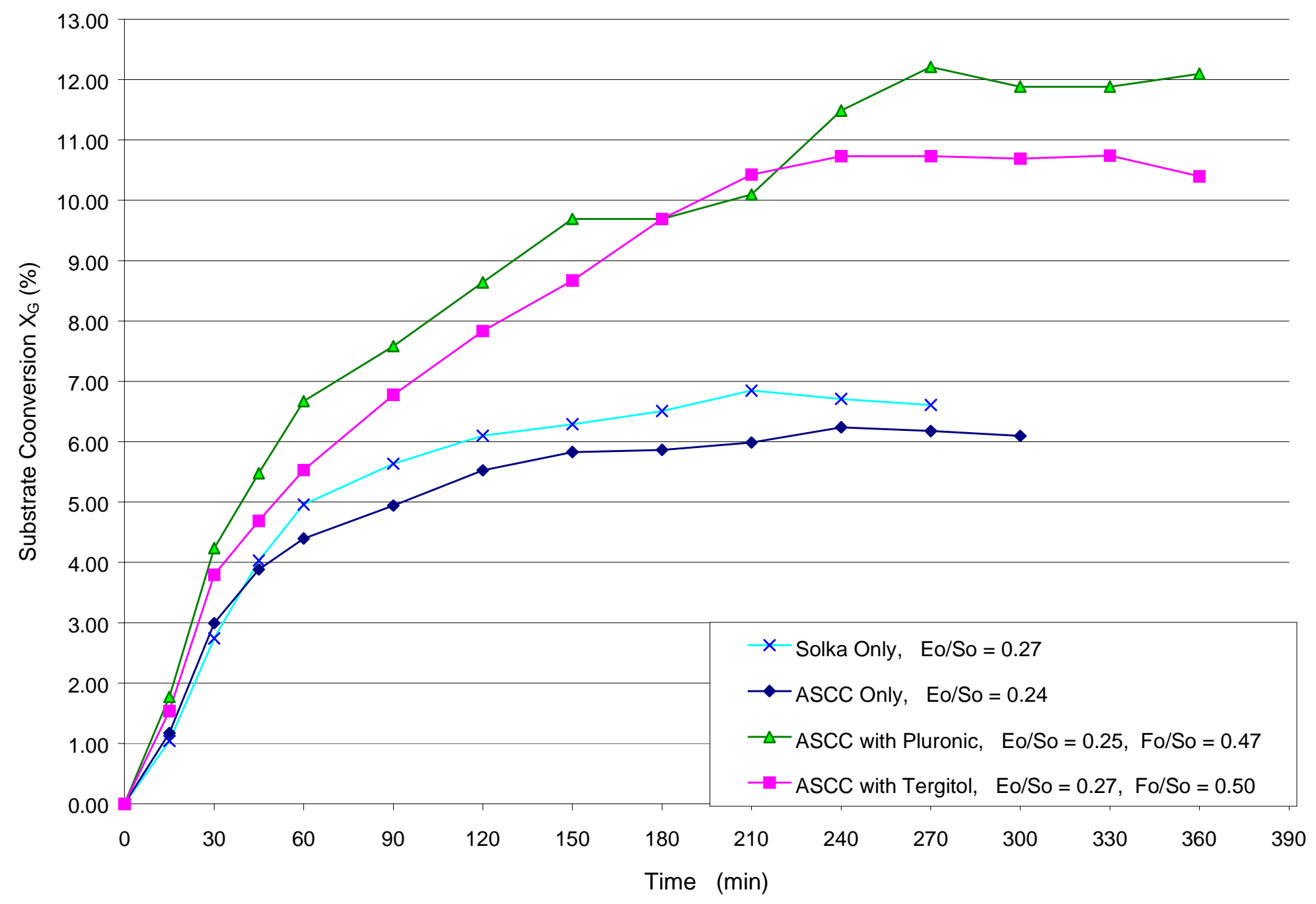

Figure 5.41. Conversion of ASCC to Glucose in a TMR 


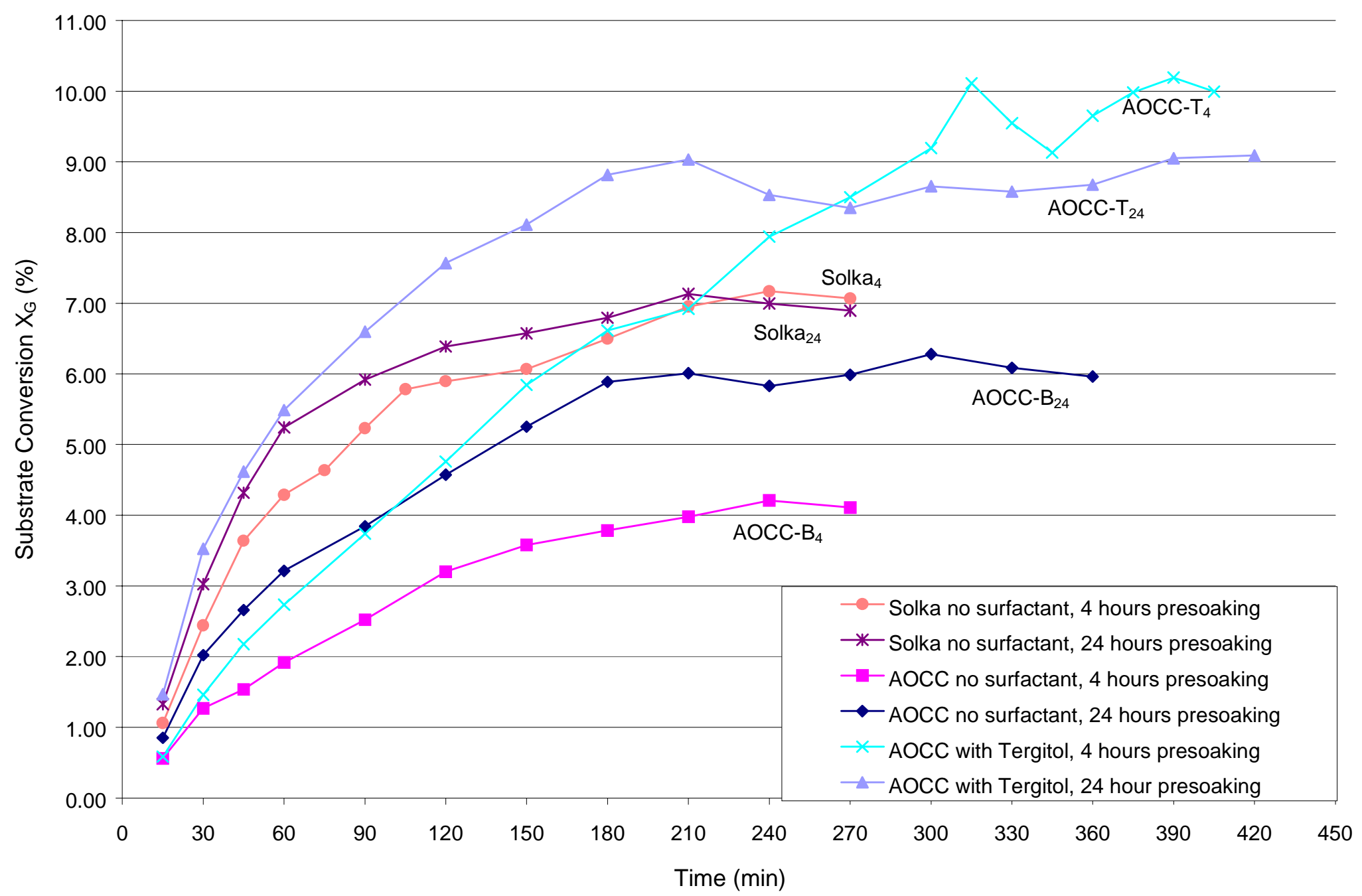

Figure 5.42. Effect of Presoaking Time on Substrate Conversion 


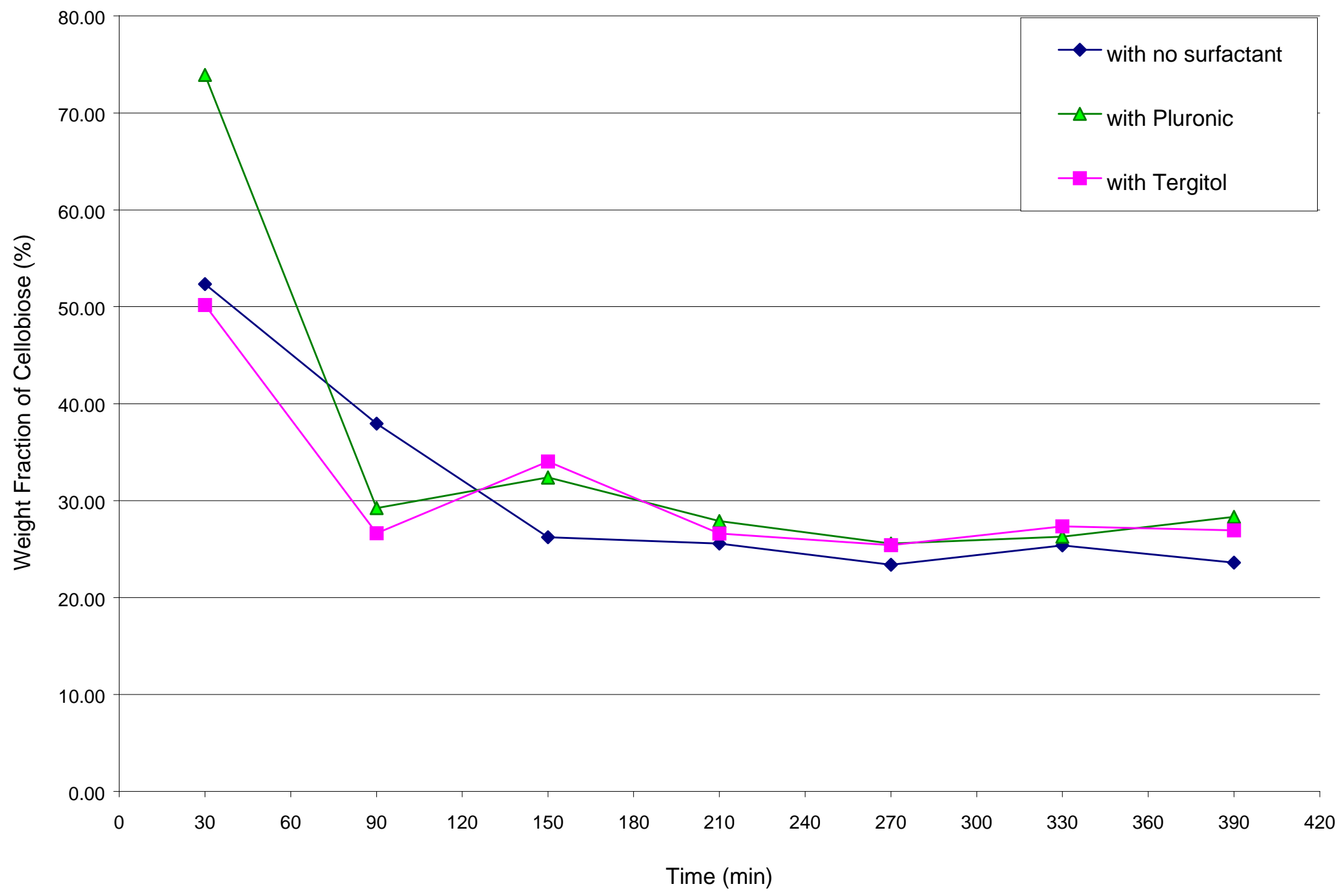

Figure 5.43. Distribution of Cellobiose in Permeate Stream --- AOYP 


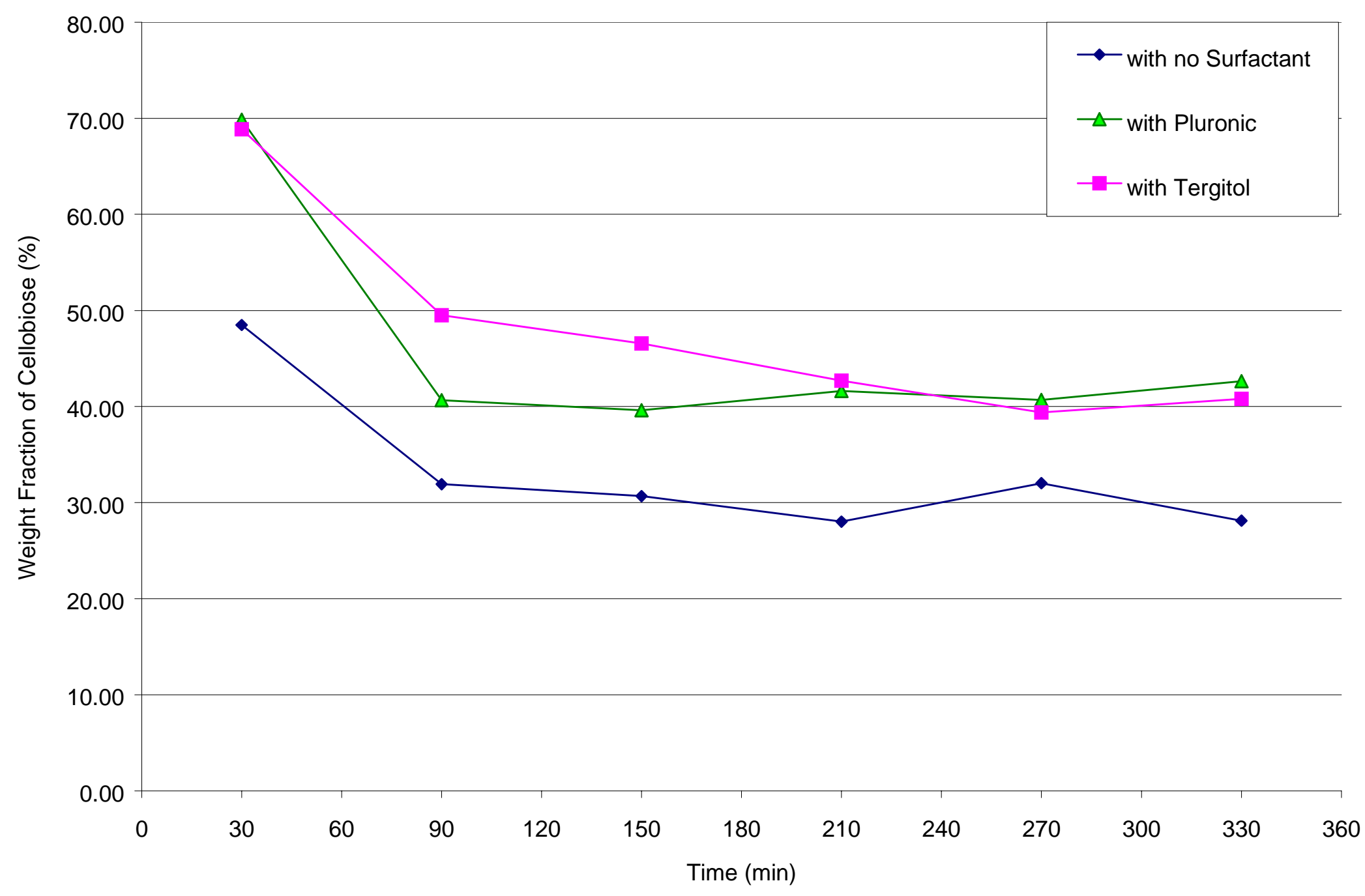

Figure 5.44. Distribution of Cellobiose in Permeate Stream --- ASYP 


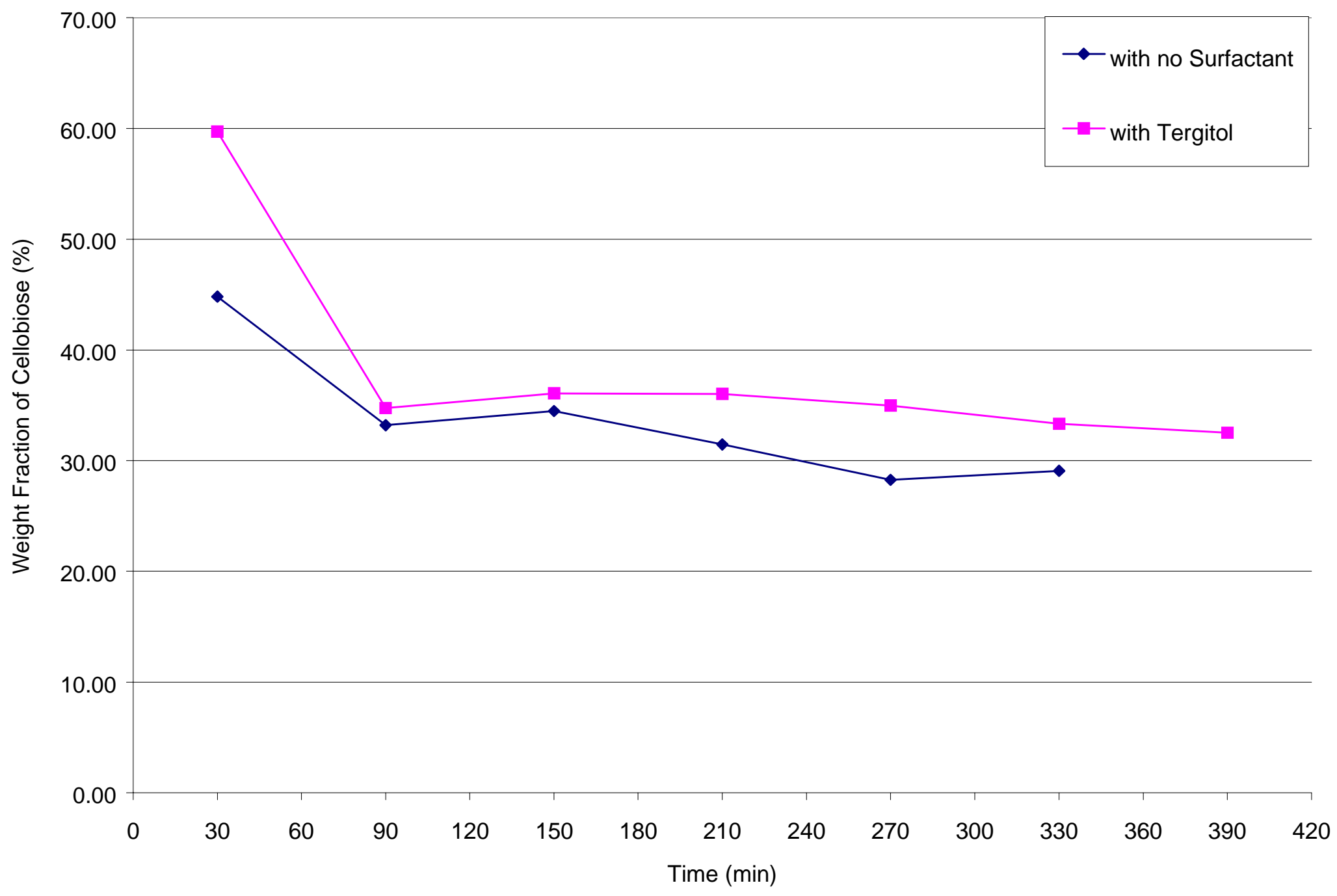

Figure 5.45. Distribution of Cellobiose in Permeate Stream --- AOCC 


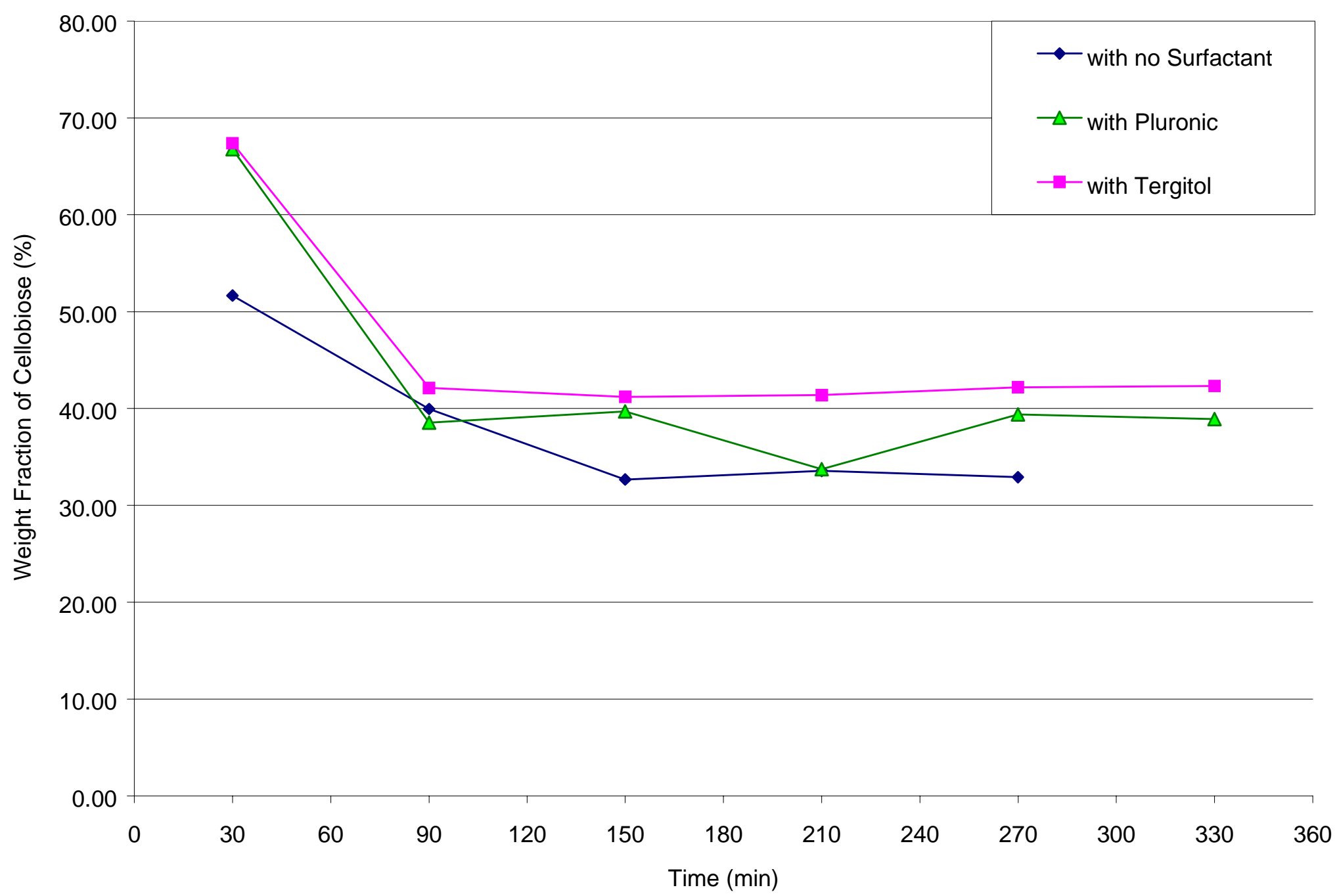

Figure 5.46. Distribution of Cellobiose in Permeate Stream --- ASCC 


\section{Chapter 6 Conclusions}

- $\quad$ Compared to ammonia steeping pretreatment, alkaline oxidation pretreatment method is more effective in removing lignin from both raw yellow poplar and corn cob used in this study. Alkaline oxidation pretreatment is also more effective in increasing the final digestible cellulose content in both substrates.

- $\quad$ For the HF membrane reactor, a combination of shaking speed and incline angle of $180 \mathrm{rpm} / 46.7^{\circ}$ can provide continuous and steady transportation of solid substrates inside the hollow fibers of the TMR. This is proven by the solid transportation experiment of four different types of substrates including: Solka Floc 200FCC, Solka Floc 900FCC, alkaline oxidation yellow poplar, and ammonia steeping corn cob.

- $\quad$ Both types of surfactants, Pluronic F68 and Tergitol NP-9, can enhance the enzymatic hydrolysis of all five types of substrates in the continuous HF membrane reactor system. These substrates include: Solka Floc 200FCC, alkaline oxidation pretreated yellow poplar, ammonia steeping pretreated yellow poplar, alkaline oxidation pretreated corn cob and ammonia steeping pretreated corn cob. Ammonia steeping pretreated corn cob, has the most significant enhancement, possibly due to its large particle size.

- In addition to glucose, considerable amount of cellobiose is present in the permeate stream during continuous hydrolysis runs of different substrates, where cellobiose concentration was monitored. This is in good agreement with the finding of Gauba (1993), where cellobiose concentration of only Solka Floc hydrolysis was conducted.

- $\quad$ Preliminary result indicates that Ucon 50-HB-5100 can recovery cellulase from buffer solution, although future studies are needed. 


\section{References}

Adney B, Baker J. 1996. Measurement of cellulase activities. National Renewable Energy Laboratory Chemical Analysis and Testing Task Laboratory Analytical Procedure, LAP- 006.

Brown L, Torget R. 1996. Enzymatic saccharification of lignocellulosic biomass. National Renewable Energy Laboratory Chemical Analysis and Testing Task Laboratory Analytical Procedure, LAP-009.

Cao NJ, Krishnan MS, Du JX, Gong CS, Ho NWY, Chen ZD, Tsao GT. 1996. Ethanol production from corn cob pretreated by the ammonia steeping process using genetically engineered yeast. Biotechnol Lett 18(9):1013-1018.

Castanon M, Wilke CR. 1981. Effects of the surfactant Tween 80 on enzymatic hydrolysis of newspaper. Biotechnol Bioeng 23:1365-1372.

Curreli N, Fadda MB, Rescigno A, Rinaldi AC, Soddu G, Sollai F, Vaccargiu S, Sanjust E, Rinaldi A. 1997. Mild alkaline/oxidative pretreatment of wheat straw. Process Biochem 32(8):665-670.

Dominguez JM, Cao NJ, Krishnan MS, Gong CS, Tsao GT. 1997. Xylitol production from hybrid poplar wood chips pretreated by the ammonia steeping process. Biotechnol Tech 11(5):339-341.

Ehrman T. 1994. Standard Method for Determination of Total Solids in Biomass. National Renewable Energy Laboratory Chemical Analysis and Testing Task Laboratory Analytical Procedure, LAP-001.

Ehrman, T. 1996. Determination of acid-soluble lignin in biomass. National Renewable Energy Laboratory Chemical Analysis and Testing Task Laboratory Analytical Procedure, LAP-004.

Fan LT, Gharpuray MM, Lee Y-H. 1987. Cellulose hydrolysis. Berlin:Springer-Verlag. 198 p. 
Gauba G. 1993. Enzymatic saccharification of cellulose in membrane bioreactors. MS Thesis. West Virginia University. (Research Advisor: R. Y. K. Yang)

Ghose TK, Kostick JA. 1970. A model for continuous enzymatic saccharification of cellulose with simultaneous removal of glucose syrup. Biotechnol Bioeng 7:921-946.

Gong CS, Cao NJ, Tsao GT. 1997. Biological production of 2,3-butanediol from renewable biomass. ACS Symp Ser 666:280-293.

Gregg DJ, Saddler JN. 1996. Factors affecting cellulose hydrolysis and the potential of enzyme recycle to enhance the efficiency of an integrated wood to ethanol process. Biotechnol Bioeng 51:375-383.

Grohmann K, Himmel M, Rivard C, Tucker M, Baker J. 1984. Chemical-mechanical methods for the enhanced utilization of straw. Biotechnol Bioeng Symp 14:137-157.

Grohmann K, Torget R, Himmel M. 1985. Optimization of dilute acid pretreatment of biomass. Biotechnol Bioeng Symp 15:59-80.

Helle SS, Duff SJB, Copper DG. 1993. Effect of surfactants on cellulose hydrolysis. Biotechnol Bioeng 42:611-617.

Henley RG, Yang RYK, Greenfield PF. 1980. Enzymatic saccharification of cellulose in membrane reactors. Enzyme Microb Technol 2(3):206-208.

Himmel ME, Ruth MF, Wyman CE. 1999. Cellulase for commodity products from cellulosic biomass. Curr Opin Biotechnol 10:358-364.

Holtzapple M, Cognata M, Shu Y, Hendrickson C. 1990. Inhibition of Trichoderma ressei cellulase by sugars and solvents. Biotechnol Bioeng 36:275-287. 
Hsu D. 1995. Preparation of dilute-acid pretreated biomass. National Renewable Energy Laboratory Chemical Analysis and Testing Task Laboratory Analytical Procedure, LAP-007.

Johansson HO, Karlström G, Mattiasson B, Tjerneld F. 1995. Effect of hydrophobicity and counter ions on the partitioning of amino acids in thermoseparating Ucon-water two-phase systems. Bioseparation 5:269-279.

Jones CK, Yang RYK. 1980. Simultaneous enzymatic hydrolysis of cellulose and sucrose. Chem Eng Commun 6(4-5):283- 291.

Karr WE, Holtzapple MT. 1998. Benefits from Tween during enzymatic hydrolysis of corn stover. Biotechnol Bioeng 59:419-427.

Kaya F, Heitmann JA Jr, Joyce TW. 1995. Influence of surfactants on the enzymatic hydrolysis of xylan and cellulose. Tappi J 78(10):150-157.

Knappert D, Grethlein H, Converse A. 1981. Partial acid hydrolysis of poplar wood as a pretreatment for enzymatic hydrolysis. Biotechnol Bioeng Symp 11:67-77.

Knappert D, Grethlein H, Converse A. 1980. Partial acid hydrolysis of cellulosic materials as a pretreatment for enzymatic hydrolysis. Biotechnol Bioeng 22:1449-1463.

Layton CJ. 1991. Enzymatic Hydrolysis of Cellulose in Hollow Fiber Membrane Reactor. MS Thesis. West Virginia University. (Research Advisor: R. Y. K. Yang)

Lehmann F. 1905. Ger Patent No.169, 800, March 26.

Lynd LR, Wyman CE, Gerngross TU. 1999. Biocommodity engineering. Biotechnol Prog 15:777-793.

McMillan JD. 1994. Pretreatment of Lignocellulosic Biomass. ACS Symp Ser 566:292-324. 
Nguyen QA, Tucker MP, Boynton BL, Keller FA, Schell DJ. 1998. Dilute acid pretreatment of softwoods. Appl Biochem Biotechnol 70-72:77-87.

Nieves RA, Ehrman CI, Adney WS, Elander RT, Himmel ME. Technical communication: Survey and analysis of commercial cellulase preparations suitable for biomass conversion to ethanol. 1998. World J Microbiol Biotechnol 14:301-304.

Park JW, Takahata Y, Kajiuchi T, Akehata T. 1992. Effects of nonionic surfactant on enzymatic hydrolysis of used newspaper. Biotechnol Bioeng 39:117-120.

Patel MM, Bhatt RM. 1992. Optimization of the alkaline peroxide pretreatment for the delignification of rice straw and its applications. J Chem Technol Biotechnol 53:253-263.

Persson J, Nyström L, Ageland H, Tjerneld F. 1999. Purification of recombinant proteins using thermoseparating aqueous two-phase system and polymer recycling. J Chem Technol Biotechnol 74:238-243.

Ruiz R, Ehrman T. 1996. Determination of carbohydrates in biomass by high performance liquid chromatography. National Renewable Energy Laboratory Chemical Analysis and Testing Task Laboratory Analytical Procedure, LAP- 002.

Reese ET. 1980. Inactivation of cellulase by shaking and its prevention by surfactants. J Appl Biochem 2:36-39.

Spindler D, Wyman C, Grohmann K. 1990. Evaluation of pretreated herbaceous crops for the simultaneous saccharification and fermentation process. Appl Biochem Biotechnol 24/25:275286.

Spindler DD, Wyman CE, Grohmann K. 1991. The simultaneous saccharification and fermentation of pretreated woody crops to ethanol. Appl Biochem Biotechnol 28/29:773-786. 
Templeton D, Ehrman T. 1995. Determination of acid-insoluble lignin in biomass. National Renewable Energy Laboratory Chemical Analysis and Testing Task Laboratory Analytical Procedure, LAP-003.

Tjerneld F, Persson I, Albertsson PA. 1985a. Enzymatic hydrolysis of cellulose in aqueous twophase system. I. Partition of cellulases from Trichoderma reesei. Biotechnol Bioeng 27:10361043.

Tjerneld F, Persson I, Albertsson PA. 1985b. Enzymatic hydrolysis of cellulose in aqueous twophase system. II. Semicontinuous conversion of a model substrate, Solka Floc BW 200. Biotechnol Bioeng 27:1044-1050.

Torget R, Himmel M, Grohmann K. 1992. Dilute-acid pretreatment of two short-rotation herbaceous crops. Appl Biochem Biotechnol 34/35:115-123.

Torget R, Hsu T-A. 1994. Two-temperature dilute-acid prehydrolysis of hardwood xylan using a percolation process. Appl Biochem Biotechnol 45/46:5-22.

Torget R, Walter P, Himmel M, Grohmann K. 1991. Dilute-acid pretreatment of corn residues and short-rotation woody crops. Appl Biochem Biotechnol 28/29:75-86.

Torget R, Werdene P, Himmel M, Grohmann K. 1990. Dilute acid pretreatment of short rotation woody and herbaceous crops. Appl Biochem Biotechnol 24/25:115-126.

Tsao GT, Cao NJ, Gong CS. 1996. Improved alcohol production employing SSF with thermotolerant yeast. Bioenergy 96': $7^{\text {th }}$ Natl Bioenergy Conf Proc: 358-363.

Wu J, Ju L-K. 1998. Enhancing enzymatic saccharification of waste newsprint by surfactant addition. Biotechnol Prog 14:649-652. 


\section{Appendices}

\section{Appendix A. Data Collected for Substrate Characterization Runs}

Table A.1a Total Solid Content of Yellow Poplar

Table A.1b \& c Total Solid Content of Lignocellulosic Materials and Solka Floc 900FCC

Table A.2 Characterization of Yellow Poplar

Table A.3 Characterization of Corn Cob

Table A.4 - 5 Enzymatic Digestibility Test of Different Substrates

\section{Appendix B. Data Collected for Substrate Transportation Runs}

Table B.1a

Table B.1b

Table B.2

Table B.3

Table B.4

Table B.5

Table B.6

Table B.7

Table B. 8

Table B.9

Solka Floc 200FCC --- 250rpm $/ 46.7^{\circ}$, retentate flow rate: $1.07 \mathrm{ml} / \mathrm{min}$

Solka Floc 200FCC--- $250 \mathrm{rpm} / 46.7^{\circ}$, retentate flow rate: $1.02 \mathrm{ml} / \mathrm{min}$

Solka Floc 200FCC --- 250rpm $/ 0^{\circ}$, retentate flow rate: $0.96 \mathrm{ml} / \mathrm{min}$

Solka Floc $200 \mathrm{FCC}$--- $0 \mathrm{rpm} / 46.7^{\circ}$, retentate flow rate: $0.92 \mathrm{ml} / \mathrm{min}$

Solka Floc $200 \mathrm{FCC}$--- $150 \mathrm{rpm} / 46.7^{\circ}$, retentate flow rate: $1.02 \mathrm{ml} / \mathrm{min}$

Solka Floc $900 \mathrm{FCC}$--- $150 \mathrm{rpm} / 46.7^{\circ}$, retentate flow rate: $1.05 \mathrm{ml} / \mathrm{min}$, permeate flow rate: $0.26 \mathrm{ml} / \mathrm{min}$

Alkaline Oxidation Yellow Poplar, first run --- $180 \mathrm{rpm} / 46.7^{\circ}$, retentate flow rate: $1.20 \mathrm{ml} / \mathrm{min}$, permeate flow rate: $0.21 \mathrm{ml} / \mathrm{min}$

Alkaline Oxidation Yellow Poplar, second run --- $180 \mathrm{rpm} / 46.7^{\circ}$, retentate flow rate: $1.07 \mathrm{ml} / \mathrm{min}$, permeate flow rate: $0.30 \mathrm{ml} / \mathrm{min}$

Ammonia Steeping Corn Cob, first run --- $180 \mathrm{rpm} / 46.7^{\circ}$, retentate flow rate: $1.08 \mathrm{ml} / \mathrm{min}$, permeate flow rate: $0.27 \mathrm{ml} / \mathrm{min}$

Ammonia Steeping Corn Cob, second run---180rpm $/ 46.7^{\circ}$, retentate flow rate: $1.08 \mathrm{ml} / \mathrm{min}$, permeate flow rate: $0.30 \mathrm{ml} / \mathrm{min}$

\section{Appendix C. Data Collected for Continuous Hydrolysis in TMR}

Table C.1 - 3 Solka Floc 200FCC Continuous Hydrolysis

Table C.4-6 Alkaline Oxidation Yellow Poplar Continuous Hydrolysis

Table C.7 - 9 Ammonia Steeping Yellow Poplar Continuous Hydrolysis

Table C.10 - 12 Alkaline Oxidation Corn Cob Continuous Hydrolysis

Table C.13 - 15 Ammonia Steeping Corn Cob Continuous Hydrolysis

\section{Appendix D. Data Collected for Enzyme Activity Test}

Table D.1a Glucose Calibration Curve

Table D.1b Enzyme Dilution vs. Glucose Concentration 


\section{Appendix A. Data Collected for Substrate Characterization Runs}

Table A.1a Total Solid Content of Yellow Poplar

\begin{tabular}{|c|c|c|c|c|c|c|}
\hline sample & $\begin{array}{c}\text { wt. of } \\
\text { WD }(\mathrm{g})\end{array}$ & $\begin{array}{c}\text { wt. of wet } \\
\text { YP }(\mathrm{g})\end{array}$ & $\begin{array}{c}\text { wt. of WD }+ \\
\text { dry YP }(\mathrm{g}) \\
17 \mathrm{hr}\end{array}$ & $\begin{array}{c}\text { wt. of dry } \\
\text { YP }(\mathrm{g}) \\
17 \mathrm{hr}\end{array}$ & $\begin{array}{c}\text { \% solid of } \\
\text { sample }\end{array}$ & $\begin{array}{c}\text { ave. \% solid } \\
\text { of YP }\end{array}$ \\
\hline $\mathrm{Oa}$ & 1.0118 & 1.0034 & 1.5868 & 0.5750 & $57.31 \%$ & \\
\hline $\mathrm{Ob}$ & 1.0143 & 1.0045 & 1.5989 & 0.5846 & $58.20 \%$ & $\mathbf{5 7 . 7 5 \%}$ \\
\hline $\mathrm{Aa}$ & 1.0002 & 0.9951 & 1.9228 & 0.9226 & $92.71 \%$ & \\
\hline $\mathrm{Ab}$ & 1.0029 & 1.0008 & 1.9284 & 0.9255 & $92.48 \%$ & $\mathbf{9 2 . 6 0 \%}$ \\
\hline $\mathrm{Wa}$ & 1.0016 & 1.0025 & 1.9352 & 0.9336 & $93.13 \%$ & \\
\hline $\mathrm{Wb}$ & 1.0049 & 1.0057 & 1.9430 & 0.9381 & $93.28 \%$ & $\mathbf{9 3 . 2 0 \%}$ \\
\hline $\mathrm{T} 1$ & 1.0055 & 1.0114 & 1.8597 & 0.8542 & $84.46 \%$ & \\
\hline $\mathrm{T} 2$ & 1.0000 & 0.9967 & 1.8427 & 0.8427 & $84.55 \%$ & $\mathbf{8 4 . 5 0 \%}$ \\
\hline
\end{tabular}

Table A.1b Total Solid Content of Lignocellulosic Materials and Solka Floc 900FCC (1)

\begin{tabular}{|c|c|c|c|c|c|c|c|}
\hline sample & $\begin{array}{c}\text { wt. of } \\
\text { WD }(\mathrm{g})\end{array}$ & $\begin{array}{c}\text { wt. of WD + } \\
\text { wet sample } \\
(\mathrm{g})\end{array}$ & $\begin{array}{c}\text { wt. of wet } \\
\text { sample }(\mathrm{g})\end{array}$ & $\begin{array}{c}\text { wt. of WD } \\
+ \text { dry } \\
\text { sample }(\mathrm{g}) \\
\text { 38hr }\end{array}$ & $\begin{array}{c}\text { wt. of dry } \\
\text { sample (g) } \\
38 \mathrm{hr}\end{array}$ & $\begin{array}{c}\text { \% solid of } \\
\text { sample }\end{array}$ & $\begin{array}{c}\text { ave. \% } \\
\text { solid of } \\
\text { sample }\end{array}$ \\
\hline $\mathrm{Oa}$ & 1.0080 & 2.0560 & 1.0480 & 1.6160 & 0.6080 & 0.5802 & \\
\hline $\mathrm{Ob}$ & 1.0118 & 2.0111 & 0.9993 & 1.5824 & 0.5706 & 0.5710 & $\mathbf{5 7 . 5 6 \%}$ \\
\hline $\mathrm{Aa}$ & 1.0123 & 2.0226 & 1.0103 & 1.9385 & 0.9262 & 0.9168 & \\
\hline $\mathrm{Ab}$ & 0.9985 & 2.0185 & 1.0200 & 1.9332 & 0.9347 & 0.9164 & $\mathbf{9 1 . 6 6 \%}$ \\
\hline $\mathrm{Wa}$ & 1.0027 & 2.0743 & 1.0716 & 1.9966 & 0.9939 & 0.9275 & \\
\hline $\mathrm{Wb}$ & 1.0043 & 2.1890 & 1.1847 & 2.1008 & 1.0965 & 0.9256 & $\mathbf{9 2 . 6 5 \%}$ \\
\hline $\mathrm{Ca}$ & 1.0043 & 2.3993 & 1.3950 & 2.3220 & 1.3177 & 0.9446 & \\
\hline $\mathrm{Cb}$ & 1.0041 & 2.0266 & 1.0225 & 1.9706 & 0.9665 & 0.9452 & $\mathbf{9 4 . 4 9 \%}$ \\
\hline $\mathrm{Sa}$ & 1.0042 & 2.0687 & 1.0645 & 2.0521 & 1.0479 & 0.9844 & \\
\hline $\mathrm{Sb}$ & 1.0005 & 1.9121 & 0.9116 & 1.8992 & 0.8987 & 0.9858 & $\mathbf{9 8 . 5 1 \%}$ \\
\hline $\mathrm{Ta}$ & 0.9910 & 2.1931 & 1.2021 & 2.0064 & 1.0154 & 0.8447 & \\
\hline $\mathrm{Tb}$ & 0.9904 & 2.0664 & 1.0760 & 1.8992 & 0.9088 & 0.8446 & $\mathbf{8 4 . 4 6 \%}$ \\
\hline
\end{tabular}

O: Original (as received) YP

A: Air-dried YP

W: Wiley-milled YP

C: Corncob (as received, $-40+60$ mesh)
S: Solka Floc 900FCC

T: Sodium Tartrate,

known to have solid content of $84.38 \%$ a $\&$ b are duplicate samples 
Table A.1c Total Solid Content of Lignocellulosic Materials and Solka Floc 900FCC (2)

\begin{tabular}{|c|c|c|c|c|c|c|c|}
\hline sample & $\begin{array}{c}\text { wt. of } \\
\text { WD (g) }\end{array}$ & $\begin{array}{c}\text { wt. of WD + } \\
\text { wet sample } \\
(\mathrm{g})\end{array}$ & $\begin{array}{c}\text { wt. of wet } \\
\text { sample }(\mathrm{g})\end{array}$ & $\begin{array}{c}\text { wt. of WD } \\
+ \text { dry } \\
\text { sample }(\mathrm{g}) \\
78 \mathrm{hr}\end{array}$ & $\begin{array}{c}\text { wt. of dry } \\
\text { sample }(\mathrm{g}) \\
78 \mathrm{hr}\end{array}$ & $\begin{array}{c}\text { \% solid of } \\
\text { sample }\end{array}$ & $\begin{array}{c}\text { ave. \% } \\
\text { solid of } \\
\text { sample }\end{array}$ \\
\hline $\mathrm{Oa}$ & 1.0087 & 5.0181 & 4.0094 & 3.2482 & 2.2395 & $55.86 \%$ & \\
\hline $\mathrm{Ob}$ & 1.0133 & 4.8471 & 3.8338 & 3.1493 & 2.1360 & $55.71 \%$ & $\mathbf{5 5 . 7 9 \%}$ \\
\hline $\mathrm{Aa}$ & 1.0124 & 3.7411 & 2.7287 & 3.5165 & 2.5041 & $91.77 \%$ & \\
\hline $\mathrm{Ab}$ & 1.0207 & 4.8343 & 3.8136 & 4.5116 & 3.4909 & $91.54 \%$ & $\mathbf{9 1 . 6 5 \%}$ \\
\hline $\mathrm{Wa}$ & 1.0101 & 6.1013 & 5.0912 & 5.7267 & 4.7166 & $92.64 \%$ & \\
\hline $\mathrm{Wb}$ & 1.0068 & 4.9948 & 3.9880 & 4.6937 & 3.6869 & $92.45 \%$ & $\mathbf{9 2 . 5 5 \%}$ \\
\hline $\mathrm{Ca}$ & 0.9985 & 6.3943 & 5.3958 & 6.0911 & 5.0926 & $94.38 \%$ & \\
\hline $\mathrm{Cb}$ & 1.0189 & 4.5927 & 3.5738 & 4.3891 & 3.3702 & $94.30 \%$ & $\mathbf{9 4 . 3 4 \%}$ \\
\hline $\mathrm{Sa}$ & 1.0112 & 2.5541 & 1.5429 & 2.5204 & 1.5092 & $97.82 \%$ & \\
\hline $\mathrm{Sb}$ & 1.0062 & 2.4913 & 1.4851 & 2.4638 & 1.4576 & $98.15 \%$ & $\mathbf{9 7 . 9 8 \%}$ \\
\hline $\mathrm{Ta}$ & 1.0076 & 4.5402 & 3.5326 & 3.9900 & 2.9824 & $84.43 \%$ & \\
\hline $\mathrm{Tb}$ & 1.0040 & 4.4408 & 3.4368 & 3.9061 & 2.9021 & $84.44 \%$ & $\mathbf{8 4 . 4 3 \%}$ \\
\hline
\end{tabular}

O: Original (as received) YP

A: Air-dried YP

W: Wiley-milled YP

C: Corncob (as received, $-40+60$ mesh)

S: Solka Floc 900FCC

T: Sodium Tartrate, known to have solid content of $84.38 \%$

a \& b are duplicate samples 
Table A.2 Characterization of Yellow Poplar

\begin{tabular}{|c|c|c|c|c|c|}
\hline yellow poplar & $\begin{array}{c}\text { \%AIL } \\
\text { (Klason) }\end{array}$ & $\%$ ASL & $\begin{array}{c}\text { total dry } \\
\text { weight loss }\end{array}$ & $\begin{array}{c}\text { total lignin } \\
\text { removal }\end{array}$ & $\begin{array}{c}\text { Klason lignin } \\
\text { removal }\end{array}$ \\
\hline raw milled YP & $24.85 \%$ & $2.45 \%$ & - & - & \\
\hline milled ASYP & & & & & \\
\hline batch 1 & $25.45 \%$ & $2.00 \%$ & $30.96 \%$ & $30.58 \%$ & $29.29 \%$ \\
\hline batch 2 & $24.63 \%$ & $2.50 \%$ & $23.78 \%$ & $24.26 \%$ & $24.46 \%$ \\
\hline average & $25.04 \%$ & $2.25 \%$ & $27.37 \%$ & $27.42 \%$ & $26.88 \%$ \\
\hline milled AOYP & & & & & \\
\hline batch 1 & $21.82 \%$ & $2.90 \%$ & $18.69 \%$ & $26.37 \%$ & $28.61 \%$ \\
\hline batch 2 & $22.11 \%$ & $3.12 \%$ & $23.19 \%$ & $29.01 \%$ & $31.65 \%$ \\
\hline average & $21.97 \%$ & $3.01 \%$ & $20.94 \%$ & $27.69 \%$ & $30.13 \%$ \\
\hline
\end{tabular}

Table A.3 Characterization of Corn Cob

\begin{tabular}{|c|c|c|c|c|c|}
\hline Corn cob & $\begin{array}{c}\% \text { AIL } \\
\text { (Klason) }\end{array}$ & $\%$ ASL & $\begin{array}{c}\text { total dry } \\
\text { weight loss }\end{array}$ & $\begin{array}{c}\text { total lignin } \\
\text { removal }\end{array}$ & $\begin{array}{c}\text { Klason lignin } \\
\text { removal }\end{array}$ \\
\hline raw CC & $17.10 \%$ & $2.39 \%$ & - & - & \\
\hline ASCC & & & & & \\
\hline batch 1 & $19.30 \%$ & $2.22 \%$ & $51.91 \%$ & $46.90 \%$ & $45.71 \%$ \\
\hline batch 2 & $18.22 \%$ & $2.61 \%$ & $46.13 \%$ & $42.43 \%$ & $42.61 \%$ \\
\hline average & $18.76 \%$ & $2.42 \%$ & $49.02 \%$ & $44.66 \%$ & $44.16 \%$ \\
\hline AOCC & & & & & \\
\hline batch 1 & $3.13 \%$ & $1.58 \%$ & $50.64 \%$ & $88.07 \%$ & $90.96 \%$ \\
\hline batch 2 & $2.61 \%$ & $1.71 \%$ & $48.12 \%$ & $88.50 \%$ & $92.08 \%$ \\
\hline average & $2.87 \%$ & $1.65 \%$ & $49.38 \%$ & $88.29 \%$ & $91.52 \%$ \\
\hline
\end{tabular}


Table A.4 Enzymatic Digestibility Test of Different Substrates, first run

\begin{tabular}{|c|c|c|c|c|c|c|c|}
\hline \multirow{2}{*}{$\begin{array}{c}\text { substrate } \\
\text { conversion }\end{array}$} & \multicolumn{7}{|c|}{ time (hours) } \\
\hline & 5.5 & 24 & 48 & 72 & 96 & 120 & 144 \\
\hline raw YP & $3.33 \%$ & $3.01 \%$ & $3.49 \%$ & $3.90 \%$ & $3.62 \%$ & $4.40 \%$ & $4.34 \%$ \\
\hline AS YP & $6.09 \%$ & $10.25 \%$ & $13.42 \%$ & $15.07 \%$ & $15.45 \%$ & $16.89 \%$ & $16.79 \%$ \\
\hline AO YP & $14.03 \%$ & $21.78 \%$ & $26.56 \%$ & $28.82 \%$ & $29.07 \%$ & $30.66 \%$ & $30.93 \%$ \\
\hline raw $\mathrm{CC}$ & $8.58 \%$ & $13.11 \%$ & $14.57 \%$ & $15.36 \%$ & $15.16 \%$ & $16.77 \%$ & $17.16 \%$ \\
\hline AS CC & $29.21 \%$ & $45.15 \%$ & $47.77 \%$ & $48.96 \%$ & $48.62 \%$ & $50.46 \%$ & $49.36 \%$ \\
\hline $\mathrm{AO} \mathrm{CC}$ & $50.33 \%$ & $55.75 \%$ & $56.36 \%$ & $55.70 \%$ & $57.29 \%$ & $55.08 \%$ & $56.56 \%$ \\
\hline Solka & $45.50 \%$ & $72.27 \%$ & $84.32 \%$ & $86.37 \%$ & $90.06 \%$ & $87.17 \%$ & $87.91 \%$ \\
\hline
\end{tabular}

Table A.5 Enzymatic Digestibility Test of Different Substrates, second run

\begin{tabular}{|c|c|c|c|c|c|c|c|c|c|}
\hline \multirow{2}{*}{$\begin{array}{c}\text { substrate } \\
\text { conversion }\end{array}$} & \multicolumn{8}{|c|}{ time (hours) } \\
\cline { 2 - 10 } & 2 & 4 & 8 & 15 & 24 & 36 & 51 & 72 & 99 \\
\hline AS YP & $5.57 \%$ & $4.18 \%$ & $6.39 \%$ & $8.20 \%$ & $10.05 \%$ & $11.91 \%$ & $13.31 \%$ & $16.03 \%$ & $14.21 \%$ \\
\hline AO YP & $9.40 \%$ & $12.03 \%$ & $15.65 \%$ & $18.96 \%$ & $21.75 \%$ & $24.01 \%$ & $25.73 \%$ & $26.60 \%$ & $27.47 \%$ \\
\hline AS CC & $19.05 \%$ & $26.68 \%$ & $35.76 \%$ & $40.29 \%$ & $42.75 \%$ & $45.52 \%$ & $46.62 \%$ & $47.01 \%$ & $46.75 \%$ \\
\hline AO CC & $39.27 \%$ & $50.41 \%$ & $53.42 \%$ & $53.88 \%$ & $54.88 \%$ & $55.50 \%$ & $54.24 \%$ & $55.93 \%$ & $53.67 \%$ \\
\hline Solka & $29.83 \%$ & $42.05 \%$ & $55.09 \%$ & $65.29 \%$ & $74.81 \%$ & $80.96 \%$ & $83.93 \%$ & $85.41 \%$ & $84.69 \%$ \\
\hline
\end{tabular}

AS: Ammonia Steeping

AO: Alkaline Oxidation

Solka: Solka Floc 200FCC 


\section{Appendix B. Data Collected for Substrate Transportation Runs}

Table B.1a Solka Floc 200FCC --- 250rpm $/ 46.7^{\circ}$, retentate flow rate: $1.07 \mathrm{ml} / \mathrm{min}$, first run

\begin{tabular}{|c|c|c|c|c|}
\hline interval & $\begin{array}{c}\text { time } \\
(\mathrm{min})\end{array}$ & $\begin{array}{c}\text { wt. of cellulose coming } \\
\text { out of HF cartridge(g) }\end{array}$ & $\begin{array}{c}\text { wt. of cellulose injected } \\
\text { into HF cartridge(g) }\end{array}$ & \% of output \\
\hline 1 & $0-45$ & 0.0682 & 0.1105 & $61.77 \%$ \\
\hline 2 & $45-90$ & 0.1102 & 0.1105 & $99.69 \%$ \\
\hline 3 & $90-135$ & 0.0962 & 0.1105 & $87.11 \%$ \\
\hline 4 & $135-180$ & 0.1077 & 0.1105 & $97.43 \%$ \\
\hline 5 & $180-225$ & 0.1176 & 0.1105 & $106.39 \%$ \\
\hline 6 & $225-270$ & 0.1178 & 0.1105 & $106.57 \%$ \\
\hline 7 & $270-315$ & 0.1055 & 0.1105 & $95.44 \%$ \\
\hline 8 & $315-360$ & 0.1063 & 0.1105 & $96.16 \%$ \\
\hline 9 & $360-405$ & 0.1138 & 0.1105 & $103.00 \%$ \\
\hline 10 & $405-450$ & 0.1222 & 0.1105 & $110.60 \%$ \\
\hline
\end{tabular}

Total input of cellulose : $1.1049(\mathrm{~g})$

Total output of cellulose: $1.0653(\mathrm{~g})$

Cellulose remaining in HF cartridge: $0.0496(\mathrm{~g})$

Material Balance: $100.9 \%$

Table B.1b Solka Floc 200FCC--- 250rpm $/ 46.7^{\circ}$, retentate flow rate: $1.02 \mathrm{ml} / \mathrm{min}$, second run

\begin{tabular}{|c|c|c|c|c|}
\hline interval & $\begin{array}{c}\text { time. } \\
(\mathrm{min})\end{array}$ & $\begin{array}{c}\text { wt. of cellulose coming } \\
\text { out of HF cartridge(g) }\end{array}$ & $\begin{array}{c}\text { wt. of cellulose injected } \\
\text { into HF cartridge(g) }\end{array}$ & \% of output \\
\hline 1 & $0-45$ & 0.0659 & 0.1105 & $59.62 \%$ \\
\hline 2 & $45-90$ & 0.1042 & 0.1105 & $94.27 \%$ \\
\hline 3 & $90-135$ & 0.1114 & 0.1105 & $100.78 \%$ \\
\hline 4 & $135-180$ & 0.1077 & 0.1105 & $97.43 \%$ \\
\hline 5 & $180-225$ & 0.0996 & 0.1105 & $90.11 \%$ \\
\hline 6 & $225-270$ & 0.1182 & 0.1105 & $106.93 \%$ \\
\hline 7 & $270-315$ & 0.1101 & 0.1105 & $99.60 \%$ \\
\hline 8 & $315-360$ & 0.1084 & 0.1105 & $98.07 \%$ \\
\hline 9 & $360-405$ & 0.1207 & 0.1105 & $109.19 \%$ \\
\hline 10 & $405-450$ & 0.1063 & 0.1105 & $96.17 \%$ \\
\hline
\end{tabular}

Total input of cellulose: $1.1054(\mathrm{~g})$

Total output of cellulose: $1.0525(\mathrm{~g})$

Cellulose remaining in HF cartridge: $0.0482(\mathrm{~g})$

Material balance: $99.58 \%$ 
Table B.2 Solka Floc 200FCC -- 250rpm/ $0^{\circ}$, retentate flow rate: $0.96 \mathrm{ml} / \mathrm{min}$

\begin{tabular}{|c|c|c|c|c|}
\hline interval & $\begin{array}{c}\text { time } \\
(\mathrm{min})\end{array}$ & $\begin{array}{c}\text { wt. of cellulose coming } \\
\text { out of HF cartridge(g) }\end{array}$ & $\begin{array}{c}\text { wt. of cellulose injected } \\
\text { into HF cartridge(g) }\end{array}$ & \% of output \\
\hline 1 & $0-45$ & 0.0453 & 0.1106 & $40.97 \%$ \\
\hline 2 & $45-90$ & 0.1062 & 0.1106 & $96.06 \%$ \\
\hline 3 & $90-135$ & 0.1275 & 0.1106 & $115.33 \%$ \\
\hline 4 & $135-180$ & 0.1045 & 0.1106 & $94.52 \%$ \\
\hline 5 & $180-225$ & 0.1045 & 0.1106 & $94.52 \%$ \\
\hline 6 & $225-270$ & 0.1173 & 0.1106 & $106.10 \%$ \\
\hline 7 & $270-315$ & 0.1005 & 0.1106 & $90.90 \%$ \\
\hline 8 & $315-360$ & 0.1144 & 0.1106 & $103.48 \%$ \\
\hline 9 & $360-405$ & 0.0976 & 0.1106 & $88.28 \%$ \\
\hline 10 & $405-450$ & 0.1098 & 0.1106 & $99.32 \%$ \\
\hline
\end{tabular}

Total Input of cellulose: $1.1056(\mathrm{~g})$

Total output of cellulose: $1.0276(\mathrm{~g})$

Cellulose remaining in HF cartridge: $0.0543(\mathrm{~g})$

Accumulation in the inlet and outlet of HF cartridge: $0.0107(\mathrm{~g})$

Material balance: $98.83 \%$

Table B.3 Solka Floc 200FCC --- 0rpm $/ 46.7^{\circ}$, retentate flow rate: $0.92 \mathrm{ml} / \mathrm{min}$

\begin{tabular}{|c|c|c|c|c|}
\hline interval & $\begin{array}{c}\text { time } \\
(\mathrm{min})\end{array}$ & $\begin{array}{c}\text { wt. of cellulose coming } \\
\text { out of HF cartridge }(\mathrm{g})\end{array}$ & $\begin{array}{c}\text { wt. of cellulose injected } \\
\text { into HF cartridge }(\mathrm{g})\end{array}$ & \% of output \\
\hline 1 & $0-45$ & 0.0000 & 0.1106 & $0.00 \%$ \\
\hline 2 & $45-90$ & 0.0047 & 0.1106 & $4.25 \%$ \\
\hline 3 & $90-135$ & 0.1178 & 0.1106 & $106.56 \%$ \\
\hline 4 & $135-180$ & 0.0805 & 0.1106 & $72.82 \%$ \\
\hline 5 & $180-225$ & 0.0668 & 0.1106 & $60.42 \%$ \\
\hline
\end{tabular}

Total input of cellulose: $0.5528(\mathrm{~g})$

Total output of cellulose: $0.2698(\mathrm{~g})$

Cellulose remaining in HF cartridge: $0.2000(\mathrm{~g})$

Accumulation in the inlet of HF cartridge: $0.0093(\mathrm{~g})$

Accumulation in the outlet of HF cartridge: $0.0602(\mathrm{~g})$

Material balance: $97.6 \%$ 
Table B.4 Solka Floc 200FCC --- $150 \mathrm{rpm} / 46.7^{\circ}$, retentate flow rate: $1.02 \mathrm{ml} / \mathrm{min}$

\begin{tabular}{|c|c|c|c|c|}
\hline interval & $\begin{array}{c}\text { time } \\
(\mathrm{min})\end{array}$ & $\begin{array}{c}\text { wt. of cellulose coming } \\
\text { out of HF cartridge(g) }\end{array}$ & $\begin{array}{c}\text { wt. of cellulose injected } \\
\text { into HF cartridge }(\mathrm{g})\end{array}$ & \% of output \\
\hline 1 & $0-45$ & 0.0524 & 0.1106 & $47.40 \%$ \\
\hline 2 & $45-90$ & 0.0853 & 0.1106 & $77.16 \%$ \\
\hline 3 & $90-135$ & 0.1080 & 0.1106 & $97.69 \%$ \\
\hline 4 & $135-180$ & 0.1067 & 0.1106 & $96.51 \%$ \\
\hline 5 & $180-225$ & 0.1126 & 0.1106 & $101.85 \%$ \\
\hline
\end{tabular}

Total input of cellulose: $0.5528(\mathrm{~g})$

Total output of cellulose: $0.4650(\mathrm{~g})$

Cellulose remaining in HF cartridge: $0.0580(\mathrm{~g})$

Accumulation in the inlet of HF cartridge: $0.0039(\mathrm{~g})$

Accumulation in the outlet of HF cartridge: $0.0225(\mathrm{~g})$

Material balance: $99 \%$

Table B.5 Solka Floc 900FCC --- 180rpm/46.7 ${ }^{\circ}$, retentate flow rate: $1.05 \mathrm{ml} / \mathrm{min}$, permeate flow rate: $0.26 \mathrm{ml} / \mathrm{min}$

\begin{tabular}{|c|c|c|c|c|}
\hline interval & $\begin{array}{c}\text { time } \\
(\mathrm{min})\end{array}$ & $\begin{array}{c}\text { wt. of cellulose coming } \\
\text { out of HF cartridge(g) }\end{array}$ & $\begin{array}{c}\text { wt. of cellulose injected } \\
\text { into HF cartridge(g) }\end{array}$ & \% of output \\
\hline 1 & $0-45$ & 0.0772 & 0.1113 & $69.37 \%$ \\
\hline 2 & $45-90$ & 0.0958 & 0.1113 & $86.08 \%$ \\
\hline 3 & $90-135$ & 0.1227 & 0.1113 & $110.25 \%$ \\
\hline 4 & $135-180$ & 0.1065 & 0.1113 & $95.69 \%$ \\
\hline 5 & $180-225$ & 0.1153 & 0.1113 & $103.60 \%$ \\
\hline
\end{tabular}

Total input of cellulose: $0.5565(\mathrm{~g})$

Total output of cellulose: $0.5175(\mathrm{~g})$

Cellulose remaining in HF cartridge: $0.0267(\mathrm{~g})$

Material balance: $97.80 \%$ 
Table B.6 Alkaline Oxidation Yellow Poplar, first run --- 180rpm $/ 46.7^{\circ}$, retentate flow rate: $1.20 \mathrm{ml} / \mathrm{min}$, permeate flow rate: $0.21 \mathrm{ml} / \mathrm{min}$

\begin{tabular}{|c|c|c|c|c|}
\hline interval & $\begin{array}{c}\text { time } \\
(\mathrm{min})\end{array}$ & $\begin{array}{c}\text { wt. of cellulose coming } \\
\text { out of HF cartridge(g) }\end{array}$ & $\begin{array}{c}\text { wt. of cellulose injected } \\
\text { into HF cartridge(g) }\end{array}$ & \% of output \\
\hline 1 & $0-45$ & 0.0867 & 0.1058 & $81.92 \%$ \\
\hline 2 & $45-90$ & 0.1057 & 0.1058 & $99.87 \%$ \\
\hline 3 & $90-135$ & 0.1016 & 0.1058 & $96.00 \%$ \\
\hline 4 & $135-180$ & 0.1072 & 0.1058 & $101.29 \%$ \\
\hline 5 & $180-225$ & 0.1034 & 0.1058 & $97.70 \%$ \\
\hline 6 & $225-270$ & 0.1055 & 0.1058 & $99.68 \%$ \\
\hline
\end{tabular}

Total input of cellulose: $0.6350(\mathrm{~g})$

Total output of cellulose: $0.6101(\mathrm{~g})$

Cellulose remaining in HF cartridge: $0.0218(\mathrm{~g})$

Material balance: $99.51 \%$

Table B.7 Alkaline Oxidation Yellow Poplar, second run --- 180rpm $/ 46.7^{\circ}$, retentate flow rate: $1.07 \mathrm{ml} / \mathrm{min}$, permeate flow rate: $0.30 \mathrm{ml} / \mathrm{min}$

\begin{tabular}{|c|c|c|c|c|}
\hline interval & $\begin{array}{c}\text { time } \\
(\mathrm{min})\end{array}$ & $\begin{array}{c}\text { wt. of cellulose coming } \\
\text { out of HF cartridge(g) }\end{array}$ & $\begin{array}{c}\text { wt. of cellulose injected } \\
\text { into HF cartridge(g) }\end{array}$ & \% of output \\
\hline 1 & $0-45$ & 0.0783 & 0.1055 & $74.22 \%$ \\
\hline 2 & $45-90$ & 0.1062 & 0.1055 & $100.67 \%$ \\
\hline 3 & $90-135$ & 0.1030 & 0.1055 & $97.64 \%$ \\
\hline 4 & $135-180$ & 0.1042 & 0.1055 & $98.77 \%$ \\
\hline 5 & $180-225$ & 0.0962 & 0.1055 & $91.19 \%$ \\
\hline 6 & $225-270$ & 0.1126 & 0.1055 & $106.74 \%$ \\
\hline
\end{tabular}

Total input of cellulose: $0.6330(\mathrm{~g})$

Total output of cellulose: $0.6005(\mathrm{~g})$

Cellulose remaining in HF cartridge: $0.0234(\mathrm{~g})$

Material balance: $98.57 \%$ 
Table B.8 Ammonia Steeping Corn Cob, first run --- 180rpm/46.7 ${ }^{\circ}$, retentate flow rate: $1.08 \mathrm{ml} / \mathrm{min}$, permeate flow rate: $0.27 \mathrm{ml} / \mathrm{min}$

\begin{tabular}{|c|c|c|c|c|}
\hline interval & $\begin{array}{c}\text { time } \\
(\mathrm{min})\end{array}$ & $\begin{array}{c}\text { wt. of cellulose coming } \\
\text { out of HF cartridge(g) }\end{array}$ & $\begin{array}{c}\text { wt. of cellulose injected } \\
\text { into HF cartridge(g) }\end{array}$ & \% of output \\
\hline 1 & $0-45$ & 0.0544 & 0.0911 & $59.71 \%$ \\
\hline 2 & $45-90$ & 0.0744 & 0.0911 & $81.67 \%$ \\
\hline 3 & $90-135$ & 0.0845 & 0.0911 & $92.76 \%$ \\
\hline 4 & $135-180$ & 0.0867 & 0.0911 & $95.17 \%$ \\
\hline 5 & $180-225$ & 0.0841 & 0.0911 & $92.32 \%$ \\
\hline 6 & $225-270$ & 0.0869 & 0.0911 & $95.39 \%$ \\
\hline
\end{tabular}

Total input of cellulose: $0.5466(\mathrm{~g})$

Total output of cellulose: $0.4710(\mathrm{~g})$

Cellulose remaining in HF cartridge: 0.0646(g)

Material balance: $97.99 \%$

Table B.9 Ammonia Steeping Corn Cob, second run---180rpm/46. $7^{\circ}$, retentate flow rate: $1.08 \mathrm{ml} / \mathrm{min}$, permeate flow rate: $0.30 \mathrm{ml} / \mathrm{min}$

\begin{tabular}{|c|c|c|c|c|}
\hline interval & $\begin{array}{c}\text { time } \\
(\mathrm{min})\end{array}$ & $\begin{array}{c}\text { wt. of cellulose coming } \\
\text { out of HF cartridge(g) }\end{array}$ & $\begin{array}{c}\text { wt. of cellulose injected } \\
\text { into HF cartridge(g) }\end{array}$ & \% of output \\
\hline 1 & $0-45$ & 0.0703 & 0.1058 & $66.47 \%$ \\
\hline 2 & $45-90$ & 0.0792 & 0.1058 & $74.88 \%$ \\
\hline 3 & $90-135$ & 0.0761 & 0.1058 & $71.95 \%$ \\
\hline 4 & $135-180$ & 0.0903 & 0.1058 & $85.38 \%$ \\
\hline 5 & $180-225$ & 0.0976 & 0.1058 & $92.28 \%$ \\
\hline 6 & $225-270$ & 0.0943 & 0.1058 & $89.16 \%$ \\
\hline
\end{tabular}

Total Input of Cellulose: 0.6346(g)

Total Output of Cellulose: $0.5078(\mathrm{~g})$

Cellulose Remaining in HF Cartridge: $0.0380(\mathrm{~g})$

Material Balance: $86.01 \%$ 


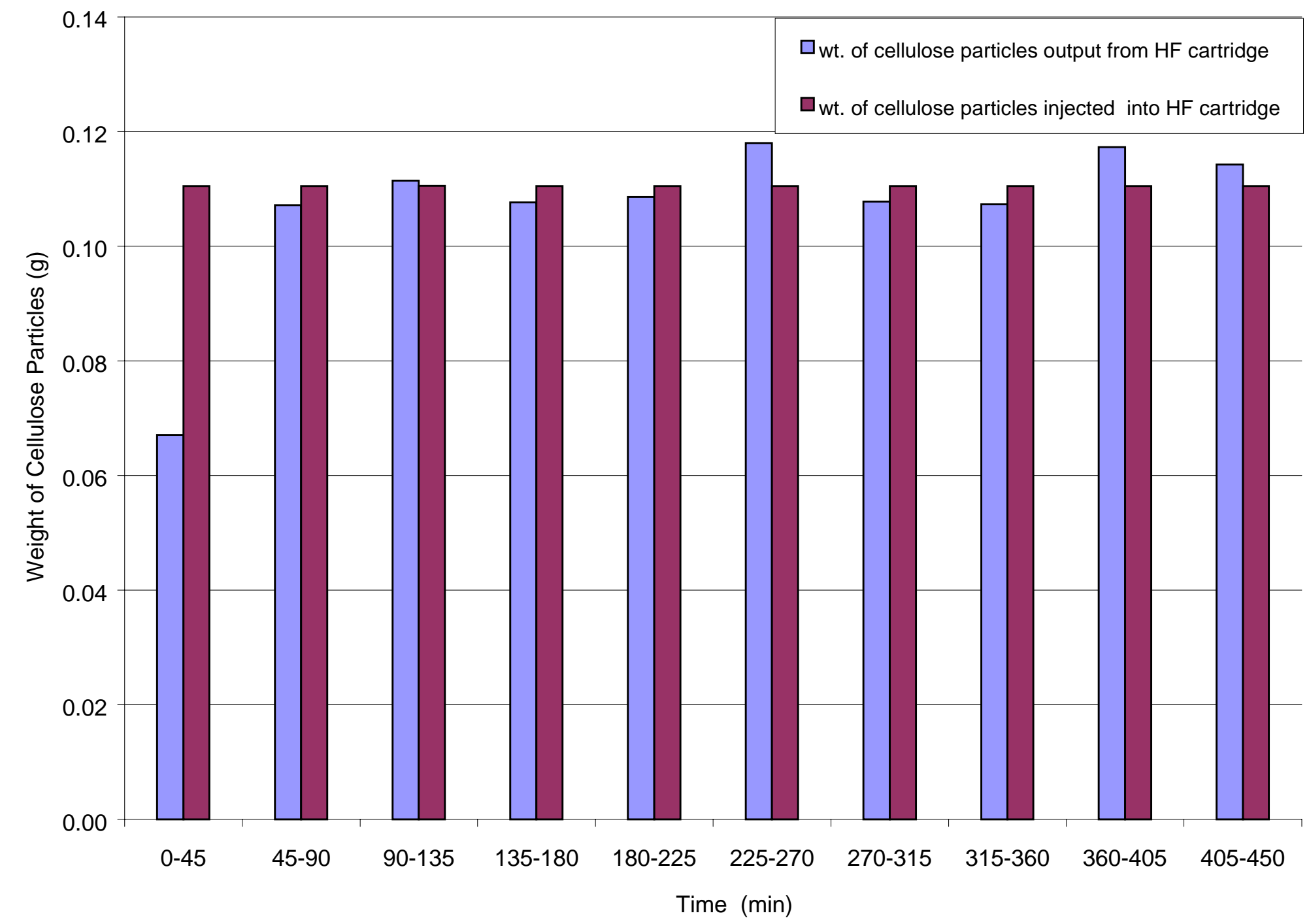

Figure B 5.3. Weight of Cellulose (Solka Floc 200FCC) vs. Time (250rpm, $46.7^{\circ}$, Retentate flow rate: $1.04 \mathrm{ml} / \mathrm{min}$ ) 


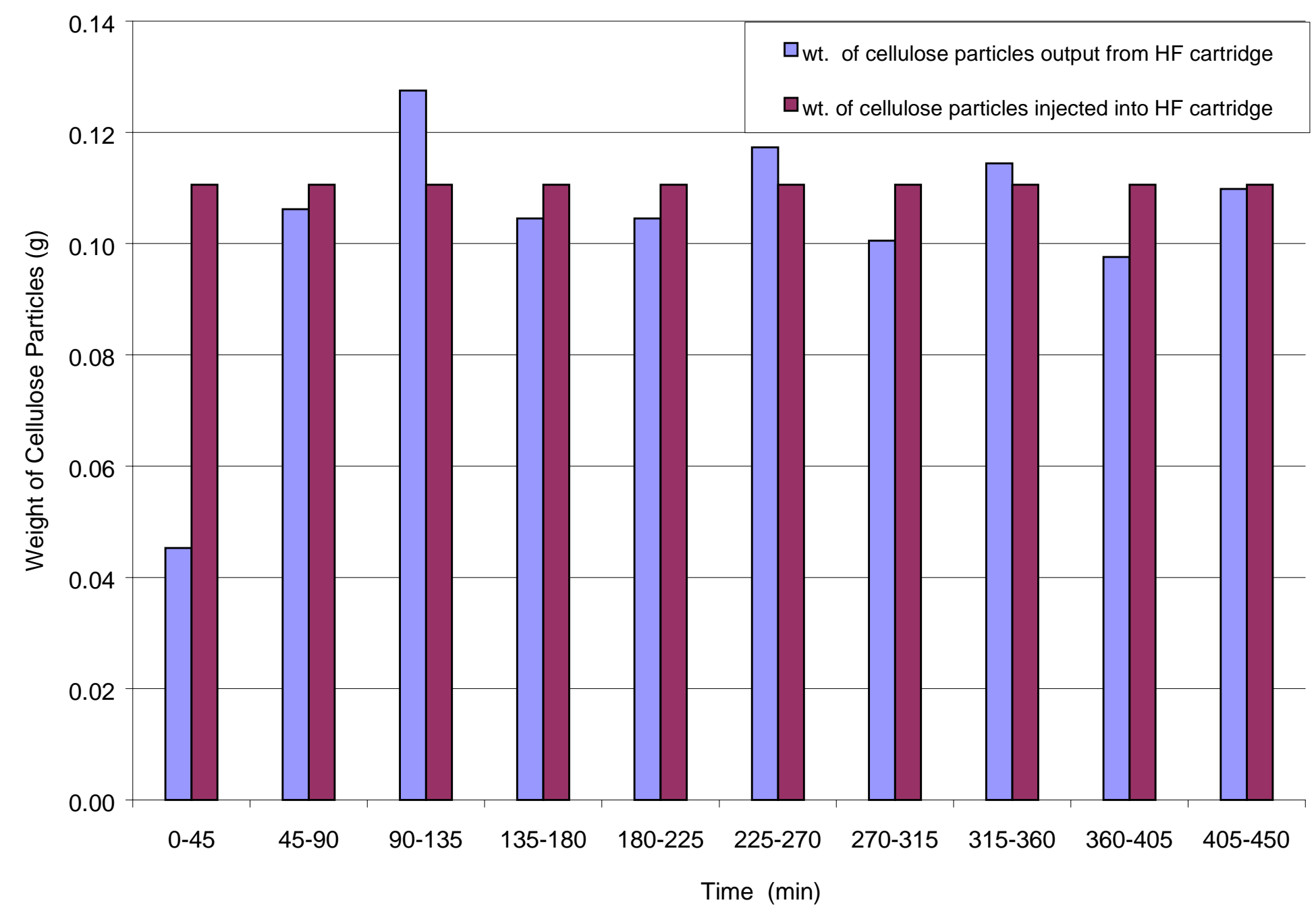

Figure B 5.4. Weight of Cellulose (Solka Floc 200FCC) vs. Time (250rpm, $0^{\circ}$, Retentate flow rate: $0.96 \mathrm{ml} / \mathrm{min}$ ) 


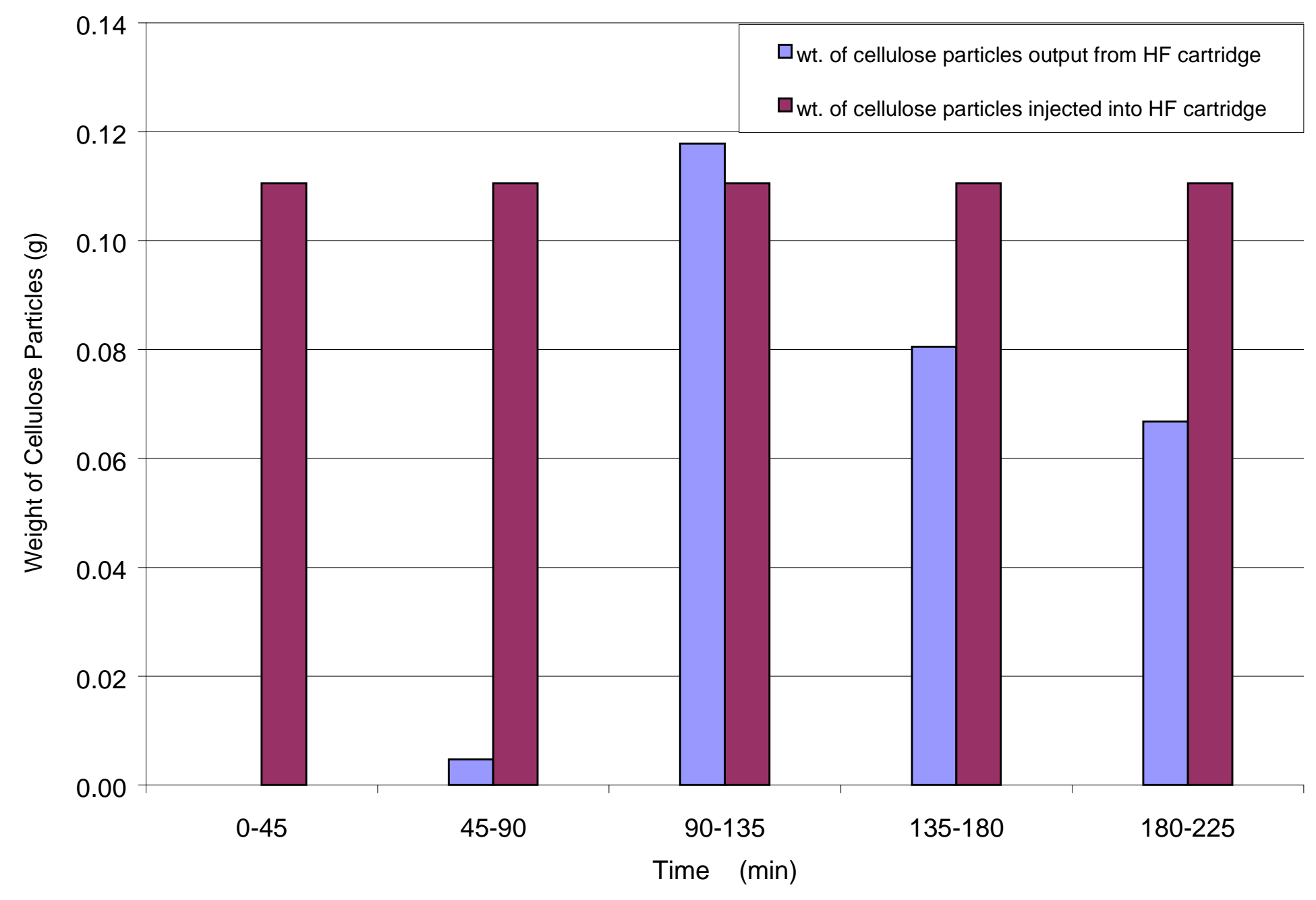

Figure B 5.5. Weight of Cellulose (Solka Floc 200FCC) vs. Time ( $0 \mathrm{rpm}, 46.7^{\circ}$, Retentate flow rate: $0.92 \mathrm{ml} / \mathrm{min}$ ) 


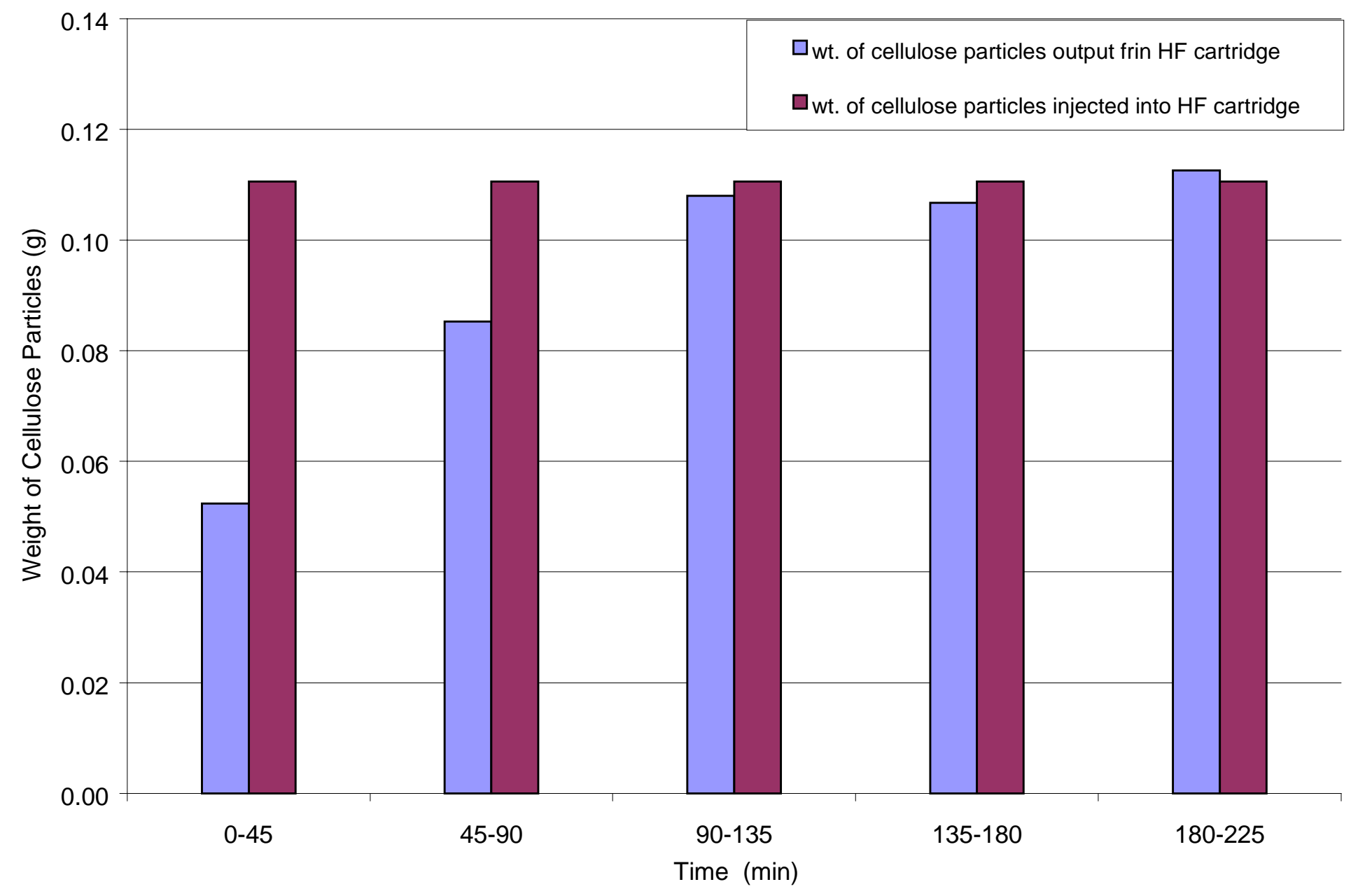

Figure B 5.6. Weight of Cellulose (Solka Floc 200FCC) vs. Time (150rpm, $46.7^{\circ}$, Retentate flow rate: $1.02 \mathrm{ml} / \mathrm{min}$ ) 


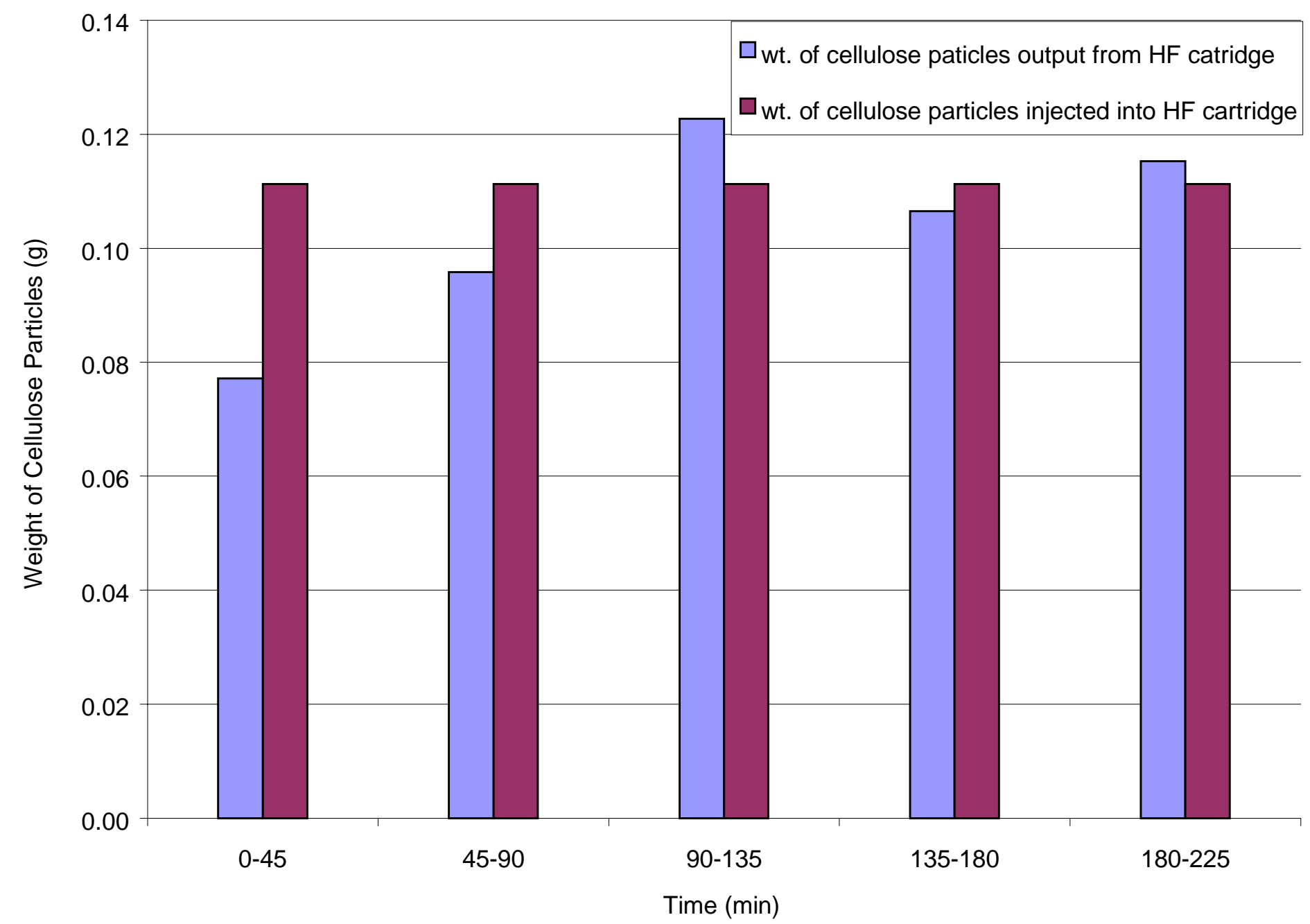

Figure B 5.7. Weight of Cellulose (Solka Floc $900 \mathrm{FCC}$ ) vs. Time (180rpm, $46.7^{0}$, Retentate flow rate: $1.05 \mathrm{ml} / \mathrm{min}$, Permeate flow rate: $0.26 \mathrm{ml} / \mathrm{min}$ ) 


\section{Appendix C. Data Collected for Continuous Hydrolysis in TMR}

Table C.1 Solka Floc 200FCC Continuous Hydrolysis --- no surfactant

$$
\begin{aligned}
& \mathrm{pH}=4.5 \\
& \mathrm{~T}=45^{\circ} \mathrm{C} \\
& \mathrm{v}_{\mathrm{r}}=1.11 \mathrm{ml} / \mathrm{min} \\
& \mathrm{S}_{\mathrm{R}}=1.70 \mathrm{mg} / \mathrm{ml} \\
& \mathrm{v}_{\mathrm{p}}=0.30 \mathrm{ml} / \mathrm{min} \\
& \mathrm{E}_{\mathrm{R}}=0.46 \mathrm{mg} / \mathrm{ml} \\
& \mathrm{t} \quad=276 \text { mins } \\
& \mathrm{S}_{\mathrm{R}} / \mathrm{E}_{\mathrm{R}}=0.27
\end{aligned}
$$

\begin{tabular}{|c|c|c|c|c|c|}
\hline $\begin{array}{c}\text { time } \\
(\mathrm{min})\end{array}$ & $\begin{array}{c}{ }^{*} \mathrm{C}_{\mathrm{gr}} \\
(\mathrm{mg} / \mathrm{ml})\end{array}$ & $\begin{array}{c}\mathrm{C}_{\mathrm{gp}} \\
(\mathrm{mg} / \mathrm{ml})\end{array}$ & $\begin{array}{c}\mathrm{C}_{\mathrm{gm}} \\
(\mathrm{mg} / \mathrm{ml})\end{array}$ & $\begin{array}{c}\text { substrate } \\
\text { conversion }\end{array}$ & $\begin{array}{c}\mathrm{C}_{\mathrm{bp}} \\
(\mathrm{mg} / \mathrm{ml})\end{array}$ \\
\hline 0 & 0.0000 & 0.0000 & 0.0000 & $0.00 \%$ & \\
\hline 15 & 0.0433 & 0.0055 & 0.0354 & $1.04 \%$ & \\
\hline 30 & 0.0700 & 0.0109 & 0.0576 & $2.74 \%$ & 0.0092 \\
\hline 45 & 0.0949 & 0.0196 & 0.0791 & $4.03 \%$ & \\
\hline 60 & 0.1059 & 0.0254 & 0.0890 & $4.96 \%$ & \\
\hline 90 & 0.1199 & 0.0348 & 0.1021 & $5.63 \%$ & 0.0107 \\
\hline 120 & 0.1229 & 0.0367 & 0.1048 & $6.10 \%$ & \\
\hline 150 & 0.1259 & 0.0430 & 0.1085 & $6.29 \%$ & 0.0129 \\
\hline 180 & 0.1299 & 0.0457 & 0.1123 & $6.51 \%$ & \\
\hline 210 & 0.1379 & 0.0522 & 0.1199 & $6.85 \%$ & 0.0140 \\
\hline 240 & 0.1239 & 0.0464 & 0.1077 & $6.71 \%$ & \\
\hline 270 & 0.1349 & 0.0473 & 0.1165 & $6.61 \%$ & 0.0140 \\
\hline SS value & $0.1324 * *$ & $0.0479 * *$ & 0.1147 & $6.76 \%$ & \\
\hline
\end{tabular}

* $\quad$ values after subtracting initial glucose concentration in the enzyme solution

** averaged value of a couple of steady state data points; the choice of these data points were decided based on the relevant curve in each corresponding Figure 
Table C.2 Solka Floc 200FCC Continuous Hydrolysis --- with Tergitol
$\mathrm{pH}=4.5$
$\mathrm{v}_{\mathrm{r}}=1.03 \mathrm{ml} / \mathrm{min}$
$\mathrm{S}_{\mathrm{R}}=1.86 \mathrm{mg} / \mathrm{ml}$
$\mathrm{T}=45^{\circ} \mathrm{C}$
$\mathrm{v}_{\mathrm{p}}=0.26 \mathrm{ml} / \mathrm{min}$
$\mathrm{E}_{\mathrm{R}}=0.44 \mathrm{mg} / \mathrm{ml}$
$\mathrm{t}=279$ mins
$\mathrm{F}_{\mathrm{R}}=0.85 \mathrm{mg} / \mathrm{ml}$
$\mathrm{S}_{\mathrm{R}} / \mathrm{E}_{\mathrm{R}}=0.24$
$\mathrm{F}_{\mathrm{R}} / \mathrm{E}_{\mathrm{R}}=0.46$

\begin{tabular}{|c|c|c|c|c|}
\hline $\begin{array}{c}\text { time } \\
(\mathrm{min})\end{array}$ & $\begin{array}{c}{ }^{*} \mathrm{C}_{\mathrm{gr}} \\
(\mathrm{mg} / \mathrm{ml})\end{array}$ & $\begin{array}{c}\mathrm{C}_{\mathrm{gp}} \\
(\mathrm{mg} / \mathrm{ml})\end{array}$ & $\begin{array}{c}\mathrm{C}_{\mathrm{gm}} \\
(\mathrm{mg} / \mathrm{ml})\end{array}$ & $\begin{array}{c}\text { substrate } \\
\text { conversion }\end{array}$ \\
\hline 0 & 0.0000 & 0.0000 & 0.0000 & $0.00 \%$ \\
\hline 15 & 0.0410 & 0.0000 & 0.0328 & $0.88 \%$ \\
\hline 30 & 0.1032 & 0.0031 & 0.0832 & $3.12 \%$ \\
\hline 45 & 0.1222 & 0.0171 & 0.1012 & $4.96 \%$ \\
\hline 60 & 0.1372 & 0.0259 & 0.1150 & $5.82 \%$ \\
\hline 90 & 0.1522 & 0.0290 & 0.1276 & $6.53 \%$ \\
\hline 120 & 0.1722 & 0.0406 & 0.1460 & $7.36 \%$ \\
\hline 150 & 0.1762 & 0.0418 & 0.1494 & $7.95 \%$ \\
\hline 180 & 0.1812 & 0.0348 & 0.1520 & $8.11 \%$ \\
\hline 210 & 0.1812 & 0.0385 & 0.1528 & $8.20 \%$ \\
\hline 240 & 0.1782 & 0.0377 & 0.1502 & $8.15 \%$ \\
\hline 270 & 0.1812 & 0.0334 & 0.1517 & $8.13 \%$ \\
\hline SS value & $0.1796 * *$ & $0.0403 * *$ & 0.1518 & $8.17 \%$ \\
\hline
\end{tabular}

* $\quad$ values after subtracting initial glucose concentration in the enzyme solution

** averaged value of a couple of steady state data points; the choice of these data points were decided based on the relevant curve in each corresponding Figure 
Table C.3 Solka Floc 200FCC Continuous Hydrolysis --- with Pluronic

$$
\begin{aligned}
& \mathrm{pH}=4.5 \\
& \mathrm{~T}=45^{\circ} \mathrm{C} \\
& \mathrm{t}=423 \text { mins }
\end{aligned}
$$

$$
\begin{aligned}
& \mathrm{v}_{\mathrm{r}}=1.09 \mathrm{ml} / \mathrm{min} \\
& \mathrm{v}_{\mathrm{p}}=0.24 \mathrm{ml} / \mathrm{min}
\end{aligned}
$$$$
\mathrm{S}_{\mathrm{R}}=1.80 \mathrm{mg} / \mathrm{ml}
$$$$
\mathrm{E}_{\mathrm{R}}=0.45 \mathrm{mg} / \mathrm{ml}
$$$$
\mathrm{F}_{\mathrm{R}}=0.85 \mathrm{mg} / \mathrm{ml}
$$$$
\mathrm{S}_{\mathrm{R}} / \mathrm{E}_{\mathrm{R}}=0.25
$$$$
\mathrm{F}_{\mathrm{R}} / \mathrm{E}_{\mathrm{R}}=0.47
$$

\begin{tabular}{|c|c|c|c|c|}
\hline $\begin{array}{c}\text { time } \\
(\mathrm{min})\end{array}$ & $\begin{array}{c}{ }^{*} \mathrm{C}_{\mathrm{gr}} \\
(\mathrm{mg} / \mathrm{ml})\end{array}$ & $\begin{array}{c}\mathrm{C}_{\mathrm{gp}} \\
(\mathrm{mg} / \mathrm{ml})\end{array}$ & $\begin{array}{c}\mathrm{C}_{\mathrm{gm}} \\
(\mathrm{mg} / \mathrm{ml})\end{array}$ & $\begin{array}{c}\text { substrate } \\
\text { conversion }\end{array}$ \\
\hline 0 & 0.0000 & 0.0000 & 0.0000 & $0.00 \%$ \\
\hline 15 & 0.0543 & 0.0000 & 0.0443 & $1.23 \%$ \\
\hline 30 & 0.1010 & 0.0020 & 0.0828 & $3.53 \%$ \\
\hline 45 & 0.1240 & 0.0127 & 0.1036 & $5.18 \%$ \\
\hline 60 & 0.1400 & 0.0243 & 0.1188 & $6.18 \%$ \\
\hline 90 & 0.1610 & 0.0466 & 0.1400 & $7.19 \%$ \\
\hline 120 & 0.1750 & 0.0605 & 0.1540 & $8.17 \%$ \\
\hline 150 & 0.1650 & 0.0685 & 0.1473 & $8.37 \%$ \\
\hline 180 & 0.1510 & 0.0653 & 0.1353 & $7.85 \%$ \\
\hline 210 & 0.1540 & 0.0703 & 0.1386 & $7.61 \%$ \\
\hline 240 & 0.1640 & 0.0856 & 0.1496 & $8.01 \%$ \\
\hline 270 & 0.1770 & 0.0734 & 0.1580 & $8.54 \%$ \\
\hline 300 & 0.1480 & 0.0745 & 0.1345 & $8.13 \%$ \\
\hline 330 & 0.1570 & 0.0712 & 0.1413 & $7.66 \%$ \\
\hline 360 & 0.1560 & 0.0664 & 0.1396 & $7.80 \%$ \\
\hline 390 & 0.1640 & 0.0667 & 0.1462 & $7.94 \%$ \\
\hline 420 & 0.1660 & 0.0741 & 0.1491 & $8.20 \%$ \\
\hline SS value & $0.1650 * *$ & $0.0750 * *$ & 0.1485 & $8.25 \%$ \\
\hline & & & & \\
\hline
\end{tabular}

* values after subtracting initial glucose concentration in the enzyme solution averaged value of a couple of steady state data points; the choice of these data points were decided based on the relevant curve in each corresponding Figure 
Table C.4 Alkaline Oxidation Yellow Poplar Continuous Hydrolysis --- no surfactant

$$
\begin{array}{lll}
\mathrm{pH}=4.5 & \mathrm{v}_{\mathrm{r}}=1.09 \mathrm{ml} / \mathrm{min} & \mathrm{S}_{\mathrm{R}}=1.77 \mathrm{mg} / \mathrm{ml} \\
\mathrm{T}=45^{\circ} \mathrm{C} & \mathrm{v}_{\mathrm{p}}=0.26 \mathrm{ml} / \mathrm{min} & \mathrm{E}_{\mathrm{R}}=0.45 \mathrm{mg} / \mathrm{ml} \\
\mathrm{t}=426 \mathrm{mins} & & \mathrm{S}_{\mathrm{R}} / \mathrm{E}_{\mathrm{R}}=0.26
\end{array}
$$

\begin{tabular}{|c|c|c|c|c|c|}
\hline $\begin{array}{c}\text { time } \\
(\mathrm{min})\end{array}$ & $\begin{array}{c}{ }^{*} \mathrm{C}_{\mathrm{gr}} \\
(\mathrm{mg} / \mathrm{ml})\end{array}$ & $\begin{array}{c}\mathrm{C}_{\mathrm{gp}} \\
(\mathrm{mg} / \mathrm{ml})\end{array}$ & $\begin{array}{c}\mathrm{C}_{\mathrm{gm}} \\
(\mathrm{mg} / \mathrm{ml})\end{array}$ & $\begin{array}{c}\text { substrate } \\
\text { conversion }\end{array}$ & $\begin{array}{c}\mathrm{C}_{\mathrm{bp}} \\
(\mathrm{mg} / \mathrm{ml})\end{array}$ \\
\hline 0 & 0.0000 & 0.0000 & 0.0000 & $0.00 \%$ & \\
\hline 15 & 0.0125 & 0.0021 & 0.0105 & $0.30 \%$ & \\
\hline 30 & 0.0163 & 0.0060 & 0.0143 & $0.70 \%$ & 0.0048 \\
\hline 45 & 0.0200 & 0.0079 & 0.0176 & $0.90 \%$ & \\
\hline 60 & 0.0232 & 0.0105 & 0.0207 & $1.08 \%$ & \\
\hline 90 & 0.0292 & 0.0134 & 0.0261 & $1.32 \%$ & 0.0077 \\
\hline 120 & 0.0346 & 0.0177 & 0.0313 & $1.62 \%$ & \\
\hline 150 & 0.0377 & 0.0207 & 0.0344 & $1.85 \%$ & 0.0067 \\
\hline 180 & 0.0388 & 0.0220 & 0.0355 & $1.97 \%$ & \\
\hline 210 & 0.0400 & 0.0244 & 0.0369 & $2.04 \%$ & 0.0086 \\
\hline 240 & 0.0393 & 0.0250 & 0.0365 & $2.07 \%$ & \\
\hline 270 & 0.0387 & 0.0245 & 0.0359 & $2.04 \%$ & 0.0072 \\
\hline 300 & 0.0392 & 0.0273 & 0.0369 & $2.05 \%$ & \\
\hline 330 & 0.0382 & 0.0260 & 0.0358 & $2.05 \%$ & 0.0089 \\
\hline 360 & 0.0406 & 0.0263 & 0.0378 & $2.08 \%$ & \\
\hline 390 & 0.0410 & 0.0273 & 0.0383 & $2.15 \%$ & 0.0084 \\
\hline 420 & 0.0372 & 0.0269 & 0.0352 & $2.07 \%$ & \\
\hline SS value & $0.0400 * *$ & $0.0268 * *$ & 0.0374 & $2.11 \%$ & \\
\hline
\end{tabular}

* values after subtracting initial glucose concentration in the enzyme solution

** averaged value of a couple of steady state data points; the choice of these data points were decided based on the relevant curve in each corresponding Figure 
Table C.5 Alkaline Oxidation Yellow Poplar Continuous Hydrolysis --- with Tergitol

$$
\begin{array}{lll}
\mathrm{pH}=4.5 & \mathrm{v}_{\mathrm{r}}=1.08 \mathrm{ml} / \mathrm{min} & \mathrm{S}_{\mathrm{R}}=1.82 \mathrm{mg} / \mathrm{ml} \\
\mathrm{T}=45^{\circ} \mathrm{C} & \mathrm{v}_{\mathrm{p}}=0.24 \mathrm{ml} / \mathrm{min} & \mathrm{E}_{\mathrm{R}}=0.45 \mathrm{mg} / \mathrm{ml} \\
\mathrm{t}=426 \mathrm{mins} & & \mathrm{F}_{\mathrm{R}}=0.85 \mathrm{mg} / \mathrm{ml} \\
& & \mathrm{S}_{\mathrm{R}} / \mathrm{E}_{\mathrm{R}}=0.25 \\
& & \mathrm{~F}_{\mathrm{R}} / \mathrm{E}_{\mathrm{R}}=0.47
\end{array}
$$

\begin{tabular}{|c|c|c|c|c|c|}
\hline $\begin{array}{c}\text { time } \\
(\mathrm{min})\end{array}$ & $\begin{array}{c}{ }^{*} \mathrm{C}_{\mathrm{gr}} \\
(\mathrm{mg} / \mathrm{ml})\end{array}$ & $\begin{array}{c}\mathrm{C}_{\mathrm{gp}} \\
(\mathrm{mg} / \mathrm{ml})\end{array}$ & $\begin{array}{c}\mathrm{C}_{\mathrm{gm}} \\
(\mathrm{mg} / \mathrm{ml})\end{array}$ & $\begin{array}{c}\text { substrate } \\
\text { conversion }\end{array}$ & $\begin{array}{c}\mathrm{C}_{\mathrm{bp}} \\
(\mathrm{mg} / \mathrm{ml})\end{array}$ \\
\hline 0 & 0.0000 & 0.0000 & 0.0000 & $0.00 \%$ & \\
\hline 15 & 0.0209 & 0.0000 & 0.0171 & $0.47 \%$ & \\
\hline 30 & 0.0248 & 0.0081 & 0.0218 & $1.07 \%$ & 0.0100 \\
\hline 45 & 0.0267 & 0.0126 & 0.0242 & $1.27 \%$ & \\
\hline 60 & 0.0290 & 0.0135 & 0.0262 & $1.39 \%$ & \\
\hline 90 & 0.0311 & 0.0256 & 0.0301 & $1.55 \%$ & 0.0093 \\
\hline 120 & 0.0336 & 0.0250 & 0.0321 & $1.71 \%$ & \\
\hline 150 & 0.0384 & 0.0311 & 0.0371 & $1.90 \%$ & 0.0163 \\
\hline 180 & 0.0404 & 0.0361 & 0.0396 & $2.11 \%$ & \\
\hline 210 & 0.0474 & 0.0337 & 0.0449 & $2.33 \%$ & 0.0135 \\
\hline 240 & 0.0461 & 0.0336 & 0.0438 & $2.45 \%$ & \\
\hline 270 & 0.0451 & 0.0366 & 0.0436 & $2.41 \%$ & 0.0122 \\
\hline 300 & 0.0453 & 0.0388 & 0.0441 & $2.42 \%$ & \\
\hline 330 & 0.0456 & 0.0323 & 0.0432 & $2.41 \%$ & 0.0138 \\
\hline 360 & 0.0488 & 0.0318 & 0.0457 & $2.45 \%$ & \\
\hline 390 & 0.0458 & 0.0347 & 0.0438 & $2.47 \%$ & 0.0132 \\
\hline 420 & 0.0449 & 0.0336 & 0.0429 & $2.39 \%$ & \\
\hline SS value & $0.0468 * *$ & $0.0347 * *$ & 0.0446 & $2.45 \%$ & \\
\hline
\end{tabular}

* values after subtracting initial glucose concentration in the enzyme solution ** averaged value of a couple of steady state data points; the choice of these data points were decided based on the relevant curve in each corresponding Figure 
Table C.6 Alkaline Oxidation Yellow Poplar Continuous Hydrolysis --- with Pluronic

$$
\begin{array}{lll}
\mathrm{pH}=4.5 & \mathrm{v}_{\mathrm{r}}=1.07 \mathrm{ml} / \mathrm{min} & \mathrm{S}_{\mathrm{R}}=1.82 \mathrm{mg} / \mathrm{ml} \\
\mathrm{T}=45^{\circ} \mathrm{C} & \mathrm{v}_{\mathrm{p}}=0.24 \mathrm{ml} / \mathrm{min} & \mathrm{E}_{\mathrm{R}}=0.45 \mathrm{mg} / \mathrm{ml} \\
\mathrm{t}=396 \mathrm{mins} & & \mathrm{F}_{\mathrm{R}}=0.85 \mathrm{mg} / \mathrm{ml} \\
& & \mathrm{S}_{\mathrm{R}} / \mathrm{E}_{\mathrm{R}}=0.25 \\
& & \mathrm{~F}_{\mathrm{R}} / \mathrm{E}_{\mathrm{R}}=0.47
\end{array}
$$

\begin{tabular}{|c|c|c|c|c|c|}
\hline $\begin{array}{c}\text { time } \\
(\mathrm{min})\end{array}$ & $\begin{array}{c}{ }^{*} \mathrm{C}_{\mathrm{gr}} \\
(\mathrm{mg} / \mathrm{ml})\end{array}$ & $\begin{array}{c}\mathrm{C}_{\mathrm{gp}} \\
(\mathrm{mg} / \mathrm{ml})\end{array}$ & $\begin{array}{c}\mathrm{C}_{\mathrm{gm}} \\
(\mathrm{mg} / \mathrm{ml})\end{array}$ & $\begin{array}{c}\text { substrate } \\
\text { conversion }\end{array}$ & $\begin{array}{c}\mathrm{C}_{\mathrm{bp}} \\
(\mathrm{mg} / \mathrm{ml})\end{array}$ \\
\hline 0 & 0.0000 & 0.0000 & 0.0000 & $0.00 \%$ & \\
\hline 15 & 0.0159 & 0.0002 & 0.0130 & $0.36 \%$ & \\
\hline 30 & 0.0247 & 0.0067 & 0.0213 & $0.94 \%$ & 0.0093 \\
\hline 45 & 0.0276 & 0.0103 & 0.0244 & $1.25 \%$ & \\
\hline 60 & 0.0297 & 0.0147 & 0.0269 & $1.41 \%$ & \\
\hline 90 & 0.0339 & 0.0237 & 0.0320 & $1.61 \%$ & 0.0086 \\
\hline 120 & 0.0318 & 0.0276 & 0.0310 & $1.73 \%$ & \\
\hline 150 & 0.0384 & 0.0304 & 0.0369 & $1.86 \%$ & 0.0137 \\
\hline 180 & 0.0436 & 0.0306 & 0.0412 & $2.14 \%$ & \\
\hline 210 & 0.0455 & 0.0315 & 0.0429 & $2.30 \%$ & 0.0127 \\
\hline 240 & 0.0460 & 0.0350 & 0.0439 & $2.38 \%$ & \\
\hline 270 & 0.0448 & 0.0354 & 0.0430 & $2.38 \%$ & 0.0114 \\
\hline 300 & 0.0503 & 0.0338 & 0.0472 & $2.47 \%$ & \\
\hline 330 & 0.0494 & 0.0366 & 0.0470 & $2.58 \%$ & 0.0117 \\
\hline 360 & 0.0509 & 0.0333 & 0.0476 & $2.59 \%$ & \\
\hline 390 & 0.0477 & 0.0326 & 0.0449 & $2.54 \%$ & 0.0106 \\
\hline SS value & $0.0502 * *$ & $0.0346 * *$ & 0.0473 & $2.59 \%$ & \\
\hline
\end{tabular}

* $\quad$ values after subtracting initial glucose concentration in the enzyme solution ** averaged value of a couple of steady state data points; the choice of these data points were decided based on the relevant curve in each corresponding Figure 
Table C.7 Ammonia Steeping Yellow Poplar Continuous Hydrolysis --- no surfactant

$$
\begin{array}{lll}
\mathrm{pH}=4.5 & \mathrm{v}_{\mathrm{r}}=1.11 \mathrm{ml} / \mathrm{min} & \mathrm{S}_{\mathrm{R}}=1.72 \mathrm{mg} / \mathrm{ml} \\
\mathrm{T}=45^{\circ} \mathrm{C} & \mathrm{v}_{\mathrm{p}}=0.27 \mathrm{ml} / \mathrm{min} & \mathrm{E}_{\mathrm{R}}=0.46 \mathrm{mg} / \mathrm{ml} \\
\mathrm{t}=369 \mathrm{mins} & & \mathrm{S}_{\mathrm{R}} / \mathrm{E}_{\mathrm{R}}=0.26
\end{array}
$$

\begin{tabular}{|c|c|c|c|c|c|}
\hline $\begin{array}{c}\text { time } \\
(\mathrm{min})\end{array}$ & $\begin{array}{c}{ }^{*} \mathrm{C}_{\mathrm{gr}} \\
(\mathrm{mg} / \mathrm{ml})\end{array}$ & $\begin{array}{c}\mathrm{C}_{\mathrm{gp}} \\
(\mathrm{mg} / \mathrm{ml})\end{array}$ & $\begin{array}{c}\mathrm{C}_{\mathrm{gm}} \\
(\mathrm{mg} / \mathrm{ml})\end{array}$ & $\begin{array}{c}\text { substrate } \\
\text { conversion }\end{array}$ & $\begin{array}{c}\mathrm{C}_{\mathrm{bp}} \\
(\mathrm{mg} / \mathrm{ml})\end{array}$ \\
\hline 0 & 0.0000 & 0.0000 & 0.0000 & $0.00 \%$ & \\
\hline 15 & 0.0090 & 0.0000 & 0.0073 & $0.21 \%$ & \\
\hline 30 & 0.0134 & 0.0013 & 0.0111 & $0.53 \%$ & 0.0033 \\
\hline 45 & 0.0138 & 0.0033 & 0.0118 & $0.66 \%$ & \\
\hline 60 & 0.0160 & 0.0057 & 0.0140 & $0.75 \%$ & \\
\hline 90 & 0.0183 & 0.0109 & 0.0169 & $0.90 \%$ & 0.0044 \\
\hline 120 & 0.0184 & 0.0119 & 0.0171 & $0.99 \%$ & \\
\hline 150 & 0.0191 & 0.0170 & 0.0187 & $1.04 \%$ & 0.0061 \\
\hline 180 & 0.0193 & 0.0182 & 0.0191 & $1.10 \%$ & \\
\hline 210 & 0.0202 & 0.0196 & 0.0201 & $1.14 \%$ & 0.0070 \\
\hline 240 & 0.0215 & 0.0213 & 0.0215 & $1.21 \%$ & \\
\hline 270 & 0.0213 & 0.0215 & 0.0214 & $1.25 \%$ & 0.0097 \\
\hline 300 & 0.0215 & 0.0211 & 0.0214 & $1.24 \%$ & \\
\hline 330 & 0.0210 & 0.0205 & 0.0209 & $1.23 \%$ & 0.0079 \\
\hline 360 & 0.0202 & 0.0204 & 0.0203 & $1.20 \%$ & \\
\hline SS value & $0.0215^{* *}$ & $0.0213^{* *}$ & 0.0214 & $1.25 \%$ & \\
\hline
\end{tabular}

* values after subtracting initial glucose concentration in the enzyme solution averaged value of a couple of steady state data points; the choice of these data points were decided based on the relevant curve in each corresponding Figure 
Table C.8 Ammonia Steeping Yellow Poplar Continuous Hydrolysis --- with Tergitol

$$
\begin{array}{lll}
\mathrm{pH}=4.5 & \mathrm{v}_{\mathrm{r}}=1.00 \mathrm{ml} / \mathrm{min} & \mathrm{S}_{\mathrm{R}}=1.88 \mathrm{mg} / \mathrm{ml} \\
\mathrm{T}=45^{\circ} \mathrm{C} & \mathrm{v}_{\mathrm{p}}=0.26 \mathrm{ml} / \mathrm{min} & \mathrm{E}_{\mathrm{R}}=0.44 \mathrm{mg} / \mathrm{ml} \\
\mathrm{t}=339 \mathrm{mins} & & \mathrm{F}_{\mathrm{R}}=0.85 \mathrm{mg} / \mathrm{ml} \\
& & \mathrm{S}_{\mathrm{R}} / \mathrm{E}_{\mathrm{R}}=0.24 \\
& & \mathrm{~F}_{\mathrm{R}} / \mathrm{E}_{\mathrm{R}}=0.45
\end{array}
$$

\begin{tabular}{|c|c|c|c|c|c|}
\hline $\begin{array}{c}\text { time } \\
(\mathrm{min})\end{array}$ & $\begin{array}{c}{ }^{*} \mathrm{C}_{\mathrm{gr}} \\
(\mathrm{mg} / \mathrm{ml})\end{array}$ & $\begin{array}{c}\mathrm{C}_{\mathrm{gp}} \\
(\mathrm{mg} / \mathrm{ml})\end{array}$ & $\begin{array}{c}\mathrm{C}_{\mathrm{gm}} \\
(\mathrm{mg} / \mathrm{ml})\end{array}$ & $\begin{array}{c}\text { substrate } \\
\text { conversion }\end{array}$ & $\begin{array}{c}\mathrm{C}_{\mathrm{bp}} \\
(\mathrm{mg} / \mathrm{ml})\end{array}$ \\
\hline 0 & 0.0000 & 0.0000 & 0.0000 & $0.00 \%$ & \\
\hline 15 & 0.0133 & 0.0032 & 0.0112 & $0.30 \%$ & \\
\hline 30 & 0.0178 & 0.0085 & 0.0159 & $0.72 \%$ & 0.0155 \\
\hline 45 & 0.0210 & 0.0139 & 0.0195 & $0.94 \%$ & \\
\hline 60 & 0.0224 & 0.0172 & 0.0213 & $1.09 \%$ & \\
\hline 90 & 0.0259 & 0.0216 & 0.0250 & $1.24 \%$ & 0.0192 \\
\hline 120 & 0.0257 & 0.0259 & 0.0258 & $1.35 \%$ & \\
\hline 150 & 0.0266 & 0.0259 & 0.0265 & $1.39 \%$ & 0.0216 \\
\hline 180 & 0.0287 & 0.0259 & 0.0281 & $1.46 \%$ & \\
\hline 210 & 0.0284 & 0.0277 & 0.0283 & $1.50 \%$ & 0.0174 \\
\hline 240 & 0.0298 & 0.0271 & 0.0293 & $1.53 \%$ & \\
\hline 270 & 0.0294 & 0.0269 & 0.0289 & $1.55 \%$ & 0.0170 \\
\hline 300 & 0.0298 & 0.0282 & 0.0295 & $1.56 \%$ & \\
\hline 330 & 0.0294 & 0.0265 & 0.0288 & $1.55 \%$ & 0.0168 \\
\hline SS value & $0.0296 * *$ & $0.0272 * *$ & 0.0291 & $1.55 \%$ & \\
\hline
\end{tabular}

* values after subtracting initial glucose concentration in the enzyme solution

** averaged value of a couple of steady state data points; the choice of these data points were decided based on the relevant curve in each corresponding Figure 
Table C.9 Ammonia Steeping Yellow Poplar Continuous Hydrolysis --- with Pluronic

$$
\begin{array}{lll}
\mathrm{pH}=4.5 & \mathrm{v}_{\mathrm{r}}=1.09 \mathrm{ml} / \mathrm{min} & \mathrm{S}_{\mathrm{R}}=1.75 \mathrm{mg} / \mathrm{ml} \\
\mathrm{T}=45^{\circ} \mathrm{C} & \mathrm{v}_{\mathrm{p}}=0.27 \mathrm{ml} / \mathrm{min} & \mathrm{E}_{\mathrm{R}}=0.45 \mathrm{mg} / \mathrm{ml} \\
\mathrm{t}=366 \mathrm{mins} & & \mathrm{F}_{\mathrm{R}}=0.85 \mathrm{mg} / \mathrm{ml} \\
& & \mathrm{S}_{\mathrm{R}} / \mathrm{E}_{\mathrm{R}}=0.26 \\
& & \mathrm{~F}_{\mathrm{R}} / \mathrm{E}_{\mathrm{R}}=0.49
\end{array}
$$

\begin{tabular}{|c|c|c|c|c|c|}
\hline $\begin{array}{c}\text { time } \\
(\mathrm{min})\end{array}$ & $\begin{array}{c}{ }^{*} \mathrm{C}_{\mathrm{gr}} \\
(\mathrm{mg} / \mathrm{ml})\end{array}$ & $\begin{array}{c}\mathrm{C}_{\mathrm{gp}} \\
(\mathrm{mg} / \mathrm{ml})\end{array}$ & $\begin{array}{c}\mathrm{C}_{\mathrm{gm}} \\
(\mathrm{mg} / \mathrm{ml})\end{array}$ & $\begin{array}{c}\text { substrate } \\
\text { conversion }\end{array}$ & $\begin{array}{c}\mathrm{C}_{\mathrm{bp}} \\
(\mathrm{mg} / \mathrm{ml})\end{array}$ \\
\hline 0 & 0.0000 & 0.0000 & 0.0000 & $0.00 \%$ & \\
\hline 15 & 0.0120 & 0.0008 & 0.0098 & $0.28 \%$ & \\
\hline 30 & 0.0171 & 0.0070 & 0.0151 & $0.71 \%$ & 0.0107 \\
\hline 45 & 0.0185 & 0.0094 & 0.0167 & $0.91 \%$ & \\
\hline 60 & 0.0214 & 0.0131 & 0.0198 & $1.05 \%$ & \\
\hline 90 & 0.0253 & 0.0163 & 0.0236 & $1.24 \%$ & 0.0093 \\
\hline 120 & 0.0236 & 0.0175 & 0.0224 & $1.32 \%$ & \\
\hline 150 & 0.0255 & 0.0184 & 0.0241 & $1.33 \%$ & 0.0114 \\
\hline 180 & 0.0251 & 0.0188 & 0.0239 & $1.37 \%$ & \\
\hline 210 & 0.0258 & 0.0215 & 0.0250 & $1.40 \%$ & 0.0144 \\
\hline 240 & 0.0264 & 0.0217 & 0.0255 & $1.44 \%$ & \\
\hline 270 & 0.0265 & 0.0225 & 0.0257 & $1.47 \%$ & 0.0133 \\
\hline 300 & 0.0251 & 0.0227 & 0.0246 & $1.44 \%$ & \\
\hline 330 & 0.0274 & 0.0208 & 0.0261 & $1.45 \%$ & 0.0132 \\
\hline 360 & 0.0266 & 0.0223 & 0.0258 & $1.49 \%$ & \\
\hline SS value & $0.0270 * *$ & $0.0225 * *$ & 0.0261 & $1.50 \%$ & \\
\hline
\end{tabular}

* $\quad$ values after subtracting initial glucose concentration in the enzyme solution

** averaged value of a couple of steady state data points; the choice of these data points were decided based on the relevant curve in each corresponding Figure 
Table C.10 Alkaline Oxidation Corn Cob Continuous Hydrolysis --- no surfactant

$$
\begin{aligned}
& \mathrm{pH}=4.5 \\
& \mathrm{~T}=45^{\circ} \mathrm{C} \\
& \mathrm{v}_{\mathrm{r}}=1.09 \mathrm{ml} / \mathrm{min} \\
& \mathrm{S}_{\mathrm{R}}=1.71 \mathrm{mg} / \mathrm{ml} \\
& \mathrm{t}=366 \mathrm{mins} \\
& \mathrm{v}_{\mathrm{p}}=0.25 \mathrm{ml} / \mathrm{min} \\
& \mathrm{E}_{\mathrm{R}}=0.45 \mathrm{mg} / \mathrm{ml} \\
& \mathrm{S}_{\mathrm{R}} / \mathrm{E}_{\mathrm{R}}=0.26
\end{aligned}
$$

\begin{tabular}{|c|c|c|c|c|c|}
\hline $\begin{array}{c}\text { time } \\
(\mathrm{min})\end{array}$ & $\begin{array}{c}{ }^{*} \mathrm{C}_{\mathrm{gr}} \\
(\mathrm{mg} / \mathrm{ml})\end{array}$ & $\begin{array}{c}\mathrm{C}_{\mathrm{gp}} \\
(\mathrm{mg} / \mathrm{ml})\end{array}$ & $\begin{array}{c}\mathrm{C}_{\mathrm{gm}} \\
(\mathrm{mg} / \mathrm{ml})\end{array}$ & $\begin{array}{c}\text { substrate } \\
\text { conversion }\end{array}$ & $\begin{array}{c}\mathrm{C}_{\mathrm{bp}} \\
(\mathrm{mg} / \mathrm{ml})\end{array}$ \\
\hline 0 & 0.0000 & 0.0000 & 0.0000 & $0.00 \%$ & \\
\hline 15 & 0.0332 & 0.0000 & 0.0270 & $0.79 \%$ & \\
\hline 30 & 0.0478 & 0.0055 & 0.0399 & $1.96 \%$ & 0.0056 \\
\hline 45 & 0.0572 & 0.0123 & 0.0488 & $2.60 \%$ & \\
\hline 60 & 0.0680 & 0.0184 & 0.0587 & $3.15 \%$ & \\
\hline 90 & 0.0786 & 0.0340 & 0.0702 & $3.78 \%$ & 0.0175 \\
\hline 120 & 0.0919 & 0.0481 & 0.0837 & $4.51 \%$ & \\
\hline 150 & 0.1017 & 0.0575 & 0.0934 & $5.19 \%$ & 0.0303 \\
\hline 180 & 0.1147 & 0.0643 & 0.1052 & $5.82 \%$ & \\
\hline 210 & 0.1047 & 0.0668 & 0.0976 & $5.95 \%$ & 0.0316 \\
\hline 240 & 0.1047 & 0.0751 & 0.0992 & $5.77 \%$ & \\
\hline 270 & 0.1087 & 0.0781 & 0.1030 & $5.93 \%$ & 0.0313 \\
\hline 300 & 0.1147 & 0.0851 & 0.1092 & $6.22 \%$ & \\
\hline 330 & 0.0997 & 0.0812 & 0.0962 & $6.02 \%$ & 0.0338 \\
\hline 360 & 0.1097 & 0.0845 & 0.1050 & $5.90 \%$ & \\
\hline SS value & $0.1092 * *$ & $0.0812 * *$ & 0.1040 & $6.10 \%$ & \\
\hline
\end{tabular}

* $\quad$ values after subtracting initial glucose concentration in the enzyme solution averaged value of a couple of steady state data points; the choice of these data points were decided based on the relevant curve in each corresponding Figure 
Table C.11 Alkaline Oxidation Corn Cob Continuous Hydrolysis --- with Tergitol

$$
\begin{array}{lll}
\mathrm{pH}=4.5 & \mathrm{v}_{\mathrm{r}}=1.12 \mathrm{ml} / \mathrm{min} & \mathrm{S}_{\mathrm{R}}=1.68 \mathrm{mg} / \mathrm{ml} \\
\mathrm{T}=45^{\circ} \mathrm{C} & \mathrm{v}_{\mathrm{p}}=0.27 \mathrm{ml} / \mathrm{min} & \mathrm{E}_{\mathrm{R}}=0.46 \mathrm{mg} / \mathrm{ml} \\
\mathrm{t}=429 \mathrm{mins} & & \mathrm{F}_{\mathrm{R}}=0.85 \mathrm{mg} / \mathrm{ml} \\
& & \mathrm{S}_{\mathrm{R}} / \mathrm{E}_{\mathrm{R}}=0.27 \\
& & \mathrm{~F}_{\mathrm{R}} / \mathrm{E}_{\mathrm{R}}=0.51
\end{array}
$$

\begin{tabular}{|c|c|c|c|c|c|}
\hline $\begin{array}{c}\text { time } \\
(\mathrm{min})\end{array}$ & $\begin{array}{c}{ }^{*} \mathrm{C}_{\mathrm{gr}} \\
(\mathrm{mg} / \mathrm{ml})\end{array}$ & $\begin{array}{c}\mathrm{C}_{\mathrm{gp}} \\
(\mathrm{mg} / \mathrm{ml})\end{array}$ & $\begin{array}{c}\mathrm{C}_{\mathrm{gm}} \\
(\mathrm{mg} / \mathrm{ml})\end{array}$ & $\begin{array}{c}\text { substrate } \\
\text { conversion }\end{array}$ & $\begin{array}{c}\mathrm{C}_{\mathrm{bp}} \\
(\mathrm{mg} / \mathrm{ml})\end{array}$ \\
\hline 0 & 0.0000 & 0.0000 & 0.0000 & $0.00 \%$ & \\
\hline 15 & 0.0588 & 0.0007 & 0.0474 & $1.41 \%$ & \\
\hline 30 & 0.0828 & 0.0125 & 0.0690 & $3.47 \%$ & 0.0172 \\
\hline 45 & 0.0988 & 0.0230 & 0.0839 & $4.56 \%$ & \\
\hline 60 & 0.1138 & 0.0345 & 0.0983 & $5.43 \%$ & \\
\hline 90 & 0.1378 & 0.0523 & 0.1210 & $6.54 \%$ & 0.0279 \\
\hline 120 & 0.1478 & 0.0612 & 0.1308 & $7.51 \%$ & \\
\hline 150 & 0.1558 & 0.0717 & 0.1393 & $8.06 \%$ & 0.0403 \\
\hline 180 & 0.1718 & 0.0835 & 0.1545 & $8.76 \%$ & \\
\hline 210 & 0.1598 & 0.0920 & 0.1465 & $8.98 \%$ & 0.0535 \\
\hline 240 & 0.1488 & 0.0919 & 0.1377 & $8.47 \%$ & \\
\hline 270 & 0.1518 & 0.0938 & 0.1404 & $8.29 \%$ & 0.0508 \\
\hline 300 & 0.1608 & 0.0950 & 0.1479 & $8.60 \%$ & \\
\hline 330 & 0.1468 & 0.1010 & 0.1378 & $8.52 \%$ & 0.0560 \\
\hline 360 & 0.1618 & 0.1080 & 0.1513 & $8.62 \%$ & \\
\hline 390 & 0.1618 & 0.1030 & 0.1503 & $8.99 \%$ & 0.0535 \\
\hline 420 & 0.1638 & 0.1070 & 0.1527 & $9.03 \%$ & \\
\hline SS value & $0.1621 * *$ & $0.1048 * *$ & 0.1508 & $9.00 \%$ & \\
\hline
\end{tabular}

* $\quad$ values after subtracting initial glucose concentration in the enzyme solution averaged value of a couple of steady state data points; the choice of these data points were decided based on the relevant curve in each corresponding Figure 
Table C.12 Alkaline Oxidation Corn Cob Continuous Hydrolysis --- with Pluronic

$$
\begin{array}{lll}
\mathrm{pH}=4.5 & \mathrm{v}_{\mathrm{r}}=1.08 \mathrm{ml} / \mathrm{min} & \mathrm{S}_{\mathrm{R}}=1.74 \mathrm{mg} / \mathrm{ml} \\
\mathrm{T}=45^{\circ} \mathrm{C} & \mathrm{v}_{\mathrm{p}}=0.27 \mathrm{ml} / \mathrm{min} & \mathrm{E}_{\mathrm{R}}=0.45 \mathrm{mg} / \mathrm{ml} \\
\mathrm{t}=483 \mathrm{mins} & & \mathrm{F}_{\mathrm{R}}=0.85 \mathrm{mg} / \mathrm{ml} \\
& & \mathrm{S}_{\mathrm{R}} / \mathrm{E}_{\mathrm{R}}=0.26 \\
& & \mathrm{~F}_{\mathrm{R}} / \mathrm{E}_{\mathrm{R}}=0.49
\end{array}
$$

\begin{tabular}{|c|c|c|c|c|}
\hline $\begin{array}{c}\text { time } \\
(\mathrm{min})\end{array}$ & $\begin{array}{c}{ }^{*} \mathrm{C}_{\mathrm{gr}} \\
(\mathrm{mg} / \mathrm{ml})\end{array}$ & $\begin{array}{c}\mathrm{C}_{\mathrm{gp}} \\
(\mathrm{mg} / \mathrm{ml})\end{array}$ & $\begin{array}{c}\mathrm{C}_{\mathrm{gm}} \\
(\mathrm{mg} / \mathrm{ml})\end{array}$ & $\begin{array}{c}\text { substrate } \\
\text { conversion }\end{array}$ \\
\hline 0 & 0.0000 & 0.0000 & 0.0000 & $0.00 \%$ \\
\hline 15 & 0.0509 & 0.0070 & 0.0421 & $1.21 \%$ \\
\hline 30 & 0.0829 & 0.0130 & 0.0689 & $3.19 \%$ \\
\hline 45 & 0.0881 & 0.0198 & 0.0744 & $4.12 \%$ \\
\hline 60 & 0.1080 & 0.0332 & 0.0930 & $4.82 \%$ \\
\hline 90 & 0.1290 & 0.0614 & 0.1154 & $6.00 \%$ \\
\hline 120 & 0.1470 & 0.0863 & 0.1348 & $7.20 \%$ \\
\hline 150 & 0.1480 & 0.1140 & 0.1412 & $7.94 \%$ \\
\hline 180 & 0.1830 & 0.1390 & 0.1742 & $9.07 \%$ \\
\hline 210 & 0.1850 & 0.1230 & 0.1725 & $9.98 \%$ \\
\hline 240 & 0.2030 & 0.1310 & 0.1885 & $10.39 \%$ \\
\hline 270 & 0.2230 & 0.1310 & 0.2045 & $11.31 \%$ \\
\hline 300 & 0.1780 & 0.1130 & 0.1649 & $10.63 \%$ \\
\hline 330 & 0.1690 & 0.1170 & 0.1586 & $9.31 \%$ \\
\hline 360 & 0.1620 & 0.1380 & 0.1572 & $9.08 \%$ \\
\hline 390 & 0.1730 & 0.1560 & 0.1696 & $9.40 \%$ \\
\hline 420 & 0.1730 & 0.1360 & 0.1656 & $9.64 \%$ \\
\hline 450 & 0.2010 & 0.1260 & 0.1859 & $10.11 \%$ \\
\hline 480 & 0.1750 & 0.1070 & 0.1613 & $9.99 \%$ \\
\hline SS value & $0.1910 * *$ & $0.1298 * *$ & 0.1787 & $10.28 \%$ \\
\hline
\end{tabular}

* $\quad$ values after subtracting initial glucose concentration in the enzyme solution ** averaged value of a couple of steady state data points; the choice of these data points were decided based on the relevant curve in each corresponding Figure 
Table C.13 Ammonia Steeping Corn Cob Continuous Hydrolysis --- no surfactant

$$
\begin{aligned}
& \mathrm{pH}=4.5 \\
& \mathrm{~T}=45^{\circ} \mathrm{C} \\
& \mathrm{v}_{\mathrm{r}}=1.04 \mathrm{ml} / \mathrm{min} \\
& \mathrm{S}_{\mathrm{R}}=1.84 \mathrm{mg} / \mathrm{ml} \\
& \mathrm{v}_{\mathrm{p}}=0.26 \mathrm{ml} / \mathrm{min} \\
& \mathrm{E}_{\mathrm{R}}=0.45 \mathrm{mg} / \mathrm{ml} \\
& \mathrm{t}=306 \text { mins } \\
& \mathrm{S}_{\mathrm{R}} / \mathrm{E}_{\mathrm{R}}=0.24
\end{aligned}
$$

\begin{tabular}{|c|c|c|c|c|c|}
\hline $\begin{array}{c}\text { time } \\
(\mathrm{min})\end{array}$ & $\begin{array}{c}{ }^{*} \mathrm{C}_{\mathrm{gr}} \\
(\mathrm{mg} / \mathrm{ml})\end{array}$ & $\begin{array}{c}\mathrm{C}_{\mathrm{gp}} \\
(\mathrm{mg} / \mathrm{ml})\end{array}$ & $\begin{array}{c}\mathrm{C}_{\mathrm{gm}} \\
(\mathrm{mg} / \mathrm{ml})\end{array}$ & $\begin{array}{c}\text { substrate } \\
\text { conversion }\end{array}$ & $\begin{array}{c}\mathrm{C}_{\mathrm{bp}} \\
(\mathrm{mg} / \mathrm{ml})\end{array}$ \\
\hline 0 & 0.0000 & 0.0000 & 0.0000 & $0.00 \%$ & \\
\hline 15 & 0.0541 & 0.0000 & 0.0432 & $1.17 \%$ & \\
\hline 30 & 0.0822 & 0.0075 & 0.0671 & $2.99 \%$ & 0.0089 \\
\hline 45 & 0.0907 & 0.0179 & 0.0760 & $3.88 \%$ & \\
\hline 60 & 0.1003 & 0.0294 & 0.0860 & $4.40 \%$ & \\
\hline 90 & 0.1103 & 0.0403 & 0.0962 & $4.94 \%$ & 0.0274 \\
\hline 120 & 0.1223 & 0.0486 & 0.1074 & $5.53 \%$ & \\
\hline 150 & 0.1213 & 0.0523 & 0.1074 & $5.83 \%$ & 0.0256 \\
\hline 180 & 0.1223 & 0.0552 & 0.1088 & $5.87 \%$ & \\
\hline 210 & 0.1243 & 0.0629 & 0.1119 & $5.99 \%$ & 0.0307 \\
\hline 240 & 0.1313 & 0.0658 & 0.1181 & $6.24 \%$ & \\
\hline 270 & 0.1213 & 0.0628 & 0.1095 & $6.18 \%$ & 0.0312 \\
\hline 300 & 0.1283 & 0.0634 & 0.1152 & $6.10 \%$ & \\
\hline SS value & $0.1263 * *$ & $0.0637 * *$ & 0.1137 & $6.17 \%$ & \\
\hline
\end{tabular}

* values after subtracting initial glucose concentration in the enzyme solution

** averaged value of a couple of steady state data points; the choice of these data points were decided based on the relevant curve in each corresponding Figure 
Table C.14 Ammonia Steeping Corn Cob Continuous Hydrolysis --- with Tergitol

$$
\begin{array}{lll}
\mathrm{pH}=4.5 & \mathrm{v}_{\mathrm{r}}=1.12 \mathrm{ml} / \mathrm{min} & \mathrm{S}_{\mathrm{R}}=1.70 \mathrm{mg} / \mathrm{ml} \\
\mathrm{T}=45^{\circ} \mathrm{C} & \mathrm{v}_{\mathrm{p}}=0.29 \mathrm{ml} / \mathrm{min} & \mathrm{E}_{\mathrm{R}}=0.46 \mathrm{mg} / \mathrm{ml} \\
\mathrm{t}=366 \mathrm{mins} & & \mathrm{F}_{\mathrm{R}}=0.85 \mathrm{mg} / \mathrm{ml} \\
& & \mathrm{S}_{\mathrm{R}} / \mathrm{E}_{\mathrm{R}}=0.27 \\
& & \mathrm{~F}_{\mathrm{R}} / \mathrm{E}_{\mathrm{R}}=0.50
\end{array}
$$

\begin{tabular}{|c|c|c|c|c|c|}
\hline $\begin{array}{c}\text { time } \\
(\mathrm{min})\end{array}$ & $\begin{array}{c}{ }^{*} \mathrm{C}_{\mathrm{gr}} \\
(\mathrm{mg} / \mathrm{ml})\end{array}$ & $\begin{array}{c}\mathrm{C}_{\mathrm{gp}} \\
(\mathrm{mg} / \mathrm{ml})\end{array}$ & $\begin{array}{c}\mathrm{C}_{\mathrm{gm}} \\
(\mathrm{mg} / \mathrm{ml})\end{array}$ & $\begin{array}{c}\text { substrate } \\
\text { conversion }\end{array}$ & $\begin{array}{c}\mathrm{C}_{\mathrm{bp}} \\
(\mathrm{mg} / \mathrm{ml})\end{array}$ \\
\hline 0 & 0.0000 & 0.0000 & 0.0000 & $0.00 \%$ & \\
\hline 15 & 0.0658 & 0.0000 & 0.0523 & $1.54 \%$ & \\
\hline 30 & 0.0942 & 0.0106 & 0.0771 & $3.80 \%$ & 0.0201 \\
\hline 45 & 0.0993 & 0.0184 & 0.0827 & $4.69 \%$ & \\
\hline 60 & 0.1253 & 0.0294 & 0.1057 & $5.53 \%$ & \\
\hline 90 & 0.1453 & 0.0478 & 0.1253 & $6.78 \%$ & 0.0320 \\
\hline 120 & 0.1613 & 0.0656 & 0.1417 & $7.84 \%$ & \\
\hline 150 & 0.1713 & 0.0857 & 0.1538 & $8.67 \%$ & 0.0584 \\
\hline 180 & 0.1973 & 0.0957 & 0.1765 & $9.69 \%$ & \\
\hline 210 & 0.1993 & 0.0989 & 0.1787 & $10.43 \%$ & 0.0755 \\
\hline 240 & 0.2083 & 0.1040 & 0.1869 & $10.73 \%$ & \\
\hline 270 & 0.1983 & 0.1030 & 0.1788 & $10.73 \%$ & 0.0730 \\
\hline 300 & 0.2063 & 0.1050 & 0.1856 & $10.69 \%$ & \\
\hline 330 & 0.1993 & 0.1070 & 0.1804 & $10.74 \%$ & 0.0726 \\
\hline 360 & 0.1913 & 0.1060 & 0.1738 & $10.40 \%$ & \\
\hline SS value & $0.2023 * *$ & $0.1050 * *$ & 0.1824 & $10.70 \%$ & \\
\hline
\end{tabular}

* $\quad$ values after subtracting initial glucose concentration in the enzyme solution

** averaged value of a couple of steady state data points; the choice of these data points were decided based on the relevant curve in each corresponding Figure 
Table C.15 Ammonia Steeping Corn Cob Continuous Hydrolysis --- with Pluronic

$$
\begin{array}{lll}
\mathrm{pH}=4.5 & \mathrm{v}_{\mathrm{r}}=1.09 \mathrm{ml} / \mathrm{min} & \mathrm{S}_{\mathrm{R}}=1.80 \mathrm{mg} / \mathrm{ml} \\
\mathrm{T}=45^{\circ} \mathrm{C} & \mathrm{v}_{\mathrm{p}}=0.24 \mathrm{ml} / \mathrm{min} & \mathrm{E}_{\mathrm{R}}=0.45 \mathrm{mg} / \mathrm{ml} \\
\mathrm{t}=366 \mathrm{mins} & & \mathrm{F}_{\mathrm{R}}=0.85 \mathrm{mg} / \mathrm{ml} \\
& & \mathrm{S}_{\mathrm{R}} / \mathrm{E}_{\mathrm{R}}=0.25 \\
& & \mathrm{~F}_{\mathrm{R}} / \mathrm{E}_{\mathrm{R}}=0.47
\end{array}
$$

\begin{tabular}{|c|c|c|c|c|c|}
\hline $\begin{array}{c}\text { time } \\
(\mathrm{min})\end{array}$ & $\begin{array}{c}{ }^{*} \mathrm{C}_{\mathrm{gr}} \\
(\mathrm{mg} / \mathrm{ml})\end{array}$ & $\begin{array}{c}\mathrm{C}_{\mathrm{gp}} \\
(\mathrm{mg} / \mathrm{ml})\end{array}$ & $\begin{array}{c}\mathrm{C}_{\mathrm{gm}} \\
(\mathrm{mg} / \mathrm{ml})\end{array}$ & $\begin{array}{c}\text { substrate } \\
\text { conversion }\end{array}$ & $\begin{array}{c}\mathrm{C}_{\mathrm{bp}} \\
(\mathrm{mg} / \mathrm{ml})\end{array}$ \\
\hline 0 & 0.0000 & 0.0000 & 0.0000 & $0.00 \%$ & \\
\hline 15 & 0.0776 & 0.0000 & 0.0637 & $1.77 \%$ & \\
\hline 30 & 0.1066 & 0.0056 & 0.0885 & $4.24 \%$ & 0.0120 \\
\hline 45 & 0.1276 & 0.0198 & 0.1083 & $5.48 \%$ & \\
\hline 60 & 0.1536 & 0.0296 & 0.1314 & $6.67 \%$ & \\
\hline 90 & 0.1596 & 0.0556 & 0.1409 & $7.58 \%$ & 0.0323 \\
\hline 120 & 0.1906 & 0.0722 & 0.1694 & $8.64 \%$ & \\
\hline 150 & 0.1986 & 0.0876 & 0.1787 & $9.69 \%$ & 0.0546 \\
\hline 180 & 0.1846 & 0.0997 & 0.1694 & $9.69 \%$ & \\
\hline 210 & 0.2106 & 0.1140 & 0.1933 & $10.10 \%$ & 0.0555 \\
\hline 240 & 0.2396 & 0.1260 & 0.2192 & $11.49 \%$ & \\
\hline 270 & 0.2396 & 0.1260 & 0.2192 & $12.21 \%$ & 0.0825 \\
\hline 300 & 0.2256 & 0.1250 & 0.2076 & $11.88 \%$ & \\
\hline 330 & 0.2406 & 0.1210 & 0.2191 & $11.88 \%$ & 0.0790 \\
\hline 360 & 0.2366 & 0.1180 & 0.2153 & $12.10 \%$ & \\
\hline SS value & $0.2391 * *$ & $0.1232 * *$ & 0.2183 & $12.16 \%$ & \\
\hline
\end{tabular}

* $\quad$ values after subtracting initial glucose concentration in the enzyme solution

** averaged value of a couple of steady state data points; the choice of these data points were decided based on the relevant curve in each corresponding Figure 


\section{Appendix D. Data Collected for Enzyme Activity Test}

-----(Genencor Multifect GC) using NREL LAP 006

Table D.1a Glucose Calibration Curve

\begin{tabular}{|c|c|c|c|c|}
\hline glucose stock $(\mathrm{ml})$ & citrate buffer $(\mathrm{ml})$ & dilution & glucose $(\mathrm{mg} / 0.5 \mathrm{ml})$ & abs. at 540 \\
\hline 1.0 & 0.5 & $1: 1.5$ & 3.35 & 0.734 \\
\hline 1.0 & 1 & $1: 2$ & 2.5 & 0.558 \\
\hline 1.0 & 2 & $1 ; 3$ & 1.65 & 0.366 \\
\hline 1.0 & 4 & $1: 5$ & 1 & 0.216 \\
\hline
\end{tabular}

Table D.1b Enzyme Dilution vs. Glucose Concentration

\begin{tabular}{|c|c|c|c|c|}
\hline enzyme (ul) & buffer $(\mathrm{ul})$ & final enzyme conc. $(\mathrm{ml} / \mathrm{ml})$ & abs. at 540nm & glucose $(\mathrm{mg} / 0.5 \mathrm{ml})$ \\
\hline 600 & 3400 & 0.00750 & 0.535 & 2.426 \\
\hline 500 & 3500 & 0.00625 & 0.480 & 2.177 \\
\hline 400 & 3600 & 0.00500 & 0.414 & 1.879 \\
\hline 300 & 3700 & 0.00375 & 0.351 & 1.594 \\
\hline
\end{tabular}

